\title{
Serotonin and bipolar disorders : serotonergic vulnerability in first-degree relatives of patients with bipolar disorder
}

Citation for published version (APA):

Sobczak, S. (2002). Serotonin and bipolar disorders : serotonergic vulnerability in first-degree relatives of patients with bipolar disorder. [Doctoral Thesis, Maastricht University]. Universiteit Maastricht. https://doi.org/10.26481/dis.20020607ss

Document status and date:

Published: 01/01/2002

DOI:

10.26481/dis.20020607ss

Document Version:

Publisher's PDF, also known as Version of record

Please check the document version of this publication:

- A submitted manuscript is the version of the article upon submission and before peer-review. There can be important differences between the submitted version and the official published version of record.

People interested in the research are advised to contact the author for the final version of the publication, or visit the DOI to the publisher's website.

- The final author version and the galley proof are versions of the publication after peer review.

- The final published version features the final layout of the paper including the volume, issue and page numbers.

Link to publication

\footnotetext{
General rights rights.

- You may freely distribute the URL identifying the publication in the public portal. please follow below link for the End User Agreement:

www.umlib.nl/taverne-license

Take down policy

If you believe that this document breaches copyright please contact us at:

repository@maastrichtuniversity.nl

providing details and we will investigate your claim.
}

Copyright and moral rights for the publications made accessible in the public portal are retained by the authors and/or other copyright owners and it is a condition of accessing publications that users recognise and abide by the legal requirements associated with these

- Users may download and print one copy of any publication from the public portal for the purpose of private study or research.

- You may not further distribute the material or use it for any profit-making activity or commercial gain

If the publication is distributed under the terms of Article $25 \mathrm{fa}$ of the Dutch Copyright Act, indicated by the "Taverne" license above, 


\section{Serotonin and bipolar disorders}

Serotonergic vulnerability in first-degree relatives of patients with bipolar disorder

Sjacko Sobczak

Maastricht, 2002 


\section{Serotonin and bipolar disorders}

Serotonergic vulnerability in first-degree relatives of patients with bipolar disorder

Sjacko Sobczak

Maastricht, 2002 
Cover picture: Toon Jacobs 'manisch-depressief' 2002

Layout: Bas van de Poel

S.Sobczak, Maastricht 2002

Production: Sobczak Communicatie

ISBN 90-9015687-9

NUGI 744

Sobczak Communicatie

Wolfhagen 75

6365 BM Schinnen

The studies described in this thesis were possible thanks to a grant from the Theodore and Vada Stanley Foundation and stichting Jos Schaap Fering.

Publication of this thesis is financially supported by Sigma Tau Ethifarma BV, Nutricia Nederland BV, UCB Pharma BV, GlaxoSmithKline BV, Sanofi-Synthelabo BV, AHP Pharma Wyeth BV, Astra Zeneca BV, Zeneca Farma BV 


\section{Serotonin and bipolar disorders}

Serotonergic vulnerability in first-degree relatives of patients with bipolar disorder

\section{PROEFSCHRIFT}

ter verkrijging van de graad van doctor aan de Universiteit Maastricht, op gezag van de Rector Magnificus, Prof. dr. A.C. Nieuwenhuijzen Kruseman, volgens het besluit van het College van Decanen, in het openbaar te verdedigen op vrijdag 7 juni 2002 om 12.00 uur

door

Sjacko Sobczak

Geboren op 21 augustus 1973 te Heerlen 


\section{Promotor}

Prof. Dr. J.J. van Os

\section{Co-promotores}

Dr. A. Honig

Dr. W.J. Riedel

\section{Beoordelingscommissie}

Prof. Dr. E. J. L. Griez (voorzitter)

Prof. Dr. G. Hornstra

Dr. L. Krabbendam

Prof. Dr. W.A. Nolen (Universiteit Utrecht)

Prof. Dr. H.G. Westenberg (Universiteit Utrecht)

The studies described in this thesis were carried out at the Maastricht Brain \& Behavior Institute, the department of Psychiatry and Neuropsychology of Maastricht University, the department of Psychiatry of the University Hospital Maastricht (AZM), the Netherlands. 


\section{Contents}

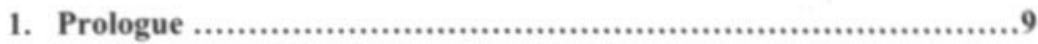

Aims and outline of the studies................................... 11

$\underline{\text { Part I }}$

2. Acute tryptophan depletion in bipolar disorders; literature review and directives for further research. 19

3. Effects of acute tryptophan depletion on mood and cortisol release in first-degree relatives of type I and type II bipolar patients and healthy matched

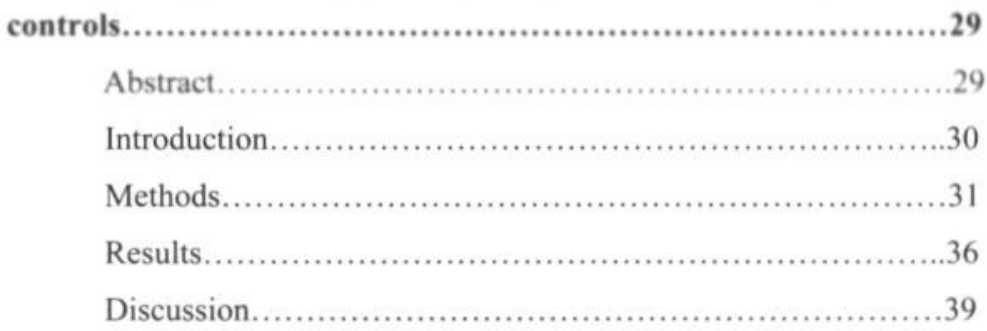

4. Cognition following acute tryptophan depletion: differences between first-degree relatives of bipolar patients and matched healthy control volunteers.......................................................45

Abstract.......................................................... 45

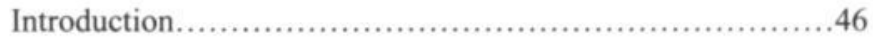

Methods................................................47

Results...................................................... 55

Discussion...................................................60 


\section{$\underline{\text { Part II }}$}

5. Serotonergic dysregulation in bipolar disorders; a literature review of serotonergic challenge studies. 69

6. Mood, prolactine and cortisol responses following intravenous L-tryptophan challenge; evidence for serotonergic vulnerability in first-degree relatives of bipolar patients...............................................89

Abstract ................................................ 89

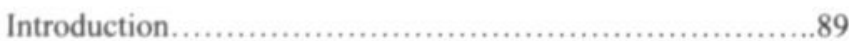

Methods .................................................. 90

Results.....................................................92

Discussion.............................................95

7. Pronounced cognitive deficits following an intravenous L-tryptophan challenge in first-degree relatives of bipolar patients compared to healthy controls................................................................101

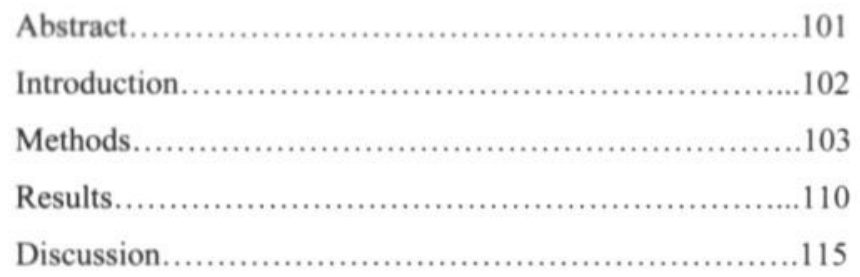

8. Lower high-density lipoprotein cholesterol, decreased $\omega 3$ and increased $\omega 6$ polyunsaturated fatty acids in first-degree relatives of bipolar patients........................................................123

Abstract.................................................... 124

Introduction............................................... 126

Methods.................................................. 127

Results................................................129

Discussion................................................. 134 
9. Epilogue...........................................................141

Summary and implication of findings.......................142

Conclusions............................................... 148

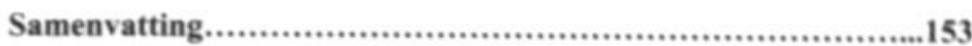

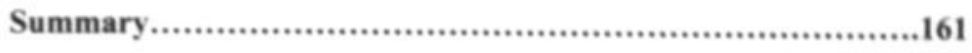

Dankwoord........................................................... 167

Curriculum vitae...................................................171

List of Publications.................................................173 


\section{Prologue}

Bipolar disorders (BD) are among the most hereditary of psychiatric syndromes (Gershon et al. 1976). Whereas the lifetime risk to develop BD in the population is $1-5 \%$ (Weissman et al. 1988), healthy first-degree relatives of $\mathrm{BD}$ patients ( $\mathrm{FH})$ show a 10-20 times increased risk to develop BD (Goodwin and Ghaemi 1998). BD is a chronic disease; more than a third of all cases develop BD before age of 20. BD Patients have to take medication for a prolonged period of time, even for the rest of their lives. The impact of illness episodes on social functioning and intellectual development is paramount. It goes without saying that healthy $\mathrm{FH}$ subjects worry about their biological vulnerability to develop BD. The present research project searches for biological determinants involved in psychopathology of BD.

Vulnerability to serotonergic dysfunctions was assessed in healthy subjects at genetic risk for $\mathrm{BD}$ and healthy controls subjects without such a genetic risk.

The appearance of emotional extremes alternated by long-term episodes of normal mood state and behavior characterizes BD. Depression is one emotional pole. During depression, there is a slowing or decrease in almost all aspects of emotion and behavior: rate of thought and speech, energy, sexuality and the ability to experience pleasure. Patients feel sad and despairing for weeks or months. The other pole is mania, which is characterized by elated or euphoric mood, faster train of thought, brisker physical and mental activity levels, irritability, heightened sexuality, and impulsivity. As opposed to hypomania, mania is more severe and may be associated with psychotic features such as delusions and hallucinations (Honig and van Praag 1994; Goodwin and Jamison 1990). Based on these symptoms, BD are classified in two major subgroups: type I and type II. The most important distinction is based on a history of full mania in BD type I patients, whereas BD type II patients are known with hypomania (Goodwin and Jamison 1990).

Serotonin (5-hydroxytryptophan or 5-HT) is a monoamine which is involved in brain information processing and regulation of mood. Serotonergic deficiency has been accepted as an underlying physiological mechanism in major depression (Charney 1998; Meltzer 1989; Price et al. 1990; Stahl 1977). In depressed and manic BD patients, there is also evidence for a 
reduced 5-HT activity (Goodwin and Jamison 1990; Prange et al. 1974; Young et al. 1994). Brain 5-HT dysfunction may be a result of disturbed lipid metabolism, i.e. abnormalities in cholesterol (Buydens-Branchey et al. 2000; Maes et al. 1997; Swartz 1990; Terao et al. 2000) and fatty-acids (FAs) (Maes et al. 1996). Several genetic abnormalities affecting the 5-HT system have been implicated in BD psychopathology (Bellivier et al. 1998; Ginns et al. 1996; Kunugi et al. 1997; Lesch et al. 1995; Oruc et al. 1997).

Central 5-HT vulnerability in FH can be described as vulnerability to 5- HT dysfunction as shown in BD patients. Useful paradigms to assess vulnerability to 5-HT dysfunction are provided by experimental procedures that acutely decrease or elevate brain 5-HT availability. Next to medication, brain 5-HT activity can be modulated by dietary challenge procedures in which availability of the amino-acid tryptophan (Trp), precursor of 5-HT, is manipulated. Acute tryptophan Depletion (ATD) is a method in which Trp and consequently brain 5-HT is depleted by giving subject an amino-acid drink devoid of Trp (Young et al. 1985).

Serotonergic functioning can be stimulated by intravenous (i.v.) administration of Trp (Charney et al. 1982). Trp is the precursor to brain 5-HT synthesis. The central production of 5-HT by the enzyme tryptophan-hydroxylase is directly dependent on the amount of Trp in the brain. ATD can be achieved by consuming an AA-drink which is rich in large-neutral amino acids (LNAAs) (i.e. valine, leucine, iso-leucine, tyrosine and phenylalanine) and devoid of Trp. LNAAs compete with Trp at the blood-brain barrier for syntake. The AA-utrink brings Trp at a relatively disadvantage for uptake which results in a central Trp depletion and lowering of 5-HT (Young et al. 1985). On the other hand, i.v. Trp loading will increase brain Trp and thus 5-HT availability. Modulations of central availability of Trp have been described to affect mood (Aberg-Wistedt et al. 1998; Young et al. 1985), cognition (Riedel et al. 1999; Schmitt et al. 2000) and hormone release (i.e. cortisol and prolactine; PRL) (Goekoop 1998; Stahl 1992). Compared to controls, 5-HT vulnerability in FH will be reflected as altered effects of ATD and Trp challenge on mood, cognition, cortisol and PRL release (Riedel et al. 2002; Stahl 1998). For example, compared to controls, major depressed patients (Delgado et al. 1990; Delgado et al. 1991) and their first-degree relatives are more vulnerable to the moodlowering effects of ATD (Klaassen et al. 1999).

It is important to differentiate between trait and state markers. State markers are biological abnormalities that are only present during illness episodes whereas trait markers are also present in patients or those at risk. Thus unlike state markers, trait markers are also present in symptom-free episodes. As healthy FH subjects are genetically at risk for BD, but do not 
show interference of psychotropic medication, they constitute an important population which is very suitable to investigate 5-HT vulnerability and other trait markers for BD.

In this thesis 5-HT vulnerability is assessed in FH subjects following ATD and i.v. Trp challenges. Effects on mood, cognition and hormonal responses in $\mathrm{FH}$ subjects are compared with effects in healthy matched controls. A distinction is made between effects in relatives of type I (FH I) and type II (FH II) BD patients. Furthermore, in search for trait markers for BD, abnormalities in baseline cholesterol and FAs and associations with central 5-HT vulnerability are investigated.

\section{Aims and outline of the studies}

In the first part of this thesis, consisting of chapters 2 to $4,5-\mathrm{HT}$ vulnerability in FH subjects is investigated by using an ATD paradigm.

A review of studies on ATD in BD patients is given in chapter 2. In major depressed patients ATD has been shown to enhance feelings of depression (Delgado et al., 1990). In order to investigate 5-HT dysfunctions in BD, literature on ATD in BD patients is reviewed. Based on the available information on ATD paradigms previously applied in BD, a research protocol will be developed to investigate the effects of ATD in FH subjects.

\section{Effects of ATD on mood and stress-induced cortisol response}

In chapter 3, the effects of ATD on mood and stress-induced cortisol release are investigated in FH I and FH II subjects and healthy matched controls. Differences between FH subjects and controls in ATD-induced mood changes may reflect a central 5-HT vulnerability. Despite the fact that stimulating effects of 5-HT on cortisol are well known, this is the first study which investigates the effects of ATD on stress-induced cortisol release. Cortisol has been described as an important biological marker in BD and cortisol response after ATD might provide an important indicator of central 5-HT vulnerability FH subjects.

\section{Cognition in FH and effects of ATD}

Cognitive impairments in healthy subjects at genetic risk for affective disorders may reflect a biological vulnerability. In depressed, manic and euthymic BD patients significant cognitive deficits has been described. The experiment described in chapter 4 addresses the issue of cognitive functioning in FH. This study questions whether FH subjects show cognitive impairments on executive functioning, memory, learning and divided and focused attention 
compared to healthy controls. Differences between FH I, FH II and controls in ATD-induced changes in cognitive performance might reflect 5-HT vulnerability affecting brain areas normally involved in these cognitive processes.

The second part of this thesis, consists of chapters 5 to 8 . In these chapters studies investigating 5-HT vulnerability in FH subjects following i.v. Trp loading are described. Neuroendocrine, mood and cognitive changes following Trp might reflect central 5-HT vulnerability in FH I and FH II subjects. The relationship between potential disturbances in normal cholesterol and FA metabolism and central 5-HT vulnerability in FH is also investigated.

Chapter 5 is a literature review of studies on 5-HT challenge paradigms in respectively euthymic, depressed and manic BD patients. Neuroendocrine parameters such as PRL and cortisol have been used extensively as biological markers of 5-HT functioning in the brain. Relatively high neuroendocrine and mood responses are indicative of post-synaptic receptor hypersensitivity whereas low responses suggest receptor hyposensitivity. Procedures and methodology of studies will be critically reviewed; the interference of mood state and psychotropic medication on effects of ATD is described.

\section{Trp challenge effects on mood and hormonal responses}

The effects of i.v. Trp challenge on mood and neuroendocrine responses in FH subjects are described in chapter 6 . In this study central 5-HT vulnerability in FH I and FH II is investigated by measuring Trp-induced mood changes and levels of cortisol and PRL. In FH subjects, changes in central 5-HT receptor sensitivity might give rise to blunted or exaggerated mood and neuroendocrine responses compared to controls, which reflect 5-HT vulnerability to $\mathrm{BD}$.

\section{The effects of Trp challenge on cognitive performance in $\mathrm{FH}$}

Brain 5-HT plays an important role in several cognitive domains. Following ATD, cognitive impairments of for instance planning, learning and memory have been reported. But in understanding the role of 5-HT in cognition, it is important to differentiate between cognitive effects of both an acute increase and decrease in brain 5-HT. Studies on cognition following acute 5-HT stimulation are limited and cognitive effects of i.v. Trp challenging have never been investigated before. The study in chapter 7 investigates changes in planning, attention, 
psychomotor performance and memory following i.v. Trp loading. Differences in cognitive changes following i.v. Trp between FH I, FH II and healthy controls indicate central 5-HT vulnerability.

\section{Altered cholesterol and fatty acids in FH and its role in 5-HT vulnerability}

Abnormalities in cholesterol and FAs metabolism have been described in depressed and manic BD patients. A decrease in cholesterol and FAs lowers membrane micro viscosity, receptor stability, membrane transport mechanisms and consequently normal 5-HT functioning in the brain and hence can cause depression. Though changes in cholesterol and FAs have been previously depicted as state markers in major depression, it is still questioned whether these abnormalities indicate trait markers. Alternatively it is suggested that changes in normal cholesterol and FA status in healthy FH subjects reflect a trait marker to BD. The study in chapter 8 investigates whether there are differences in cholesterol and FAs between FH and healthy matched controls. The association between cholesterol and FAs status and 5HT function as assessed by neuroendocrine responses to i.v. Trp challenge is described.

In chapter 9 a summary of the findings and a general discussion of the combined results is provided. Implications for further research are given.

\section{References}

Aberg-Wistedt A, Hasselmark L, Stain-Malmgren R, Aperia B, Kjellman BF, Mathe AA. (1998) Serotonergic 'vulnerability' in affective disorder: a study of the tryptophan depletion test and relationships between peripheral and central serotonin indexes in citalopram-responders. Acta Psychiatr Scand 97: 374-80

Bellivier F, Leboyer M, Courtet P, Buresi C, Beaufils B, Samolyk D, Allilaire J, Feingold J, Mallet J, Malafosse A. (1998) Association between the tryptophan hydroxylase gene and manic-depressive illness. Arch. Gen.

Psychiatry 55: 33-7

Buydens-Branchey L, Branchey M, Hudson J, Fergeson P (2000) Low HDL cholesterol, aggression and altered central serotonergic activity. Psychiatry Res 93: 93-102.

Charney DS (1998) Monoamine dysfunction and the pathophysiology and treatment of depression. J Clin Psychiatry 59 Suppl 14:11-4

Charney DS, Heninger GR, Reinhard JF, Jr., Sternberg DE, Hafstead KM (1982) The effect of IV L-tryptophan on prolactin, growth hormone, and mood in healthy subjects. Psychopharmacology Berl 78: 38-43

Delgado PL, Charney DS, Price LH, Aghajanian GK, Landis H, Heninger GR (1990) Serotonin function and the mechanism of antidepressant action. Reversal of antidepressant-induced remission by rapid depletion of plasma tryptophan [see comments]. Arch Gen Psychiatry 47: 411-8 
Delgado PL, Price LH, Miller HL, Salomon RM, Licinio J, Krystal JH, Heninger GR, Charney DS (1991) Rapid serotonin depletion as a provocative challenge test for patients with major depression: relevance to antidepressant action and the neurobiology of depression. Psychopharmacol Bull 27: 321-30

Gershon ES, Bunney WE, Jr., Leckman JF, Eerdewegh M, DeBauche BA (1976) The inheritance of affective disorders: a review of data and of hypotheses. Behav Genet 6: 227-61

Ginns EI, Ott J, Egeland JA, Allen CR, Fann CS, Pauls DL, Weissenbachoff J, Carulli JP, Falls KM, Keith TP, Paul SM (1996) A genome-wide search for chromosomal loci linked to bipolar affective disorder in the Old Order Amish. Nat Genet 12: 431-5

Goekoop JG (1998) De regulatie van de hypothalamus-hypofyse-bijnier-as in de pathogenese van depressieve stoornissen. Acta Neuropsychiatrica 10: 1-6

Goodwin FK, Jamison KR (1990) Manic-Depressive Illness. Oxford University Press, Oxford University Press

Goodwin FK, Ghaemi SN (1998) Understanding manic-depressive illness. Arch Gen Psychiatry 55: 23-5

Honig A, van Praag HM (1994) Manie: kliniek, oorzaak en behandeling. Ned Tijdschr Geneeskd 138(18): 894-8.

Klaassen T, Riedel WJ, van Someren A, Deutz NEP, Honig A, van Praag HM (1999) Mood effects of 24-hour tryptophan depletion in healthy first degree relatives of patients with affective disorders. Biol Psychiatry 46: 489-97 Kunugi H, Hattori M, Kato T, Tatsumi M, Sakai T, Sasaki T, Hirose T, Nanko S (1997) Serotonin transporter gene polymorphisms: ethnic difference and possible association with bipolar affective disorder. Mol Psychiatry 2: 457-62

Lesch KP, Gross J, Franzek E, Wolozin BL, Riederer P, Murphy DL (1995) Primary structure of the serotonin transporter in unipolar depression and bipolar disorder. Biol Psychiatry 37: 215-23

Maes M, Smith R, Christophe A, Cosyns P, Desnyder R, Meltzer H (1996) Fatty acid composition in major depression: decreased omega 3 fractions in cholesteryl esters and increased C20:4 omega 6/C20:5 omega 3 ratio in cholesteryl esters and phospholipids. J Affect Disord 38: 35-46.

Maes M, Smith R, Christophe A, Vandoolaeghe E, Van Gastel A, Neels H, Demedts P, Wauters A, Meltzer HY (1997) Lower serum high-density lipoprotein cholesterol (HDL-C) in major depression and in depressed men with serious suicidal attempts: relationship with immune-inflammatory markers. Acta Psychiatr Scand 95: 212 21.

Meltzer H (1989) Serotonergic dysfunction in depression. Br J Psychiatry Suppl : 25-31

Oruc L, Verheyen GR, Furac I, Jakovljevic M, Ivezic S, Raeymaekers P, Van Broeckhoven C (1997) Association analysis of the 5-HT2C receptor and 5-HT transporter genes in bipolar disorder. Am J Med Genet 74: 504-6

Prange AJ, Jr., Wilson IC, Lynn CW, Alltop LB, Stikeleather RA (1974) L-tryptophan in mania. Contribution to a permissive hypothesis of affective disorders. Arch Gen Psychiatry 30: 56-62

Price LH, Charney DS, Delgado PL, Heniger GR (1990) Lithium and serotonin function:implications for the serotonin hypothesis of depression. Psychopharmacology 100: 3-12

Riedel WJ, Klaassen T, Griez E, Honig A, Menheere PPCA, van Praag HM (2002) Dissociable hormonal, cognitive and mood responses to neuroendocrine challenge: evidence for receptor-specific serotonergic dysregulation in depressed mood. J Psychopharmacol 26(3): 358-67.

Riedel WJ, Klaassen T, Deutz NEP, van Someren A, van Praag HM (1999) Tryptophan depletion in normal volunteers produces selective impairment in memory consolidation. Psychopharmacology 141: 362-9 
Schmitt J, Jorissen B, Sobczak S, Van Boxtel MPJ, Hogervorst E, Deutz NEP, Riedel WJ (2000) Tryptophan depletion impairs memory consolidation, but improves focused attention in healthy young volunteers. J Psychopharmacol 14(1): 21-9

Stahl SM (1977) The human platelet. A diagnostic and research tool for the study of biogenic amines in psychiatric and neurologic disorders. Arch Gen Psychiatry 34: 509-16

Stahl SM (1992) Neuroendocrine markers of serotonin responsivity in depression. Prog Neuropsychopharmacol Biol Psychiatry 16: 655-9

Stahl SM (1998) Mechanism of action of serotonin selective reuptake inhibitors. Serotonin receptors and pathways mediate therapeutic effects and side effects. J Affect Disord 51: 215-35

Swartz CM (1990) Albumin decrement in depression and cholesterol decrement in mania. J Affect Disord 19: 173-6

Terao T, Nakamura J, Yoshimura R, Ohmori O, Takahashi N, Kojima H, Soeda S, Shinkai T, Nakano H, Okuno T (2000) Relationship between serum cholesterol levels and meta- chlorophenylpiperazine-induced cortisol responses in healthy men and women. Psychiatry Res 96: 167-73

Weissman MM, Leaf PJ, Tischler GL, Karno M, Bruce ML, Florio LP (1988) Affective disorders in five United States communities. Psychol Med 18: 141-53

Young LT, Warsh JJ, Kish SJ, Shannak K, Hornykeiwicz O (1994) Reduced brain 5-HT and elevated NE turnover and metabolites in bipolar affective disorder. Biol Psychiatry 35: $121-7$

Young SN, Smith SE, Pihl RO, Ervin FR (1985) Tryptophan depletion causes a rapid lowering of mood in normal males. Psychopharmacology Berl 87: 173-7 
PART I 


\title{
Acute Tryptophan Depletion in bipolar disorders; literature review and directives for further research
}

\begin{abstract}
Serotonin (5-hydroxytryptophan; 5-HT) has been implicated in the pathophysiology of bipolar disorders. Acute Tryptophan Depletion (ATD), which decreases serotonergic turnover, is an established paradigm to study serotonergic vulnerability in affective disorders. Literature on the application of ATD as a research tool in bipolar patients is limited to three studies, which revealed inconsistent results on mood modification. These inconsistencies may be attributed to differences in methodological procedures and / or characteristics of included patients. Patient selection, methodological aspects and procedures of these studies are critically considered and recommendations given. A research protocol to test the 5-HT vulnerability in bipolar disorder is proposed.
\end{abstract}

Sobczak S, Honig A, Riedel WJ. Acta Neuropsychiatrica, 12(3), 2000

\section{Introduction}

In bipolar disorders, there is some evidence for a reduced activity of serotonin (5-hydroxytryptophan; 5-HT) in both depressed and manic states. Increased platelet serotonin and lower maximal velocity (Vmax) of 5-HT-platelet uptake, has been reported in untreated bipolar depressed patients (Marazziti et al. 1991). Post-mortem studies of brains of bipolar patients have indicated decreased 5-hydroxyindoleacetic acid (5HIAA, the major metabolite of 5-HT) to 5-HT ratios, which is indicative of reduced 5-HT turnover, in cerebral cortex (Young et al. 1994). In the pathophysiology of bipolar disorders, genetic modifications 
affecting the 5-HT system, e.g. in the 5-HT transporter, 5-HT receptors and the tryptophan hydroxylase gene have been described (Lesch et al. 1995; Bellivier et al. 1998). No single specific 5-HT marker has yet been discovered and there is growing interest in various indices of 5-HT function in bipolar disorders.Acute Tryptophan Depletion (ATD) is a useful method to investigate central 5-HT vulnerability. In this paradigm a low brain 5-HT turnover is obtained by giving subjects a $50-100 \mathrm{~g}$ balanced amino acid-drink (AA-drink) including Large Neutral Amino Acids (LNAAs) like tyrosine, phenylalanine, leucine, isoleucine, valine and devoid of tryptophan (Trp). The ingested amino acids lower plasma Trp levels by stimulating peripheral protein synthesis thereby using free Trp. Next Trp competes at a relative disadvantage with LNAAs to cross the blood-brain barrier. Subsequently, central Trp depletion occurs and as the rate-limiting step in 5-HT synthesis is dependent on the availability of Trp, central Trp depletion will transiently reduce central 5-HT activity. Within 5-7 hours, ATD leads to an 80-95\% reduction of plasma and CSF Trp and a 30\% reduction of cerebrospinal fluid 5-HIAA concentrations (Carpenter et al. 1998). First-degree relatives, with no prior depressive episodes, are biologically predisposed to increased vulnerability to the mood-lowering effects of ATD (Benkelfat et al. 1994) (Klaassen et al. 1999). It has been

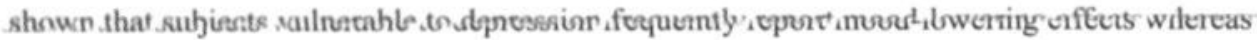
remitted patients may show clinical relapse after Trp depletion (Delgado et al. 1990). Thus, Trp depletion may be useful in identifying individuals vulnerable to serotonergic imbalance and at risk for future depressive episodes.

In this article, literature on Trp depletion in bipolar patients and their first-degree relatives will be considered first; methodological procedures and patient selection will be critically reviewed. Secondly, recommendations for future investigation are given.

\section{Literature review}

Literature was searched for in electronic libraries: MEDLINE and PSYCHLIT, year 1960 to 2000. To complete the selection, all references in retrieved papers were included in the review. The keyword, on which the literature was selected, was 'tryptophan depletion'. All papers on Trp depletion were checked. Only papers describing studies into the effects of ATD in bipolar patients and their first-degree relatives were included in the review. Papers describing subjects solely as major depressed and papers, which failed to describe their subjects as either bipolar or unipolar depressed patients, were not included in the review. 


\section{Results}

Fifty papers describing ATD studies were found. Only three studies applied the ATD paradigm in lithium-remitted bipolar patients (see table I) (Benkelfat et al. 1995; Cassidy et al. 1998; Cappiello et al. 1997). Five papers on ATD described the number of unipolar and bipolar depressed patients in the research population (Delgado et al. 1990; Price et al. 1998; Neumeister 1998; Leyton et al. 1997). Three papers described the effects of ATD in healthy first-degree relatives of unipolar and bipolar depressed patients (Klaassen et al. 1999; Delgado et al. 1990; Ellenbogen et al. 1999).

\section{1) ATD in bipolar disorders}

Three papers described the effects of ATD in type I bipolar patients. These studies were all carried out according to a double-blind counterbalanced placebo-controlled design (Benkelfat et al. 1995; Cassidy et al. 1998; Cappiello et al. 1997). Benkelfat et al. (Benkelfat et al. 1995) did not find any changes in affective symptoms in long-term (at least one year) remitted bipolar patients. Mood scales used were Hamilton Depression Rating Scale (HDRS), Beigel and Murphy Manic-State Rating Scale (BMMS), Zung Depression Scale (ZDS) and Visual Analogue Mood Scales (VAMS). Patients were 10 men (mean \pm SD, age, $39 \pm 15$ years) who fulfilled DSM-III-R criteria for bipolar disorders; the duration of illness was $14 \pm 11$ years. At time of entry in the study, all patients were on lithium monotherapy (daily dose, $930 \pm 386$ $\mathrm{mg} / \mathrm{d})$ and had been euthymic for at least one year $(4 \pm 11$ years $)$. After ATD, plasma Trp levels decreased by $85 \%$, whereas in the placebo condition plasma Trp levels were elevated by $39 \%$.

Cappiello et al. (Cappiello et al. 1997) applied the ATD paradigm in seven remitted bipolar patients ( 4 women, 3 men; aged 26-58 years). All subjects met DSM-IV criteria for bipolar manic episode, one patient had a schizoaffective diagnosis, none rapid cycling or mixed. Patients were on lithium therapy, five additionally on an antipsychotic ( 3 on haloperidol, 2-10 $\mathrm{mg} / \mathrm{d}$, and 2 on perphenazine, 12-48 mg/d). The AA-drink was given as a full-strength drink (depletion drink) or as a $25 \%$ strength mixture (sham drink). Plasma Trp levels decreased significantly in the Trp depleted condition. Exact changes of plasma Trp levels were not given and no corrections for plasma lithium, haloperidol or perphenazine level or were made. After Trp depletion, patients reported increased manic symptoms on Young Mania Rating Scale (YMRS) scores for three days. 
Cassidy et al. (Cassidy et al. 1998) applied the ATD paradigm in 4 recently remitted manic bipolar patients ( 2 women, 2 men, age 52.5 years). Patients were on lithium monotherapy for 1 month $(31 \pm 16.5$ days $)$. The ATD paradigm consisted of full-strength and a $25 \%$ strength sham drink. Mood was rated using YMRS, HDRS and the Carroll Depression Scale (CDS). Plasma Trp levels decreased $77 \%$ in the depletion condition and decreased $7 \%$ after the placebo AA-drink. No clinical changes in manic or depressive symptoms were observed during Trp depletion. An overview of the studies is given in table I.

Table I: Double blind (DB) studies on ATD in bipolar patients (BP) and in subjects with a $1^{\text {th }}$ degree family history of bipolar disorders

\begin{tabular}{|c|c|c|c|c|c|c|}
\hline Author & Subjects & Medication & Method & Design & Mood & Result \\
\hline Benkelfat 1995 & 10 remitted (1 year) BP & lithium & Classic ATD paradigm & DB PC CO & $\begin{array}{l}\text { HDRS, BMMS, } \\
\text { ZDS, VAS }\end{array}$ & $\begin{array}{l}\text { no changes in } \\
\text { mood }\end{array}$ \\
\hline Cappiello 1997 & 7 remitted ( 1 month) BP & $\begin{array}{l}\text { lithium } \boldsymbol{\alpha} \\
\text { neuroleptics }\end{array}$ & $\begin{array}{l}\text { Alternative ATD: } 10 \% \\
\text { and } 25 \% \text { strength drink }\end{array}$ & DB PC CO & YMRS & $\begin{array}{l}\text { increased manic } \\
\text { symptoms }\end{array}$ \\
\hline Casside 1998 & 4 remitted (1 month) BP & lithium & $\begin{array}{l}\text { Altemative ATD: } 10 \% \\
\text { and } 25 \% \text { strength drink }\end{array}$ & DB PC CO & $\begin{array}{l}\text { YMRS, HDRS, } \\
\text { CDS }\end{array}$ & no changes in mood \\
\hline Delgodo 1990 & 21 remitted patients (5 BP) & $\begin{array}{l}\text { antidepressants } 8 \\
\text { lithium }\end{array}$ & Classic ATD paradigm & DB PC CO & HDRS, HRS-A & depressive relapse \\
\hline Leyton 1997 & 14 remitted patients ( 2 BP) & no & Classic ATD paradigm & $\mathrm{DB} \mathrm{PC} \mathrm{CO}$ & $\begin{array}{l}\text { HDRS, BMMS, } \\
\text { VAS }\end{array}$ & no changes in mood \\
\hline Price 1998 & 22 remitted patients (4BP) & no & Classic ATD paradigm & DB PC CO & $\begin{array}{l}\text { HDRS, BDI, } \\
\text { VAS }\end{array}$ & $\begin{array}{l}\text { slight effects on } \\
\text { mood }\end{array}$ \\
\hline Price 1907 & 38 remitted patients (4BP) & no & Classic ATD paradigm ${ }^{*}$ & DB PC CO & $\begin{array}{l}\text { HDRS, BDI, } \\
\text { VAS }\end{array}$ & $\begin{array}{l}\text { slight effects on } \\
\text { mood }\end{array}$ \\
\hline Veumeister 1998 & 30 remitted patients (10 BP) & no & Classic ATD paradigm & DB PC CO & HDRS, VAS & no changes in mood \\
\hline Benkelfat 1994 & $20 \mathrm{FH}+, 19 \mathrm{FH}-$ & no & Classic ATD paradigm & $\mathrm{DB} \mathrm{PC} \mathrm{CO}$ & $\begin{array}{l}\text { HDRS, VAS, } \\
\text { BDI, STAI }\end{array}$ & $\begin{array}{l}\text { FH+ more mood- } \\
\text { lowering }\end{array}$ \\
\hline Klaassen 1999 & $16 \mathrm{FH}+11 \mathrm{FH}-$ & no & Classic ATD paradigm" & DB PC CO & VAS & $\begin{array}{l}\text { FH+ more mood- } \\
\text { lowering }\end{array}$ \\
\hline Ellenbogen 1999 & $14 \mathrm{FH}+$ & no & Classic ATD paradigm & DB PC CO & VAS & no changes in mood \\
\hline
\end{tabular}


ATD in unipolar and bipolar depressed patients

Five studies described the effects of ATD in a research population including both unipolar and bipolar depressed patients (Delgado et al. 1990; Price et al. 1997; Price et al. 1998; Neumeister 1998; Leyton et al. 1997). All studies were conducted according to a double-blind placebo-controlled cross-over design, and applied the classical ATD paradigm. Subjects were bipolar and unipolar depressed patients in remission (see table I). In the study of Delgado et al., (Delgado et al. 1990) subjects were receiving antidepressant treatment at the time of investigation. In the remaining four reviewed studies, testing occurred during a placebo treatment period (Price et al. 1997; Price et al. 1998; Neumeister 1998; Leyton et al. 1997). Three of the five studies reported a mood-lowering effect of ATD, using Visual Analogue Mood Scales (VAS) (Delgado et al. 1990; Price et al. 1997; Price et al. 1998). However, the authors failed to describe differences in mood-response between unipolar and bipolar depressives. As the number of included bipolar patients was relatively small in these studies (maximal 10 in a population of 30 subjects) compared to unipolar patients, the study outcomes might mainly be attributed to ATD effects in unipolar depressive patients.

\section{3)}

\section{ATD in first-degree relatives of depressed patients}

Three papers describing ATD in first-degree relatives of depressed (including unipolar and bipolar depressed) patients were available (Klaassen et al. 1999; Benkelfat et al. 1994; Ellenbogen et al. 1999), see table I. The three studies were all conducted according to a double-blind placebo-controlled cross-over design. Subjects were free of psychiatric diagnosis in past and present and were taking no medication except oral contraceptives. Klaassen et al. (Klaassen et al. 1999) and Benkelfat et al. (Benkelfat et al. 1994) showed enhanced moodlowering effects, on the Profile of Mood States depression scale (POMS) scores, in subjects with a positive family history for depression. Ellenbogen et al. (Ellenbogen et al. 1999) could not confirm these findings in women with a multi-generation family history of psychiatric illness. These negative results have been attributed to the exclusion of a large number of women who had already experienced an episode of depression. All papers failed to describe differences in mood changes between relatives of bipolar or unipolar depressed patients. There were no studies investigating ATD in first-degree relatives of bipolar patients exclusively. 


\section{Discussion}

No definitive conclusion on the effects of ATD in bipolar patients can be drawn from the reviewed literature. First, in the three reviewed studies, all subjects were on psychotropic medication. Lithium treatment has been shown to alter central 5-HT sensitivity. An increased prolactine response to $\operatorname{Trp}$ after short-term lithium treatment, but not after long-term lithium treatment has been reported (Price et al. 1989). Lithium does not only affect 5-HT turnover, but may also be involved in post-synaptic second messenger systems (G proteins or phosphatidyl inositol) (Bowden and Dickson 1997). Second, the sham condition in the alternative paradigm is not a useful placebo. It might therefore be premature to draw general conclusions about the 5-HT vulnerability in bipolar disorders, indicated by ATD.

To investigate the 5-HT vulnerability, ATD should be applied to bipolar patients off medication, which rises serious ethical concerns. Consequently, the effects of ATD must be investigated in subjects with no prior psychiatric diagnosis, but at genetic risk for bipolar disorders.

Until now, a valid comparison of studies is hampered by differences in methodological aspects and procedures. To draw general conclusions about the effects of ATD in bipolar disorders, methodological deficits should be improved with regard to several aspects.

1) To increase the power, ATD should be applied to a larger research population including healthy matched control subjects. The number of subjects in reviewed papers was maximal 10 (Benkelfat et al. 1995). In none of the studies control subjects were included.

2) The research population must be specified. Several factors including melancholia or a history of refractoriness to anti-depressant drug can influence the vulnerability to relapse following ATD. Melancholic traits, suicidal behavior, medical treatment, history of refractoriness, psychotic features, family history, type of bipolar disorder (both type I and type II) and last episode must all be described (Delgado et al. 1990; Delgado et al. 1994). Only Cappiello et al. (Cappiello et al. 1997) described their patients with respect to schizoaffective, rapid cycling and mixed bipolar disorder.

3) The ATD paradigm must be applied according to a standardized method (the classic method is according to Young (Young et al. 1985). It is recommended to minimize the total amount of amino acid intake (50-75g); offering too much leads to variability because of vomiting or not ingesting the excessive drink. Beside, different ATD paradigms may result in different changes in plasma Trp levels. This holds true for reviewed studies; Cassidy et al. (Cassidy et al. 1998) found a decrease in plasma Trp levels of $77 \%$ after 
ATD and an increase of $7 \%$ in the placebo condition using the alternative ATD paradigm. Benkelfat et al. (Benkelfat et al. 1995) used the classic method and reported a decrease of $85 \%$ after Trp depletion and an increase of $45 \%$ in the placebo condition.

4) Ratio Trp: LNAAs must be assessed to indicate the effect.

5) Women should be tested in their follicular phase of the menstrual cycle because premenstrual mood change, hormonal levels and altered amino acid kinematics may confound mood change following ATD. To correct for confounding related to menstrual cycle, Benkelfat et al. (Benkelfat et al. 1995) applied the ATD paradigm in male subjects. Cassidy et al. (Cassidy et al. 1998) and Cappiello et al. (Cappiello et al. 1997) did not correct for menstrual cycle in women.

6) Mood changes should be assessed 5-7 hours after Trp depletion. To investigate changes in 5-HT receptor sensitivity, mood should be reassessed following Trp loading after ATD. Delgado et al. (Delgado et al. 1994) reported a bimodal mood response on the day after ATD; subjects refractory to treatment became more depressed, while anti-depressant responders became less depressed.

7) Mood should be rated using mania and depression scales and bimodal VAS, such as the bimodal POMS. ATD might elevate or lower mood in bipolar patients, probably dependent on previous episode. Measuring quick altering mood states can best be done by using VAS (like POMS) instead of clinical symptom checklists (HDRS or YMRS) (McNair et al. 1971). Cappiello et al. (Cappiello et al. 1997) and Cassidy et al. (Cassidy et al. 1998) did not use VAS scales, and therefore might have underestimated mood changes. Hence, Cappiello et al. (Cappiello et al. 1997) did report a mood-enhancing effect on YMRS scores.

In summary, until now, studies on ATD in bipolar patient were primary developed to investigate the 5-HT modulatory properties of lithium treatment. To investigate the serotonergic vulnerability in bipolar disorders per se, the ATD paradigm should be applied in remitted bipolar patients off medication, which is ethically and practically impossible. Therefore it is recommended to test the ATD paradigm in subjects with no prior psychiatric diagnosis but at a genetic risk for bipolar disorders. A standard ATD paradigm including control of confounding factors will enhance successful investigation of 5-HT vulnerability in psychiatric disorders. The effects of ATD have now been reported in first-degree relatives of unipolar depressives (Ellenbogen et al. 1999). 
First-degree relatives of depressed patients have been shown to report greater mood-lowering effect after Trp depletion compared to healthy control subjects (Benkelfat et al. 1994; Klaassen et al. 1999). As ATD in bipolar patients off medication is practically impossible, ATD needs to be done in healthy first-degree relatives of bipolar patients (type I and II) and healthy matched controls. Mood changes are suggested to be more pronounced in subjects with a positive family history of bipolar disorder compared to healthy matched controls.

\section{Protocol design}

Based on the available information on ATD paradigms previously applied in bipolar disorders, a research protocol has been developed to investigate the effects of ATD in firstdegree relatives of bipolar patients. The study has a placebo-controlled, double blind, crossover experimental design. The research population includes both women and men; premenopausal women will be tested in their follicular phase of the menstrual cycle. All subjects are free of any psychiatric diagnosis but have at least one first-degree relative with bipolar disorder, which is a major inclusion criterion. An explicit distinction is made between relatives with a bipolar disorder type I or type II diagnosis according to DSMIV criteria. Healthy matched control subjects are the reference group to whom mood effects are compared. Number of participants will be at least 15 per group according to previous findings in first-degree relatives in depressed patients (Klaassen et al. 1999). Treatment consists of a $75 \mathrm{~g}$ Trp-deficient AA-drink (see also Young et al. 1985)). The placebo mixture is supplemented with $3 \mathrm{~g}$ Trp (i.e. $4 \%$ ). Effects on mood (bimodal POMS) will be assessed before and within 5-7 hours after ATD. In statistical analyses, the between group's factor consists of three levels being no relative with bipolar disorder, a type I relative and a type II relative. It is hypothesized that subjects at genetic risk for bipolar disorders show more pronounced mood changes following ATD. The effects of ATD in first-degree relatives of bipolar patients may give insight in the 5-HT vulnerability in bipolar disorders.

\section{References}

Bellivier F, Leboyer M, Courtet P, Buresi C, Beaufils B, Samolyk D, Allilaire J, Feingold J, Mallet J, Malafosse A (1998) Association between the tryptophan hydroxylase gene and manic-depressive illness. Arch Gen Psychiatry 55: 33-7

Benkelfat C, Ellenbogen MA, Dean P. Palmour RM, Young SN (1994) Mood-lowering effect of tryptophan depletion. Enhanced susceptibility in young men at genetic risk for major affective disorders. Arch Gen Psychiatry 51: 687-97 
Benkelfat C, Seletti B, Palmour RM, Hillel J, Ellenbogen M, Young SN (1995a) Tryptophan depletion in stable lithium-treated patients with bipolar disorder in remission [letter; comment]. Arch Gen Psychiatry 52: 154-6 Bowden CL, Dickson J, Jr. (1997) Mania from dexfenfluramine [letter]. J Clin Psychiatry 58: 548-9 Cappiello A, Sernyak MJ, Malison RT, McDougle CJ, Heninger GR, Price LH (1997) Effects of acute tryptophan depletion in lithium-remitted manic patients: a pilot study. Biol Psychiatry 42: 1076-8 Carpenter LL, Anderson GM, Pelton GH, Gudin JA, Kirwin PD, Price LH, Heninger GR, MeDougle CJ (1998) Tryptophan depletion during continuous CSF sampling in healthy human subjects. Neuropsychopharmacology 19: $26-35$

Cassidy F, Murry E, Carroll BJ (1998) Tryptophan depletion in recently manic patients treated with lithium. Biol Psychiatry 43: 230-2

Delgado PL, Charney DS, Price LH, Aghajanian GK, Landis H, Heninger GR (1990) Serotonin function and the mechanism of antidepressant action. Reversal of antidepressant-induced remission by rapid depletion of plasma tryptophan [see comments]. Arch Gen Psychiatry 47: 411-8

Delgado PL, Price LH, Miller HL, Salomon RM, Aghajanian GK, Heninger GR, Charney DS (1994) Serotonin and the neurobiology of depression. Effects of tryptophan depletion in drug-free depressed patients. Arch Gen Psychiatry 51: 865-74

Ellenbogen MA, Young SN, Dean P, Palmour RM, Benkelfat C (1999) Acute tryptophan depletion in healthy young women with a family history of major affective disorder. Psychol Med 29: 35-46

Klaassen T, Riedel WJ, van Someren A, Deutz NEP, Honig A, van Praag HM (1999) Mood effects of 24-hour tryptophan depletion in healthy first degree relatives of patients with affective disorders. Biol Psychiatry 46: 489-97

Gross J, Franzek E, Wolozin BL, Riederer P, Murphy DL (1995) Primary structure of the serotonin transporter in unipolar depression and bipolar disorder. Biol Psychiatry 37: 215-23

Leyton M, Young SN, Blier P, Ellenbogen MA, Palmour RM, Ghadirian AM, Benkelfat C (1997) The effect of tryptophan depletion on mood in medication-free, former patients with major affective disorder.

Neuropsychopharmacology 16: 294-7

Marazziti D, Lenzi A, Cassano GB (1991) Serotonergic dysfunction in bipolar disorder. Pharmacopsychiatry 24: $164-7$

McNair DM, Lorr M, Droppleman LF (1971) Manual for the Profile of Mood States. Educational and Industrial Testing Service, Educational and Industrial Testing Service

Neumeister A, Praschak-Rieder N, Hesselmann B, Vitouch O, Rauh M, Barocka A, Tauscher J, Kasper S (1998) Effects of tryptophan depletion in drug-free depressed patients who responded to total sleep deprivation. Arch Gen Psychiatry 55: 167-72

Price LH, Charney DS, Delgado PL, Heninger GR (1989) Lithium treatment and serotoninergic function. Neuroendocrine and behavioral responses to intravenous tryptophan in affective disorder [see comments]. Arch Gen Psychiatry 46: 13-9

Price LH, Malison RT, McDougle CJ, McCance Katz EF, Owen KR, Heninger GR (1997) Neurobiology of tryptophan depletion in depression: effects of m-chlorophenylpiperazine (mCPP). Neuropsychopharmacology 17: $342-50$ 
Price LH, Malison RT, McDougle CJ, Pelton GH, Heninger GR (1998) The neurobiology of tryptophan depletion in depression: effects of intravenous tryptophan infusion. Biol Psychiatry 43: 339-47 Young LT, Warsh JJ, Kish SJ, Shannak K, Hornykeiwicz (1994) Reduced brain 5-HT and elevated NE turnover and metabolites in bipolar affective disorder. Biol Psychiatry 35: $121-7$

Young SN, Smith SE, Pihl RO, Ervin FR (1985) Tryptophan depletion causes a rapid lowering of mood in normal males. Psychopharmacology Berl 87: 173-7 


\title{
Effects of Acute Tryptophan Depletion on mood and cortisol release in first-degree relatives of type I and type II bipolar patients and healthy matched controls
}

\begin{abstract}
Biological vulnerability for bipolar disorders $(\mathrm{BD})$ in relatives of $\mathrm{BD}$ patients has not as yet been established. Serotonergic vulnerability was studied, using Acute Tryptophan Depletion (ATD), in healthy first-degree relatives of BD patients and healthy controls. The effects of ATD on mood and cortisol release in 30 healthy adult, lifetime symptom free, unaffected first-degree relatives of BD patients (Family History; FH) were compared with effects in 15 healthy matched controls in a placebo-controlled, double-blind, crossover design. During ATD and placebo, salivary cortisol response was also assessed during a stress-inducing speech task (SIST).

First-degree relatives of type II BD patients (FH II) showed an elevation of mood, whereas control subjects and relatives of type I BD patients (FH I) showed a lowering of mood after ATD. ATD was followed by a decrease in cortisol level in both FH subgroups, but not in the controls.

The results suggest a serotonergic vulnerability that affected mood in FH II subjects and cortisol release in both FH I and FH II subjects.
\end{abstract}

S Sobczak, A Honig, NA Nicolson, WJ Riedel. Neuropsychopharmacology, accepted 


\section{Introduction}

In the pathophysiology of bipolar disorders (BD), several lines of evidence support the hypothesis of an underlying dysfunction of the serotonergic system.

Increased platelet serotonin (5-hydroxytryptamine or 5-HT), a lower maximal velocity $(V \max )$ of 5-HT platelet uptake and decreased central serotonergic neurotransmitter activity, indicated by decreased 5HIAA/5-HT ratios, have been reported in untreated bipolar depressed patients (Wirz Justice and Puhringer 1978; Marazziti et al.1991; Leake et al. 1991; Young et al. 1994). Polymorphism in the 5-HT-transporter, 5-HT receptors and the tryptophan hydroxylase gene have been associated with the pathophysiology of BD (Kunugi et al. 1997; Oruc et al. 1997; Bellivier et al. 1998).

Acute Tryptophan depletion (ATD) is a direct method to investigate central serotonergic vulnerability (Delgado et al. 1994). In this procedure, a lowering of central 5-HT synthesis is accomplished by giving subjects a $50-100 \mathrm{~g}$ balanced amino acid-drink (AA-drink), composed of amino-acids, including large neutral amino acids (LNAAs: tyrosine, valine, leucine, isoleucine and phenylalanine), and devoid of tryptophan (Trp) (Young 1991). In remitted depressed patients, ATD induced depressive symptoms (Smith 1997; Aberg-Wistedt et al.1998; Moreno 2000). In healthy first-degree relatives of depressed patients, ATD induced a modest lowering of mood, compared to healthy control subjects (Benkelfat et al. 1994; Klaassen et al. 1999). It thus appears that individuals without prior depressive episodes, but at a genetic risk for depression, may be biologically predisposed to mood-lowering effects of ATD.

Until now, little attention has been paid to the effects of ATD in BD, and results are inconsistent (Sobczak et al. 2000). Cappiello et al. (1997) reported a significant increase in manic symptoms in recently remitted 91 month) lithium-treated manic patients. In BD patients who were stable for a longer period (1-15 years), ATD did not induce significant mood changes (Benkelfat et al. 1995; Cassidy et al. 1998; Hughes et al. 2000). In BD patients abnormalities in cortisol homeostasis has been described. Cortisol may therefore be used as a biological marker of BD. Serotonin increases cortisol release by stimulating 5- $\mathrm{HT}_{1 \mathrm{~A}}$ and 5- $\mathrm{HT}_{2 \mathrm{~A}}$ receptors in hippocampal areas (Nurnberger et al. 1990; Swann et al. 1992; Vieta et al. 1999). Changes in cortisol following challenge with selective 5-HT stimulating agents are possible biological markers to assess brain 5-HT function (Abel and Cleare 1999; Cleare et al., 1998). A blunted cortisol response following an intravenous Trp challenge in BD patients, as compared to controls, provides evidence for brain 5-HT 
dysfunction (Nurnberger et al., 1990). To our knowledge, the effects of ATD on stressinduced cortisol release have never been described, but might provide an important indicator of central 5-HT vulnerability. Symptoms (according to DSM IV) of BD psychopathology might contribute to effects of ATD. Therefore we differentiated between relatives of BD type I and BD type II patients. This is the first study of 5-HT vulnerability in which such a distinction was made between first-degree relatives of type I (FH I) and type II BD (FH II) patients.

To gain additional insight into the nature of this biological vulnerability, the current study investigated serotonergic vulnerability, as reflected in mood and cortisol responses to ATD in healthy first-degree relatives of BD patients (FH). ATD effects in FH subjects were compared with those in healthy matched controls. We hypothesized central serotonergic vulnerability in FH subjects to be reflected by i) an elevation in mood, as has been reported in BD patients, ii) more pronounced blunting of stress-induced cortisol release following ATD compared to controls iii) mood and cortisol effects of ATD were hypothesized to be different in FH I and FH II subjects.

\section{Methods}

\section{Subjects}

Subjects were first-degree relatives of BD patients and healthy matched controls (see Table I). Family members were recruited via BD patients in treatment at the Department of Psychiatry, University Hospital Maastricht, via the consumer organization for manic-depressive patients and their families, and via advertisements in local newspapers. Healthy control subjects were also recruited via a newspaper advertisement.

Of the 47 subjects who enrolled in the study, 2 subjects in the $\mathrm{FH}$ group were excluded during the experiment because of intolerance of the drink.

The included subjects were $30 \mathrm{FH}$ ( 8 men and 22 women) and 15 controls ( 4 men, 11 women), aged 19-64 years. Table 1 shows demographic characteristics of all subjects who completed the experiment. Relatives were daughters $(n=11)$, sons $(n=4)$, siblings $(n=4)$, mothers $(n=8)$ and fathers $(n=3)$. Nineteen had a first-degree relative with a BD type I diagnosis, and eleven subjects were relatives of BD type II patients. Control subject were successfully matched to FH subjects with respect to age, body mass index (BMI) and intelligence quotient (IQ). There were no differences between $\mathrm{FH}$ subjects and controls with 
respect to number of pre-menopausal versus postmenopausal women or to use of oral anticonceptives or other medication. Overall, 22 female subjects were pre-menopausal and 11 were postmenopausal. Seven women used oral anticonceptives. Seven subjects were taking medication with no interference on ATD or cortisol.

Table I. Demographic characteristics, bipolar disorder family loading $\left(1^{\text {tt }}, 2^{\text {nd }}\right.$ and $3^{\text {rd }}$ degree), SCL-90, Young Mania Rating Scale (YMRS), Hamilton Depression Rating Scale (HDRS), total scores and General Behavior Inventory (GBI) scores of the subjects; mean ( \pm SE).

\begin{tabular}{|c|c|c|}
\hline \multicolumn{3}{|l|}{$($ mean \pm se $)$} \\
\hline Women & $\mathrm{n}=22$ & $\mathrm{n}=11$ \\
\hline Men & $n=8$ & $n=4$ \\
\hline Rel. of Type I & $n=19$ & \\
\hline \multirow{2}{*}{\multicolumn{3}{|c|}{ Family members: }} \\
\hline & & \\
\hline Bipolar disorder & 1.3 & 0.0 \\
\hline Age & $41.4 \pm 2.6$ & $40.3 \pm 4.0$ \\
\hline 10 & $117.2 \pm 2.0$ & $117.3 \pm 4.1$ \\
\hline BMI & $24.7 \pm 0.6$ & $24.3 \pm 0.9$ \\
\hline SCL-90 & $103.5 \pm 2.4$ & $100.3 \pm 2.7$ \\
\hline - depression & $18.6 \pm 0.6$ & $17.1 \pm 0.3$ \\
\hline YMRS & $1.2 \pm 0.4$ & $0.9 \pm 0.4$ \\
\hline HDRS & $1.4 \pm 0.3$ & $1.2 \pm 0.4$ \\
\hline \multicolumn{3}{|l|}{ GBI } \\
\hline - depression & $55.7 \pm 1.7$ & $53.6 \pm 2.7$ \\
\hline - mania/hypomania & $23.9 \pm 0.7$ & $24.6 \pm 1.8$ \\
\hline - biphasic & $8.3 \pm 0.4$ & $8.3 \pm 0.7$ \\
\hline
\end{tabular}

\section{Design}

The study used a placebo-controlled, double blind, crossover design. The within subjectsfactor treatment condition consisted of two levels: placebo and ATD. The order of treatment was balanced over two test days, spaced 1-2 weeks apart. The between-subjects factor FH differentiated subjects with $(\mathrm{FH})$ or without (controls) at least one first-degree relative with BD. A further distinction was made between having a relative with a type I or type II BD (FH I vs. FH II).

To eliminate possible bias due to premenstrual symptoms, all pre-menopausal women were tested in the follicular phase of the menstrual cycle (Menkes et al. 1994; Rasgon et al. 2000). 


\section{Amino Acid Mixtures}

The Trp-deficient AA-drink contained a total of $75 \mathrm{~g}$ of different amino acids with the amounts of each specific amino acid according to the proportions described by Young et al. (1985): $4.1 \mathrm{~g}$ L-alanine, $2.4 \mathrm{~g}$ glycine, $2.4 \mathrm{~g}$ L-histidine, $6.0 \mathrm{~g} \mathrm{~L}$-isoleucine, $10.1 \mathrm{~g} \mathrm{~L}$-leucine, $6.7 \mathrm{~g}$ L-lysine, $4.3 \mathrm{~g}$ L-phenylalanine, $9.2 \mathrm{~g}$ L-proline, $5.2 \mathrm{~L}$-serine, $4.3 \mathrm{~g}$ L-threonine, $5.2 \mathrm{~g} \mathrm{~L}$ tyrosine, $6.7 \mathrm{~g} \mathrm{~L}$-valine, $3.7 \mathrm{~g} \mathrm{~L}$-arginine, $2.0 \mathrm{~g}$ L-cysteine, $3.0 \mathrm{~g}$ L-methionine. The placebo mixture contained the same amino-acids, plus $3.0 \mathrm{~g}$ tryptophan. To provide caloric energy, $20 \mathrm{~g}$ of a maltodextrin (MD/ fat mix) (33\% sunflower and $67 \%$ maltodextrin) was added. Both drinks were prepared by adding $300 \mathrm{ml}$ tap water with the addition of strawberry or banana flavoring to compensate for the unpleasant taste (see also Schmitt et al. 2000).

\section{Procedure}

\section{Subjects}

In the $\mathrm{FH}$ group, the main inclusion criterion was having at least one first-degree relative with BD. Control subjects were free of any psychopathologic family loading. To assess $\mathrm{FH}$, all subjects were interviewed with an abbreviated version of the Family History Research Diagnostic Criteria (FHRDC) (Endicott et al.1975). Individual diagnoses (type I or type II $\mathrm{BD}$, according to DSMIV) of the patients were verified via each patient's own psychiatrist. All participants were given a standardized psychiatric examination (Mini International Neuropsychiatric Interview; MINI) (Sheehan 1994) to determine the present psychiatric state, according to DSM IV criteria. The 17-item Hamilton Depression Rating Scale (HDRS) (Hamilton 1967), the Young Mania Rating Scale (YMRS) (Young et al. 1978) and the SCL90 (Arrindell and Ettema 1986) were used to verify the absence of depressive, manic and general psychiatric symptomatology. As an extra check on psychopathology, all subjects filled out the General Behavior Inventory (GBI), which identifies lifetime sub-clinical affective symptoms (Depue et al. 1981; Depue et al. 1985; Depue et al.1989; Klein et al.1986). Included control and FH subjects did not differ on GBI scores, which meant that they were successfully matched (see Table 1).

Exclusion criteria were current or past use of psychopharmacological medication, lifetime psychiatric disorder including alcohol or drug abuse, current active physical illness, lactation and pregnancy. Physical health was assessed by means of a health questionnaire, a standard physical examination by a physician and a urine screening. The urine test (Combur $\mathbb{B}$ ) included assessment of leukocytes, nitrite, $\mathrm{pH}$, protein, glucose, ketones, urobilinogen, 
bilirubin and erythrocytes. A Quick View, one-step pregnancy test (Quidel囚) was carried out in female subjects to check for unsuspected pregnancy.

One control subject was matched with 2 FH subjects with respect to sex, age, BMI and IQ. Intelligence (IQ) was estimated using Groninger Intelligence Test (GIT) subtasks (Vocabulary, Mental Rotation, Mental Arithmetic and Word Analogies) (Luteijn 1966). The Medical Ethics Committee of the Academic Hospital of Maastricht approved the study. All participants gave written informed consent.

The test days

On each test day, the subjects arrived at 8:30 a.m. after an overnight fast. At 10:00 a.m. $\left(\mathrm{t}_{0}\right)$ (all timepoints $\mathrm{t}(-)_{\mathrm{X}}$ refer to $\mathrm{X}$ hours (before) after $\mathrm{t}_{0}$ ) the subjects were administered the AAdrink, which had to be consumed within two hours. At $t_{2}$, all subjects ate a protein-poor lunch which consisted of protein-free bread, tomatoes, marmalade, apples, oranges and herbal tea or decaffeinated coffee.

Mood assessment was completed at baseline at 8:45 am (t. $)$, and at $\mathrm{t}_{5}$ and $\mathrm{t}_{7}$. The SIST started at $t_{6.75}$, when the effects of ATD were expected to be present. Three baseline cortisol measurements were collected before the SIST, at $t_{5}, t_{6.5}$ and $t_{6.75}$. After the SIST, saliva cortisol samples were taken every 15 minutes; at $t_{7}, t_{7.25}, t_{7.5}$ and finally at $t_{7.75}$. Previous studies (van Eck et al., 1996) showed cortisol response to the SIST to be maximal during this time interval.

Blood samples were taken twice, at $t_{0}$ and $a t_{6.5}$. Blood pressure and pulse rate were assessed before mood rating at $t_{0}$, and at $t_{5}$.

\section{Mood assessments}

Mood was assessed with the abbreviated bimodal Profile of Mood States (POMS) (McNair et al. 1971) and the Bond \& Lader (B\&L) (Bond and Lader 1974) visual analogue scales. The POMS consists of 32 bipolar sets of adjectives, which measure 5 mood dimensions: anger, depression, fatigue, tension and vigor.

The B\&L is composed of 16 mood items, which measure alertness, contentment, and calmness.

\section{Stress Inducing Speech Task (SIST)}

The SIST consisted of a 5-minute oral presentation, in front of a video-camera, preceded by 10 minutes of preparation. In a slightly modified version of the task used by van Eck et al. 
(1996), subjects were first given a list of 4 mood terms. Three parallel versions of the list were available. Subjects were instructed to elaborate on personal experiences evoked by these mood terms and were told that the speech would be video-recorded for later evaluation by a panel of psychiatrists and psychologists (van Eck et al. 1996; Nicolson et al. 1997). After the screening a SIST practice session, in which an identical version of the mood term list was used. At the end of the second test day subjects were debriefed.

\section{Salivary cortisol measurements}

Saliva was collected with a cotton roll (Salivette $\&$, Sarstedt). Uncentrifuged samples were stored at $-20^{\circ} \mathrm{C}$ until analysis. Free cortisol levels were determined in duplicate by direct radioimmunoassay, using an HPLC-purified preparation of cortisol-3-CMO-histamine ${ }^{125} \mathrm{I}$ (Ansseau et al. 1984; Sulon, personal communication).

\section{Somatic side effects}

Severity of side effects was determined by a questionnaire with 17 items rated on 4-point scales. The total sum of reported complaints represents the overall severity of side effects.

\section{Serum amino acids}

Serum was taken by venapuncture in sodium heparin tubes. Blood samples were immediately set on ice and centrifuged ( $3000 \mathrm{rpm}, 10$ minutes) within one hour. Plasma samples were mixed with sulfasalicyl acid and frozen at $-80^{\circ} \mathrm{C}$ until analysis. Total concentrations of plasma Trp and ratio of Trp: LNAAs were determined by high-performance liquid chromatography (HPLC) (van Eijk et al. 1993).

\section{Statistical analysis}

Outcome variables were analyzed using General Linear Model (GLM) for repeated measures. Within-subjects factor was treatment ( 2 levels: ATD or placebo); the between-subjects factor was family history ( 3 levels: controls, FH I, or FH II). Univariate contrasts were used to test the primary hypothesis of difference between controls and FH subjects (controls vs. FH I + II) as well as the hypotheses of differences between controls and $\mathrm{FH} \mathrm{I}$ and $\mathrm{FH} \mathrm{II}$ relatives separately (controls vs. FH I and controls vs. FH II). Differences in baseline values between test sessions were assessed using GLM. When no baseline differences were found, baseline values were left out of analyses. 
Cortisol values were ${ }^{10} \log$-transformed prior to statistical testing, since cortisol distributions were skewed. Missing values were corrected by using mean of previous and next cortisol values.

Wilcoxon Matched-Pairs Signed-Ranks Test was used to test differences in physical complaints. Statistical analyses were performed with SPSS 9.0 for Windows.

\section{Results}

\section{Plasma Trp levels}

Due to procedural difficulties $1.4 \%$ of serum samples were missing.

Plasma Trp concentrations and ratio Trp: LNAAs did not differ at baseline between groups or treatment conditions, but decreased significantly $[F(1,28)=151.11, \mathrm{p}<0.001]$ over time in the ATD condition. Relative to baseline, ATD resulted in a 57\% decrease in plasma Trp and a $70 \%$ decrease in ratio Trp: LNAAs. After receiving placebo, there was a $36 \%$ increase in plasma Trp and $1.0 \%$ increase in the ratio Trp: LNAAs. Results are summarized in Figure 1.

Ratio L-Trp: LNAA's

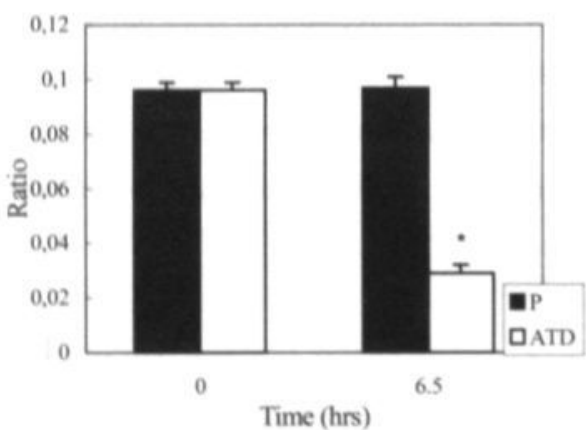

Plasma Trp

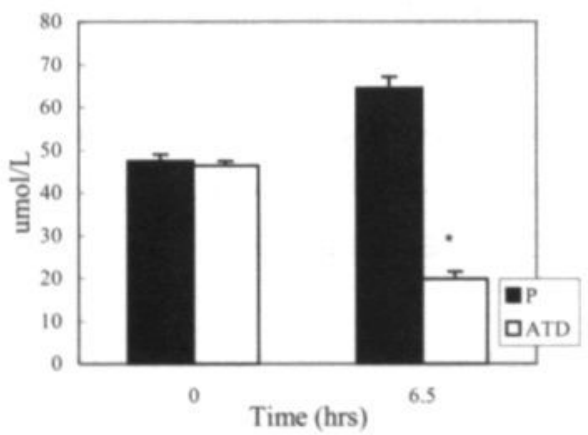

Figure 1. Mean $\left( \pm\right.$ SE) serum ratio Trp/ LNAAs (right) and Trp concentrations (left), at $t_{0}$ and $t_{65 .}{ }^{*} p=0.05$.

\section{Subjective mood ratings}

One subjects was excluded from the analyses due to 2 missing POMS scores.

At baseline, POMS scores did not differ significantly between $\mathrm{FH}$ and controls or experimental conditions. Figure 2 shows the mood response after ATD compared to placebo. Controls and FH I did not differ in ATD induced mood response, but compared to these 
groups, FH II subjects reported an overall improvement in mood, indicated by the POMS total score $[F(2,40)=3.35, \mathrm{p}<0.05]$, a decrease in fatigue $[F(2,40)=3.65, \mathrm{p}<0.05]$ and a trend towards lower anger $[F(2,40)=3.13, p<0.1]$. This is an overall effect; within each $\mathrm{FH}$ group mood changes following ATD were not significant. There was no main effect of ATD, overall interaction effect of $\mathrm{FH}$ with ATD, or effect of treatment order.

Scores on B\&L subscales did not differ at baseline and after ATD between experimental conditions or FH groups.

Difference POMS Total score (P minus ATD)

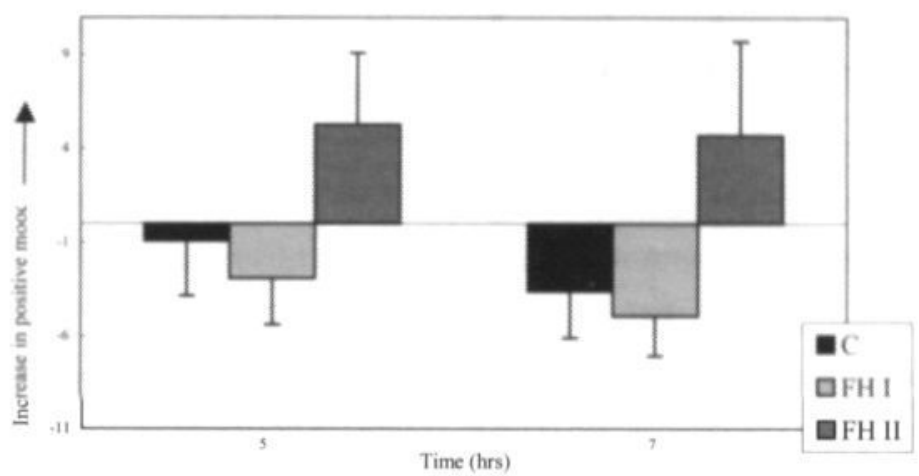

Figure 2. Effect (mean $\pm \mathrm{SE}$ ) of type BD (C, control subjects; first-degree relatives; FH I and FH II subjects) and ATD on POMS total score at $\mathrm{t}_{5}$ and $\mathrm{t}_{7}$. Values are corrected for placebo (P).

\section{Cortisol measurements}

Cortisol response to the SIST

In both ATD and placebo conditions, cortisol levels increased over time in response to the SIST $[F(6,36)=3.60, \mathrm{p}<0.05]$. A cortisol peak occurred immediately after the speech $\left(\mathrm{t}_{7}\right)$. Compared to pre-speech levels $\left(\mathrm{t}_{5}\right)$, cortisol was increased by a mean of $21 \%$. The three groups did not differ in pre-speech cortisol levels or in the magnitude of the SIST-induced cortisol response .

\section{Effects of ATD}

Figure 3 shows the effect of ATD on cortisol release compared to placebo (the cortisol values in the placebo condition were subtracted). 
In FH subjects (both FH I and FH II) ATD resulted in a significant decrease in cortisol $[F(1,28)=5.26, \mathrm{p}<0.05]$ compared to placebo. In controls cortisol was lower after ATD compared to placebo. There were no effects of treatment order.

Of the 630 cortisol samples, $0.4 \%$ were missing; two subjects ( $1 \mathrm{FH}$ and 1 control) were not included in cortisol data analyses, because of extremely high cortisol levels (above 1600 $\mathrm{nmol} / \mathrm{l})$ probably in response to difficulties in taking blood.

Effects of ATD on cortisol (ATD minus P)

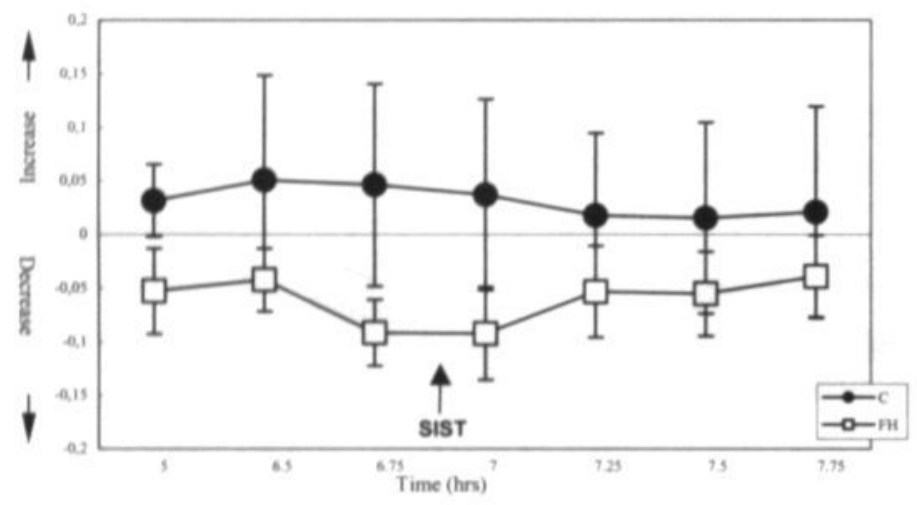

Figure 3. SIST-induced cortisol response after ATD (mean \pm SE), expressed as difference from the placebo (P) condition. Effect of family history (FH) (C, control subjects) on salivary cortisol (10-log concentration: $\mu \mathrm{g} / \mathrm{dl})$.

\section{Somatic side effects}

Sum of reported side effects did not differ at baseline or between the two experimental conditions. Correlation analysis of B\&L and POMS mood ratings with side effects revealed no significant correlations of sum complaints with mood changes following ATD.

\section{Intercorrelations}

Pearson's correlation analyses showed no significant associations between ATD-induced cortisol response and changes in mood ratings. 


\section{Discussion}

The aim of the study was to investigate central 5-HT vulnerability in first-degree relatives of BD patients following a double-blind placebo-controlled ATD paradigm. Plasma ratio Trp: LNAAs and Trp decreased significantly, which indicates an adequate ATD. Tyrosine availability did not appear to have interfered with the effects of ATD, as levels did not differ between experimental conditions.

We found no overall differences between controls and FH subjects in ATD-induced mood response. However, FH II subjects reported a tendency to mood elevation, whereas FH I subjects and controls experienced a slight mood lowering following ATD. Side effects were unlikely to have interfered with mood changes after ATD, as the sum of reported side effects did not differ between ATD and placebo.

There are no studies available that describe effects of ATD on different types of BD. Our results are in line with a previous report of elevated mood in recently remitted BD patients, who were not further differentiated as type I or type II, following ATD (Cappiello et al. 1997).

Previous studies of ATD in BD patients suggest that BD patients who were recently in remission were more vulnerable to the effects of ATD compared to BD patients who were in remission for a longer period (Benkelfat et al., 1995; Cappiello et al. 1997). It was suggested that successful short-term lithium treatment was more dependent on 5-HT availability than successful long-term prophylaxis with lithium. This implies a strong influence of 'state' variables on vulnerability to ATD in BD patients. However previous studies on ATD in BD patients did not include healthy subjects as a control group and drawing conclusions about 'trait' influence on mood changes following ATD is therefore hampered. ATD-induced mood lowering in depressed patients and their first-degree relatives suggest central serotonergic vulnerability (Klaassen et al. 1999; Delgado et al. 1991). We suggest that mood changes after ATD in FH II subjects might be explained by the same vulnerability. The discrepancy that FH II of BD patients report an increase in mood whereas relatives of unipolar patients report a decrease in mood may possibly be due to vulnerability to mania in FH II subjects. Both mania and depression have been associated with hyposerotonergic activity (Goodwin, 1990; Price, 1990; Young et al., 1994).

Suicide has also been associated with low central 5-HT (Pfeffer et al. 1998; Asberg 1997). Meltzer et al. (1984) described an increased serotonergic vulnerability in depressed patients with a history of suicidal activity. 
Higher rates of suicide has been described in BD type II compared to BD type I patients (Rihmer and Pestality 1999). It is speculated that suicide is another independent factor which may contribute to serotonergic vulnerability in BD type II psychophysiology.

Compared to controls, FH I subjects did not show mood changes after ATD, which may suggest a biological distinction between BD type I and type II. FH I subjects are characterized by cognitive deficits (Sobczak et al. in press). Cognitive dysfunctions in BD patients show a pattern similar to schizophrenia (Krabbendam et al. 2000). Cognitive deficits have been described in FH I and not in FH II subjects (Sobczak et al. in press). It was suggested that BD type I share more similarities with a primary psychotic spectrum whereas BD type II is characterized by primary affective symptoms. This hypothesis appears to be consistent with the absence of mood changes observed in schizophrenic patients after ATD (Sharma et al. 1997). Inconsistent findings of previous studies on ATD in BD may possibly be due to a failure to take differences in BD type I and BD type II into account.

The significant decrease in cortisol release in FH subjects following ATD suggests a 5-HT vulnerability in FH subjects affecting the HPA-axis. Decrease in cortisol response is consistent with previous described changes in 5-HT responsivity in BD (Vieta et al. 1999) a blunted cortisol response has been described in $\mathrm{BD}$ compared to controls following intravenous Trp challenge (Nurnberger et al. 1990).

ATD-induced blunted cortisol response might have been attenuated due to the weak stressinducing effect of the SIST procedure. The cortisol peak after the SIST (21\%) was modest compared to the previously reported $( \pm$ ) $90 \%$ increase in saliva cortisol concentrations (van Eck et al. 1996) possibly due to procedural differences in our experiment. First, we used a modified and perhaps less stressful version of the SIST; in the van Eck et al. study (1996), subjects were unaware that they would be asked to deliver a speech. Second, our subjects underwent the SIST three times: once as a training procedure, once after ATD, and once after placebo.

The ATD-induced mood changes are not likely to be attributable to changes in cortisol release. First, correlation analyses revealed no significant association. Second, the reported mood changes were specific for FH II subjects, whereas the cortisol response did not differ between FH I or FH II subjects. Third, mood ratings showed no differences between assessments immediately before and after the SIST.

In conclusion, this study provides evidence for 5-HT vulnerability affecting the HPA-axis and mood in FH subjects. The 5-HT vulnerability affecting mood was present only in FH II subjects and not in FH I subjects. This is consistent with a primarily psychotic 
psychopathology in BD type I and a primarily affective psychopathology in BD type II patients.

These findings should be replicated in a larger research population with BD type I and type II patients as well as their relatives.

\section{References}

Abel KM, Cleare AJ (1999) Peripheral hormonal responses to D-fenfluramine as a probe of central serotonergic function in humans. Psychopharmacol 142(1): 68-72

Aberg-Wistedt A, Hasselmark L, Stain-Malmgren R, Aperia B, Kjellman BF, Mathe AA (1998) Serotonergic vulnerability in affective disorder: a study of the tryptophan depletion test and relationships between peripheral and central serotonin indexes in citalopram-responders. Acta Psychiatr Scand 97: 374-80

Ansseau M. Sulon J, Doumont A, Cerfontaine JL, Legros JJ, Sodoyez JC, Demey-Ponsart E ( 984 ) Use of saliva cortisol in the dexamethasone suppression test. Psychiatry Res 13(3): 203-11

Arrindell WA, Ettema JHM (1986) SCL-90. Een multidimensionele psychopathologic indicator [SCL-90. A multidimensional indicator of psychopathology]. Lisse, The Netherlands, Swets \& Zeitlinger.

Asberg M (1997) Neurotransmitters and suicidal behavior. The evidence from cerebrospinal fluid studies. Ann N Y Acad Sci 836: 158-81.

Bellivier F, Leboyer M, Courtet P, Buresi C, Beaufils B, Samolyk D, Allilaire J, Feingold J, Mallet J, Malafosse A (1998) Association between the tryptophan hydroxylase gene and manic-depressive illness. Arch Gen Psychiatry 55: 33-7

Benkelfat C, Ellenbogen MA Dean P, Palmour RM, Young SN (1994) Mood-lowering effect of tryptophan depletion. Enhanced susceptibility in young men at genetic risk for major affective disorders. Arch Gen Psychiatry 51(9): 687-97

Benkelfat C, Seletti B, Palmour RM, Hillel J, Ellenbogen M, Young SN (1995) Tryptophan depletion in stable lithium-treated patients with bipolar disorder in remission [letter; comment]. Arch Gen Psychiatry 52(2): 154-6 Bond A, Lader M (1974) The use of analogue scales in rating subjective feelings. Br J Med Psych 80: $1-46$ Cappiello A, Sernyak MJ, Malison RT, McDougle CJ, Heninger GR, Price LH (1997) Effects of acute tryptophan depletion in lithium-remitted manic patients: a pilot study. Biol Psychiatry 42(11): 1076-8 Cassidy F, Murry E Carroll BJ (1998)Tryptophan depletion in recently manic patients treated with lithium. Biol Psychiatry 43(3): 230-2

Cleare AJ, Murray RM, Sherwood RA, O'Keane V (1998) Abnormal 5-HT1D receptor function in major depression: a neuropharmacological challenge study using sumatriptan. Psychol Med 28(2): 295-300

Delgado PL, Charney DS, Price LH, Aghajanian GK, Landis H, Heninger GR (1990) Serotonin function and the mechanism of antidepressant action. Reversal of antidepressant-induced remission by rapid depletion of plasma tryptophan [see comments]. Arch Gen Psychiatry 47(5): 411-8

Delgado PL, Price LH, Miller HL, Salomon RM, Aghajanian GK, Heninger GR, Charney DS (1994) Serotonin and the neurobiology of depression. Effects of tryptophan depletion in drug-free depressed patients. Arch Gen Psychiatry 51(11): 865-74 
Delgado PL, Price LH, Miller HL, Salomon RM, Licinio J, Krystal JH, Heninger GR, Charney DS (1991) Rapid serotonin depletion as a provocative challenge test for patients with major depression: relevance to antidepressant action and the neurobiology of depression. Psychopharmacol Bull 27(3): $321-30$

Depue RA, Slater J, Wolfstetter-Kausch H, Klein D, Goplerud E, Farr D (1981) A behavioral paradigm for identifying persons at risk for bipolar depressive disorder: A conceptual framework and five validation studies [Monograph]. J Abnorm Psychol 90: 381-437

Depue RA, Kleiman RM, Davis P, Hutchinson M, Krauss SP (1985) The behavioral high-risk paradigm and bipolar affective disorder, VIII: Serum cortisol in nonpatient cyclothemic subjects selected by the general behavior inventory. Am J Psychiatry 142: 175-81

Depue RA, Krauss S, Spoont MR, Arbisi P (1989) General behavior inventory identification of unipolar and bipolar affective conditions in a nonclinical university population. J Abnorm Psychol 98 (2): 117-26

Endicott J, Andreasen NC, Spitzer RL (1975) Family History -Research Diagnostic Criteria. New York, Biometrics Research, New York State Psychiatric Institute Goodwin F, Ghaemi SN (1998) Understanding manic-depressive illness. Arch Gen Psychiatry 55(1): 23-5 Hamilton M (1967) Development of a rating scale for primary depressive illness. Br J Soc Clin Psychol 6(4): 278-96

Holsboer F, Lauer CJ, Schreiber W, Krieg JG (1995) Altered hypothalamic-pituitary-adrenocortical regulation in healthy subjects at high familial risk for affective disorders. Neuroendocinology $62: 340-7$

Hughes JH, Dunne F, Young AH (2000) Effects of acute tryptophan depletion on mood and suicidal ideation in bipolar patients symptomaticafily stabie on fithium. Br S Psychiatry i 77: 447-5i

Klaassen T, Riedel WJ, van Someren A, Deutz NEP, Honig A, van Praag HM (1999) Mood effects of 24-hour tryptophan depletion in healthy first degree relatives of patients with affective disorders. Biol Psychiatry 46 : 489-97

Klein D, Depue RA, Slater J (1986) Inventory identification of cyclothymia: IX. Validation in offspring of bipolar I patients. Arch Gen Psychiatry 43: 441-5

Krabbendam L, Honig A, Wiersma J, Vuurman EFPM, Hofman PAM, Derix MMA, Nolen WA, Jolles J (2000) Cognitive dysfunctions and white matter lesions in patients with bipolar disorder in remission [In Process Citation]. Acta Psychiatr Scand 101(4): 274-80

Kunugi H, Hattori M, Kato T, Tatsumi M, Sakai T, Sasaki T, Hirose T, Nanko S (1997) Serotonin transporter gene polymorphisms: ethnic difference and possible association with bipolar affective disorder. Mol Psychiatry 2(6): 457-62

Leake A, Fairbaim AF, McKeith IG, Ferrier IN (1991) Studies on the serotonin uptake binding site in major depressive disorder and control post-mortem brain: Neurochemical and clinical correlates. Psychiatry Res 39: $155-65$

Luteijn F (1966) [A new abbreviated Groninger Intelligence Test]. Ned Tijdschr Psychol 21(10): 675-82

Maj M, Ariano MG, Arena F, Kemali D (1984) Plasma cortisol, catecholamine and cyclic AMP levels, response to dexamethasone suppression test and platelet MAO activity in manic-depressive patients. A longitudinal study. Neuropsychobiology $11(3): 168-73$

Marazziti D, Lenzi A, Cassano GB (1991) Serotoninergic dysfunction in bipolar disorder. Pharmacopsychiatry 24(5): $164-7$ 
McNair DM, Lorr M, Droppleman LF (1971) Manual for the profile of mood states. San Diego, CA, Educational and Industrial Testing Services

Meltzer HY, Perline R. Tricou BJ, Lowy M, Robertson A (1984) Effect of 5-hydroxytryptophan on serum cortisol levels in major affective disorders. II. Relation to suicide, psychosis, and depressive symptoms. Arch Gen Psychiatry 41(4): 379-87

Menkes DB, Coates DC. Fawcett JP (1994) Acute tryptophan depletion aggravates premenstrual syndrome. J Affect Disord 32(1): 37-44

Moreno FA, Heniger GR, McGahuey CA, Delgado PL (2000) Tryptophan depletion and risk of depression relapse: a prospective study of tryptophan depletion as a potential predictor of depressive episodes. Biol Psychiatry 48(4): 327-9

Nicolson N, Storms C, Ponds R, Sulon J (1997) Salivary cortisol levels and stress reactivity in human aging. J Geront: Med Sci 52A: M68-75

Nordstrom P, Samuelsson M, Asberg M, traskman-bendz L, Asberg-Wistedt A, Nordin C, Bertilsson L. (1994) CSF 5-HIAA predicts suicide risk after attempted suicide. Suicide Life Threat Behav 24(1): 1-9

Numberger JI Jr, Berrettini W, Simmons Alling S, Lawrence D, Brittain H (1990) Blunted ACTH and cortisol response to afternoon tryptophan infusion in euthymic bipolar patients. Psychiatry Res 31(1): 57-67

Oruc L, Verheyen GR, Furac I, Jakovljevic M, Ivezic S, Raeymaekers P. Van Broeckhoven C (1997)

Association analysis of the 5-HT2C receptor and 5-HT transporter genes in bipolar disorder. Am J Med Genet $74(5): 504-6$

Pfeffer CR, McBride PA, Anderson GM, Kakuma T, Fensterheim L, Khait V (1998) Peripheral serotonin measures in prepubertal psychiatric inpatients and normal children: associations with suicidal behavior and its risk factors. Biol Psychiatry 44: 568-77

Price LH, Charney DS, Delgado PL, Heniger GR (1990) Lithium and serotonin function:implications for the serotonin hypothesis of depression. Psychopharmacol 100: 3-12

Rasgon N, McGuire M, Tanavoli S, Fairbanks L, Rapkin A (2000) Neuroendocrine response to an intravenous L-tryptophan challenge in women with premenstrual syndrome. Fertil Steril 73(1): 144-9

Reilly JG, McTavish SF, Young AH (1997) Rapid depletion of plasma tryptophan: a review of studies and experimental methodology. J Psychopharmacol Oxf 11(4): 381-92

Rihmer Z, Pestality P (1999) Bipolar II disorder and suicidal behavior. Psychiatr Clin North Am 22 (3): $667-73$

Schmitt JAJ, Jorissen BL, Sobczak S, Van Boxtel MPJ, Hogervorst E, Deutz NEP, Riedel WJ (2000)

Tryptophan depletion impairs memory consolidation, but improves focused attention in healthy young volunteers. J Psychopharmacol 14(1): 21-9

Sharma RP, Shapiro LE, Kamath SK, Soll EA, Watanabe MD, Davis JM (1997) Acute dietary tryptophan depletion: effects on schizophrenic positive and negative symptoms. Neuropsychobiology 35(1): 5-10 Sheehan D, Lecrubier Y, Janavs J (1994) MINI international Neuropsychiatric Interview. Tampa: University of South Florida.

Smith KA, Fairburn CG, Cowen PJ (1997) Relapse of depression after rapid depletion of tryptophan. Lancet 349 (29): $915-9$

Sobczak S, Honig A, Riedel WJ (2000) Acute Tryptophan Depletion in bipolar disorders; literature review and directives for further research. Acta Neuropsychiatrica 12 (3): 69-72 
Sobczak S, Riedel WJ, Booij L, aan het Rot M, Deutz NEP, Honig A (in press) Cognitive performance following Acute Tryptophan Depletion: differences between first-degree relatives of bipolar patients and healthy matched controls. Neuropsychopharmacol

Swann AC, Stokes PE, Casper R, Secunda SK, Bowden CL, Berman N, Katz MM, Robins E (1992) Hypothalamic-pituitary-adrenocortical function in mixed and pure mania. Acta Psychiatr Scand 85(4): 270-4 van Eck MM, Nicolson NA, Berkhof H, Sulon J (1996) Individual differences in cortisol responses to a laboratory speech task and their relationship to responses to stressful daily events. Biol Psychology 43: 69-84 van Eijk HM, Rooyakkers DR, Deutz, NE (1993) Rapid routine determination of amino acids in plasma by highperformance liquid chromatography with a 2-3 microns Spherisorb ODS II column. J Chromatogr 620(1): 143-8 Vieta E, Martinez-De-Osaba MJ, Colom F, Martinez-Aran A, Benabarre A, Gasto C (1999) Enhanced corticotropin response to corticotropin-releasing hormone as a predictor of mania in euthymic bipolar patients. Psychol Med 29(4): 971-8

Wirz Justice A, Puhringer W (1978) Increased platelet serotonin in bipolar depression and hypomania. J Neural Transm 42(1): 55-62

Young LT, Warsh JJ, Warsh JJ, Kish SJ, Shannak K, Hornykeiwicz O (1994) Reduced brain 5-HT and elevated NE turnover and metabolites in bipolar affective disorder. Biol Psychiatry 35(2): 121-7

Young RC, Biggs JT, Ziegler VE, Meyer DA (1978) A rating scale for mania: reliability, validity and sensitivity. Br J Psychiatry 133: 429-35

Young SN (1991) Some effects of dietary components (amino acids, carbohydrate, folic acid) on brain serotonin synthesis, mood, and behavior. Can J Physiol Pharmacol 69: 893-903

Young SN, Smith SE, Pihl RO, Ervin FR (1985) Tryptophan depletion causes a rapid lowering of mood in normal males. Psychopharmacology Berl 87(2): 173-7 


\title{
Cognition following acute tryptophan depletion: differences between first- degree relatives of bipolar disorder patients and matched healthy control volunteers
}

\begin{abstract}
Serotonergic circuits have been proposed to mediate cognitive processes, particularly learning and memory. Cognitive impairment is often seen in bipolar disorders (BD), in relation to a possible lowered serotonergic turnover. We investigated the effects of Acute Tryptophan Depletion (ATD) on cognitive performance in healthy first-degree relatives of bipolar patients (FH) $(n=30)$ and matched controls $(n=15)$ in a placebo-controlled, double-blind cross-over design. Performance on planning, memory and attention tasks were assessed at baseline and 5 hours after ATD. Following ATD, speed of information processing on the planning task was impaired in the FH group but not in the control group. FH subjects with a BD type I relative (FH I) showed impairments in planning and memory, independent of ATD. In all subjects, ATD impaired long-term memory performance and speed of information processing. ATD did not affect short-term memory and focused and divided attention. The results suggest serotonergic vulnerability affecting frontal lobe areas in FH subjects, indicated by impaired planning. Biological vulnerability in FH I subjects is reflected in impaired planning and memory performance. In conclusion, the cognitive dysfunctions in $\mathrm{FH}$ subjects indicate an endophenotype constituting a possible biological marker in bipolar psychopathology. Serotonin appears to be involved in speed of information processing, verbal and visual memory and learning processes.
\end{abstract}




\section{Introduction}

Cognitive deficits have been demonstrated in bipolar disorders (BD) (Savard et al. 1980; Wolfe et al. 1987; Coffman et al. 1990; Krabbendam et al. 2000). In mania, planning and reaction time (RT) were impaired (Murphy et al. 1999).

In euthymic BD patients, persistent impairments on visuo-spatial recognition, verbal and nonverbal memory and learning, retrieval of information from semantic memory an increased RT on a planning task has been described (Coffman et al. 1990; Atre-Vaidya et al. 1998; Ferrier et al. 1999; Rubinsztein et al. 2000).

Cognitive impairments persist during remission of BD (van Gorp et al. 1998; Ferrier et al. 1999; Krabbendam et al. 2000; Rubinsztein et al. 2000; Scott et al. 2000) bipolar disorder type I patients and patients with recurrent episodes appear to show more impairments (Kessing 1998; Krabbendam et al. 2000; Martinez-Aran et al. 2000). These impairments might be considered as indicators of a biological vulnerability. In remitted BD patients, poor cognitive performance may be partly attributed to medical treatment. Therefore, assessment of cognitive performance in first-degree relatives of $\mathrm{BD}$ patients may provide a powerful design to investigate a biological vulnerability in BD (Sobczak et al. 2000).

There is ample evidence showing serotonin (5-hydroxytryptamine, 5-HT) to be involved in cognitive functioning, particularly learning, memory and attention processes (Young et al. 1985). Acute Tryptophan Depletion (ATD) is a direct method to investigate the effects of an acute reduction in central 5-HT activity. Following ATD, a relapse in remitted depressed patients has been reported (Salomon et al. 1993; Berman et al. 1996; Smith et al. 1997; Aberg-Wistedt et al. 1998). Healthy first-degree relatives of depressed patients, show pronounced mood-lowering effects of ATD compared to healthy control subjects, indicating a serotonergic vulnerability (Benkelfat et al. 1994; Klaassen et al. 1999).

In healthy subjects no effects of ATD on planning has been found (Park et al. 1994; Schmitt et al. 2000) but an impaired long-term memory following ATD, including deficits in learning and memory consolidation has been reported (Park et al. 1994; Riedel et al. 1999; Rogers et al. 1999; Schmitt et al. 2000; Rubinsztein et al. 2001). After ATD an improvement in focused attention (Coull et al. 1995; Schmitt et al. 2000) has been reported, which might be explained by a decrease in 5-HT mediated inhibition of cholinergic neurones in frontal brain areas (Grafman 1995; Steckler et al. 1995; Riekkinen et al. 1998).

The present study was designed to investigate differences in 5-HT-related cognitive performance in first-degree relatives of BD patients and healthy matched controls. Four 
specific hypotheses were formulated. The first was subjects with at least one first-degree relative with BD will be more vulnerable to the effects of ATD compared to healthy control subjects. Therefore, they will exhibit more pronounced changes in cognitive performance following ATD. Cognitive performance was measured in the domains of planning, learning, working memory, retrieval, focused and divided attention and concept-shifting. Secondly, a biological vulnerability in first-degree relatives of BD patients may be reflected in impaired cognitive performance on planning and memory tasks, independent of ATD. Third, a biological distinction between relatives of bipolar type I (FH I) and type II (FH II) patients may be reflected in differences between their cognitive performances and vulnerability to ATD.

Fourth, based on previous findings (Riedel et al. 1999; Schmitt et al. 2000) we hypothesized ATD to improve, frontal lobe mediated, planning, retrieval and focused attention performance and to impair learning and memory. In order to further study the previous observation of the ATD effect on consolidation memory, we compared a new picture learning task with the previously used word learning task.

\section{Methods}

\section{Subjects}

Family members were recruited via BD patients treated at the Department of Psychiatry, Academic Hospital Maastricht, via the local organization for manic-depressive patients and their families, and via advertisements in local newspapers. Healthy controls were also recruited via a newspaper advertisements.

Thirty first-degree relatives of BD patients ( 8 men and 22 women) and 15 controls ( 4 men, 11 women) completed the experiment, aged 19 to 64 years (mean 41.0, sd 14.4 years). Relatives were daughters $(n=11)$, sons $(n=4)$, siblings $(n=4)$, mothers $(n=8)$ and fathers $(n=3)$. Nineteen had a first-degree relative with a $\mathrm{BD}$ type I diagnosis, and 11 subjects were relatives of $\mathrm{BD}$ type II patients (see table 1). The FH and control group did not differ significantly with respect to age, Body Mass Index (BMI) or Intelligence Quotient (IQ).

Of the female subjects, 22 were pre-menopausal and 11 were postmenopausal. Seven women used oral anticonceptives and 7 were taking other medicines which were unlikely to interfere with ATD. 
Table I. Demographic characteristics of first-degree relatives $(\mathrm{FH})$ and control subjects $(\mathrm{C})$, inclusive mean number of bipolar depressed family members ( $\left(1^{\text {th }}, 2^{\text {nd }}\right.$ and $3^{\text {rd }}$ degree), age, IQ and body mass index (BMI); mean $( \pm \mathrm{SE})$.

\begin{tabular}{|lll|}
\hline $\begin{array}{l}\text { (mean } \pm \text { se) } \\
\text { Measure }\end{array}$ & FH & C \\
\hline & & \\
\hline Women & $\mathrm{n}=22$ & $\mathrm{n}=11$ \\
Men & $\mathrm{n}=8$ & $\mathrm{n}=4$ \\
FH I & $\mathrm{n}=19$ & \\
FH II & $\mathrm{n}=11$ & \\
Family members: & 1.3 & 0.0 \\
Bipolar disorder & $41.40 \pm 2.57$ & $40.33 \pm 4.00$ \\
Age & $117.17 \pm 1.95$ & $117.27 \pm 4.14$ \\
IQ & $24.71 \pm 0.63$ & $24.34 \pm 0.91$ \\
BMI & & \\
\hline
\end{tabular}

\section{Design}

The study used a placebo-controlled, double blind, crossover design.

The within subjects-factor was treatment and consisted of two levels: placebo and ATD. The order of treatment was balanced over two test days, spaced 1-2 weeks apart. The betweensubjects factor was $\mathrm{FH}$ of $\mathrm{BD}$ : with $(\mathrm{FH})$ or without (controls) at least one first-degree relative with bipolar disorder. A distinction was made between having a relative with a type I or type II bipolar disorder.

\section{Amino Acid Mixtures}

The AA-drink consisted of fifteen amino acids in a total amount of $75 \mathrm{~g}$. Relative contribution (per $100 \mathrm{~g}$ ) of each amino acid is according to the composition described by Young et al. (1985) with the exception of the amount Trp in the placebo mixture. We used a mixture of $4 \%$ Trp compared to $2.3 \%$ Trp in Young et al. (1985). The preparation of the drink was according to the procedure described in Schmitt et al. (2000).

\section{Procedure}

\section{Screening}

In the $\mathrm{FH}$ group, the main inclusion criterion was having at least one first degree relative with BD. Control subjects were free from any psychopathologic family loading. They were matched with FH subjects with respect to gender, age, Body Mass Index (BMI) and Intelligence Quotient (IQ). IQ was estimated using four Groninger Intelligence Test (GIT) 
subtasks (Vocabulary, Mental Rotation, Mental Arithmetic and Word Analogies) (Luteijn 1966).

All subjects were interviewed with an abbreviated version of the Family History Research Diagnostic Criteria (FHRDC) to assess their family history (Endicott et al. 1975). Individual diagnoses (type I or type II according to DSMIV) of the patients were verified via the patient's psychiatrist.

Exclusion criteria were: current or history of use of psychopharmacological medication, lifetime psychiatric disorder including alcohol or drug abuse, current active physical illness, lactation and pregnancy. Physical health was assessed by means of a health questionnaire, a standard physical examination by a physician and a urine screening. A Quick View, Quidel $\otimes$, one-step pregnancy test was carried out in female subjects to check for unsuspected pregnancy.

The Mini International Neuropsychiatric Interview (MINI) was taken to examine current psychiatric disorders and alcohol or drug abuse (Sheehan 1994).

The Medical Ethics Committee of the Academic Hospital of Maastricht approved the study. All participants signed informed consent.

\section{Test days}

To eliminate response bias due to premenstrual symptoms, all pre-menopausal women were tested in the follicular phase of the menstrual cycle (Menkes et al. 1994; Rasgon et al. 2000). Figure 1 provides an overview of the test day.

On each test day, subjects arrived at 8.30 a.m. after an overnight fast. At 10:00 a.m. ( $\left.\mathrm{t}_{0}\right)$ they were offered the AA-drink, which had to be ingested within two hours (all timepoints $t_{x}$ refer to $x$ hours after $t_{0}$ ). At $t_{2}$, a protein-poor lunch was offered (Riedel et al. 1999).

To correct for possible differences in cognitive performance between test sessions, a baseline cognitive assessment was completed before $t_{0}$ on each test day. Thereafter cognitive performance was assessed at $\mathrm{t}_{5}$. Memory performance was also assessed at $\mathrm{t}_{7.25}$. Blood samples were taken at $t_{0}$ and at $t_{6.5}$. A physical complaints list was given each time prior to cognitive assessments (at $t_{0}, t_{5}$ and $\left.t_{7}\right)$. 


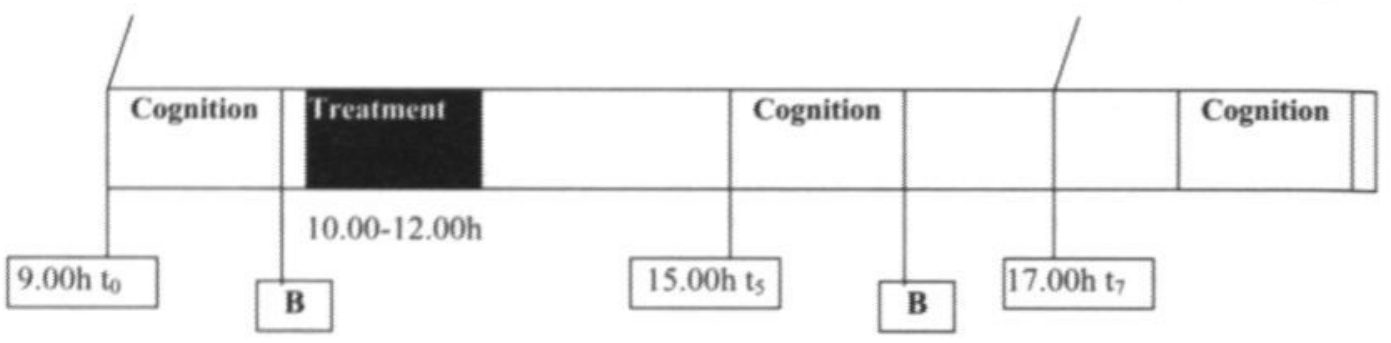

Figure 1. Schematic overview of the test day; Cognition was assessed three times; at $t_{0}, t_{5}$ and $t_{7}$. There were 2 occasions of word learning in the Visual Verbal Learning Task (VVLT), before (word learning 1), and after ATD (word learning 2). B, blood sampling.

\section{Cognitive assessments}

The cognitive test battery took approximately 60 minutes to complete and consisted of tasks measuring planning, learning, working memory, retrieval, concept-shifting, focused attention and divided attention.

\section{Planning: Computerised Tower of London (compu-TOL) (Owen et al. 1995)}

Planning capacity was assessed by a modified version of the One-touch Tower of London (TOL) task (Owen et al. 1995). Subjects were initially trained the original non-computerisedTOL (Shallice 1982). Thereafter, the compu-TOL was introduced. On a computer screen, two arrays of differently coloured balls (red, yellow and blue) on sticks were presented. Each arrangement contained three balls, which were held on three sticks; one stick had a capacity of 3 balls, another could hold two balls and the third could only hold 1 ball. The subjects were requested to indicate the minimal number of steps necessary to rearrange the balls on the lower configuration to match the arrangement presented on the top half of the screen. The rules were: each ball must be replaced separately, once a ball is taken it must be put on a stick, it is not allowed to put one ball aside and continue with the other balls.

The subjects had to rearrange the balls in their mind's eye (without actually moving the balls). Once the ideal solution had been found, the subject was asked to count the number of moves and then respond by pressing the appropriate response button, which represented the right number of steps necessary to rearrange the balls (2-5). The subjects were instructed to respond as quickly as possible, but the importance of accuracy was emphasised. They were told that performance on the task was indicated by both response accuracy and RT. 
There was no response-feedback and subjects were allowed to give just one response to each problem.

The complexity of the task is dependent on the minimal number of steps the rearrangement can be achieved; $2,3,4$ and 5 steps. The training consisted of 10 trials and the test of 40 trials, with an equal number of 2, 3, 4 and 5-steps problems, which were presented in a fixed pseudorandom order. Only once subjects were entirely familiar with the rules governing the movements of balls and the concepts involved with solving the compu-TOL problems, were they given the test form of the task.

The dependent measure was the median RT as a function of difficulty. The number of errors was checked for confounding of the RT variable.

\section{Learning: Picture Learning Task (PLT) (Lezak 1995)}

The PLT is a modified version of Rey's Visual design learning Test (Lezak 1995). In the PLT, subjects were presented three identical trials of 20 unrelated highly recognizable pictures which were easy to verbalise (e.g. 'bridge' or 'tiger'). Pictures were taken from a large file of pictures used in a longitudinal study of cognitive ageing of the Brain and Behaviour Institute in Maastricht. The pictures were showed on a computer screen in black ink on a white background and were presented for $1000 \mathrm{~ms}$ at a rate of one picture per $2000 \mathrm{~ms}$. Each trial ended with a free verbal recall of the pictures (immediate recall). Thirty minutes after the third trial, the subject was requested to recall as many pictures as possible without prior presentation (delayed recall). A yes/no recognition test, consisting of 10 previously presented and 10 new (comparable) pictures, was given after the delayed recall test. The pictures remained on the screen for $2000 \mathrm{msec}$ or until the subject responded. Another 1000 msec elapsed before the next picture appeared on the screen. After presentation of each picture the subject had to respond "YES / NO" as fast as possible to indicate recognition of the picture (delayed recognition). The RT was recorded. According to the theory of signal detection (Pollack and Norman 1964), the proportion of correctly recognised (cr) and the proportion of falsely recognised (fr) words constitute the nonparametric sensitivity measure: $A^{\prime}=1-1 / 4$ $(\mathrm{fr} / \mathrm{cr}+(1-\mathrm{cr}) /(1-\mathrm{fr})) . \mathrm{A}^{\prime}$ is in fact the proportion of correctly recognised pictures, corrected for the subject's response tendency. Because the distribution of $A^{\prime}$ is skewed due to a ceiling effect, A' was arcsin transformed before being used in statistical analysis.

In this study a picture list was presented at $t_{5}$. After $t_{5}$, delayed recall and recognition were assessed once, after a delay of 30 minutes $\left(t_{5} \rightarrow 5\right)$. 
The variables used were the total number of pictures recalled after the first three trials as a measure of short-term memory, the number of correct pictures on delayed free recall as a measure of retrieval from long-term memory (LTM), A' as a measure of storage in LTM, and the median RT of correctly recognised target pictures as a measure of speed of retrieval from LTM. In each of the assessments, a different pictures list was presented. The lists were comparable with regard to their level of abstraction and the affective tone of the pictures. Parallel lists were order balanced over assessments.

\section{Learning: The Visual Verbal Learning Test (VVLT)}

The VVLT is an adapted version of the Rey Auditory Verbal Learning Test (Lezak 1995). The test consisted of a list of 30 monosyllabic words ( 18 nouns and 12 adjectives) in Dutch, which were presented in three trials on a computer screen. The words occur very frequently in Dutch and are acquired early in life. Items were presented in the same sequence at a rate of one per 2 seconds. Parallel picture lists were order balanced over the assessments.

The procedure of the VVLT was comparable with that of the PLT; assessments of immediate recall, delayed recall and recognition were according the same procedure. A yes/no recognition test, consisting of 15 former words and 15 new but comparable words, was given after the delayed recall test. There were two different recognition lists to probe the long-term retention of each 30 word list. Both recognition lists consisted of 15 formerly learned and 15 new words (distractors).

The dependent variables were: total number of correct words on immediate recall and delayed recall, $A^{\prime}$ and median RT $^{\prime}$ on the recognition task (see PLT).

In this study word lists were presented at $t_{0}$ and at $t_{7}$. After $t_{0}$, delayed recall and recognition were assessed twice: once after a delay of 30 minutes $\left(t_{0-0}\right)$ and once after a delay of 7 hours $\left(t_{0 \rightarrow 7}\right)$. After the list presented at $t_{7}$ recall and recognition were assessed only once after a delay of 30 minutes $\left(t_{7 \rightarrow 7}\right)$.

For learning tasks, measures of delayed recall of words and pictures were considered primary outcome measures, as previous observations had consistently shown that these measures are most sensitive to ATD (Riedel et al. 1999; Schmitt et al. 2000; Rubinsztein et al. 2001). The primary outcome measures were corrected for multiple testing of the same hypothesis according to the rule of Bonferroni. The measures of immediate recall, recognition and RT were considered secondary and are reported for the purpose of completeness of description. 
Working Memory: Stermberg Memory Scanning (Stermberg 1975)

The subjects were briefly shown a set of 1,2 or 3 letters and told to memorise them. This is called the "memory set" (Sternberg 1969). Subjects then saw a series of 75 letters, each of them displayed for $1000 \mathrm{msec}$ on a VCR connected to an IBM computer, followed by another $2000 \mathrm{msec}$ before the next letter appeared. Half of the presented letters were part of the memory set and had to be recognised as targets. The subjects' task was to decide and respond as rapidly as possible by pressing either 'YES' or 'NO' to indicate whether or not each successive letter was one of those contained in the memory set. The median RT of correct responses (targets and non-targets) was taken as a dependent variable. Memory sets and stimulus sets were generated at random by the computer before each subtask. RT on set size regression functions were calculated. This function is defined by the equation $R T=A * S s+B$, in which: $A=$ slope of the function (i.e. the amount of extra time needed per item in the memory set), $\mathrm{Ss}=$ size of the memory set, and $\mathrm{B}=$ intercept with the $\mathrm{Y}$-axis. The dependent variable in this task is RT as a function of memory load. Effects of independent variables on intercept are expressed as main effects and effects on slope are expressed as interaction effects of independent variables with memory load.

\section{Retrieval: Verbal Fluency Test (Luteijn and van der Ploeg 1983)}

The fluency test measures strategy-driven retrieval of information from semantic memory. The subjects are asked to report as many four-letter words with the same initial letter within one minute. The number of correct words was taken as the dependent measure. Nonsense words were not accepted, but names, conjugations and plurals were allowed. Starting letters were H, L, M and R (Schmitt et al. 2000).

\section{Focused Attention: Stroop Colour Word Test (SCWT) (Stroop 1935)}

The SCWT consisted of three cards displaying each 100 stimuli. The first card included colour names, which had to be read as quickly as possible. The second card included colour patches, which had to be named. The third card consisted of colour names printed in incongruously coloured ink. The colour of the ink had to be named, without paying attention to the word itself. Outcome variable was interference. The interference, which indicates focused attention and response inhibition, denotes the percentage extra time needed to complete the third card relative to the average of the first and second card: (time card III / [(time card I + time card II) /2)] * 100\% (Houx et al. 1993). 


\section{Divided- and Focused Attention: Dichotic Listening Task (DLT) (Kimura and D'Amico 1989)}

The DLT tests both focused attention and divided attention for auditory stimuli. Subjects received different auditory stimuli simultaneously through a headphone on each side. The stimuli were numbers ranging from 1-200, presented at random and natural-speech spoken by a male voice. The test consisted of three subtasks in which the subjects were instructed to focus to either the numbers presented in the right ear or the left ear while ignoring the contralateral ear, or to focus both ears simultaneously, and remember the numbers presented. The subtask in which the subjects were instructed to focus to one side, while ignoring the other, can be regarded as a measure of focused attention. The subtask in which the subjects had to remember the numbers presented in both ears is a divided attention task. Each of the three subtasks is made up of 9 trials, in which 2,3 or 4 stimuli pairs are presented in random order. After each trial, the subject had to identify the presented numbers from a list of numbers on a computer screen. The numbers included all presented numbers plus the same amount of other, numbers (distracter stimuli). Measures were: total number of correct identifications, total number of stimuli identified from the ignored side, and number of false alarms (not presented at all).

'Arifrmance on each subtask' was calculated by the A'sensitivity measure (see PLT).

\section{Concept-shifting: Attentional Set Shifting Task (AST) (Vink and Jolles 1985)}

The AST consisted of three parts: on each test sheet 16 small circles (diameter $=15 \mathrm{~mm}$ ) were grouped in a large circle (diameter $=8 \mathrm{~cm}$ ) in which numbers (a), letters (b) or both (c) were presented in a fixed random order (Jolles et al. 1995). The subject were requested to cross out the items as fast as possible in correct climbing order. In parts a and b the subjects had to connect the numbers (1-2-3 etc.) and the letters (a-b-c etc.) respectively. In part C, the subject was requested to alternate between these sequences (1-a-2-b etc.) in climbing number and letter order (c). The interference, indicated slowing due to shifting between concepts and was calculated by subtracting the average time to complete both tasks separately ( $a$ and $b$ ) from the time necessary to complete both tasks alternately.

\section{Plasma parameters}

Plasma was taken by venapuncture in sodium heparin tubes. Blood samples were set on ice immediately and centrifuged $(3000 \mathrm{rpm}, 10$ minutes) within one hour. Plasma $(100 \mu \mathrm{l})$ was mixed with $4 \mathrm{mg}$ sulfasalicyl acid and were frozen at $-80^{\circ} \mathrm{C}$ until analysis. Total 
concentrations of plasma Trp and ratio of Trp: Large Neutral Amino Acids (LNAAs) were determined by high-performance liquid chromatography (HPLC) (van Eijk et al. 1993).

\section{Somatic side effects}

The severity of side effects was determined by a 4-point scales questionnaire, which included 17 items. The sum of reported complaints represents the overall severity of side effects.

\section{Statistical Analysis}

Primary and secondary outcome variables were analyzed using General Linear Model (GLM) of variance for repeated measures. Within subjects factors were treatment condition (ATD or placebo) and time $\left(\mathrm{t}_{5} / \mathrm{t}_{7}\right)$. Between subjects factor was family history (controls, FH I and FH II). Univariate contrasts were used to analyze differences between controls and FH subject groups. Differences in cognitive baseline values between test-sessions were assessed using general linear model. In case of absence of baseline differences between treatment conditions, baseline values were left out of analyses.

Order of treatment (placebo/ATD or ATD/placebo) was included as between-subjects factor in the analysis to check for a possible interaction with treatment.

Where possible, for each task, only one statistical test was used. For Tower of London and Sternberg tasks, this was accomplished by analyzing RT as a function of task difficulty and test this model as a function of the independent variables: ATD, time and FH. For tests yielding multiple variables a distinction was made for primary outcome measures for hypothesis testing and secondary outcome measures, reported for descriptive purposes. Multiple tests of the same domain, such as Verbal Learning and Picture Learning and Stroop Interference and Auditory Focused Attention, were subjected to Bonferroni correction. All statistical analyses were performed with SPSS 9.0 for Windows.

\section{Results}

Baseline performance on all cognitive tests did not differ, between experimental conditions. Of the 47 subjects ( $32 \mathrm{FH}, 15$ controls) who were included, 2 subjects in the FH group withdrew during the experiment because of intolerance to the drink 
Table 2 shows mean ( \pm se) of dependent variables of the primary and secondary outcome measures of learning, working memory, retrieval, divided and focused attention and concept shifting.

\section{Planning}

On the TOL, there was a significant interaction of family history and ATD on median RT $[F(1,39)=4.71, \mathrm{p}<0.05]$; FH subjects showed an increase in RT after ATD, whereas it tended to decrease in the control group. The three-way interaction of family history by number of steps by ATD on median RT was significant $[F(3,37)=4.79, \mathrm{p}<0.05]$. Univariate contrasts showed that this effect can be ascribed to a significant increase in median RT of the 4-steps problems $[F(1,42)=7.26, \mathrm{p}<0.05]$ exclusively in the $\mathrm{FH}$ group and not in the control group. See figure 2. Furthermore, a significant interaction of $\mathrm{FH}$ and $\operatorname{ATD}[F(2,38)=3.81, \mathrm{p}<0.05]$ indicated that the slowing of RT following ATD in the FH group could be mainly attributed to an increase in $\mathrm{RT}$ in the $\mathrm{FH} \mathrm{I}$ group.

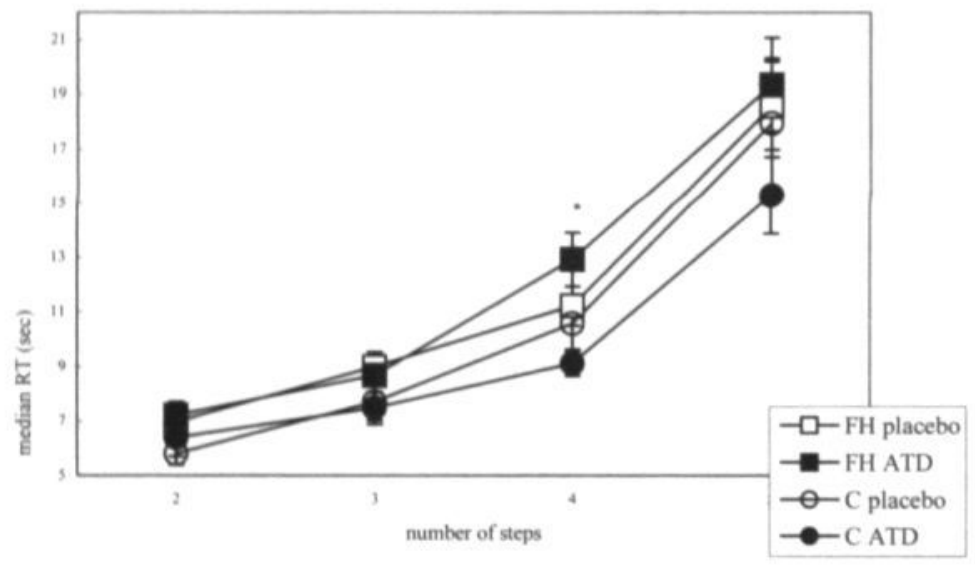

Figure 2. Effect of family history and ATD and placebo on TOL performance in FH and control (C) subjects; median reaction time (mean $\pm \mathrm{SE}$ ) of the correct responses in the 2, 3, 4 and 5 steps problems.

There was a main effect of $\mathrm{FH}[F(2,38)=6.47$, p $<0.05]$ on median RT; FH I subjects showed an overall impaired RT compared to the other groups $(\mathrm{p}<0.05)$.

There was no effects of ATD and FH on number of correct responses. Missing values were $1.4 \%$. 
Learning

ATD significantly impaired delayed recall performance on the VVLT at $t_{7} \rightarrow[F(1,41)=5.95$, $\mathrm{p}<0.025]$ and on the PLT at $t_{5}[F(1,43)=4.04$, p<0.05; significant after Bonferroni correction $]$. The effect on the PLT showed a treatment by order interaction $[F(1,43)=13.50, \mathrm{p}<0.005]$; subjects receiving the ATD mixture on day 1, showed greater impairment after ATD compared to subjects receiving the ATD mixture on day 2.

ATD did not affect picture recognition and tended to impair word recognition $\mathrm{A}^{\prime}[F(1,37)=$ $4.78, p<0.05]$ at $t_{7} \rightarrow$, but this effect was not maintained after Bonferroni correction.

There were no significant effects of ATD on delayed recall and recognition of words learned at baseline and recalled at $t_{0}\left(t_{0} \rightarrow 0\right)$ and $t_{7}\left(t_{0}, 7\right)$. No effects of ATD on immediate recall and speed (RT) of recognition were present for both tasks. Missing values on the VVLT were $0.4 \%$. Missing values on the PLT were $4.2 \%$.

Family history did not affect performance on the PLT. In the VVLT, subjects in the FH group showed impaired recognition performance, at $\left.t_{0} \rightarrow 00(1,40)=4.63, \mathrm{p}<0.05\right]$ and at $t_{0} \rightarrow$ ? $[F(1,42)=4.94, \mathrm{p}<0.05]$. Recognition $\mathrm{RT}$ was impaired in $\mathrm{FH}$ at $\mathrm{t}_{7}$ for words learned at $t_{0}\left(t_{0}->7\right)[F(2,36)=3.34, \mathrm{p}<0.05] ; \mathrm{FH} 1$ performed worse $(\mathrm{p}<0.05)$ compared to $\mathrm{FH}$ II. 
Table 2: Mean ( \pm SE) of the primary and secondary outcome measures of learning, working memory, retrieval, divided and focused attention and concept shifting at $t_{s}$ and $t_{7}$. Results are broken down by family history (controls; C/FH I/ FH II) and treatment (ATD/ placebo; P). • $p<0.05$

\begin{tabular}{|c|c|c|c|c|}
\hline$($ mean $\pm \mathrm{se})$ & & & & \\
\hline Measure & Treatment & $\mathrm{C}(n=15)$ & FH I $(n=20)$ & FH II $(n=10)$ \\
\hline $\begin{array}{l}\text { Learning } \\
\text { PLT }\end{array}$ & & & & \\
\hline Delayed recall & ATD* & $13.5(0.8)$ & $13.0(1.0)$ & $40.1(2.0)$ \\
\hline (\#words) & $\mathbf{P}$ & $15.2(0.7)$ & $13.4(0.8)$ & $40.2(1.8)$ \\
\hline Immediate recall & ATD & $38.8(2.1)$ & $13.0(1.0)$ & $13.8(0.9)$ \\
\hline (\#words) & $\mathbf{P}$ & $41.7(1.9)$ & $13.4(0.8)$ & $13.6(1.4)$ \\
\hline Recognition $\mathrm{A}^{\prime}(\%)$ & ATD & $98(1)$ & $97(2)$ & $99(1)$ \\
\hline & $\mathbf{P}$ & $97(1)$ & $97(1)$ & $99(1)$ \\
\hline Recognition RT (ms) & ATD & $640(38)$ & $728(47)$ & $587(23)$ \\
\hline & $\mathbf{P}$ & $633(26)$ & $677(24)$ & $603(28)$ \\
\hline$V V L T$ & & & & \\
\hline Delayed recall $\left(t_{>}>>_{7}\right)$ & ATD* & $11.1(1.8)$ & $7.2(5.7)$ & $9.00(1.86)$ \\
\hline (\#words) & $\mathbf{P}$ & $12.5(1.9)$ & $8.2(5.9)$ & $12.70(2.02)$ \\
\hline Delayed recall $\left(t_{0}>>_{7}\right)$ & ATD & $11.3(1.9)$ & $7.2(5.2)^{\bullet}$ & $9.40(1.31)$ \\
\hline ("twords) & $\mathbf{P}$ & $11.4(1.6)$ & $6.4(4.7)$ & $8.80(1.55)$ \\
\hline Immediate recall & ATD & $39.7(4.0)$ & $30.3(12.6)$ & $38.30(3.31)$ \\
\hline (\#words) & $\mathbf{P}$ & $43.0(3.9)$ & $31.4(12.6)$ & $39.40(3.52)$ \\
\hline Recognition $\mathrm{A}^{\prime}\left(\mathrm{t}_{r}>_{7}\right)$ & ATD & $89(3)$ & $85(4)^{*}$ & $84(4)$ \\
\hline$(\%)$ & $\mathbf{P}$ & $91(2)$ & $89(2)$ & $92(3)$ \\
\hline Recognition $A^{\prime}\left(t_{0}>7\right)$ & ATD & $89(3)$ & $82(3)$ & $86(2)$ \\
\hline$(\%)$ & $\mathbf{P}$ & $87(4)$ & $79(3)$ & $87(4)$ \\
\hline Recognition RT $\quad\left(t_{r}>_{7}\right)$ & ATD & $647(19)$ & $686(26)$ & $614(27)$ \\
\hline (ms) & $\mathbf{P}$ & $640(19)$ & $673(24)$ & $591(17)$ \\
\hline Recognition RT $\left(\mathrm{t}_{0}>\right.$, $)$ & ATD & $632(19)$ & $701(25)^{*}$ & $602(22)$ \\
\hline (ms) & $\mathbf{P}$ & $634(22)$ & $681(23)$ & $627(33)$ \\
\hline Working memory & & & & \\
\hline Memory scanning & & & & \\
\hline Slope (ms) & ATD & $46(5)$ & $48(5)$ & $35(5)$ \\
\hline & $\mathbf{P}$ & $43(5)$ & $41(5)$ & $37(5)$ \\
\hline 1 -intercept (ms) & ATD* & $448(13)$ & $460(14)$ & $432(18)$ \\
\hline & $\mathbf{P}$ & $436(13)$ & $469(12)$ & $425(13)$ \\
\hline Retrieval & & & & \\
\hline Fluency & & & & \\
\hline No. correct words $(\#)$ & ATD & $13.8(1.1)$ & $13.2(1.1)$ & $11.6(1.4)$ \\
\hline & $\mathbf{P}$ & $13.6(1.2)$ & $11.8(0.9)$ & $12.4(1.2)$ \\
\hline Focussed and divided atts & ention & & & \\
\hline SCWT & & & & \\
\hline Interference $(\%)$ & ATD & $56.9(5.2)$ & $58.9(4.4)$ & $56.2(5.6)$ \\
\hline & $\mathbf{P}$ & $62.0(4.9)$ & $60.4(5.4)$ & $59.2(3.0)$ \\
\hline DLT & & & & \\
\hline Left side $A^{\prime}(\%)$ & ATD & $90(3)$ & $84(4)$ & $85(4)$ \\
\hline & $\mathbf{P}$ & $91(2)$ & $84(4)$ & $85(4)$ \\
\hline Right side $A^{\prime}(\%)$ & ATD & $92(2)$ & $91(2)$ & $90(2)$ \\
\hline & $\mathbf{P}$ & $92(5)$ & $85(5)$ & $87(4)$ \\
\hline Both sides $A^{\prime}(\%)$ & ATD & $85(10)$ & $84(1)$ & $85(2)$ \\
\hline & $\mathbf{P}$ & $85(10)$ & $84(9)$ & $82(1)$ \\
\hline $\begin{array}{l}\text { Concept shifting } \\
\text { AST }\end{array}$ & & & & \\
\hline Interference $(\%)$ & ATD & $46.3(8.3)$ & $31.5(5.4)$ & $66.8(20.5)$ \\
\hline & $\mathbf{P}$ & $42.9(7.3)$ & $49.3(9.6)$ & $39.4(13.2)$ \\
\hline
\end{tabular}




\section{Working Memory}

As expected, the memory scanning task showed increased RT with increasing memory set $[F(2,41)=177.21, \mathrm{p}<0.001]$. Independent of memory set, ATD significantly slowed overall RT $[F(1,42)=4,67, \mathrm{p}<0.05]$, which indicated an ATD-induced increased intercept of the memory scanning regression function. No effect on slope of the memory scanning function was present. There was a trend significant interaction of family history and ATD on RT in the memory scanning task; the slowing of RT tended to be due to a decrease in RT after ATD in control subjects and not in FH subject. No main effect of family history was present. Missing values were $0.5 \%$.

\section{Retrieval}

No effects of ATD and FH were seen on the fluency task.

\section{Focussed and Divided Attention}

The interference measure of the Stroop test did not show significant effects of ATD and FH. On the DLT, subjects performed better on the 'right' subtask No significant effects of ATD and $\mathrm{FH}$ on performance of the subtasks 'right', 'left' or 'both' were present. Missing values on the DLT were $1.1 \%$.

\section{Concept Shifting}

No effects of ATD and FH were seen on AST.

\section{Somatic side effects}

Sum of reported physical complaints did not differ at baseline and between both experimental conditions.

\section{Plasma Trp levels}

Plasma Trp concentrations and ratio Trp: LNAAs did not differ at baseline between groups and experimental conditions, but decreased significantly $[F(1,28)=151.11, \mathrm{p}<0.001]$ in the ATD condition. Relative to baseline, ATD resulted in a 57\% decrease in plasma Trp and $70 \%$ decrease in ratio Trp: LNAAs. After receiving placebo, there was a $36 \%$ increase in plasma Trp and $1.0 \%$ increase in the ratio Trp: LNAAs. There was no effect of treatment order. As a 
consequence of difficulties in taking blood and during analyses, 1.4\% of serum samples were missing. Results are summarised in figure 3.

Ratio L-Trp: LNAA's

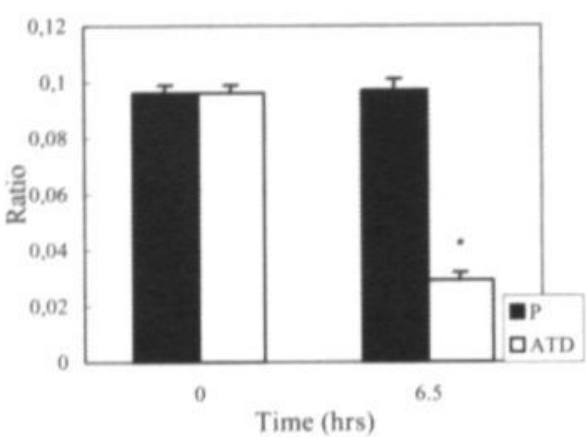

Plasma Trp

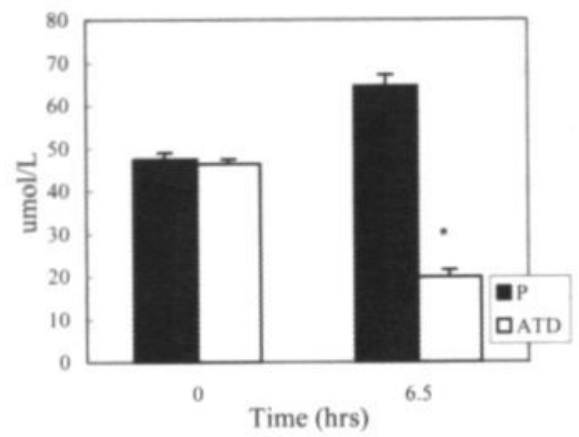

Figure 3. Mean ( \pm SE) serum ratio Trp/ LNAAs (right) and Trp concentrations (left), at baseline $\left(t_{0}\right)$ and 6.5 hours $\left(\mathrm{t}_{6}, 5\right)$ after $\mathrm{ATD}$ and placebo $(\mathrm{P})$.

\section{Discussion}

This is the first paper in which an investigation into 5-HT manipulation of cognitive functioning in healthy first-degree relatives of BD patients is described. ATD resulted in decreased RT on the compu-TOL, in FH subjects but not in control subjects. FH I subjects showed impaired baseline RT and seemed to be most vulnerable to ATD-induced impairment in planning.

Independent of ATD, deficits in planning RT, verbal memory recall and recognition were found in FH I subjects only. In both FH and controls, ATD impaired delayed recall of visual and verbal information.

In FH I, the initial suboptimal planning performance in $\mathrm{FH} \mathrm{I}$ increases vulnerability to detrimental effects of ATD. This may explain why this subgroup shows an impairment in planning following ATD, whereas previous studies did not describe effects of ATD on planning in healthy subjects (Park et al. 1994; Schmitt et al. 2000).

These results suggest a 5-HT mediated frontal lobe dysfunction as a biological marker in BD type I (Damasio 1994; Dagher et al. 1999; Elliott et al. 1997; Murphy et al. 1999; Owen et al. 1990; Rubinsztein et al. 2000). Rubinsztein et al. (2000) showed planning dysfunction in BD patients to improve after clinical recovery (Rubinsztein et al. 2000). As remission is associated with an increase in 5-HT activity (Risch and Nemeroff 1992), our results are 
consistent with the improvement in planning after clinical recovery. Planning deficits in BD might thus be related to a depleted 5-HT state.

Compared to FH II and controls, the FH I subjects showed cognitive deficits on planning and memory tasks. Indeed, in BD patients planning (or executive functions) and memory dysfunctions has been repeatedly described (Henry et al. 1973; van Gorp et al. 1998; Ferrier et al. 1999; Murphy et al. 1999; Krabbendam et al. 2000; Rubinsztein et al. 2000).

Independent of mood state, specific impairments in memory or executive functions has been described in remitted BD patients (Atre-Vaidya et al. 1998; Ferrier et al. 1999; Krabbendam et al. 2000; Rubinsztein et al. 2000). Cognitive impairments in FH I, implicate BD type I patients to show more specific similarities of a primary psychotic spectrum, in contrast to BD type II patients, showing a spectrum more consistent with an affective pattern (Morice 1990; Krabbendam et al. 2000; Sobczak et al. accepted). Cognitive deficits may be regarded as a trait marker in BD type I psychopathology.

Cognitive deficits in BD may be partially explained by abnormalities in functional brain structures or metabolism. In BD patients, frontal and temporal lobe areas show decreased blood flow, metabolism, neuroanatomic changes and a reduction in midsagittal brain structures (Coffman et al. 1990), which has been linked to cognitive performance (Buchsbaum 1986; Soares and Mann 1997; Roy et al. 1998; Strik et al. 1998). The specific cognitive impairments in FH subjects, found in this study, may reflect some underlying neuroanatomic abnormality.

In this study, ATD specifically impaired memory performance. The results on memory tasks might confirm previous findings demonstrating ATD-induced impairments of delayed verbal recognition (Riedel et al. 1999; Schmitt et al. 2000), visual recognition memory (Rubinsztein et al. 2001), visuospatial paired associative learning (Park et al. 1994) and stimulus-reward associations learning (Rogers et al. 1999).

After ATD long-term memory (LTM) performance was impaired for verbal and visual stimuli on the VVLT and PLT. On the PLT, impairments on LTM were smaller than on the VVLT. This attenuated effect may be explained by learning pictures being easier than learning words. The high percentage of correct responses $(97 \%)$ on the PLT recognition, suggests a possible ceiling effect. Consequently the PLT might be less sensitive to register changes in memory performance. The simplicity of picture learning might be attributed to the more differentiating and specific characteristics of pictures over words (Emmelkamp and Zimmer 1994). The easier learning of pictures over words may be reflected in a faster consolidation of visual information, which is a possible explanation of the trend significance impairments in short- 
term memory (STM) performance on the PLT (Izquierdo 1989; Jolicoeur and Dell'Acqua 1998). The decrease in power and sensitivity of the PLT compared to the VVLT might be further related to less stimuli (one third smaller) presented, no baseline measures or interference of procedural learning. No effects of ATD were present on retrieval of information acquired earlier in life, indicated by the Fluency. This provides further evidence for a consolidation deficit underlying the impairment in LTM. The impaired LTM performance for both verbal and visual stimuli, confirms the robustness of the effects of ATD on memory.

The impaired RT in the memory scanning task showed a decrease in the intercept and not in the slope of the memory scanning function, which provides evidence for a decrease in sensorimotor speed after ATD. This detrimental effect of ATD on RT does not seem to be related to changes in impulsivity, as no effects of ATD on number of errors was found. These findings are in line with the results of a study of Hasbroucq et al. (1997), who showed lowering of 5-HT to impair RT, whereas stimulation of central 5-HT activity shortens RT in healthy volunteers following Fluvoxamine treatment (Hasbroucq et al. 1997). However, a lack of influence of ATD on memory scanning in normal controls and first-degree relatives of depressed patients was previously found in our lab (Riedel et al. 1999).

Our study found no effects on attention indicated by DLT, AST and Stroop. A significant improvement in focused attention on Stroop interference and DLT performance after ATD has been described in healthy subjects (Schmitt et al. 2000). Table 2 shows that mean interference tended to decrease following ATD, but this was not significant. In our study, an attenuated improvement in attention following ATD may be due to differences in research populations; Schmitt et al. included healthy young (aged 20-29 years) volunteers which were free of any psychiatric family loading whereas our research population was heterogeneous with respect to age, psychiatric family loading and thus possible cognitive performance (Houx et al. 1992; Houx et al. 1993; Schmitt et al. 2000).

The cognitive effects of ATD were not expected to be due to changes in mood for 3 reasons; there were no differences in baseline mood ratings between FH subjects, controls, ATD or placebo, FH I subjects seemed to be more vulnerable to the cognitive effects of ATD whereas mood effects of ATD were pronounced in $\mathrm{FH} \mathrm{II}$, correlation analyses revealed no significant associations between mood and cognition. The effects on mood have been described elsewhere (Sobczak et al. accepted).

ATD resulted in a significant decrease in plasma ratio Trp: LNAAs $(70 \%)$ and $\operatorname{Trp}(57 \%)$ levels. Tyrosine levels and the summated side-effects score did not differ between 
experimental conditions, therefore we suggest that both did not interfere with cognitive effects of ATD.

In conclusion, this study shows ATD-induced planning impairment specifically in FH subjects, indicating a specific serotonergic vulnerability putatively originating from frontal lobe areas. FH I subjects performed worse on planning and memory tasks. These cognitive dysfunctions may indicate an endophenotype constituting a possible biological marker in bipolar psychopathology.

After ATD, the findings of a decrease in sensorimotor speed and LTM performance for both visual and verbal stimuli confirm the robustness of the effects of ATD on memory and shows that the deficits might not be modality-specific. Imaging studies should provide further evidence on the meaning of cognitive deficits in subjects at risk for BD.

\section{References}

Aberg-Wistedt A, Hasselmark L, Stain-Malmgren R, Aperia B, Kjellman BF, Mathe AA (1998) Serotonergic 'vulnerability' in affective disorder: a study of the tryptophan depletion test and relationships between peipheral and central serotonin indexes in citalopram-responders. Acta Psychiatric Scandinavia 97: 374-80

Atre-Vaidya N, Taylor MA, Seidenberg M, Reed R, Perrine A, Glick-Oberwise F (1998) Cognitive deficits, psychopathology, and psychosocial functioning in bipolar mood disorder. Neuropsychiatry Neuropsychol Behav Neurol 11: 120-6

Benkelfat C, Ellenbogen MA, Dean P, Palmour RM, Young SN (1994) Mood-lowering effect of tryptophan depletion. Enhanced susceptibility in young men at genetic risk for major affective disorders. Arch Gen Psychiatry 51: 687-97

Berman RM, Delgado PL, Miller HL, Price LH, Heniger GR, Charney DS (1996) Correlates of depressive relapse in medicated depressed subjects undergoing acute tryptophan depletion. Society for Neuroscience 22 :

2066 (A8.11.10)

Buchsbaum MS (1986) Brain imaging in the search for biological markers in affective disorder. J Clin Psychiatry 47 Suppl: $7-12$

Coffman JA, Bornstein RA, Olson SC, Schwarzkopf SB, Nasrallah HA (1990) Cognitive impairments and cerebral structure by MRI in biplar disorder. Biol Psychiatry 27: 1188-96

Coull JT, Sahakian BJ, Middleton HC, Young AH, Park SB, McShane RH, Cowen PJ, Robbins TW (1995) Differential effects of clonidine, haloperidol, diazepam and tryptophan depletion on focused attention and attentional search. Psychopharmacology Berl 121: 222-30

Dagher A, Owen AM, Boecker H, Brooks DJ (1999) Mapping the network for planning: a correlational PET activation study with the Tower of London task. Brain 122: 1973-87

Damasio AR (1994). Descartes' Error. Emotion, Reason and the Human Brain. London, Papermac, MacMillan Publishers. 
Elliott R, Sahakian BJ, Matthews K, Bannerjea A, Rimmer J, Robbins TW (1997) Effects of methylphenidate on spatial working memory and planning in healthy young adults. Psychopharmacology 131: 196-9

Emmelkamp J, Zimmer HD (1994) Human memory, A multimodel approach. Hogrefe\& Huber publishers, Hogrefe\& Huber publishers

Endicott J, Andreasen NC, Spitzer RL (1975) Family History-Research Diagnostic Criteria. Biometrics

Research, New York State Psychiatric Institute, New York

Ferrier IN, Stanton BR, Kelly TP, Scott J (1999) Neuropsychological function in euthymic patients with bipolar disorder. British Journal of Psychiatry 17: 246-51

Grafman J (1995) Similarities and distinctions among current models of prefrontal cortical functions. Ann N Y Acad Sci 769: 337-68

Hasbroucq T, Rihet P, Blin O, Possamai CA (1997) Serotonin and Human Information Processing: Fluvoxamine can Improve Reaction Time Performance. Neuroscience Letters 229(3): 204-8

Henry GM, Weingartner H, Murphy DL (1973) Influence of affective states and psychoactive drugs on verbal learning and memory. Am J Psychiatry 130: 966-71

Houx PJ, Vreeling FW, Jolles J (1992) Usual and successful cognitive aging and health factors. International Journal of Psychology 27(3-4): 389

Houx PJ, Jolles J (1993) Age-related decline of psychomotor speed: Effects of age, brain health, sex and education. Perceptual and Motor Skills 76: 195-211

Izquierdo I (1989) Different forms of post-training memory processing. Behav Neural Biol 51: 171-202

Jolles J, Verhey FRJ, Riedel WJ, Houx PJ (1995) Cognitive Impairment in Elderly People: Predisposing Factors and Implications for Experimental Drug Studies. Drugs \& Aging 7(6): 459-79

Jolicoeur P, Dell'Acqua R (1998) The demonstration of short-term consolidation. Cognit Psychol 36: 138-202

Kessing LV (1998). Cognitive impairment in the euthymic phase of affective disorder. Psychological Medicine 28(5): $1027-38$

Kimura D, D'Amico C (1989) Evidence for subgroups of adextrals based on speech lateralization and cognitive patterns. Neuropsychologia 27: 977-986

Klaassen T, Riedel, WJ, van Someren A, Deutz NEP, Honig A, van Praag HM (1999) Mood effects of 24-hour tryptophan depletion in healthy first degree relatives of patients with affective disorders. Biol Psychiatry 46: 489-97

Krabbendam L, Honig A, Wiersma J, Vuurman EF, Hofman PA, Derix MM, Nolen WA, Jolles J (2000) Cognitive dysfunctions and white matter lesions in patients with bipolar disorder in remission. Acta Psychiatr Scand 101: 274-80

Lezak MD (1995) Neuropsychological Assessment, $3^{\text {rd }}$ edition. Oxford University Press, Oxford University Press

Luteijn F (1966) [A new abbreviated Groninger Intelligence Test]. Ned Tijdschr Psychol 21: 675-82

Martinez-Aran A, Vieta E, Colom F, Reinares M, Benabarre A, Gasto C, Salamero M (2000) Cognitive dysfunctions in bipolar disorder: evidence of neuropsychological disturbances. Psychother Psychosom 69: 2-18 Menkes DB, Coates DC, Fawcet JP (1994) Acute tryptophan depletion aggravates premenstrual syndrome. J Affect Disord 32: 37-44 
Morice R (1990) Cognitive inflexibility and pre-frontal dysfunction in schizophrenia and mania. Br J Psychiatry 157: $50-4$

Murphy FC, Sahakian BJ, Rubinsztein JS, Michael A, Rogers RD, Robbins TW, Paykel ES (1999) Emotional bias and inhibitory control processes in mania and depression. Psychol Med 29: 1307-21

Owen AM, Sahakian BJ, Hodges JR, Polkey CE, Summers BA, Robbins TW (1995) Dopamine-dependent fronto-striatal planning deficits in early Parkinson's Disease. Neuropsychology 9: 126-40

Park SB, Coull JT, McShane RH, Young AH, Sahakian BJ, Robbins TW, Cowen PJ (1994) Tryptophan depletion in normal volunteers produces selective impairments in learning and memory. Neuropharmacology 33: 575-88

Pollack 1, Norman DA (1964) A non-parametric analysis of recognition experiments. Psychonomic Sciences I: $125-6$.

Rasgon N, McGuire M, Tanavoli S, Fairbanks L, Rapkin A (2000) Neuroendocrine response to an intravenous L-tryptophan challenge in women with premenstrual syndrome. Fertil Steril 73: 144-9

Riekkinen P, Kejonen K, Laakso MP, Soininen H, Partanene K, Riekkinen M (1998). Hippocampal atrophy is related to impaired memory, but not frontal functions in non-demented Parkinson's disease patients. Neuroreport 9(7): $1507-11$

Reilly JG, McTavish SF, Young AH (1997) Rapid depletion of plasma tryptophan: a review of studies and experimental methodology. J Psychopharmacol Oxf 11: 381-92

Riedel WJ, Klaassen T, Deutz NEP, van Someren A, van Praag HM (1999) Tryptophan depletion in normal volunteers produces selective impairment in memory consolidation. Psychopharmacology 141: 362-9

Risch SC, Nemeroff CB (1992). Neurochemical alterations of serotonergic neuronal systems in depression. J Clinl Psychiatry 53 Suppl: 3-7

Robbins TW (2000) From arousal to cognition: the integrative position of the prefrontal cortex. Prog Brain Res 126: 469-83

Rogers RD, Blackshaw AJ, Middleton HC, Matthews K, Hawtin K, Crowley C, Hopwood A, Wallace C, Deakin JF, Sahakian BJ, Robbins TW (1999) Tryptophan depletion impairs stimulus-reward learning while methylphenidate disrupts attentional control in healthy young adults: implications for the monoaminergic basis of impulsive behaviour. Psychopharmacology (Berl) 146: 482-91

Roy PD, Zipursky RB, Saint-Cyr JA, Bury A, Langevin R, Seeman MV (1998). Temporal horn enlargement is present in schizophrenia and bipolar disorder. Biol Psychiatry 44(6): 418-22

Rubinsztein JS, Rogers RD, Riedel WJ, Mehta MA, Robbins TW, Sahakian BJ (2001) Acute dietary tryptophan depletion impairs maintenance of "affective set" and delayed visual recognition in healthy volunteers. Psychopharmacology (Berl) 154: 319-26

Salomon RM, Miller HL, Delgado PL, Charney D (1993) The use of tryptophan depletion to evaluate central serotonin function in depression and other neuropsychiatric disorders. Int Clin Psychopharmacol 8 Suppl 2: 41-6 Savard RJ, Rey AC, Post RM (1980) Halstead-Reitan Category Test in bipolar and unipolar affective disorders. Relationship to age and phase of illness. J Nerv Ment Dis 168: 297-304

Schmitt J, Jorissen, B, Sobczak S, Van Boxtel MPJ, Hogervorst E, Deutz NEP, Riedel WJ (2000) Tryptophan depletion impairs memory consolidation, but improves focused attention in healthy young volunteers. J Psychopharmacology 14(1): 21-29 
Scott J, Stanton B, Garland A, Ferrier IN (2000) Cognitive vulnerability in patients with bipolar disorder. Psychol Med 30: 467-72

Shallice T (1982) Specific impairments of planning. Phil. Trans. of the Royal Society of London 298: 199-209 Sheehan D, Lecrubier Y, Janavs J, Knapp E, Weiller E (1994) MINI International Neuropsychiatric Interview. University of South Florida, Tampa

Smith KA, Morris JS, Friston KJ, Cowen PJ, Dolan RJ (1999) Brain mechanisms associated with depressive relapse and associated cognitive impairment following acute tryptophan depletion. Br J Psychiatry 174: 525-9 Soares JC, Mann JJ (1997) The functional neuroanatomy of mood disorders. J Psychiatr Res 31: 393-432 Sobczak S, Honig A, Riedel WJ (2000) Acute Tryptophan Depletion in bipolar disorders; literature review and directives for further research. Acta Neuropsychiatrica 12 (3): 69-72

Sobczak S, Honig A, Nicolson N, Riedel WJ (accepted) Acute Tryptophan Depletion enhances mood in firstdegree relatives of type II bipolar patients but not in first-degree relatives of type I bipolar patients and healthy matched controls. Neuropsychopharmacology

Steckler T, Sahgal A (1995) The role of serotonergic-cholinergic interactions in the mediation of cognitive behaviour. Behav Brain Res 67: 165-99

Sternberg S (1969) Memory scanning: mental processes revealed by reaction time experiments. Am sci 57: 42157

Strik WK, Ruchsow M, Abele S, Faugatter AJ, Mueller TJ (1998). Distinct neurophysiological mechanisms for manic and cycloid psychoses: evidence from a P300 study on manic patients. Acta Psychiatrica Scandinavica 98(6) : 459-66

Stroop JR (1935) Studies of interference in serial verbal reactions. Journal of Experimental Psychology 18: 643662

van Eijk HM, Rooyakkers DR, Deutz NE (1993) Rapid routine determination of amino acids in plasma by highperformance liquid chromatography with a 2-3 microns Spherisorb ODS II column. J Chromatogr 620: 143-8 van Gorp WG, Altshuler L, Theberge DC, Wilkins J, Dixon W (1998) Cognitive impairment in euthymic bipolar patients with and without prior alcohol dependence. Arch Gen Psychiatry 55: 41-6

Vink M, Jolles J (1985) A new version $f$ the Trial Making Test as an information processing task. J Clin Neuropsychol 7: 162.

Wolfe J, Granholm E, Butters N, Saunders E, Janowsky D (1987) Verbal memory deficits associated with major affective disorders: a comparison of unipolar and bipolar patients. J Affect Disord 13: 83-92

Young SN, Smith SE, Pihl RO, Ervin FR (1985) Tryptophan depletion causes a rapid lowering of mood in normal males. Psychopharmacology Berl 87: 173-7 
PART II 


\title{
Serotonergic dysregulation in bipolar disorders; a literature review of serotonergic challenge studies
}

\begin{abstract}
Serotonin (5-hydroxytryptamine; 5-HT) and endocrine abnormalities have been repeatedly reported in bipolar disorders (BD). Useful methods to investigate a 5-HT responsivity and the interaction with neuroendocrine functioning are provided by acute 5-HT challenge and depletion paradigms. In this review 5-HT challenges are limited to paradigms that stimulate 5HT activity in bipolar disorders.

Literature was searched for in electronic libraries: MEDLINE and PSYCHLIT, period 1966 to 2001. Papers describing effects of an acute 5-HT challenge on neuroendocrine functioning in $\mathrm{BD}$ patients were selected.

Review of the literature revealed 15 studies; 5 papers described the effects of 5 -HT challenges in manic BD patients, 4 papers in euthymic BD and 7 in depressed BD patients. The reviewed 5-HT challenge paradigms are acute administration of oral and intravenous (i.v.) dosage of d,l-fenfluramine, tryptophan, 5-hydroxytryptophan, ipsapirone and buspirone. There were no papers which investigated neuroendocrine effects of m-chlorophenylpiperazine, clomipramine and citalopram in BD patients and were therefore not reviewed.

The literature on 5-HT challenge procedures in BD shows evidence for a blunted prolactin (PRL) in mania and depression as well as blunted cortisol in euthymic BD patients. This suggests that in both mania and depression similar changes in the 5-HT system are involved. It is speculated that blunting of cortisol responses in euthymic BD patients may be a result of chronically altered 5-HT functioning, whereas changes in PRL release following 5-HT challenges reflect more state-dependent changes in 5-HT activity. 5-HT responsivity in BD
\end{abstract}


patients has also been associated with pharmacological treatment, suicidal behavior, weight loss and age. Recommendations for future research are given.

S Sobczak, A Honig, MA van Duinen, WJ Riedel. Bipolar Disorders, accepted

\section{Introduction}

Serotonergic (5-HT) dysregulation has been shown to be involved in the pathophysiology of various psychiatric disorders like depression, anxiety disorders, schizophrenia and bipolar disorders (BD). Neuroendocrine parameters such as prolactin (PRL), growth hormone (GH), cortisol and adrenocorticotropic hormone (ACTH) have been used extensively as biological markers of 5-HT functioning in the brain. 5-HT precursors, releasing agents, reuptake inhibitors, receptor agonists and antagonists have been used as probes in neuroendocrine tests to study 5-HT. These agents can be regarded as 5-HT challenge agents.

In this paper we evaluate the 5-HT dysregulation hypothesis in $\mathrm{BD}$ as assessed by those challenge paradigms which enhance central 5-HT functioning. Various challenge paradigms and methodological procedures will be reviewed and recommendations for future investigations given.

\section{Principle of 5-HT challenges}

5-HT containing raphe nuclei innervate hypothalamic areas and stimulate release of PRL, GH, cortisol and ACTH (Quattrone et al. 1978; Abel and Cleare 1999; Cleare et al. 1996; Goekoop 1998; Nurnberger et al. 1990; Cleare et al. 1998). ACTH and cortisol release is mediated by activation of 5- $\mathrm{HT}_{1 \mathrm{a}}$ and 5- $\mathrm{HT}_{2 \mathrm{a}}$ receptors in the raphe - Hypothalamus Pituitary Adrenal-axis (HPA-axis) pathway (Goekoop 1998; Stahl et al. 1993). GH and PRL release reflects hypothalamic-pituitary stimulation by 5-HT. 5-HT increases release of GH releasing hormone (GHRH) but has no direct effect on somatostatin (which decreases GH release) (Murakami et al. 1986; Chihara et al. 1979). Stimulating effects of 5-HT on PRL might be a net effect of $5-\mathrm{HT}_{2 \mathrm{a} / 2 \mathrm{e}}$ receptor stimulation and dopaminergic inhibition in the hypothalamus in humans (Di Renzo et al. 1989; Van de Kar et al. 1989; McNeilly 1986). 
5-HT stimulating agents can be used to assess central 5-HT receptor sensitivity in hypothalamic areas by measuring endocrine responses, e.g. cortisol, PRL, GH and ACTH. Central 5-HT responsivity can be reflected in levels of hormones released (hypothalamic 5-HT pathway) following administration of a challenge agent (Stahl 1998). Relatively high neuroendocrine responses may be indicative of post-synaptic receptor hypersensitivity whereas low responses suggest post-synaptic receptor hyposensitivity (Riedel et al. 2002). Changes in postsynaptic signal transduction, presynaptic transporter mechanisms and dysregulation of the endocrine pathways themselves may also be responsible for changes in hormonal release following 5-HT stimulation (Coccaro et al. 1989; Mann et al. 1992). For example, in depressed patients compared to healthy controls reduced cortisol and PRL responses have been described in response to fenfluramine challenge (Abel et al. 1997; Cleare et al. 1996, Cleare and Bond 1995; Lucey et al. 1992).

In this paper, studies applying agents which enhance 5-HT activity will be reviewed, i.e. 5-HT precursors, 5-HT reuptake inhibitors, 5-HT agonists, and 5-HT releasing drugs (Yatham and Steiner 1993).

\section{5-HT responsivity in $B D$}

5-HT abnormalities have repeatedly been reported in BD; e.g. increased 5-HT in platelets, a lower maximal velocity (Vmax) of 5-HT platelet uptake, decreased brain 5-HT neurotransmitter activity and decreased postmortem 5HIAA/5-HT ratios (Wirz Justice and Puhringer 1978; Marazziti et al. 1991; Leake et al. 1991; Prange et al. 1974; Price et al.1990; Young et al. 1994). Central 5-HT dysregulation in BD may be due to altered 5-HT metabolism, modifications in the 5-HT-transporter gene, 5-HT receptor genes or tryptophan hydroxylase gene (Ginns et al. 1996; Kunugi et al. 1997; Oruc et al. 1997; Bellivier et al. 1998; Lesch et al. 1995). 5-HT responsivity has also been described in healthy first-degree relatives of BD patients; more pronounced effects on cortisol and mood following Acute Tryptophan Depletion (ATD) were seen in first-degree relatives of BD patients compared to matched controls (Sobczak et al. accepted). 


\section{Methods}

\section{Literature Review}

Literature was searched for in electronic libraries: MEDLINE and PSYCHLIT, period 1966 to 2001. The used keywords were: 'serotonin', 'bipolar disorder', 'depression', 'prolactin', 'cortisol', 'growth hormone' and 'ACTH'. To complement the selection all references in found articles were checked. Papers describing effects of an acute 5-HT challenge on neuroendocrine functioning and mood in BD patients were selected. The following 5-HT challenge procedures were reported: d,l-fenfluramine, tryptophan (Trp), 5-hydroxytryptophan (5-HTP), ipsapirone, buspirone, m-chlorophenylpiperazine (m-CPP), clomipramine and citalopram.

Selection criteria for papers were: 1) papers must include BD patients and control groups, 2) and must present results separately for BD and unipolar depression (UD) patients, 3) number of $\mathrm{BD}$ patients must be 5 or more.

\section{Results}

Twenty-eight papers describing 5-HT challenge procedures in BD were found. Of these papers 11 were not reviewed because they did not fulfill the selection criteria. Eliminated papers were on d,l-fenfluramine (Shapira et al., 1992; Lerer et al., 1996; Lichtenberg et al., 1992 (2); Kasper et al. 1990), Trp (Price et al. 1989; Price et al. 1998), 5-HTP (Ansseau et al. 1983; Maes et al. 1997), m-CPP (Anand et al. 1994; Price et al. 1997), clomipramine (Golden et al. 1992) and citalopram (Kapitany et al. 1999).

Fifteen papers were reviewed: 5 papers studied the effects of 5-HT challenges in manic BD patients, 4 papers in euthymic BD and 7 in depressed BD patients. Reviewed 5-HT challenge paradigms are acute administration of oral and intravenous (i.v.) dosage of: d,l-fenfluramine $(\mathrm{n}=7)$, tryptophan $(\mathrm{n}=3), 5$-hydroxytryptophan $(\mathrm{n}=3)$ ipsapirone $(\mathrm{n}=1)$ and buspirone $(\mathrm{n}=1)$. An overview of these papers is given in table 1. 
Table 1: Studies using acute 5-HT challenge procedures in bipolar disorder (BD) patients. Effects on mood, prolactin (PRL), cortisol (CRT), adrenocorticotropic hormone (ACTH) and growth hormone (GH). Study designs were: parallel groups (PG), placebo-controlled (PC), double -blind (DB), cross-over design (CO). Control subjects (C), unipolar depressed (UD), dysthemic (D), schizophrenic (S) and schizoaffective (SA) patients.

Reference ( $m$ )Subjects Medication Method Design Result

\section{ALFenluramins}

Mohlhouer ef al. 1984

Mohilhauer et al. 1985

Minchell et al., 1990

Lichienkere et al, $1992(2)$

Thakore et al.. 1996

Yatham et al., 1996

Mannel et al., 1997

\section{Irvptophan}

Deakin et al., 1990

Numberger et al., 1990

Price te al., 1991

\section{S-hydroxvtryptophan}

Meltzer et al., 1984,

1983; 1984 (1. II. III)

Takahashi et al., 1973

Westenberg et al., 1982

Buspirone

Yatham et al., 1994

Ipsapirone

Shiah et al, 1998

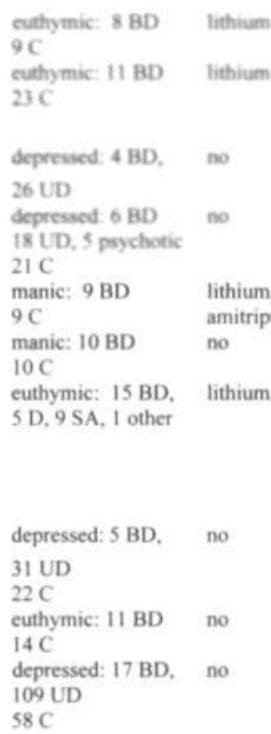

depressed: 5 BD, no

31 UD

$22 \mathrm{C}$

euthymic: $11 \mathrm{BD}$ no

$14 \mathrm{C}$

depressed: $17 \mathrm{BD}$, no

109 UD

$58 \mathrm{C}$

depressed: $14 \mathrm{BD}$, no

22 UD, 8SA.

manic: $21 \mathrm{BD}$

$25 \mathrm{C}$

manic: 5 BD

depressed: 9 UD

depressed: 5 BD. no

9 UD

$12 \mathrm{C}$

manic: $11 \mathrm{BD}$ no
$11 \mathrm{C}$
depressed: $8 \mathrm{BD}$ no
$26 \mathrm{C}$

$\begin{array}{ll}60 \mathrm{mg} \text { oral }(d, 1) & \text { PG } \\ 60 \mathrm{mg} \text { oral }(d, 1) & \text { PG } \\ 60 \mathrm{mg} \text { oral } & \text { PG } \\ 60 \mathrm{mg} \text { oral } & \text { PC DE CO } \\ 30 \mathrm{mg} \text { oral (d) } & \text { PG } \\ 60 \mathrm{mg} \text { oral (d,1) } & \text { PG } \\ 60 \mathrm{mg} \text { oral (d,1) } & \text { PG }\end{array}$

No differences between groups in PRI

Enhanced CRT response in BD on lithium

Bhunted PRL in endogenous BD (and UD). reduced basal PRL. in BD, no effects CRT Bhunted PRL. response in BD (and UD)

Blunted PRL, but not CRT response in BD

No differences between groups, PRL. CRT

Blunted CRT response in $\mathrm{BD}$

$100 \mathrm{mg} / \mathrm{kg}$ i.v. $\quad P G$

Blunted GH and PRL in BD (and UD)

$50 \mathrm{mg} / \mathrm{kg}$ i.v. $\quad$ PC DB CO

$7 \mathrm{~g}$ i.v.

PG

Blunted ACTH and CRT in BD,

no differences in PRI. GH

Blunted GH in BD (+ UD). No effects PRI.
$200 \mathrm{mg}$ oral $\quad P C$

$200 \mathrm{mg}$ oral $\quad P G$

$5.0 \mathrm{~g}$ oral $\quad \mathrm{PC}$

$0.5 \mathrm{mg} / \mathrm{kg}$ oral $\quad P G$

$0.3 \mathrm{mg} / \mathrm{kg}$ oral $\quad P C$
Enhanced CRT in depressed and manic BD patients. Increase related to suicide attempts and non-psychotic features.

Enhanced $\mathrm{GH}$ response in manic BD

No stimulating effects on GH. TSH, PRL. CRT

No differences in PRL response between groups

No differences CRT response between groups 


\section{5-HT releasing agents}

1) d,l-Fenfluramine

The effects of d,l-fenfluramine on the 5-HT system are multiple; it increases presynaptic 5-HT release, blocks synaptic 5-HT reuptake, and stimulates postsynaptic 5-HT receptors $\left(5-\mathrm{HT}_{2 \mathrm{a} / 2 \mathrm{c}}\right.$ ) both directly and indirectly (Rowland and Carlton 1986). The $d$-isomer of fenfluramine has been suggested to act more selectively on the 5-HT system compared to the l-isomer (Rowland and Carlton 1986; Goodwin et al. 1994), but Coccaro et al. (1996) concluded that $\mathrm{d}, \mathrm{l}$-fenfluramine does not have a detectable effect on dopamine in men. Fenfluramine is administrated orally (60mg d,l-mixture, $30 \mathrm{mg} \mathrm{d}$-mixture) and appears to be well tolerated by healthy subjects (Coccaro et al. 1988).

Thakore et al. (1996) used a $30 \mathrm{mg} \mathrm{d}$-fenfluramine challenge, all other studies used $60 \mathrm{mg}$ oral d,l-fenfluramine.

In lithium-treated euthymic patients, there were no effects on PRL response (Muhlbauer 1984). Compared to UD patients, cortisol response was blunted in euthymic BD patients using lithium and carbamezapine (Mannel et al. 1997). Euthymic patients showed lower baseline cortisol, and the d,l-fenfluramine induced cortisol response was exaggerated in lithium treated BD patients compared to healthy control subjects (Muhlbauer and MullerOerlinghausen 1985).

In medicated manic BD patients, Thakore et al. (1996) found increased basal cortisol levels and reduced ( $30 \mathrm{mg}$ oral) d-fenfluramine induced PRL responses compared to control subjects (Thakore et al. 1996). Yatham (1996) found no differences in baseline and d,l-fenfluramine induced PRL and cortisol responses between medication-free manic patients and healthy matched control subjects (Yatham 1996).

In medication-free depressive subjects, a blunted PRL response was found in BD and UD patients compared to healthy control subjects (Lichtenberg et al. $1992 \mathrm{I}$ ). Mitchell et al (1990) reported reduced basal PRL levels in medication-free BD patients compared to UD (Mitchell et al. 1990).

In summary, following d,l-fenfluramine there was a tendency to blunted PRL release in manic and depressed BD patients off medication compared to healthy controls. In euthymic patients off medication, PRL response was unchanged compared to healthy controls. Effects on cortisol response following d,l-fenfluramine did not show clear differences between euthymic, manic and depressed BD patients and controls. 


\section{5-HT precursors}

\section{2) Tryptophan (Trp)}

Trp is the precursor of 5-HT. Trp loading stimulates the 5-HT system in an aspecific way by increasing the conversion of Trp to 5-HTP.

The essential amino acid Trp administered $i v$. causes a reliable increase in PRL and GH (Charney et al., 1982). Oral Trp administration results in a less pronounced increase PRL and GH response (Power and Cowen 1992; Yatham and Steiner 1993; Westenberg et al. 1982). The reported effective dosage of i.v. Trp is between $50 \mathrm{mg} / \mathrm{kg}$ and $100 \mathrm{mg} / \mathrm{kg}$ (Nurnberger et al. 1990); gastrointestinal side effects can be expected at higher dosages (Nurnberger et al. 1990). Most prominent side effects are nausea, drowsiness and fatigue, which occur more frequently at higher dosages (Yatham and Steiner 1993).

Blunted cortisol and ACTH responses to 50-mg/ $\mathrm{kg}$ i.v. Trp were reported in medication-free euthymic BD patients compared to healthy controls. There were no differences in PRL and GH responses (Nurnberger et al. 1990).

There were no studies on $\operatorname{Trp}$ in manic BD patients. Compared to healthy controls, GH and PRL responses to $7.0 \mathrm{~g}$ respectively $100-\mathrm{mg} / \mathrm{kg}$ i.v. Trp were blunted in both depressed BD and UD patients (Price et al. 1991; Deakin et al. 1990).

In sum following Trp challenge, cortisol and ACTH responses were blunted in euthymic BD patients compared to healthy controls. GH and PRL responses were lower in depressed BD patients than in healthy control subjects.

\section{3) 5-Hydroxytryptophan (5-HTP)}

5-HTP stimulates the 5-HT system aspecifically. 5-HTP is converted to 5-HT by the enzyme amino acid decarboxylase. Due to the wide distribution of this enzyme in the brain, 5-HT is not only synthesized in 5-HT neurons, but also in catecholaminergic neurons, acting as a false catecholaminergic neurotransmitter (Van Praag et al. 1987).

5-HTP administered in high doses (>150mg p.o.) influences PRL and GH release. 5-HTP administered i.v. may cause severe side effects, especially at higher doses (van Vliet et al. 1996; den Boer and Westenberg 1990). Oral administration is less reliable as most 5-HTP is degraded in the liver (Power and Cowen 1992; Ansseau et al. 1983; Westenberg et al. 1982). Administration of a decarboxylase inhibitor after oral 5-HT administration is to be recommended as this increases the availability of oral 5-HTP to the brain (van Praag et al., 1976). 
With one exception, all studies used a $200 \mathrm{mg}$ oral 5 HTP challenge. Westenberg et al. (1982) found no changes in plasma hormones to a $5.0 \mathrm{~g}$ oral 5 HTP challenge (Westenberg et al., 1982). No papers described effects of 5-HTP in euthymic BD patients.

In both medicated and medication-free manic BD patients, plasma GH and cortisol response following oral 5-HTP were more pronounced compared to depressed UD patients (Takahashi et al. 1973; Meltzer et al. 1983; Meltzer et al. 1984 I, 1984 II, 1984 III). Depressed BD patients also showed an enhanced 5-HTP induced cortisol response compared to depressed UD patients.

Tricyclic antidepressants (TCA) augmented the 5-HTP induced cortisol response whereas lithium and monoamine oxidase inhibitors (MAOI) attenuated this response (Meltzer et al. 1984 III). Increased cortisol response was associated with history of suicide attempts (Meltzer et al. 1984 I; Meltzer et al. 1984 II).

Thus, compared to UD depressed patients, cortisol response to 5-HTP is increased in both manic and depressed BD patients and $\mathrm{GH}$ response is increased in manic BD patients.

\section{5-HT receptor agonists}

4) Buspirone

Buspirone, a postsynaptic 5- $\mathrm{HT}_{\mathrm{la}}$ receptor agonist, belongs to the azapirones (Power and Cowen 1992). Oral buspirone administration $(5-10 \mathrm{mg})$ has been shown to increase PRL (Meltzer and Maes 1994; Anderson and Cowen 1992). However, effects on ACTH and cortisol are not consistent and would not be suitable measures of 5-HT functioning (Yatham and Steiner 1993). Buspirone also has demonstrated affinities for dopaminergic and $\alpha_{2}$ receptors (Yatham et al. 1999). Although buspirone may cause nausea and drowsiness, it is generally well tolerated.

There were no studies on buspirone in euthymic or depressed BD patients. In unmedicated manic BD patients, no differences in PRL response following $0.5-\mathrm{mg} / \mathrm{kg}$ oral buspirone were found compared to healthy controls (Yatham 1994). 


\section{5) Ipsapirone}

Ipsapirone, a central acting pyrimidinylpiperazine derivate is one of the azapirones, a group of selective partial agonists of pre- and post-synaptic 5- $\mathrm{HT}_{1 \mathrm{a}}$ receptors (Power and Cowen 1992). Administered orally, ipsapirone $(>0.1 \mathrm{mg} / \mathrm{kg}$ ) produces a dose-dependent increase in plasma cortisol and ACTH in healthy volunteers (Yatham et al. 1999). HPA-axis activation following ipsapirone administration provides a valid paradigm to evaluate both post- and presynaptic 5 $\mathrm{HT}_{1 \mathrm{a}}$ receptor functions in vivo (Lesch et al. 1992). Oral administration (0.1-0.3 mg/kg) of ipsapirone is generally well tolerated (Lesch et al. 1989). Typically single oral doses of 10 and $20 \mathrm{mg}$ are reported in most studies.

No differences in cortisol responses were reported in unmedicated depressed BD patients and healthy control subjects following a $0.3 \mathrm{mg} / \mathrm{kg}$ oral ipsapirone probe (Shiah et al. 1998). Effects of ipsapirone challenge in manic or euthymic BD patients were not reported.

\section{Discussion}

The aim of this review was to investigate the 5-HT dysregulation hypothesis in BD patients following 5-HT challenges.

In euthymic BD patients PRL response following d,l-fenfluramine and Trp were unchanged compared to healthy controls (Mühlbauer et al., 1984; Nurnberger et al., 1990). Cortisol responses following d,l-fenfluramine was blunted in euthymic BD compared to UD patients (Mannel et al., 1997). D,l-fenfluramine induced cortisol response in euthymic BD stabilized on lithium patients was enhanced (Mühlbauer et al., 1985). Following Trp, cortisol and $\mathrm{ACTH}$ responses were less pronounced in euthymic BD patients than in healthy controls (Nurnberger et al., 1990).

In manic and depressed BD patients a tendency towards blunted PRL release following d,1fenfluramine (Thakore et al., 1996) and Trp (Mitchell et al., 1990; Lichtenberg et al., 1992 (2)) compared to UD patients and healthy controls was reported. Trp showed a blunted GH response in depressed BD patients compared to healthy controls (Deakin et al,, 1990; Price et al., 1991). Following d,l-fenfluramine, cortisol response was unchanged in manic and depressed BD patients as compared to UD patients and healthy controls. On the other hand, stimulation with 5-HTP seems to enhance cortisol response in manic and depressed BD patients as compared to UD patients and healthy controls. ACTH response to 5-HT challenges was not investigated in manic and depressed BD patients. 


\section{5-HT responsivity and phase of illness}

The reported blunted PRL and cortisol responses following d,l-fenfluramine in manic and depressed BD patients might be explained by pre- and / or post-synaptic changes. In keeping with the classical indolamine hypothesis, blunting might be a result of a relative 5-HT deficit at the synapse (Mann et al., 1995). Receptors and signal transduction at the post-synaptic element might also be impaired, e.g. due to receptor desensitization, i.e. post-synaptic 5- $\mathrm{HT}_{2 \mathrm{a}} /$ 5- $\mathrm{HT}_{2 \mathrm{e}}$ (Goodall et al., 1993; Coccaro et al. 1996a; Riedel et al. 2002; Siever et al.1983). On the other hand, blunted cortisol and PRL responses to d,l-fenfluramine might also be indicative of reduced availability of presynaptic 5-HT release and following increased neuronal firing in depression and mania (Fishbein et al., 1989; Carboni and di Chiara, 1989). The fact that PRL response was also blunted in depressed BD patients following Trp (Deakin et al., 1990) makes the explanation of presynaptic 5-HT depletion less probable. It is also suggested that cortisol hypersecretion in depression influences spontaneous as well as 5-HT induced PRL release (Dinan and Scott, 1996). Hypersecretion of cortisol in manic and depressed BD patients was found following 5-HTP challenge (Meltzer et al., 1984 I, II, III), but these studies did not investigate PRL release. Mitchell et al. (1990) reported an increased PRL response in BD compared to UD patients but no difference in cortisol response following d,l-fenfluramine. These findings do not support a direct relationship between cortisol levels and PRL release. Blunted neuroendocrine responses in both mania and depression described in this review provides evidence for similar changes in brain 5-HT functioning contributing to both mood states. Indeed, in BD patients both mania and depressive episodes have been associated with reduced 5-HT activity (Marazziti et al. 1991; Young et al. 1994). In the euthymic phase of BD, PRL response following d,l-fenfluramine and Trp does not differ from healthy controls, suggesting a restabilisation of 5-HT functioning. Hence following d,l-fenfluramine challenges cortisol response was lower in euthymic BD patients as compared to UD patients (Mannel et al., 1997). Cortisol and ACTH responses were also blunted following Trp in euthymic BD patients compared to healthy controls (Nurnberger et al., 1990).

Thus it seems that in euthymic BD patients 5-HT challenges result in blunted cortisol and ACTH responses and no changes in PRL, whereas in mania and depression PRL secretion is significantly blunted but no effects on cortisol. 5-HT controls the release of cortisol and

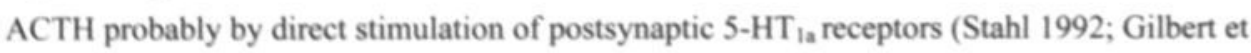
al., 1987). Possibly, functioning of 5- $\mathrm{HT}_{2 \mathrm{a}}$ and 5- $\mathrm{HT}_{2 \mathrm{e}}$ receptors are state-dependent whereby sensitivity changes during manic and depressive episodes. It may be speculated that 
sensitivity of 5- $\mathrm{HT}_{1 \mathrm{a}}$ receptors are more a trait phenomenon related to chronic 5-HT dysfunctions (e.g. decreased presynaptic 5-HT release ) in BD developing during the course of illness.

According to the kindling and stress-sensitization theory the number of illness episodes may lead to structural neural changes, more neurotransmitter dysfunctions and may ultimately influence vulnerability to future illness episodes (Post and Weiss, 1997). Vulnerability to 5HT dysfunctions may therefore be a direct consequence of history of illness episodes. Such a relationship has been found in depressed patients by Booij et al. (submitted); in this study mood lowering effects of ATD were positively related to number of illness episodes.

\section{Disease-related factors}

Another possible explanation might be that 5-HT dysregulation is not so much directly related to the etiology of $\mathrm{BD}$, but to certain disease-related factors such as suicidal behavior (Coccaro et al., 1989; Malone et al., 1986; Cocarro and Kavoussi, 1994), co-morbid personality disorders (Coccaro et al., 1994 I, 1994 II), aggression and impulsivity (Coccaro et al., 1989). Indeed, increased cortisol response to 5-HTP seemed to be related to suicidal behavior; patients with a history of suicide attempts show an enhanced 5-HT induced cortisol response (Meltzer et al. 1984 II; Meltzer et al. 1984 III). After ATD, 5-HT dysfunction has also been related to suicidal behavior in depressed UD patients (Van der Does 2001; Booij et al., submitted).

Blunted PRL responses to Trp or d,l-fenfluramine in depressed patients has also been associated with nonmelancholic features (Price et al., 1991), younger age (Mann et al., 1995; Lerer et al., 1996) and weight-loss (Lichtenberg et al. 1992 I; Deakin et al. 1990).

\section{Psychotropic medication}

5-HT responsivity in $\mathrm{BD}$ may change during pharmacological treatment and with an increasing number of episodes. Indeed, after treatment with lithium and valproate an increase in cortisol response to respectively d,l-fenfluramine (Mühlbauer et al., 1985) and 5-HTP (Maes et al., 1997) has been reported. 5-HT responsivity to 5-HT challenges is thus dependent on the concurrent use of psychotropic medication. Possibly, pharmacological treatment induces post-synaptic sensitization of 5-HT receptors in the raphe- HPA pathway. Changes in 5-HT receptor sensitivity may then influence neuroendocrine responses to 5-HT challenges. 
Peripheral 5-HT metabolism

In addition to central 5-HT responsivity, blunted or enhanced neuroendocrine response might be explained by changes in peripheral 5-HT metabolism in BD. More rapid Trp clearance in depressed patients compared to controls has been reported after Trp infusion (Deakin et al. 1990). Amamoto (1976) reported a delay in elevation of plasma 5-HT and 5HIAA concentrations and a delay in 5HIAA urinary excretion in depressed BD patients compared to control subjects (Amamoto and Sarai 1976).

\section{Methodological considerations}

The direct comparison of reviewed papers is hampered by differences in methodology: First, a major complication in comparing the papers on 5-HT challenges is the use of different 5-HT challenge paradigms. Neuroendocrine responses depend very much on the specificity of the applied 5-HT challenge agent. TCAs may interfere with dopaminergic and noradrenergic systems and neuroendocrine effects may therefore partly be explained by changes in cathecholaminergic neurotransmission (Yatham and Steiner, 1993; Van Praag et al. 1987). 5-HT precursors or 5-HT releasing drugs are probably most valuable in the assessment of overall 5-HT responsivity as these agents have stimulating effects on both pre- and postsynaptic 5-HT receptors of all types. Selective agonists (e.g. 5- $\mathrm{HT}_{\mathrm{la}}$ ) activate the 5-HT system more selectively and are best used as an indicatation of 5-HT receptor sensitivity. Nowadays, selective reuptake inhibitors seem to be most promising as acute 5-HT challenge agents; citalopram significantly increases PRL and cortisol in healthy subjects (Kapitany et al. 1999). Second, the lack of consistent findings in this review might be due to differences in research populations, as some papers included only BD patients, other papers included mixed research populations of both BD and UD patients. Drawing conclusions about 5-HT functioning in BD from papers which included mixed research populations are therefore hazardous. No papers specified a type I or type II BD diagnosis. There is some indication to the importance of this issue as BD type II seem to be more associated with a central 5-HT dysfunction than BD type I (Sobczak et al. accepted). Not all papers included healthy control subjects as a reference group, some papers included only UD patients as controls. Selected patients also differed in their mood state, i.e. manic, depressed or euthymic.

Third, the use of psychotropic medication might have influenced neuroendocrine responding to 5-HT challenges (Mannel et al., 1997; Mühlbauer et al., 1984; Mühlbauer et al., 1985; Thakore et al., 1996; Meltzer et al. 1984 II; Meltzer et al. 1984 III; Maes et al. 1997). 
Recommendations

To draw general conclusions on effects of 5-HT challenge procedures in BD patients the following methodological recommendations should be considered:

1) Despite their popularity, 5-HT challenge agents have been criticized. Agents which have a more overall 5-HT stimulating effects may be very useful in the exploration of 5-HT responsivity in BD. Probes with specific receptor agonists like ipsapirone and buspirone give only an indication of post-synaptic 5-HT functioning, whereas nonselective receptor agonists and such as m-chlorophenylpiperazine (mCPP), d,l-fenfluramine, Trp and 5-HTP act both presynaptically and postsynaptically and provide therefore an overall indication of the 'net' activity of the 5-HT system (Van Praag et al., 1987; Coccaro and Kavoussi, 1994) Both d- and d,l-fenfluramine are not available anymore because of side-effects, increased risk for hart valve pathology and pulmonary hypertension (McCann et al., 1997). Trp and 5-HTP have been criticized for their interference with noradrenergic and dopaminergic neurotransmitter systems (Yatham and Steiner, 1993; van Praag et al., 1987). Reuptake-inhibitors may be useful 5 -HT challenge agents. Intravenous clomipramine challenge ( $>10 \mathrm{mg})$, a tricyclic antidepressant (TCA), leads to consistent increases (dose-dependent) in PRL and cortisol levels in healthy volunteers (Manji et al. 1991) and demonstrated a blunting of PRL response, as well as a trend toward blunted $\mathrm{ACTH}$ and cortisol response in BD and UD depressed patients (Golden et al. 1992). Compared to clomipramine citalopram is a highly specific selective serotonin reuptake inhibitor (SSRI) (Stahl 1998); 20 mg i.v. citalopram challenge shows similar results in healthy subjects and depressed patients (Kapitany et al. 1999). Therefore citalopram challenge should be preferred over clomipramine challenge as a 5 -HT probe.

2) As 5-HT responsivity has been suggested to differ between BD type I and BD type II (Sobczak et al., accepted), the effects of 5-HT challenges should preferably be investigated in research populations composed of equal number of both types of BD patients. Diagnoses of BD should preferably be made following structured psychiatric interview.

3) To investigate 5-HT responsivity in $\mathrm{BD}$, patients should be off-medication for at least 2 weeks, or preferably drug-naive. Alternatively, 5-HT challenge paradigms might be investigated in healthy first-degree relatives of BD patients (Sobczak et al. 2000).

4) Preferably, papers should control for factors which have been described to interfere with neuroendocrine effects to 5-HT challenge agents, i.e. psychotropic medication, 
number of illness episodes, illness episode, melancholia, history of refractoriness to medical treatment, co-morbid personality disorders, psychotic features, phase of menstrual cycle, recent weight loss and family history of affective disorders (Coccaro et al ., 1989; Clear and Bond 1997; O, Keane et al., 1991; Fitzgerald et al., 1997).

5) Alterations in 5-HT activity can induce changes in mood and cognition (Riedel et al. 1999; Klaassen et al. 1999). Changes in mood following 5-HT challenges do not necessary correlate with hormonal responses (Sobczak et al. accepted 2). As central 5HT responsivity might be reflected by changes in mood and cognition after stimulation of the 5-HT system (Cappiello et al. 1997; Sobczak et al. accepted 1), it is advised to use mood and cognitive measures as dependent variables to assess 5-HT responsivity. Mood changes should preferably be assessed using Visual Analogue Scales (VAS).

6) The power of studies using a parallel groups design is less as compared to studies using a crossover design with the same number of subjects. To increase the power of the experimental studies using acute 5-HT challenge paradigms, studies should preferably use a placebo controlled crossover design, including healthy matched control subjects. In crossover studies, the risk of carry-over effects can be reduced by using a washout period of at least 2 weeks and taking baseline measures (see also Newman et al., 1998).

\section{References}

Abel KM, Cleare AJ (1999) Peripheral hormonal responses to d-fenfluramine as a probe of central serotonergic function in humans. Psychopharmacology 142(1): 68-72.

Abel KM, O'Keane, V, Murray RM, Cleare AJ (1997) Serotonergic function and negative and depressive symptomatology in schizophrenia and major depression. Psychoneuroendocrinology 22(7):539-48.

Amamoto T, Sarai K (1976) On the tryptophan-serotonin metabolism in manic-depressive disorders. Changes in plasma 5-HT and 5-HIAA levels and urinary 5-HIAA excretion following oral loading of L-5-HTP in patients with depression. Hiroshima J Med Sci 25(2-3):135-40.

Anand A, Charney DS, Delgado PL, MeDougle CJ, Heniger GR, Price LH (1994) Neuroendocrine and behavioral responses to intravenous m-chlorophenylpiperazine (mCPP) in depressed patients and healthy comparison subjects. Am J Psychiatry 151 (11):1626-9.

Anderson IM, Cowen PJ (1992) Effect of pindolol on endocrine and temperature responses to buspirone in healthy volunteers. Psychopharmacology 106(3):428-32.

Ansseau M, Doumont A, Thiry D, Geenen V, Legros JJ (1983) Interest of 5-hydroxytryptophan (5-HTP) as a neuroendocrine marker in depressive illness. A negative report. Acta Psychiatr Belg 83(1):50-6. 
Bellivier F, Leboyer M, Courtet P, Buresi C, Beaufils B, Samolyk D, Allilaire J, Feingold J, Mallet J, Malafosse A (1998) Association between the tryptophan hydroxylase gene and manic-depressive illness. Arch. Gen. Psychiatry 55:33-7.

Booij L, Van der Does AJW, Benkelfat C, Bremner JD, Cowen PJ, Fava M, Gillin JC, Leyton M, Moore P. Smith KA, Van der Kloot WA (submitted) Predictores of response to Tryptophan Depletion: a Re-analysis. Cappiello A, Sernyak MJ, Malison RT, MeDougle CJ, Heninger GR, Price LH (1997) Effects of acute tryptophan depletion in lithium-remitted manic patients: a pilot study. Biol Psychiatry 42(11):1076-8. Carboni E, di Chiara G (1989) Serotonin release estimated by transcortical dialysis in freely-moving rats. Neuroscience 32: $637-45$.

Charney DS, Heninger GR, Reinhard JF Jr., Sternberg DE, Hafstead KM (1982) The effect of IV L-tryptophan on prolactin, growth hormone, and mood in healthy subjects. Psychopharmacology Berl 78: 138-43.

Chihara K, Arimura A, Schally AV (1979) Effect of intraventricular injection of dopamine, noreprinephrine, acetylcholine, and 5-hydroxytryptamine on immunoreactive somatostatin release into rat hypophyseal portal blood. Endocrinology 104(6):1656-562.

Cleare AJ, Forsling M, Bond AJ (1998) Neuroendocrine and hypothermic effects of 5-HTIA receptor stimulation with ipsapirone in healthy men: a placebo-controlled study. Int Clin Psychopharmacol 13(1):23-32.

Clear AJ, Bond AJ (1997) Does central serotonergic function correlate inversely with aggression? A study using d-fenfluramine in healthy subjects. Psych Res 69: 89-95.

Cleare AJ, Bond AJ (1995) The effect of tryptophan depletion and enhancement on subjective and behavioural aggression in normal male subjects. Psychopharmacology Berl 118(1):72-81.

Cleare AJ, Murray RM, O'Keane V(1996) Reduced prolactin and cortisol responses to d-fenfluramine in depressed compared to healthy matched control subjects. Neuropsychopharmacology 14(5):349-54.

Coccaro EF, Siever LJ, Klar HM, Cochrane K, Cooper TB, Mohs RC, Davis KL (1989) Serotonergic studies in patients with affective and personality disorders: correlates with suicidal and impulsive-aggressive behaviour. Arch Gen Psychiatry 46:587-99.

Coccaro EF, Siever LJ, Kourides IA, Adan F, Campbell G, Davis KL (1988) Central serotoninergic stimulation by fenfluramine challenge does not affect plasma thyrotropin-stimulating hormone levels in man.

Neuroendocrinology 47(4):273-6.

Coccaro EF, Kavoussi RJ (1994) Neuropsychopharmacologic challenge in biological psychiatry, Clin Chem 40 : 319-27.

Coccaro EF, Kavoussi RJ, Oakes M, Cooper TB, Hauger R (1996) 5-HT-2a/2c receptor blockade by amesergide fully attenuates prolactin response to $\mathrm{d}$-fefluramine challenge in physically healthy human subjects. Psychopharmacology 126: 24-30.

Coccaro EF, Klar H, Siever LJ (1994 I) Reduced prolactine response to fenfluramine challenge in personality disorder patients is not due to deficiency of pituitary lactotrophs. Biol Psychiatry 36: 344-54.

Coccaro EF, Silverman JM, Klar HM, Horvath TB, Siever LJ (1994 II) Familial correlates of reduced central serotonergic system function in patients with personality disorders. Arch Gen Psychiatry 51: 318-24.

Deakin JF, Pennell I, Upadhyaya AJ, Lofthouse R (1990) A neuroendocrine study of 5HT function in depression: evidence for biological mechanisms of endogenous and psychosocial causation.

Psychopharmacology 101(1):85-92. 
den Boer JA, Westenberg HG (1990). Behavioral, neuroendocrine, and biochemical effects of 5hydroxytryptophan administration in panic disorder. Psychiatry Res 31(3):267-78.

Dinan TG, Scott LV (1996) The influence of cortisol on spontaneous and 5-HT stimulated prolactine release in man. J Basic Clin Physiol Pharmacol 7: 45-56.

Di Renzo G, Amoroso S, Taglialatela M, Canzoniero L, Basile V, Fatatis A, Annunziato L (1989) Pharmacological characterization of serotonin receptors involved in the control of prolactin secretion. Eur $\mathrm{J}$ Pharmacol 162(2):371-3.

Fischbein DH, Lozovsky D, Jaffe JH (1989) Impulsivity, aggression and neuroendocrine responses to serotonergic stimulation in substance abusers. Biol Psychiatry 25: 1049-66.

Fitzgerald M, Malone K, Li S, Harrison WM, McBride PA, Endicott J, Cooper T, Mann JJ (1997) Blunted serotonin response to fenfluramine challenge in premenstrual dysphoric disorder. Am J Psych 54: 556-8.

Gilbert F, Stahl SM, Tricklebank M (1987) Characterization of the 5-HT receptor subtype mediating ACTH release in the rat. Brit J Pharmacol 91: 495P.

Ginns EI, Ott J, Egeland JA, Allen CR, Fann CS, Pauls DL, Weissenbachoff J, Carulli JP, Falls KM, Keith TP, Paul SM (1996) A genome-wide search for chromosomal loci linked to bipolar affective disorder in the Old Order Amish. Nat Genet 12(4):431-5.

Goekoop JG (1998) De regulatie van de hypothalamus-hypofyse-bijnier-as in de pathogenese van depressieve stoornissen. Acta Nuropsychiatrica 10(1):1-6.

Goldew RN, Ekstrom D, Broww TM, Rugg R, Evans DL, Haggerty J dr, Garbutt JC, Pedersen CA, Mason GA, Browne J, Carson SW (1992) Neuroendocrine effects of intravenous clomipramine in depressed patients and healthy subjects. Am J Psychiatry 149(9):1168-75.

Goodall IM, Cowen PJ, Franklin M, Silverstone T (1993) Ritanserin attenuates anorectic, endocrine and thermic responses to d-fenfluramine in human volunteers. Psychopharmacology 112: 461-6.

Goodwin GM, Murray CL, Bancroft J (1994) Oral D-fenfluramine and neuroendocrine challenge: problems with the $30 \mathrm{mg}$ dose in men. J Affect Disord 30(2):117-22.

Kapitany T, SchindI M, Schindler SD, Hesselmann B, Fureder T, Barnas C, Sieghart W, Kasper S (1999) The citalopram challenge test in patients with major depression and in healthy controls. Psychiatry Res 88(2):75-88. Kasper S, Vieira A, Schmidt R, Richter P (1990) Multiple hormone responses to stimulation with dlFenfluramine in patients with major depression before and after antidepressive treatment. Pharmacopsychiat 23:76-84.

Kunugi H, Hattori M, KatoT, Tatsumi M, Sakai T, Sasaki T, Hirose T, Nanko S (1997) Serotonin transporter gene polymorphisms: ethnic difference and possible association with bipolar affective disorder. Mol Psychiatry 2(6):457-62.

Leake A, Fairbaim AF, McKeith IG, Ferrier IN(1991) Studies on the serotonin uptake binding site in major depressive disorder and control post-mortem brain: neurochemical and clinical correlates. Psychiatry Res 39(2):155-65.

Lerer B, Gillon D, Lichtenberg P, Gorfine M, Gelfin Y, Shapira B (1996) Interrelationship of age, depression. and central serotonergic function: evidence from fenfluramine challenge studies. Int Psychogeriatr 8(1):83-102. Lesch KP, Gross J, Franzek E, Wolozin BL, Riederer P, Murphy DL (1995) Primary structure of the serotonin transporter in unipolar depression and bipolar disorder. Biol Psychiatry 37(4):215-23. 
Lesch K., Rupprecht R, Poten B, Muller U, Sohnle K, Fritze J, Schulte HM (1989) Endocrine responses to 5. hydroxytryptamine-1A receptor activation by ipsapirone in humans. Biol Psychiatry; 26(2):203-5.

Lesch KP. Wiesmann M, Hoh A, Muller T, Disselkamp-Tietze J, Osterheider M, Schulte HM (1992) 5-HT1A receptor-effector system responsivity in panic disorder. Psychopharmacology; 106(1):111-7.

Lichtenberg P, Shapira B, Gillon D, Kindler S, Cooper TB, Newman ME, Lerer B (1992 I) Hormone responses to fenfluramine and placebo challenge in endogenous depression. Psychiatry Res 43(2):137-46.

Lichtenberg P, Shapira B, Blacker M, Gropp C, Calev A, Lerer B (1992 II) Effect of fenfluramine on mood: a double-blind placebo-controlled trail. Biol Psychiatry 31:351-6.

Lucey JV, O'Keane V, Butcher G, Clare AW, Dinan TG (1992) Cortisol and prolactin responses to dfenfluramine in non-depressed patients with obsessive-compulsive disorder: a comparison with depressed and healthy controls. Br J Psychiatry 161:517-21.

Maes M, Calabrese J, Jayathilake K, Meltzer HY (1997) Effects of subchronic treatment with valproate on L-5. HTP-induced cortisol responses in mania: evidence for increased central serotonergic neurotransmission.

Psychiatry Res 71(2):67-76.

Malone KM, Corbitt EM, Li S, Mann JJ (1996) Prolactin response to fenfluramine and suicide attempt lethality in major depression. Br J Psychiatry 168: 324-9.

Manji HK, Hsiao JK, Risby ED, Oliver J, Rudorfer MV, Potter WZ (1991) The mechanisms of action of lithium. 1. Effects on serotoninergic and noradrenergic systems in normal subjects. Arch Gen Psychiatry 48(6):505-12. Mann J., MeBride PA, Brown RP, Linnoila M. Leon AC, DeMeo M. Mieczkowski T, Meyers JE, Stanley M (1992) The relationship between central and peripheral serotonin indices in depressed and suicidal psychiatric inpatients. Arch Gen Psychiatry 49: 442-6.

Mann JJ, McBride PA, Malone KM, DeMeo M, Keilp J (1995) Blunted serotonergic responsivity in depressed inpatients. Neuropsychopharmacology 13: 53-64.

Mannel M, Muller-Oerlinghausen B, Czernik A, Sauer H (1997) 5-HT brain function in affective disorder: d,1fenfluramine-induced hormone release and clinical outcome in long-term lithium/carbamazepine prophylaxis. J Affect Disord 46(2):101-13.

Marazziti D, Lenzi A, Cassano GB (1991) Serotoninergic dysfunction in bipolar disorder. Pharmacopsychiatry 24(5):164-7.

McCann UD, Seiden LS, Rubin LJ, Ricaurte GA (1997) Brain serotonin neurotoxicity and primary pulmonary hypertension from fenfluramine and dexfenfluramine. J Am Med Ass 278: 666-72.

McNeilly AS (1986) Prolactin. In: Lightman SL, Everitt BJ (ed), Neuroendocrinology. Blackwell Scientific Publications, Cambridge.

Meltzer HY, Lowy M, Robertson A, Goodnick P, Perline R (1984 III) Effect of 5-hydroxytryptophan on serum cortisol levels in major affective disorders. III. Effect of antidepressants and lithium carbonate. Arch Gen Psychiatry 41(4):391-7.

Meltzer HY, Maes M (1994) Effects of buspirone on plasma prolactin and cortisol levels in major depressed and normal subjects. Biol Psychiatry 35(5):316-23.

Meltzer HY, Perline R, Tricou BJ, Lowy M, Robertson A (1984 II) Effect of 5-hydroxytryptophan on serum cortisol levels in major affective disorders. II. Relation to suicide, psychosis, and depressive symptoms. Arch Gen Psychiatry 41(4):379-87. 
Meltzer HY, Uberkoman-Wiita B, Robertson A, Tricou BJ, Lowy M (1983) Enhanced serum cortisol response to 5-hydroxytryptophan in depression and mania. Life Sci 33(25):2541-49.

Meltzer HY, Umberkoman Wiita B, Robertson A, Tricou BJ, Lowy M, Perline R (1984 I) Effect of 5hydroxytryptophan on serum cortisol levels in major affective disorders. I. Enhanced response in depression and mania. Arch Gen Psychiatry 41(4):366-74.

Mitchell P, Smythe G, Parker G, Wilhelm K, Hickie I, Brodaty H, Boyce P (1990) Hormonal responses to fenfluramine in depressive subtypes. Br J Psychiatry 57:551-7.

Muhlbauer HD (1984) The influence of fenfluramine stimulation on prolactin plasma levels in lithium longterm-treated manic-depressive patients and healthy subjects. Pharmacopsychiatry 17(6):191-3.

Muhlbauer HD, Muller-Oerlinghausen B (1985) Fenfluramine stimulation of serum cortisol in patients with major affective disorders and healthy controls: further evidence for a central serotonergic action of lithium in man. J Neural Transm 61(1-2): 81-94.

Murakami Y, Kato Y, Kabayama Y, Tojo K, Inoue T, Imura H (1986) Involvement of growth hormone (GH)releasing factor in $\mathrm{GH}$ secretion induced by serotoninergic mechanisms in conscious rats. Endocrinology 119(3):1089-92.

Newman ME, Shapira B, Lerer B (1998) Evaluation of central serotonergic function in affective and related disorders by the fenfluramine challenge test: a critical review. Int J Neuropsychopharmacol 1: 49-69.

Nurnberger JJr., Berrettini W, Simmons-Alling S, Lawrence D, Brittain H (1990) Blunted ACTH and cortisol response to afternoon tryptophan infusion in euthymic bipolar patients. Psychiatry Res 31(1):57-67.

O'Keane Cv, O'Hanlon M, Webb M, Dinan T (1991) D-fenfluramine / prolactine response throughout the menstrual cycle: evidence for an estrogen-induced alteration. Clin Endocrin 34: 289-92.

Oruc L, Verheyen GR, Furac I, Jakovljevic M, Ivezic S, Raeymaekers P, Van Broeckhoven C (1997)

Association analysis of the 5-HT2C receptor and 5-HT transporter genes in bipolar disorder. Am J Med Genet 74(5):504-6.

Post RM, Weiss SRB (1997) Kindling and stress sensitization. In: Young LT, Joffe RT (Eds), Bipolar Disorder.

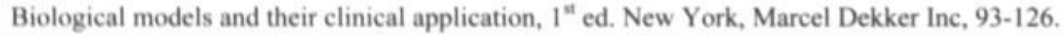

Power AC, Cowen PJ (1992) Neuroendocrine challenge tests: assessment of 5-HT function in anxiety and depression. Mol Aspects Med 13(3):205-20.

Prange AJJr., Wilson IC, Lynn CW, Alltop LB, Stikeleather RA (1974) L-tryptophan in mania. Contribution to a permissive hypothesis of affective disorders. Arch Gen Psychiatry 30(1):56-62.

Price LH, Charney DS, Delgado PL, Heniger GR (1990) Lithium and serotonin function:implications for the serotonin hypothesis of depression. Psychopharmacology 100:3-12.

Price LH, Malison RT, McDougle CJ, Pelton GH, Heniger GR (1998) The neurobiology of tryptophan depletion in depression: effects of intravenous tryptophan infusion. Soc Biol Psychiatry 43:339-47.

Price LH, Charney DS, Delgado PL. Heninger GR (1989) Lithium treatment and serotoninergic function. Neuroendocrine and behavioral responses to intravenous tryptophan in affective disorder [see comments]. Arch Gen Psychiatry 46(1):13-9.

Price LH, Charney DS, Delgado PL, Heninger GR (1991) Serotonin function and depression: neuroendocrine and mood responses to intravenous L-tryptophan in depressed patients and healthy comparison subjects [see comments]. Am J Psychiatry 148(11):1518-25. 
Price LH, Malison RT, McDougle CJ, McCance Katz EF, Owen KR, Heninger GR (1997) Neurobiology of tryptophan depletion in depression: effects of m-chlorophenylpiperazine (mCPP). Neuropsychopharmacology 17(5):342-50.

Quattrone A, DiRenzo GF, Schettini G, Tedeschi G, Scopacasa F (1978) Increased plasam prolactine levels induced in rats by d-fenfluramine: relation to central serotonergic stimulation. Eur J Pharmacol 49; $163-7$. Riedel WJ, Klaassen T, Griez E, Honig A, Menheere PPCA, van Praag HM (2002) Dissociable hormonal, cognitive and mood responses to neuroendocrine challenge: evidence for receptor-specific serotonergic dysregulation in depressed mood. J Psychopharmacol 26(3): 358-67.

Rowland NE, Carlton J (1986) Neurobiology of an anorectic drug: fenfluramine. Prog Neurobiol 27(1):13-62. Shapira B, Lerer B, Kindler S, Lichtenberg P, Gropp C, Cooper T, Calev A (1992) Enhanced serotonergic responsivity following electroconvulsive therapy in patients with major depression. Br J Psychiatry 160:223-9. Shiah IS, Yatham LN, Lam RW, Tam EM, Zis AP (1998) Cortisol, hypothermic, and behavioral responses to ipsapirone in patients with bipolar depression and normal controls. Neuropsychobiology 38(1):6-12.

Sobczak S, Honig A, Riedel WJ (2000) Acute Tryptophan Depletion in bipolar disorders; literature review and directives for further research. Acta Neuropsychiatrica 12(3):69-72.

Sobczak S, Honig A, Nicolson NA, Riedel WJ (accepted 1) Acute Tryptophan Depletion enhances mood in firstdegree relatives of type II bipolar patients but not in first-degree relatives of type I bipolar patients and healthy matched controls. J Neuropsychopharmacol.

Sobczak S, Honig A, Van Duinen MA, Granzier JMM, Riedel WJ (accepted 2) Mood, prolactine and cortisol responses following Intravenous L-tryptophan challenge; evidence for serotonergic vulnerability in first-degree relatives of bipolar patients. Int J Neuropsychopharmacol.

Stahl SM. Mechanism of action of serotonin selective reuptake inhibitors (1998) Serotonin receptors and pathways mediate therapeutic effects and side effects. J Affect Disord 51(3):215-35.

Stahl SM. Neuroendocrine markers of serotonin responsivity in depression (1992) Prog NeuroPsychopharmacol. \& Biol Psychiat 16:655-9.

Stahl SM, Hauger RL, Rausch JL, Fleishaker JC, Hubbell-Alberts E (1993) Downregulation of serotonin receptor subtypes by nortriptyline and adinazolam in major depressive disorder: neuroendocrine and platelet markers. Clin Neuropharmacol 16(Suppl 3):S19-31.

Takahashi S, Kondo H, Yoshimura M, Ochi Y, Yoshimi T (1973) Growth hormone responses to administration of L-5-hydroxytryptophan (L-5-HTP) in manic-depressive psychoses. Folia Psychiatr Neurol Jpn 27(3):197-206. Thakore JH, O'Keane V, Dinan TG (1996) d-fenfluramine-induced prolactin responses in mania: evidence for serotonergic subsensitivity. Am J Psychiatry 1996 153(11):1460-3.

Van der Does AJW (2001). The effect of tryptophan depletion on mood and psychiatric symptoms: review. J Affect Disord.

Van de Kar LD, Lorens SA, Urban JH, Bethea CL (1989) Effect of selective serotonin (5-HT) agonists and 5 HT2 antagonist on prolactin secretion. Neuropharmacology; 28(3):299-305.

Van Praag HM, Korf J, Lequin RM (1976) An unexpected effect of 1-5-hydroxytryptophan-ethyl-ester combined with a peripheral decarboxylase inhibitor on human serum prolactin. Psychopharmacol Commun 2: 369-78.

Van Praag HM, Lemus C, Kahn R (1987) Hormonal probes of central serotonergic activity: do they really exist? Biol Psychiatry 22(1):86-98. 
van Vliet IM, Slaap BR, Westenberg HG, Den Boer JA (1996) Behavioral, neuroendocrine and biochemical effects of different doses of 5-HTP in panic disorder. Eur Neuropsychopharmacol; 6(2): 103-10.

Westenberg HG, van Praag HM, de Jong JT, Thijssen JH (1982) Postsynaptic serotonergic activity in depressive patients: evaluation of the neuroendocrine strategy. Psychiatry Res 7(3):361-71.

Wirz Justice A, Puhringer W (1978) Increased platelet serotonin in bipolar depression and hypomania. J Neural Transm 42(1):55-62.

Yatham LN (1994) Buspirone induced prolactin release in mania. Biol Psychiatry 35(8):553-6.

Yatham LN (1996) Prolactin and cortisol responses to fenfluramine challenge in mania. Biol Psychiatry $39(4): 285-8$.

Yatham LN, Shiah IS, Lam RW, Tam EM, Zis AP (1999) Hypothermic, ACTH, and cortisol responses to ipsapirone in patients with mania and healthy controls. J Affect Disord 54(3):295-301.

Yatham LN, Steiner M (1993) Neuroendocrine probes of serotonergic function: a critical review. Life Sci 53(6):447-63.

Young LT, Warsh JJ, Kish SJ, Shannak K, Hornykeiwicz O (1994) Reduced brain 5-HT and elevated NE turnover and metabolites in bipolar affective disorder. Biol Psychiatry 35(2):121-27. 


\title{
Mood, prolactin and cortisol responses following intravenous L- Tryptophan challenge; evidence for serotonergic vulnerability in first- degree relatives of bipolar patients
}

\begin{abstract}
Central serotonergic vulnerability indicated by altered mood and neuroendocrine responses to an intravenous (i.v.) tryptophan (Trp) challenge was assessed in healthy adult unaffected firstdegree relatives of bipolar disorder (BD) patients $(n=30)$ (Family History; FH). The effects of a single dose of $7.0 \mathrm{~g}$ Trp on mood, cortisol and prolactin (PRL) in FH subjects were compared with healthy matched controls $(n=15)$ in a placebo-controlled, double blind crossover design.

PRL and cortisol responses increased following Trp. Overall, Trp lowered mood. Hormonal and mood effects did not differ between FH and controls. Results show some evidence for differences in serotonergic vulnerability between relatives of type I BD patients and relatives of type II BD patients.
\end{abstract}

S Sobczak, A Honig, MA van Duinen, M Maes, WJ Riedel. The International Journal of Neuropsychopharmacology, accepted

\section{Introduction}

Serotonin (5-hydroxytryptophan; 5-HT) has been implicated in the pathophysiology of bipolar disorders (BD). Changes in plasma prolactin (PRL), growth hormone $(\mathrm{GH})$, cortisol and adrenocorticotropic hormone $(\mathrm{ACTH})$, following challenge with selective 5-HT stimulating 
agents are important biological markers to assess brain 5-HT function (Nurnberger et al., 1990). Changes in 5-HT responsivity may be explained by post-synaptic sensitization of 5-HT receptors, changes in postsynaptic signal transduction, presynaptic transporter mechanisms and dysregulation of the endocrine pathways themselves (Coccaro et al., 1989; Mann et al., 1992). Manic BD patients show reduced PRL and exaggerated cortisol responses compared to controls after acute 5-HT stimulation with 30 or $60 \mathrm{mg}$ of respectively d- and d,1- fenfluramine (Muhlbauer and Muller-Oerlinghausen, 1985; Thakore et al., 1996). In euthymic BD patients, blunted cortisol and ACTH responses have been described compared to controls (Nurnberger et al., 1990). These findings suggest altered 5-HT responsivity in BD which may reflect dysregulation of the 5-HT system.

Effects of Trp on mood in euthymic BD and Unipolar Depression (UD) patients were decreased talkativeness and energy, and increased drowsiness and elevated mood as measured with the Visual Analogue Scales (VAS) (Price et al., 1989).

FH subjects show a 10-20\% increased risk to develop BD and genetic modifications affecting the 5-HT system have been associated with BD pathophysiology (Bellivier, 1998). Investigation of FH subjects is a useful method to assess 5-HT vulnerability in BD psychophysiology.

The purpose of this study was to show 5-HT vulnerability in FH subjects, including relatives of type I (FH I) and type II (FH II) bipolar patients, compared to matched control subjects, as measured by cortisol, PRL and mood responses following i.v. Trp challenge. It is suggested that 5-HT vulnerability in FH will be reflected in increased hormone and mood responses. Based on previous findings, we predict that $\mathrm{FH}$ II subjects are more vulnerable to the effects of $\operatorname{Trp}$ (Sobczak et al., accepted 1).

\section{Methods}

\section{Subjects}

Subjects were lifetime physically and psychiatrically healthy $\mathrm{FH}$ subjects ( $\mathrm{n}=30 ; 10 \mathrm{men}, 20$ women) and healthy matched controls, free from any psychiatric family history ( $\mathrm{n}=15 ; 4$ men, 11 women). FH subjects had at least one first-degree relative with a type I BD $(n=22)$ or type II BD diagnosis $(\mathrm{n}=8)$. Subjects were selected using an abbreviated version of the Family History Research Diagnostic Criteria (FHRDC) (Endicott et al., 1975), (17-item), HamiltonDepression Rating Scale (HDRS) (Hamilton, 1967), the Young Mania Rating Scale (YMRS) 
(Young et al., 1978), the SCL-90 and a standardized psychiatric examination (Mini International Neuropsychiatric Interview; MINI) (Sheehan et al. 1994). Subjects were free of cardiac, endocrine and other significant medical problems.

Relatives were children $(n=19)$, parents $(n=9)$ and siblings $(n=2)$. The FH and control group did not differ significantly with respect to age, body mass index (BMI), intelligence quotient (IQ) (see Table 1), but FH subjects scored significant higher on baseline Hamilton Depression Rating Scale (HDRS) $[\mathrm{F}(1,43)=4.30, \mathrm{p}<0.05]$ and Young Mania Rating Scale (YMRS) $[\mathrm{F}(1,43)=4.71, \mathrm{p}<0.05]$.

Of the female subjects, 21 were pre-menopausal and 10 were postmenopausal.

Table 1. Demographic characteristics; bipolar disorder family loading ( $1^{\mathrm{N}}, 2^{\mathrm{m}}$ and $3^{\mathrm{Nd}}$ degree), Young Mania Rating Scale (YMRS) and Hamilton Depression Rating Scale (HDRS) total scores; mean \pm SE.

\begin{tabular}{|l|ll|}
\hline Measure & FH & Controls \\
\hline Women & $\mathrm{n}=20$ & $\mathrm{n}=11$ \\
Men & $\mathrm{n}=10$ & $\mathrm{n}=4$ \\
\hline FH I & $\mathrm{n}=22$ & \\
FH II & $\mathrm{n}=8$ & \\
Family members: & 1.3 & 0.0 \\
Bipolar disorder & & $40 \pm 3.7$ \\
Age & $41 \pm 2.9$ & $118 \pm 2.6$ \\
IQ & $117 \pm 2.8$ & $25.0 \pm 0.7$ \\
BMI & $25.3 \pm 0.6$ & $0.27 \pm 0.2$ \\
YMRS & $0.67 \pm 0.2$ & $0.33 \pm 0.2$ \\
\hline HDRS & $1.30 \pm 0.3$ & \\
\hline
\end{tabular}

\section{Experimental design and treatment}

The study was conducted according to a mixed between / within groups $(3 * 2)$ design. The between-groups factor was family history: FH (FH I / FH II) or controls. The within subjectsfactor consisted of two levels of treatment (placebo and i.v. Trp loading) which were administrated according to a double-blind, order-balanced cross-over design. The order of treatment was balanced over two test days, spaced 3-5 days apart. Trp or placebo were administered intravenously at a dose of $7.0 \mathrm{~g} / 1000 \mathrm{cc}$ water respectively $1000 \mathrm{cc}$ saline over a 60 -min period. 


\section{Procedure}

All pre-menopausal women were tested in the follicular phase of the menstrual cycle. After an overnight fast subjects arrived at 9.00 a.m.. Immediately the i.v. cannula was inserted in a forearm vein. At 9.30 a.m. (t-30) mood was assessed and baseline blood samples were taken. At 10.00 a.m. $\left(t_{0}\right)$ the Trp or placebo mixture was administrated. Blood samples were taken at $t_{60}, t_{75}, t_{90}$ and $t_{105}$ (all time points $t_{x}$ refer to $X$ minutes after $t_{0}$, when the treatment administration started). Mood assessments, including the abbreviated Bimodal Profile of Mood States (POMS) (McNair et al., 1971) and Bond \& Lader (B\&L) (Bond and Lader, 1974) VAS, were completed at 10.30 a.m. $\left(t_{30}\right)$, at $t_{60}$, $t_{90}$ and at $t_{120}$. At $t_{175}$ manic symptoms were rated using an abbreviated version of the YMRS (abr-YMRS), which consisted of 7 items. Item 4 (sleep), 8 (content), 10 (appearance) and 11 (insight) were omitted, because these items were not expected to change within a few hours.

Cortisol and PRL analyses were performed using an Automated Chemiluminescence System (ACS: centaur) from Bayer, Germany. Total concentrations of plasma Trp and ratio of Trp: Large Neutral Amino Acids (LNAAs; valine, isoleucine, leucine, phenylalanine, tyrosine) were determined by high-performance liquid chromatography (HPLC).

Severity of side effects was determined by a for 5-HT challenges specially designed questionnaire (17 four-point items) (Sobczak et al., accepted 1).

Outcome variables were analyzed using General Linear Model (GLM) for repeated measures (SPSS 9.0) (Horton, 1978). Within subjects factor was treatment condition (Trp or placebo). Between subjects factor was family history (controls vs FH). Significant effects of Trp were analyzed using treatment order (Trp-placebo or placebo-Trp) as a between subjects variable. Post-hoc contrasts were used to analyze the secondary hypotheses of differences between controls and FH I and FH II. When baseline differences between conditions were detected, difference scores were constructed and used for GLM analyses of treatment and FH. Wilcoxon Matched-Pairs Signed-Ranks Test and Mann-Whitney-U Tests were used to test differences in abr-YMRS scores and physical complaints. Effects of treatment order (Trpplacebo or placebo -Trp) were analysed

\section{Results}

\section{Plasma Trp levels}

At baseline, plasma Trp concentrations $[\mathrm{F}(1,42)=41,2, \mathrm{p}<0.01]$ and ratio Trp: LNAAs $[\mathrm{F}(1,42)=22,6, \mathrm{p}<0.01] \quad$ were significantly higher in the placebo compared to the $\operatorname{Trp}$ 
condition. There was a significant interaction of $\operatorname{Trp}[\mathrm{F}(1.42)=11.7, \mathrm{p}<0.01]$ and ratio Trp: LNAAs $[F(1,42)=16.9, p<0.01]$ with treatment order, Trp values on the second test day were higher in those subjects who received Trp on the first test day. This carry-over effect on plasma Trp concentration (not on the ratio) was more pronounced in controls which may explain the significant baseline differences in plasma $\operatorname{Trp}[F(1.43)=7.3, p<0.05]$ between $F H$ and controls in the placebo condition. After correction for baseline differences, plasma $\operatorname{Trp}[F(1,42)=978.7, p<0.01]$ and ratio Trp: LNAAs $[F(1,42)=502.3, p<0.01]$ increased significantly following Trp but not after receiving placebo. Relative to baseline, the mean peak of plasma Trp and ratio Trp: LNAAs to i.v. Trp were respectively $1049 \mu \mathrm{mol} / \mathrm{L}$ and 2,3 .

$P R L$ and cortisol release

Trp significantly increased PRL $[\mathrm{F}(1,41)=30,17, \mathrm{p}<0.01]$ and cortisol $[\mathrm{F}(1,41)=10,86$, $\mathrm{p}<0.01]$ release. Hormonal responses to Trp did not differ at baseline and between $\mathrm{FH}$ groups and controls. Figure $1 \mathrm{a} / \mathrm{b}$ shows that $\mathrm{PRL}$ and cortisol responses tended to be higher in $\mathrm{FH} \mathrm{II}$ compared to $\mathrm{FH} \mathrm{I}$ and controls.

a) Cortisol release after Trp

b) PRL release after $T r p$
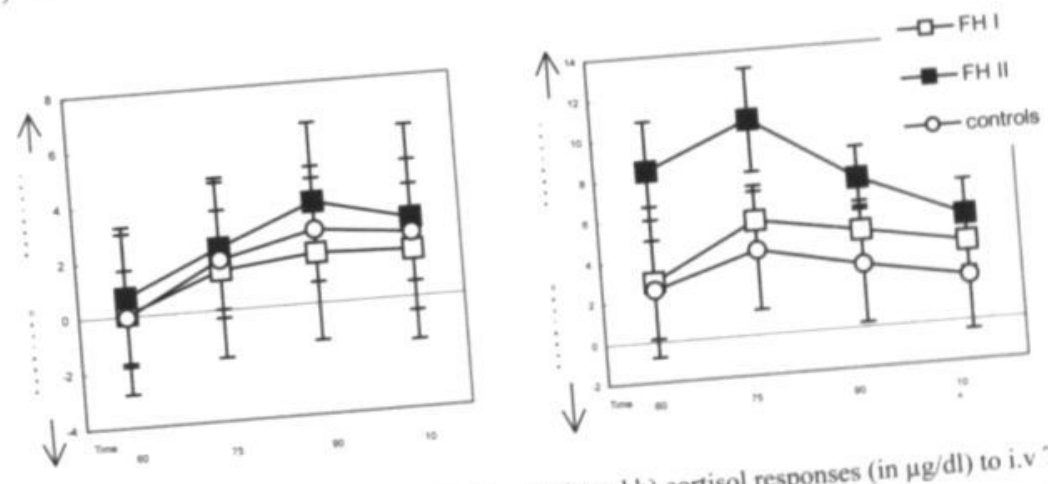

Figure $\mathrm{l} \mathrm{a} / \mathrm{b}$. a) Plasma prolactin (PRL) (in $\mathrm{ng} / \mathrm{ml}$ ) and b) cortisol responses (in $\mu \mathrm{g} / \mathrm{dl}$ ) to i.v Trp loading or

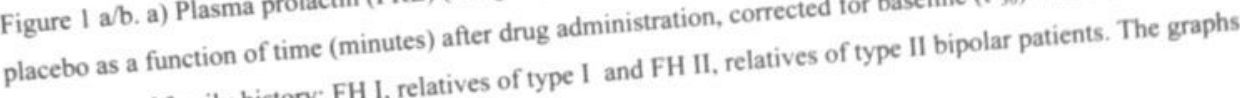
SE); effect of family history; FH I, rela 


\section{Mood rating}

Effects of Trp on mood are shown in table $2 \mathrm{a} / \mathrm{b}$.

Table 2. Effects of Trp on mood. Baseline and mean peak values following Trp and placebo (P) are shown, and are broken down by family history (FH) and controls. a) POMS and B\&L subscales b) abr-YMRS.

a)

\begin{tabular}{|c|c|c|c|c|c|c|}
\hline & mean (SE) & & $\begin{array}{l}\mathbf{F H} \\
\text { baseline }\end{array}$ & peak & $\begin{array}{l}\text { controls } \\
\text { baseline }\end{array}$ & peak \\
\hline \multirow[t]{10}{*}{ POMS } & \multirow[t]{2}{*}{ anger } & Trp & $70,6(2,3)$ & $71,2(2,3)$ & $64,2(4,3)$ & $66,2(4,6)$ \\
\hline & & $\mathbf{P}$ & $68,9(2,8)$ & $73,6(2,7)$ & $64,6(4,4)$ & $67,4(4,8)$ \\
\hline & \multirow[t]{2}{*}{ depression } & Trp & $69,9(2,4)$ & $73,0(2,8)$ & $63,8(4,0)$ & $66,7(4,7)$ \\
\hline & & $P$ & $68,2(2,7)$ & $70,2(2,4)$ & $64,5(4,3)$ & $65,7(4,4)$ \\
\hline & \multirow[t]{2}{*}{ fatigue } & Trp & $65,6(2,5)$ & $64,3(2,6)$ & $59,5(3,6)$ & $60,3(3,7)$ \\
\hline & & $P$ & $64,9(2,7)$ & $71,7(2,6)$ & $60,7(3,8)$ & $65,2(4,5)$ \\
\hline & \multirow[t]{2}{*}{ tension } & Trp & $69,8(2,4)$ & $74,6(2,8)$ & $63,9(4,9)$ & $67,8(4,9)$ \\
\hline & & $\mathbf{P}$ & $68,4(2,7)$ & $71,4(2,4)$ & $64,3(4,4)$ & $67,3(4,5)$ \\
\hline & \multirow[t]{2}{*}{ vigor } & Trp & $65,0(3,3)$ & $64,3(3,1)$ & $58,1(3,4)$ & $58,0(3,0)$ \\
\hline & & $P$ & $64,1(2,8)$ & $70,2(3,2)$ & $58,4(3,0)$ & $65,5(4,3)$ \\
\hline \multirow[t]{6}{*}{ B\&L } & \multirow[t]{2}{*}{ alertness } & Trp & $67,2(2,6)$ & $64,6(2,7)$ & $60,6(3,5)$ & $59,5(3,9)$ \\
\hline & & $P$ & $65,0(2,9)$ & $69,6(2,9)$ & $60,7(3,5)$ & $64,6(4,4)$ \\
\hline & \multirow[t]{2}{*}{ contentedness } & Trp & $67,5(2,3)$ & $70,7(2,8)$ & $64,8(4,7)$ & $66,0(4,6)$ \\
\hline & & $\mathbf{P}$ & $67.5(2,7)$ & $68,5(2,4)$ & $64,3(4,5)$ & $63,8(4,2)$ \\
\hline & \multirow[t]{2}{*}{ calmness } & Trp & $64,6(3,0)$ & $70,9(2,5)$ & $63,4(4,7)$ & $67,0(4,9)$ \\
\hline & & $\mathbf{P}$ & $66,7(2,9)$ & $72,5(3,0)$ & $59,9(4,0)$ & $66,9(4,8)$ \\
\hline
\end{tabular}

b)

\begin{tabular}{|c|c|c|c|c|}
\hline \multirow[b]{2}{*}{ YMRS } & \multicolumn{2}{|l|}{ mean (SE) } & $\mathbf{F H}$ & controls \\
\hline & $\overline{\text { mood }}$ & Trp & $0(0)$ & $0(0)$ \\
\hline & & $P$ & $0(0)$ & $0,07(0,07)$ \\
\hline & energy & Trp & $0,17(0,07)$ & $0,07(0,07)$ \\
\hline & & $\mathbf{P}$ & $0,07(0,05)$ & $0,13(0,09)$ \\
\hline & irritation & Trp & $0,14(0,10)$ & $O(0)$ \\
\hline & & $P$ & $O(0)$ & $O(0)$ \\
\hline & speaking & Trp & $0,03(0,03)$ & $0,07(0,07)$ \\
\hline & & $\mathbf{P}$ & $O(0)$ & $0,07(0,07)$ \\
\hline & thinking & Trp & $0,17(0,09)$ & $0,13(0,09)$ \\
\hline & & $\mathbf{p}$ & $0,21(0,08)$ & $0,13(0,09)$ \\
\hline & agression & Trp & $0,03(0,03)$ & $0(0)$ \\
\hline & & $\mathbf{P}$ & $0,03(0,03)$ & $O(0)$ \\
\hline
\end{tabular}

In all groups, Trp significantly increased feelings of anger $[F(1,42)=6.52, \mathrm{p}<0.05]$, depression $[F(1,42)=187.92, \mathrm{p}<0.001]$, fatigue $[F(1,42)=22.17, \mathrm{p}<0.01]$, tension $[F(1,42)=6.06, \mathrm{p}<0.05]$ and decreased feelings of vigor $[F(1,42)=12.12, \mathrm{p}<0.01]$ on the POMS and decreased feelings of alertness $[F(1,41)=16.05, \mathrm{p}<0.01]$ on the B\&L (see table $2 \mathrm{a}$ ). There was no main effect of 
Trp on abr-YMRS. There were no significant differences in mood at baseline and following Trp between $\mathrm{FH}$ and control subjects.

After Trp, FH II subjects scored significantly higher on the item irritation [Chi-square=9,214, $\mathrm{df}=2, \mathrm{p}<0.01]$ of the abr-YMRS and trend-significant on total abr-YMRS scores compared to FH I and controls (see table 2b). POMS and B\&L ratings after Trp did not differ between FH I, FH II and controls.

\section{Intercorrelations of mood and hormonal responses}

Correlational analyses of PRL and cortisol responses to Trp, expressed as drug-placebo difference, with abr-YMRS, POMS and B\&L scores revealed no significant associations.

\section{Somatic side effects}

Reported physical side-effects were significantly higher following $\operatorname{Trp}[Z=-3,95$, df $=1$, $\mathrm{p}<0.01]$ compared to the placebo, but did not differ at baseline or between $\mathrm{FH}$ groups. Reported complaints were: tiredness, nausea, drowsiness, dizziness, headache, dullness, feelings of weakness, loss of concentration and diminished energy.

There were significant positive correlations between total reported complaints after Trp and scores on POMS fatigue at $t_{90}[r=-0.44, n=36, p<0.05], t_{120}[r=-0.50, n=36, p<0.05]$ and vigor scores at $t_{60}[r=-0.45, n=36, p<0.05], t_{90}[r=-0.38, n=36, p<0.05], t_{120}[r=-0.47, n=36, p<0.05]$ and with $B \& L$ alertness score at $t_{60}[r=-0.50, n=36, p<0.05], t_{90}[r=-0.48, n=36, p<0.05]$ and at $\mathrm{t}_{120}[\mathrm{r}=-0.45, \mathrm{n}=36, \mathrm{p}<0.05]$. Physical side effects did not correlate with abr-YMRS scores.

\section{Discussion}

The aim of the study was to investigate central 5-HT vulnerability in healthy first-degree relatives of $\mathrm{BD}$ patients following i.v. Trp challenge. Trp administration was successful and resulted in significant increase in plasma Trp and ratio Trp: LNAAs. There was a carry-over effect of Trp; plasma Trp values were significantly higher on the test day after receiving Trp. The carry-over effect was lower in FH compared to controls. Trp resulted in robust elevations of PRL and cortisol in all groups. Following Trp, subjects reported increased depressed mood, fatigue and tension and decreased vigor and alertness. Mood responses did not differ between $\mathrm{FH}$ and controls. Trp induced feelings of irritation in FH II but not in FH I and controls. In euthymic or depressed BD patients blunted cortisol and PRL responses have been reported compared to controls (Deakin et al., 1990; Nurnberger et al., 1990). 5-HT dysregulation in 
$\mathrm{BD}$ has been indicated by blunted PRL or cortisol response after (d,l-) fenfluramine challenges (Mannel et al., 1997; Thakore et al., 1996). Yatham et al. (1996) found no differences in fenfluramine induced PRL and cortisol responses between BD patients and healthy controls (Yatham et al., 1996). In BD patients, 5-HT responsivity following challenging may be associated with disease-related factors, such as current treatment with psychotropic agents (e.g. lithium), personality traits or suicidal behavior (Meltzer et al., 1984; Sobczak et al., accepted 2). Hormonal responses to Trp did not differ between FH subjects and control subjects in this study. A functional distinction between FH I and FH II subjects has been previously described by our group; following ATD, FH II subjects show mood changes and FH I subjects are characterized by cognitive deficits (Sobczak et al., in press; Sobczak et al., accepted 1). For this reason we were interested in differences in hormonal responses and / or mood changes following Trp between FH I and FH II subjects. Figure Ib shows a slightly increased PRL response in FH II compared to the other groups. However this effects was not significant. Mood assessments indicated an increase in irritation on abrYMRS following Trp FH II. Irritation may be interpreted as a feature of mania, depression or both. Gender differences between groups were not expected to explain possible differences between FH II and FH I. PRL response following Trp was higher in women compared to men $[\mathrm{F}(1,43)=4,1, \mathrm{p}<0.05]$, but relative contribution of females in the FH I , FH II and control groups did not differ significantly. Mood and hormonal responses did not differ between preand postmenopausal women. There was also no effect of age.

The Trp-induced mood changes in FH, as measured on POMS and B\&L, are in agreement with findings in BD. Euthymic BD patients reported decrements in talkativeness and energy, and enhanced drowsiness following Trp (Price et al. 1989). As correlation analyses revealed no significant association between mood rating and hormonal release, the observed pattern of mood responses is assumed not to be related to hormonal responses.

Previous observations described 5-HT vulnerability in specifically FH II subjects following ATD (Sobczak et al., accepted 1). The present findings do not provide additional evidence for this hypothesis but is also not contradictory to a theory of 5-HT vulnerability in FH II. We speculate that increased feelings of irritation on abr-YMRS and the slightly higher PRL response following Trp might be indicative for central 5-HT vulnerability in FH II. 5-HT vulnerability in BD type II patients might be related to suicidal ideations, which are more prevalent in type II than in type I BD patients (Van der Does et al., 2001; Rihmer, 1999). Meltzer et al. (1984) also found an exaggerated cortisol response following 5-HTP challenge to be associated with a positive history of suicide attempts in BD (Meltzer et al., 1984). 
Trp is known to induce indolase-activity and via this negative feedback-loop Trp lowers its own activity. The carry-over effects of $\operatorname{Trp}$ was therefore an unexpected finding. Probably, the indolase-activity is limited to a critical level and an overdose of Trp takes longer then 3 days to be fully eliminated. A shorter time interval between test days revealed higher baseline Trp values, but this effects was not significant. The carry-over effect was significant lower in $\mathrm{FH}$ which suggests that Trp catabolism is higher in FH subjects compared to controls. More rapid Trp clearance in depressed patients compared to controls has been reported after Trp infusion (Deakin et al. 1990). Amamoto (1976) reported a delay in elevation of plasma 5-HT and 5HIAA concentrations and a delay in SHIAA urinary excretion in depressed BD patients compared to control subjects (Amamoto and Sarai 1976).

Shortcoming of this study are: First, the low number of FH II subjects reduced the power of this study. FH I subjects showed higher motivations to participate and therefore outnumber the FH II subjects. Second, physical side effects and sedation induced by Trp might interfere with effects on mood. Direct effects of 5-HT on vigilance and the conversion of Trp to melatonin by the enzymes 5-HT N-acetylase and 5-hydroxy indole $\mathrm{O}$-methyl transferase may explain the sedating effects of Trp. Physical side effects after Trp decreased physical wellbeing and might have interfered with mood and may thus explain the decrease in mood following Trp. Sedation may be experienced as a stressor and can therefore elicit feelings of irritation (Gaillard at al., 1993), but no interaction of side-effects on abr-YMRS was shown which makes this explanation less reliable. Third, Trp significantly increased PRL, but the specificity of PRL to reflect 5-HT activity has been discussed. Changes in PRL may also be the result of changes in dopamine synthesis related to availability of tyrosine. Trp can decrease influx of tyrosine in the brain by competing for the same carrier transport mechanism (Van Praag et al., 1987). Hence, the ratio tyrosine: LNAAs did not change following Trp loading. The reported cortisol response following Trp was modest. Usage of a cortisol challenge paradigm, e.g. a stress-inducing procedure, might be useful in assessment of cortisol responses after 5-HT modulations. A blunted cortisol response to a stress-inducing speech task was shown in FH subjects after Acute Tryptophan Depletion (ATD) (Sobczak et al., accepted 1). Fourth, FH subjects have a 10-20\% increased risk to develop BD. This means that of our research population only 3-6 subjects will develop BD in the future. This study was not designed to investigate the relationship between 5-HT vulnerability and absolute risk to develop BD. Therefore a cohort of $\mathrm{FH}$ subject should be investigated and followed over time. 
In conclusion, this study shows no significant differences in Trp-induced hormonal and mood changes between $\mathrm{FH}$ subjects and healthy matched controls. FH II subjects showed altered 5HT responsivity, but findings are borderline and must first be replicated in a larger sample including FH I, FH II and controls before drawing definite conclusions.

\section{References}

Amamoto T, Sarai K (1976) On the tryptophan-serotonin metabolism in manic-depressive disorders. Changes in plasma 5-HT and 5-HIAA levels and urinary 5-HIAA excretion following oral loading of L-5-HTP in patients with depression. Hir J Med Sciences 25(2-3), 135-40

Bellivier F, Leboyer M, Courtet P, Buresi C, Beaufils B, Samolyk D, Allilaire J, Feingold J, Mallet J, Malafosse A (1998) Association between the tryptophan hydroxylase gene and manic-depressive illness. Arch Gen Psychiatry 55, 33-7

Bond A, Lader M (1974) The use of visual analogue scales in rating subjective feelings. Br J Med Psychol 80, 146

Coccaro EF, Siever LJ, Klar HM, Cochrane K, Cooper TB, Mohs RC, Davis KL (1989) Serotonergic studies in patients with affective and personality disorders: correlates with suicidal and impulsive-aggressive behaviour.

Arch Gen Psychiatry 587-99

Deakin JF, Pennell I, Upadhyaya AJ, Lofthouse R (1990) A neuroendocrine study of 5HT function in depression: evidence for biological mechanisms of endogenous and psychosocial causation.

Psychopharmacology 101(1), 85-92

Endicott J, Andreasen NC, Spitzer RL (1975) Family History-Research Diagnostic Criteria. New York:

Biometrics Research / New York State Psychiatric Institute.

Gaillaird AW (1993) Comparing the concepts of mental load and stress. Ergonomics 36(9), 991-1005.

Horton RL (1978) The general linear model. McGraw-Hill, New York

Mann JJ, McBride PA, Brown RP, Linnoila M, Leon AC, DeMeo M, Mieczkowski T, Meyers JE, Stanley M (1992) The relationship between central and peripheral serotonin indices in depressed and suicidal psychiatric inpatients. Arch Gen Psychiatry 49, 442-6

Mannel M, Muller-Oerlinghausen B, Czernik A, Sauer H (1997). 5-HT brain function in affective disorder: d,Ifenfluramine-induced hormone release and clinical outcome in long-term lithium/carbamazepine prophylaxis. J Affect Disord 46(2), 101-13

McNair DM, Lorr M, Droppleman LF (1971) Manual for the Profile of Mood States. San Diego: Educational and Industrial Testing Service

Meltzer HY, Perline R, Tricou BJ, Lowy M, Robertson A (1984) Effect of 5-hydroxytryptophan on serum cortisol levels in major affective disorders. II. Relation to suicide, psychosis, and depressive symptoms. Arch Gen Psychiatry 41(4), 379-87

Muhlbauer HD, Muller-Oerlinghausen B (1985) Fenfluramine stimulation of serum cortisol in patients with major affective disorders and healthy controls: further evidence for a central serotonergic action of lithium in man. J Neural Transm 61(1-2), 81-94 
Nurnberger JI Jr., Berrettini W, Simmons-Alling S, Lawrence D, Brittain H (1990). Blunted ACTH and cortisol response to afternoon tryptophan infusion in euthymic bipolar patients. Psychiatry Res 31(1), 57-67

Price LH, Charney DS, Delgado PL, Heninger GR (1989) Lithium treatment and serotoninergic function.

Neuroendocrine and behavioral responses to intravenous tryptophan in affective disorder [see comments]. Arch Gen Psychiatry 46(1), 13-9

Rihmer Z, Pestality P (1999) Bipolar II disorder and suicidal behavior. The Psychiatric Clinics of North America $22(3), 667-73$

Sheehan D, Lecrubier Y, Janavs J, Knapp E, Weiller E. (1994) MINI International Neuropsychiatric Interview. Tampa, University of South Florida.

Sobczak S, Honig A, N Nicolson, Riedel WJ (accepted 1) Acute Tryptophan Depletion enhances mood in firstdegree relatives of type II bipolar patients but not in first-degree relatives of type I bipolar patients and healthy matched controls. Neurosychopharmacology.

Sobczak S, Honig A, van Duinen MA, Riedel WJ (accepted 2) Serotonergic dysregulation in bipolar disorders; a literature review of 5-HT challenge studies. Bipolar Disorders.

Sobczak S, Riedel WJ, Booij L, Aan het Rot M, Deutz NEP, Honig A (in press). Cognition following Acute Tryptophan Depletion: differences between first-degree relatives of bipolar disorder patients and matched healthy control volunteers. Psychol Med.

Thakore JH, O'Keane V. Dinan TG (1996). d-fenfluramine-induced prolactin responses in mania: evidence for serotonergic subsensitivity. Am J Psychiatry 153(11), 1460-3

Van der Does AJW (2001) The mood-lowering effect of tryptophan depletion: possible explanation for discrepant findings. Arch Gen Psychiatry 58(2), 200-2

Van Praag HM, Lemus C, Kahn R (1987) Hormonal probes of central serotonergic activity: do they really exist? Biol Psychiatry 22(1), 86-98

Yatham LN (1996) Prolactin and cortisol responses to fenfluramine challenge in mania. Biol Psychiatry 39(4), 285-8

Young RC, Biggs JT, Ziegler VE, Meyer DA (1978). A rating scale for mania: reliability, validity and sensitivity. Br J Psychiatry 133, 429-35 


\title{
Pronounced cognitive deficits following an intravenous l-Tryptophan challenge in first-degree relatives of bipolar patients compared to healthy controls
}

\begin{abstract}
Cognitive impairment has repeatedly been described in bipolar disorders (BD). Serotonin (5$\mathrm{HT}$ ) is possibly involved in these cognitive processes, more particularly in executive functions, learning, memory and attention. The aim of this study was to investigate serotonergic vulnerability and its relation to cognitive functioning in healthy first-degree relatives of $\mathrm{BD}$ patients. We investigated the effects of an intravenous (i.v.) tryptophan (Trp) challenge and placebo on cognitive performance in 30 healthy first-degree relatives of bipolar patients (FH) and 15 matched controls in a double-blind cross-over design. A distinction was made between relatives of type I BD patients (FH I) and type II BD patients (FH II).

Performance on planning, memory, attention and psychomotor tasks were assessed 3 hours after Trp infusion.

After Trp, planning and attention were impaired in $\mathrm{FH}$ subjects but not in controls. Independent of Trp, FH subjects showed cognitive deficits on memory, focused and divided attention and psychomotor performance. FH I subjects showed more pronounced cognitive impairments then FH II and controls. In all groups, Trp impaired memory and psychomotor performance significantly. Cognitive deficits in FH following Trp may reflect a central 5-HT vulnerability in frontal brain areas. Independent of Trp, cognitive deficits in FH provide evidence for a trait maker for BD.
\end{abstract}




\section{Introduction}

In bipolar disorders (BD) cognitive deficits have been reported repeatedly (Coffman et al. 1990; Savard et al. 1980; Wolfe et al. 1987; Krabbendam et al. 2000). Manic patients showed impairments on planning and reaction time (RT) (Murphy et al. 1999). During remission, cognitive deficits may persist (van Gorp et al 1998; Ferrier et al. 1999; Krabbendam et al. 2000; Rubinsztein et al. 2000; Scott et al. 2000). Euthymic BD patients showed impairments on visuo-spatial recognition, verbal and nonverbal memory and learning, retrieval of information from semantic memory an increased RT on a planning task (Coffman et al. 1990; Atre-Vaidya et al. 1998; Ferrier et al. 1999; Rubinsztein et al. 2000). Euthymic patients with recurrent episodes appear to show more cognitive impairments (Kessing 1998; Martinez-Aran et al. 2000). This suggests that these cognitive deficits indicate a trait marker in BD. As firstdegree relatives of $\mathrm{BD}$ patients $(\mathrm{FH})$ are free of psychopathology and interference of psychotropic medication, assessment of cognitive performance in $\mathrm{FH}$ subjects may provide a powerful design to investigate biological vulnerability in BD (Sobczak et al. 2000). Compared to matched control subjects, healthy first-degree relatives of BD patients showed impaired speed of information processing, on a planning task, and memory performance (Sobczak et al. in press).

Serotonin (5-hydroxytryptophan; 5-HT) has been implicated in psychopathology of BD and has also been associated with cognitive performance, particularly learning and memory (Young et al. 1994; Riedel et al. 1999; Schmitt et al. 2000). Changes in cognitive performance following selective 5-HT modulations are important biological markers for brain 5-HT receptor sensitivity (Sobczak et al. accepted 1; Sobczak et al. accepted 2; Riedel, et al. 2002). Cognitive deficits seem to be more prevalent in relatives of patients with BD type I psychopathology (FH I) compared to relatives of BD type II patients (FH II) (Sobczak et al. in press). Acute Tryptophan Depletion (ATD) impaired planning performance in FH subjects whereas performance increased in controls, which suggests serotonergic vulnerability in $\mathrm{FH}$ subjects affecting frontal lobe areas (Sobczak et al. in press).

In healthy subjects, independent of FH, ATD impaired memory consolidation (Sobczak et al. in press; Park et al. 1994; Riedel et al. 1999; Rogers et al. 1999; Schmitt et al. 2000; Rubinsztein et al. 2001) and improved focused attention (Coull et al. 1995; Schmitt et al. 2000). Acute 5 -HT challenges showed impaired memory performance after $5-\mathrm{HT}_{1 \mathrm{~A}}$ challenge with ipsapirone and impaired signal detection after 5- $\mathrm{HT}_{2 \mathrm{C}}$ challenge with m-CPP (Riedel et 
al. 2002) and impaired psychomotor performance after 5-HT $2 \mathrm{c}$ challenge with $\mathrm{m}$-CPP (Riedel et al. 2002) and i.v. Trp loading (Winokur et al. 1986).

The present study was designed to investigate 5-HT related cognitive functioning in $\mathrm{FH}$ subjects and healthy matched controls. The hypotheses were: Trp will induce more pronounced cognitive changes in $\mathrm{FH}$ subjects; $\mathrm{FH}$ subjects will show impaired planning and memory independent of Trp (implying a trait marker in BD); detrimental effects of Trp will be more pronounced in FH I; based on previous findings, Trp will improve frontal lobe mediated planning and attention whereas it will decrease memory and psychomotor performance independent of $\mathrm{FH}$.

\section{Methods}

\section{Subjects}

Subjects were family members and healthy matched controls. Family members were recruited via $\mathrm{BD}$ patients treated at the Department of Psychiatry, University Hospital Maastricht, via the consumer organization for manic-depressive patients and their families, and via advertisements in local newspapers. Healthy control subjects were also recruited via a newspaper advertisement and were free from any psychiatric family history.

FH subjects had at least one first-degree relative with a type I BD or type II BD diagnosis. All subjects were interviewed with an abbreviated version of the Family History Research Diagnostic Criteria (FHRDC) to assess FH (Endicott et al. 1975). Individual diagnoses (type I or type II BD, according to DSMIV) of the patients were verified via the patients' own psychiatrist.

A standardized psychiatric examination (Mini International Neuropsychiatric Interview; MINI) (Sheehan et al. 1994) was taken of all participants to examine the present psychiatric state according to DSM IV criteria. The Hamilton Depression Rating Scale (HDRS) (Hamilton 1967), the Young Mania Rating Scale (YMRS) (Young et al. 1978) and the SCL-90 (Arrindell and Ettema 1986) were used to verify the absence of depressive, manic and general psychiatric symptomatology.

Exclusion criteria were: current or past use of psychoactive medication, lifetime psychiatric disorder including alcohol or drug abuse, current active physical illness, lactation and pregnancy.

Physical health was assessed by means of a health questionnaire, a standard physical examination by a physician and urine screening. The urine test (Combur $\$$ ) included 
assessment of leukocytes, nitrite, $\mathrm{pH}$, protein, glucose, ketones, urobilinogen, bilirubin and erythrocytes. A Quick View, one-step pregnancy test (Quidelß) was carried out in female subjects to check for unsuspected pregnancy.

Of the 47 subjects who participated, 2 subjects did not complete the experiment due to reasons unrelated to the study. The included subjects who completed the experiment were 30 FH ( 10 men and 20 women) and 15 controls ( 4 men, 11 women). Table 1 shows the demographic characteristics of all subjects who completed the experiment. Relatives were children $(n=19)$, parents $(n=9)$ and siblings $(n=2)$. Twenty-two were FH I and 8 were FH II subjects. The FH and control group did not differ significantly with respect to age, body mass index (BMI), intelligence quotient (IQ) and SCL-90 total score, but FH subjects scored significant higher on baseline (HDRS) $[F(1,43)=4.30, \mathrm{p}<0.05]$ and YMRS $[F(1,43)=4.71$, $\mathrm{p}<0.05]$.

Of the female subjects, 21 were pre-menopausal and 10 were postmenopausal. Thirteen women used oral contraceptives.

Each control subject was matched with 2 FH subjects with respect to sex, age, BMI and IQ. Intelligence (IQ) was estimated using Groninger Intelligence Test (GIT) subtasks (Vocabulary, Mental Rotation, Mental Arithmetic and Word Analogies) (Luteijn 1966). The Medical Ethics Committee of the University Hospital of Maastricht approved of the study. All participants signed informed consent.

Table 1. Demographic characteristics; bipolar disorder family loading $\left(1^{\text {tt }}, 2^{\text {nd }}\right.$ and $3^{\text {rd }}$ degree $)$, SCL-90, Young Mania Rating Scale (YMRS) and Hamilton Depression Rating Scale (HDRS) total scores; mean \pm SE.

\begin{tabular}{|l|ll|}
\hline \multicolumn{2}{|l|}{ Measure } & Controls \\
\hline FH I & $\mathrm{n}=22$ & \\
FH II & $\mathrm{n}=8$ & \\
& & \\
Women & $\mathrm{n}=20$ & $\mathrm{n}=11$ \\
Men & $\mathrm{n}=10$ & $\mathrm{n}=4$ \\
Family members: & & \\
Bipolar disorder & 1.3 & 0.0 \\
Age & $41 \pm 2.9$ & $40 \pm 3.7$ \\
IQ & $117 \pm 2.8$ & $118 \pm 2.6$ \\
BMI & $25.3 \pm 0.6$ & $25.0 \pm 0.7$ \\
SCL-90 & $102.2 \pm 1.8$ & $98.7 \pm 1.8$ \\
YMRS & $0.7 \pm 0.2$ & $0.3 \pm 0.2$ \\
HDRS & $1.3 \pm 0.3$ & $0.3 \pm 0.2$ \\
\hline
\end{tabular}




\section{Experimental design and treatment}

The study was conducted according to a mixed between / within groups $(3 * 2)$ design. The between-groups factor was FH with 3 levels: controls, FH I and FH II.

Treatment, the within subjects-factor, consisted of two levels: placebo and Trp loading. Trp was administered i.v. according to a double-blind, order-balanced cross-over design. The two test days were spaced 3-5 days apart.

\section{i.v. Trp loading}

Trp infusions were prepared by dissolving $7.0 \mathrm{~g}$ Trp in $1000 \mathrm{cc}$ water. Saline solution $(\mathrm{NaCl})$ was added to ensure an isotonic solution $(\mathrm{pH}=7.4)$. Each Trp solution was sterilized by passage through a $0.22-\mathrm{mm}$ polymer (Millipore) filter and tested for pyrogenicity and sterility. $1000 \mathrm{cc}$ Saline solution was given on a separate day as a placebo mixture. The $1000 \mathrm{cc}$ solution was administered within 60 minutes. The appearances of solutions were identical.

\section{Procedure}

To eliminate response bias due to premenstrual symptoms, all pre-menopausal women were tested in the follicular phase of the menstrual cycle (Menkes et al. 1994; Rasgon et al. 2000). On each test day, the subjects arrived at 9.00 a.m. after an overnight fast. Immediately after arrival the i.v. cannula was inserted immediately in a forearm vein. At $10.00 \mathrm{a} . \mathrm{m}$. $\left(\mathrm{t}_{0}\right)$ the saline solution, with or without Trp, was administered.

During the experiment, the subjects remained in the testing room where they were allowed to do non-strenuous activities. Subjects were allowed to drink decaffeinated coffee, herbal tea or water and to eat protein-poor fruits like apples and oranges.

Blood samples for assessment of plasma Trp were taken at $t_{-30}, t_{60}, t_{75}, t_{90}$ and $t_{105}$ (all time points $\mathrm{t}_{\mathrm{X}}$ refer to (-)X minutes (before)/ after $\mathrm{t}_{0}$ ). Cognitive assessment was completed at $\mathrm{t}_{180}$.

\section{Cognitive assessments}

The cognitive test battery took approximately 60 minutes to complete and consisted of tasks measuring planning, attention, psychomotor performance and memory.

\section{Planning}

Computerized Tower of London (compu-TOL)

Planning capacity was assessed by a modified version of the One-touch Tower of London (TOL) task (Owen et al. 1995). Subjects were initially trained the original non-computerized- 
TOL (Shallice 1982). Thereafter, the comp-TOL was introduced. On a computer screen, two arrays of differently colored balls (red, yellow and blue) on sticks were presented. Each arrangement contained three balls, which were held on three sticks; one stick had a capacity of 3 balls, another could hold two balls and the third could only hold 1 ball. The subject were requested to indicate the minimal number of steps necessary to rearrange the balls on the lower configuration to match the arrangement presented on the top half of the screen. The rules were: each ball must be replaced separately, once a balls is taken it must be put on a stick, it is not allowed to put one ball aside and continue with the other balls.

The subjects had to rearrange the balls in their mind's eye (without actually moving the balls). Once the ideal solution had been found, the subject was asked to count the number of moves and then respond by pressing the appropriate response button, which represented the right number of steps necessary to rearrange the balls (2-5). The subjects were instructed to respond as quickly as possible, but the importance of accuracy was emphasized. They were told that performance on the task was indicated by both response accuracy and reaction time.

There was no response-feedback and subjects were allowed to give just one response to each problem.

The complexity of the task is dependent on the minimal number of steps the rearrangement can be achieved: $2,3,4$ and 5 steps. The training consisted of 10 trials and the test of 40 trials, with an equal number of 2,3,4 and 5-steps problems, which were presented in a fixed pseudorandom order. Only once subjects were entirely familiar with the rules governing the movements of balls and the concepts involved with solving the compu-TOL problems, were they given the test form of the task.

Performance was indicated by median RT as a function of the number of steps. Number of correct responses was checked for possible confounding of the RT results.

\section{Secondary outcome variables}

\section{Attention}

Go / NoGo Task (GONT)

The GONT measures response readiness. Every second one digit (0-9) was shown on a computer screen for $500 \mathrm{msec}$. The subject was asked to push a button as soon as he saw the digit except when he saw a 'target-digit'. When the subject saw the target digit he had to inhibit pushing the button. The target digit was revealed to the subject prior to the test. Number of correct responses and RT to the distracters were assessed. This task was aimed at 
measuring attention failures and was adopted after a version described by Robertson et al. (Robertson et al. 1997).

\section{Stroop Color Word Test (SCWT)}

The SCWT has often been used to test focused attention and response inhibition (Stroop 1935). The test consisted of three cards displaying each 100 stimuli. The first card included color names, which had to be read as quickly as possible. The second card included color patches, which had to be named. The third card consisted of color names printed in incongruously colored ink. The color of the ink had to be named, without paying attention to the word itself. Outcome variable was interference. The interference denotes the percentage extra time needed to complete the third card relative to the average of the first and second card: (time card III / [(time card I + time card II) / 2)] * 100\% (Houx and Jolles 1993).

\section{Left Right Choice Reaction Time (CRT)}

This is a parametric version of the well-known color-word response conflict task (Stroop 1935). The words Left and Right are displayed either at the left or the right side of a computer screen. Response instructions are to respond as quickly as possible to the location of the word irrespective of its meaning. The subjects' task is to respond by pressing a corresponding button. The output parameters are the RT and accuracy of responding as a function of task difficulty.

\section{Dichotic Listening Task (DLT)}

The DLT measures both focused and divided attention for auditory stimuli (Kimura and D'Amico, 1989). Subjects received different auditory stimuli simultaneously through a headphone on each side. The stimuli were numbers ranging from 1-200, presented at random and natural-speech spoken by a male voice. The test consisted of two subtasks in which the subjects were instructed to focus to either the numbers presented in the right ear, which is a more sensitive measure than performance on the left ear, or both ears, and remember the numbers presented (Schmitt et al. 2000). The subtask in which the subjects were instructed to focus to one side, while ignoring the other, can be regarded as a measure of focused attention. The subtask in which the subjects had to remember the numbers presented in both ears is a divided attention task. Each of the two subtasks is made up of nine trials, in which two, three or four stimuli pairs are presented in random order. After each trial, the subject had to identify the presented numbers from a list of numbers on a computer screen. The numbers included all 
presented numbers plus the same amount of other, numbers (distracter stimuli). Performance on each subtask was calculated by the A' sensitivity measure (see VVLT).

\section{Psychomotor performance}

Motor Choice Reaction Time (MCRT)

The MCRT measures sensorimotor speed, choice-reaction speed, and choice-reaction speed with response competition (Houx and Jolles, 1993). The subjects held one button and were asked to press one of five other buttons located at equal distance from the hold button when lit. This yields RTs consisting of an initiation phase (time from stimulus onset until release of the hold button) and a movement phase (time from release of the hold button until the response button is pushed). The subjects responded either to a single button (simple RT), to one of 3 buttons that lit up (3-choice RT), or to the right of the lit button (incompatible 3choice RT) as quickly as possible. Dependent variables were movement time and initiation time as a function of task complexity.

\section{Memory}

The Visual Verbal Learning Test (VVLT)

The VVLT measures, short-term memory (STM) and long-term memory (LTM) performance. The VVLT is an adapted version of the Rey Auditory Verbal Learning Test (Lezak 1995). The test consisted of a list of 30 monosyllabic words (18 nouns and 12 adjectives) in Dutch, which were presented in three trials on a computer screen. The words occur very frequently in Dutch and are acquired early in life. Items were presented in the same sequence at a rate of one per 2 seconds.

Each trial ended with a free verbal recall of the words (immediate recall). Thirty minutes after the third trial, the subject was requested to recall as many words as possible without prior presentation (delayed recall). A yes/no recognition test, consisting of 15 formerly learned words and 15 new but comparable words (distracters), was given after the delayed recall test (recognition). The words remained on the screen for $2000 \mathrm{msec}$ or until the subject responded. Another $1000 \mathrm{msec}$ elapsed before the next word appeared on the screen. After presentation of each word the subject had to respond "YES / NO" as fast as possible to indicate recognition of the word.

The RTs were recorded. According to the theory of signal detection (Pollack 1964), the proportion of correctly recognized words (cr) and the proportion of falsely recognized (fr) constitute the nonparametric sensitivity measure: $A^{\prime}=1-1 / 4(f r / c r+(1-c r) /(1-f r)) . A^{\prime}$ is in 
fact the proportion of correctly recognized words, corrected for the subject's response tendency. Because the distribution of $\mathrm{A}^{\prime}$ is skewed due to a ceiling effect, $\mathrm{A}^{ }$was arc sin transformed before being used in statistical analysis.

The variables used were the total number of words recalled after the first three trials as a measure of STM, the number of correct words on delayed free recall as a measure of retrieval from LTM, A' as a measure of storage in LTM, and the median RT of correctly recognized target words as a measure of speed of retrieval from LTM.

In each of the assessments, a different words list was presented. The lists were comparable with regard to their level of abstraction and the affective tone of the words. Parallel lists were order balanced over assessments.

\section{Verbal Fluency Test (Fluency)}

The fluency test measures strategy-driven retrieval of information from semantic memory. The subjects are asked to report as many four-letter words with the same initial letter within one minute. The dependent variable is the number of correct reported words. Nonsense words were not accepted, but names, conjugations and plurals were allowed. Starting letters were $\mathrm{H}$, L, M and R (Schmitt et al. 2000).

\section{Statistical Analysis}

Outcome variables were analyzed using General Linear Model (GLM) for repeated measures. Within-subjects factor was treatment ( 2 levels: Trp or placebo); the between-subjects factor was family history ( 3 levels: controls, FH I, or FH II). Univariate contrasts between groups were used to test the primary hypothesis of difference between controls and FH subjects (controls vs. FH I + II) as well as the hypotheses of differences between controls and $\mathrm{FH} \mathrm{I}$ and FH II relatives separately (controls vs. FH I and controls vs. FH II).

Mann-Whitney-U Tests was used to test differences in side-effects.

Relationships between effects of $\operatorname{Trp}$ (determined as difference: $\operatorname{Trp}$ minus placebo) on cognitive measures and mood, peak prolactine and cortisol responses (determined as maximal response after Trp minus placebo) were evaluated by means of Pearson's product moment correlation.

Statistical analyses were performed with SPSS 9.0 for Windows. 


\section{Results}

\section{Plasma Trp levels}

Plasma Trp concentrations $[\mathrm{F}(1,42)=41.2, \mathrm{p}<0.01]$ and ratio Trp: $\operatorname{LNAAs}[\mathrm{F}(1,42)=22.6$, $\mathrm{p}<0.01]$ were significantly higher at baseline in the placebo condition. FH subjects showed lower baseline plasma $\operatorname{Trp}[\mathrm{F}(1,42)=6.4, \mathrm{p}<0.05]$ compared to controls. After correction for baseline differences, plasma $\operatorname{Trp}[\mathrm{F}(1,42)=978.7, \mathrm{p}<0.001]$ and ratio Trp: LNAAs $[F(1,42)=502.3, p<0.001]$ increased significantly after i.v. Trp loading. Relative to baseline, the mean peak of plasma Trp and ratio Trp: LNAAs to i.v. Trp loading were $1049.4 \mu \mathrm{mol} / \mathrm{L}$ respectively 2.3 . Following placebo, there was no change in plasma Trp and ratio Trp:

LNAAs.

There were no effects of treatment order and FH on increase in Trp values after challenging.

\section{Cognitive assessments}

Table 2 shows mean ( \pm se) of planning variables, separated for $\mathrm{FH}$ and control subjects.

\section{Planning}

compu-TOL

The three-way interaction of family history by number of steps by Trp on number of correct responses was significant $[F(3,41)=3.01, \mathrm{p}<0.05]$ but there were no differences between $\mathrm{FH} \mathrm{I}$ and $\mathrm{FH}$ II subjects. There was also a main effect of $\operatorname{Trp}[F(1,42)=85.53, \mathrm{p}<0.01]$ on median RT and a significant two-way interaction of number of steps by $\operatorname{Trp}$ on median $\mathrm{RT}[F(3,40)=$ 21.50, $p<0.01$ ]; median RT was increased after Trp on the 3 and 4 steps problems. There were no effects of treatment order. 
Table 2. Mean ( \pm SE) of the primary cognitive outcome measures ( planning) Results are broken down by family history (controls; CFH V FH II) and treatment (Trp/ placebo; P).

- $p<0.05, " p<0.1$

\begin{tabular}{|c|c|c|c|c|c|}
\hline Measure & & Treatment & $\mathrm{C}(n=15)$ & FH I $(n=22)$ & FH II $(n=8)$ \\
\hline \multicolumn{6}{|c|}{ Compu-TOL } \\
\hline \multicolumn{6}{|c|}{ Correct responses (\#) } \\
\hline & 2 steps & TRP & $9.2(0.2)$ & $8.9(0.3)$ & $8.6(0.6)$ \\
\hline & & $\mathbf{P}$ & $9.7(0.2)$ & $8.6(0.4)$ & $9.0(0.5)$ \\
\hline & 3 steps & TRP & $9.0(0.2)$ & $9.2(0.1)$ & $9.0(0.4)$ \\
\hline & & $\mathbf{P}$ & $8.9(0.4)$ & $8.6(0.4)$ & $9.0(0.3)$ \\
\hline & 4 steps & TRP & $7.2(0.4)$ & $7.4(0.4)$ & $7.9(0.4)$ \\
\hline & & $\mathbf{P}$ & $7.9(0.4)$ & $8.0(0.4)$ & $8.1(0.9)$ \\
\hline & 5 steps & TRP & $8.2(0.2)$ & $7.0(0.4)$ & $7.0(0.7)$ \\
\hline & & $\mathbf{P}$ & $8.3(0.4)$ & $7.3(0.5)$ & $8.8(0.5)$ \\
\hline \multicolumn{6}{|c|}{ Median RT (msec) } \\
\hline & 2 steps & TRP & $4880(262)$ & $5425(433)$ & $6035(761)$ \\
\hline & & $\mathbf{P}$ & $5721(693)$ & $5899(603)$ & $5899(875)$ \\
\hline & 3 steps & TRP & $7170(896)$ & $7774(772)$ & $7885(928)$ \\
\hline & & $\mathbf{P}$ & $6802(656)$ & $7514(690)$ & $7166(822)$ \\
\hline & 4 steps & TRP & $9941(808)$ & $11155(1201)$ & $9798(1163)$ \\
\hline & & $\mathbf{P}$ & $8797(738)$ & $11547(1111)$ & $9554(1256)$ \\
\hline & 5 steps & TRP & $13623(1904)$ & $17665(1266)$ & $17225(2242)$ \\
\hline & & $\mathbf{P}$ & $15463(1970)$ & $18347(1899)$ & $16641(3024)$ \\
\hline
\end{tabular}

Table 3 shows mean ( \pm se) of other outcome variables, separated for $\mathrm{FH}$ and control subjects.

\section{Attention}

GONT

There was a significant interaction of $\operatorname{Trp}$ and $\mathrm{FH}$ on number of correct response inhibitions; after $\operatorname{Trp} \mathrm{FH}$ subjects showed less correct response inhibitions $[F(1,43)=8.76, \mathrm{p}<0.01]$ but controls did not. There were no effects on RT of correct responses nor did performance differ between treatment order or FH I and FH II subjects.

\section{SCWT}

The interference measure of the Stroop test did not show significant effects of FH, Trp and treatment order.

\section{CRT}

On incompatible stimuli RT showed a significant interaction effect of Trp and FH (both FH I and $\mathrm{FH})[F(1,43)=3.98, \mathrm{p}<0.05]$; RT was impaired after Trp in $\mathrm{FH}$ but not in controls, on 
number of correct responses this interaction was trend significant; FH subjects showed less correct responses after Trp. Independent of Trp, FH subjects tended to be slower on incompatible stimuli.

There were no significant effects of Trp and FH on accuracy or RT of compatible responses and there were no effects of treatment order.

\section{DLT}

FH subjects showed impaired performance on focused attention subtasks 'right' $[F(1,43)=$ $7.24, \mathrm{p}<0.05]$ and divided attention subtask 'both' $[F(1,43)=9.53, \mathrm{p}<0.01]$ independent of Trp.

There were no main effects of Trp or treatment order. There were no differences between FH $\mathrm{I}$ and FH II.

\section{MCRT}

Movement time was increased after $\operatorname{Trp}[F(1,43)=4.42, \mathrm{p}<0.05]$. There was a main effect of $\mathrm{FH}$ on movement time $[F(1,43)=5.09, \mathrm{p}<0.05]$; prolonged movement time in $\mathrm{FH}$ was due to prolonged movement time in FH I subjects $[F(2,42)=4.24, \mathrm{p}<0.05]$. There were no effects on initiation time and of treatment order.

\section{Memory}

VVLT

Trp significantly impaired performance on delayed recall $[F(1,43)=7.76, \mathrm{p}<0.01]$ and recognition $\mathrm{A}^{\prime}[F(1,43)=4.15, \mathrm{p}<0.05]$. Performance on the recognition task showed a significant interaction of $\operatorname{Trp}$ with treatment order $[F(1,43)=5.12, \mathrm{p}<0.05]$; subjects receiving Trp on the first test day show an improvement in A' following placebo on the second test day, whereas subjects receiving placebo first were also better on the second test day.

Following Trp, there was a trend towards impaired immediate recall performance $[F(1,43)=$ $3.84, \mathrm{p}<0.1]$.

Performance on recognition $\mathrm{A}^{\prime}$ was impaired in $\mathrm{FH}$ subjects $[F(1,43)=5.93, \mathrm{p}<0.05]$; more specifically in $\mathrm{FH}$ I subjects $[F(2,42)=4.21, \mathrm{p}<0.05]$.

There were no effects on median RT of the recognition task. 
There were no effects of Trp, FH or treatment order on number of correct reported words.

\section{Somatic side effects}

In the Trp condition, significantly more side effects $[\mathrm{Z}=-3,95, \mathrm{df}=1, \mathrm{p}<0.001]$ were reported compared to the placebo condition. Reported side effects after Trp were: tiredness, nausea, drowsiness, dizziness, headache, dullness, feelings of weakness, loss of concentration and diminished energy. Side effects did not differ between FHI, FH II or control subjects. Correlation analyses revealed no significant correlation of total physical side effects and dependent variables on cognitive tasks.

\section{Correlations of behavioral, physiological and cognitive effects}

Changes in mood were assessed by the profile of mood states (POMS) consisting of the subscales anger, depression, fatigue, tension and vigor. Following Trp, decrease in vigor was positively correlated with decrease in delayed recall performance on the VVLT [ $\mathrm{r}=0.39$, $\mathrm{p}<0.01]$. Detrimental effects of $\operatorname{Trp}$ on recognition $\mathrm{A}^{*}$ showed a significant positive correlation with peak cortisol response following $\operatorname{Trp}[\mathrm{r}=0.37, \mathrm{p}<0.05]$.

There were no significant correlations between other POMS subscales, prolactine response and effects of Trp on planning, attention and pychomotor performance. 


\begin{tabular}{|lll|}
\hline Measure & Treatment $\quad$ C $(n=15) \quad$ FH I $(n=22) \quad$ FH II $(n=8)$ \\
\hline
\end{tabular}

\begin{tabular}{|c|c|c|c|c|}
\hline \multicolumn{5}{|l|}{ GONT } \\
\hline \multirow[t]{2}{*}{ RT (msec) } & TRP & $325(10)$ & $351(13)$ & $323(18)$ \\
\hline & $\mathbf{P}$ & $331(11)$ & $342(11)$ & $307(14)$ \\
\hline \multirow[t]{2}{*}{ No. Correct (\#) } & TRP & $8.8(0.3)$ & $8.1(0.3)$ & $8.0(0.5)$ \\
\hline & $\mathbf{P}$ & $8.2(0.3)$ & $8.6(0.3)$ & $8.3(0.5)$ \\
\hline \multicolumn{5}{|l|}{ SCWT } \\
\hline \multirow[t]{2}{*}{ Interference (\%) } & TRP & $41(1)$ & $41(1)$ & $37(1)$ \\
\hline & $\mathbf{P}$ & $43(1)$ & $41(1)$ & $38(2)$ \\
\hline \multicolumn{5}{|l|}{ CRT } \\
\hline \multicolumn{5}{|l|}{ RT (msec) } \\
\hline \multirow[t]{2}{*}{ incompatible } & TRP & $700(18)$ & $772(26)$ & $683(27)$ \\
\hline & $\mathbf{P}$ & $712(21)$ & $732(22)$ & $661(17)$ \\
\hline \multirow[t]{2}{*}{ compatible } & TRP & $690(17)$ & $711(16)$ & $664(27)$ \\
\hline & $\mathbf{P}$ & $686(24)$ & $688(15)$ & $661(15)$ \\
\hline \multicolumn{5}{|l|}{ No. Correct (\#) } \\
\hline \multirow[t]{2}{*}{ incompatible } & TRP & $15.5(0.2)$ & $15.1(0.2)$ & $15.4(0.3)$ \\
\hline & $\mathbf{P}$ & $15.3(0.2)$ & $15.5(0.2)$ & $15.4(0.3)$ \\
\hline \multirow[t]{2}{*}{ compatible } & TRP & $15.8(0.1)$ & $15.4(0.2)$ & $15.5(0.3)$ \\
\hline & $\mathbf{P}$ & $15.9(0.1)$ & $15.5(0.2)$ & $15.6(0.2)$ \\
\hline \multicolumn{5}{|l|}{$\begin{array}{l}\text { DLT } \\
A^{\prime}(\%)\end{array}$} \\
\hline \multirow{3}{*}{ Right } & & & & \\
\hline & TRP & 94(9) & $89(2)$ & $79(5)$ \\
\hline & $\mathbf{P}$ & $93(1)$ & $89(2)$ & $89(3)$ \\
\hline \multirow[t]{2}{*}{ Both } & TRP & $86(8)$ & $83(8)$ & $81(2)$ \\
\hline & $\mathbf{P}$ & $86(8)$ & $83(7)$ & $82(2)$ \\
\hline \multirow{2}{*}{\multicolumn{5}{|c|}{$\begin{array}{l}\text { MCRT } \\
\text { RT (msec) }\end{array}$}} \\
\hline & & & & \\
\hline \multirow[t]{2}{*}{ Simple } & TRP & $114(6)$ & $121(7)$ & $111(6)$ \\
\hline & $\mathbf{P}$ & $110(7)$ & $127(7)$ & $105(5)$ \\
\hline \multirow[t]{2}{*}{ Choice } & TRP & $125(6)$ & $131(7)$ & $116(7)$ \\
\hline & $\mathbf{P}$ & $123(7)$ & $133(6)$ & $115(6)$ \\
\hline \multirow[t]{2}{*}{ Incompatible } & TRP & $132(9)$ & $139(8)$ & $125(11)$ \\
\hline & $\mathbf{P}$ & $130(10)$ & $137(8)$ & $119(8)$ \\
\hline \multicolumn{5}{|l|}{ Movement time (msec) } \\
\hline & TRP & $1046(28)$ & $1185(40)$ & $1087(40)$ \\
\hline & $\mathbf{P}$ & $1032(33)$ & $1166(37)$ & $1049(30)$ \\
\hline \multicolumn{5}{|l|}{$V V L T$} \\
\hline No. correct words $(\#)$ & & & & \\
\hline Immediate rec. & TRP & $42.6(2.8)$ & $33.8(2.6)$ & $40.6(4.5)$ \\
\hline & $\mathbf{P}$ & $42.1(3.2)$ & $38.8(3.0)$ & $41.0(5.0)$ \\
\hline Delayed rec. & TRP & $14.5(1.5)$ & $10.5(1.3)$ & $14.1(2.4)$ \\
\hline & $\mathbf{P}$ & $15.1(1.6)$ & $12.8(1.5)$ & $16.1(2.0)$ \\
\hline Recognition $\mathrm{A}^{\prime}(\%)$ & & & & \\
\hline & TRP & $53(9)$ & $56(5)$ & $49(8)$ \\
\hline & $\mathbf{P}$ & $58(7)$ & $60(4)$ & $49(6)$ \\
\hline Recognition RT (ms) & & & & \\
\hline & TRP & $647(20)$ & $833(39)$ & $729(39)$ \\
\hline & $\mathbf{P}$ & $640(19)$ & $852(42)$ & $713(24)$ \\
\hline Fluency & & & & \\
\hline No. correct words ( $(\#)$ & TRP & $12.9(1.4)$ & $11.0(0.8)$ & $12.1(1.2)$ \\
\hline & $\mathbf{P}$ & $11.8(1.0)$ & $10.7(1.0)$ & $12.4(1.5)$ \\
\hline
\end{tabular}

Table 3. Mean ( \pm SE) of the secondary cognitive outcome measures ( attention, psychomotor speed and memory) Results are broken down by family history (controls; C/FH V/ FH II) and treatment (Trp/ placebo; $\mathrm{P})$. ${ }^{*} p<0.05,{ }^{t s} p<0.1$ 


\section{Discussion}

The primary goal of this study was to investigate 5-HT vulnerability in FH subjects indicated by cognitive performance following i.v. Trp challenge.

Impaired planning performance and attention after Trp was found in FH subjects but not in controls, indicated by number of correct responses on the compu-TOL, correct response inhibitions on GONT and RT and accuracy on the CRT. There were no significant interaction effects of FH and Trp on memory and motor RT.

Independent of Trp, FH subjects showed cognitive deficits on memory, psychomotor performance, focused and divided attention as indicated by performance on recognition, movement time on MCRT and DLT sensitivity measures. Cognitive deficits on memory and psychomotor performance were more pronounced in $\mathrm{FH} I$ than $\mathrm{FH} \mathrm{II.}$

There was a main effect of Trp on memory and psychomotor performance; surprisingly. Trp impaired delayed recall memory performance, recognition and motor RT on MCRT.

Changes in performance on planning and attention following 5-HT modulations has now repeatedly been described and represent valid parameters of central 5-HT vulnerability of frontal brain areas (Sobczak et al. In press; Schmitt et al. 2000). Impaired performance in FH on planning and attention following Trp suggest central 5-HT vulnerability in frontal brain areas (Dagher et al. 1999; Elliott et al. 1997; Murphy et al. 1999; Owen et al. 1990; Rubinsztein et al. 2001). The findings on planning are in agreement with data of a previous study of our group, which showed pronounced planning deficits in FH following ATD (Sobczak et al. In press). Thus both a decrease and increase in central Trp may impair planning performance in FH. This may be explained by the following mechanism: in FH subjects the 5-HT system may be vulnerable to abnormalities. As FH subjects do not show psychopathology and related central 5-HT dysfunctions, it is suggested that an endogenous 5HT compensatory brain mechanism conceals the potential central 5-HT dysfunction in FH subjects. Independent of the direction of 5-HT modulations, acute changes in central 5-HT may be regarded as a stressor and thereby disturb the equilibrium between 5- HT and the 5-HT compensatory mechanism transiently. Consequently cognitive impairments will occur. This hypothesis is consistent with the kindling and stress sensitization theory of Post et al. (Post and Weiss 1997) which includes adaptations in second messengers, genetic transcription, receptors, neurotransmitters and neurons which may occur in response to stressors in the premorbid state. In $\mathrm{FH}$ subjects, who have a biological vulnerability to $\mathrm{BD}$, this stress sensitization may ultimately result in BD psychopathology. Thus, FH subjects are more 
vulnerable to the effects of Trp on planning and attention, which may be explained by a biological vulnerability in FH probably associated with 5-HT mediated functions in frontal brain areas.

After ATD, attention may be improved (Rosse et al. 1992; Schmitt et al. 2000; Sobczak et al. in press). We found impaired attention after $\operatorname{Trp}$ in $\mathrm{FH}$ which is thus in agreement with a linear negative association of 5-HT with (focused) attention.

Independent of Trp, FH subjects showed cognitive deficits on memory, movement time and attention. This is in agreement with findings previous findings of our group, which showed cognitive impairments in FH subjects. Impairments on planning, memory and attention have also been described in manic, depressed and euthymic BD patients (Zubieta et al. 2000; Rossi et al. 2000a; Rossi, et al. 2000b; Martinez-Aran et al. 2000; Ferrier et al. 1999; Murphy et al. 1999; Rubinsztein et al. 2000). The cognitive deficits in BD may be partially explained by abnormalities in functional brain structures and / or metabolism (Stoll et al. 2000; Manji et al. 2000; Buchsbaum 1986; van Gorp et al 1999; Coffman et al. 1990). In BD smaller temporal lobes, temporal horn enlargement, abnormal frontal cortex inositol levels, and phosphor metabolism (Soares and Mann 1997; Rossi et al. 1991; Shimon et al. 1997; Deicken et al. 1995) have been described. Cognitive impairments persist during clinical remission in BD and in FH subjects suggesting that these parameters are a trait marker for BD in FH (Zubieta et al. 2000; Henry et al 1973; van Gorp et al 1998; Murphy et al. 1999; Krabbendam et al. 2000; Coffman et al. 1990; Atre-Vaidya et al. 1998; Ferrier et al. 1999; Rubinsztein et al. 2000).

Overall, there was a tendency of FH I subjects to show more pronounced cognitive impairments compared to FH II. Previous findings showed FH I subjects to be more vulnerable to cognitive deficits following ATD. However, FH II subjects appear to be more vulnerable to ATD and Trp-induced mood-changes (Sobczak et al. accepted 1; Sobczak et al. accepted 2). This difference in vulnerability in FH I and FH II may suggest a biological distinction (Sobczak et al. in press). Cognitive deficits in BD type I patients show similarities with cognitive dysfunctions in schizophrenia, whereas BD type II patients show more characteristics of unipolar depression (Dickerson et al. 2001; Krabbendam et al. 2000; Borkowska and Rybakowski 2001).

The unexpected Trp-induced decrements in memory indicate impairments in consolidation affecting LTM performance. As there was a trend towards impaired immediate recall performance, the effects on LTM might probably be ascribed to impairments in STM. Deficits 
in STM have also been described following acute 5-HT challenges with ipsapirone (Riedel et al. 2002) and fenfluramine (Luciana et al. 1998) in healthy subjects.

Previous studies showed that an acute lowering of Trp following ATD induced impairments of delayed verbal and visual recognition (Sobczak et al. in press; Riedel et al. 1999; Schmitt et al. 2000; Rubinsztein et al. 2001), visuospatial-paired associative learning (Park et al. 1994) and stimulus-reward associations learning (Rogers et al. 1999). The detrimental effects of Trp on memory were comparative with those described following ATD. The fact that both an increase and decrease in Trp results in memory dysfunction may also suggest that there is an optimal 5-HT level for cognitive performance.

The Trp-induced impairment on movement time on MCRT is in agreement with results of Winokur et al. (Winokur et al. 1986) who showed decreased motor performance on a symbolcopying test following i.v. Trp. Hence, Winokur (1986) reported a positive association of sedation and RT impairments. In our study, confounding analyses showed that sedation was not likely to explain effects on psychomotor performance.

Possible confounding factors that might have interfered with cognitive effects of Trp are physical side-effects and changes in mood and cortisol release following Trp. Direct effects of 5-HT on vigilance and the conversion of Trp to melatonin by the enzymes 5-HT N-acetylase and 5-hydroxy indole O-methyl transferases may explain the sedating effects of Trp (Cooper et al. 1991; Schmitt and Riedel 2001) and melatonin may impair directly cognitive performance (Slotten and Krekling 1996; Jean-Louis et al. 1998). The effects of Trp on mood (see: Sobczak et al. accepted 3), showed sedation and mood-lowering after Trp indicated by increased fatigue, decreased vigor and increased anger, depression and tension respectively. Correlation analyses showed sedation to be positively associated with impaired memory performance. There were no other interfering effects of mood and physical side effects. Cortisol is another potential factor, which might have interfered with cognitive performance. There is now evidence that acute elevation of cortisol may enhance memory performance (Buchanan and Lovallo 2001; Adler and Jajcevic 2001) as opposed to more chronically elevated cortisol levels impair memory (Walder et al. 2000; Greendale et al. 2000). In this study, Trp induced a significant increase in plasma cortisol (described elsewhere: Sobczak et al. accepted 3). There was a positive association of cortisol response following Trp and memory performance suggesting that a blunted cortisol response following Trp is associated with Trp-induced memory impairments. Taking these findings together, the effects of Trp on memory might possibly have been influenced independently by both sedation and cortisol after Trp. 
In conclusion, this study showed Trp-induced planning and attention impairments in $\mathrm{FH}$ subjects. These cognitive deficits reflect a 5-HT vulnerability to BD psychopathology affecting frontal brain functions. Cognitive deficits in $\mathrm{FH}$ on memory, psychomotor performance and attention independent of Trp, provide evidence for a trait maker for BD. Independent of $\mathrm{FH}$, the major findings of Trp on cognition were impaired memory and psychomotor performance. It is suggested that an acute change in central 5-HT following Trp may disturb an optimal 5-HT activity in frontal and temporal brain areas and hence cause specific cognitive deficits. Imaging studies in combination with specific 5-HT challenges should provide further insight in 5-HT dysfunction and vulnerability and the relation to cognitive processes in respectively $\mathrm{BD}$ patients and $\mathrm{FH}$ subjects.

\section{References}

Adler G, Jajcevic A (2001) Post-dexamethasone cortisol level and memory performance in elderly depressed patients. Neurosci Lett 298(2), 142-4

Arrindell WA, Ettema JHM (1986) SCL-90 Een multidimensionele psychopathologie indicator [SCL-90. A multidimensional indicator of psychopathology]. Lisse, Swets \& Zeitlinger

Atre-Vaidya N, Taylor MA, Seidenberg M, Reed R, Perrine A, Glick-Oberwise F (1998) Cognitive deficits, psychopathology, and psychosocial functioning in bipolar mood disorder. Neuropsychiatry Neuropsychol Behav Neurol I1(3), 120-6

Borkowska A, Rybakowski JK (2001) Neuropsychological frontal lobe tests indicate that bipolar depressed patients are more impaired than unipolar. Bipolar Disorders 3, 88-94

Buchanan TW, Lovallo WR (2001) Enhanced memory for emotional material following stress-level cortisol treatment in humans. Psychoneuroendocrinology 26(3), 307-17

Buchsbaum MS (1986) Brain imaging in the search for biological markers in affective disorder. J Clin Psychiatry 47 Suppl, 7-12

Buhot MC, Martin S, Segu L (2000) Role of serotonin in memory impairment. Ann Med 32(3), 210-21 Coffman JA, Bornstein RA, Olson SC, Schwarzkopf SB, Nasrallah HA (1990) Cognitive impairment and cerebral structure by MRI in bipolar disorder. Biol Psychiatry 27(11), 1188-96

Cooper J, Bloom FE, Roth RH (1991) The Biochemical Basis of Neuropharmacology. (Sixth edition ed.). New York, Oxford University press

Coull JT, Sahakian BJ, Middleton HC, Young AH, Park SB, McShane RH, Cowen PJ, Robbins TW (1995)

Differential effects of clonidine, haloperidol, diazepam and tryptophan depletion on focused attention and attentional search. Psychopharmacology Berl 121(2), 222-30

Dagher A, Owen AM, Boecker H, Brooks DJ (1999) Mapping the network for planning, a correlational PET activation study with the Tower of London task. Brain 122(Pt 10), 1973-87

Deicken RF, Fein G, Weiner MW (1995) Abnormal frontal lobe phosphorous metabolism in bipolar disorder. Am J Psychiatry 152(6), 915-8 
Dickerson FB, Sommerville J, Origoni AE, Ringel NB, Parente F (2001) Outpatients with schizophrenia and bipolar 1 disorder, Do they differ in their cognitive and social functioning? Psychiatry Res 102(1), 21-7

Elliot R, Sahakian BJ, Matthews K, Bannerjea A, Rimmer J, Robbins TW (1997) Effects of methylphenidate on spatial working memory and planning in healthy young adults. Psychopharmacology 131(2), 196-9

Endicott J, Andreasen NC, Spitzer RL (1975) Family History-Research Diagnostic Criteria . Biometrics Research, New York State Psychiatric Institute

Ferrier IN, Stanton BR, Kelly TP, Scott J (1999) Neuropsychological function in euthymic patients with bipolar disorder. Br J Psychiatry 175, 246-51

Greendale GA, Kritz-Silverstein D, Seeman T, Barrett-Connor E (2000) Higher basal cortisol predicts verbal memory loss in postmenopausal women, Rancho Bernardo Study. J Am Geriatr Soc 48(12), 1655-8

Hamilton M (1967) Development of a rating scale for primary depressive illness. Br J Soc Clin Psychol 6(4), $278-96$

Henry GM, Weingartner H, Murphy DL. (1973) Influence of affective states and psychoactive drugs on verbal learning and memory. Am J Psychiatry 130 (9), 966-70

Houx PJ, Jolles J (1993) Age-related decline of psychomotor speed, Effects of age, brain health, sex and education. Perceptual and Motor Skills 76, 195-211

Jean-Louis G, von Gizycki H, Zizi F (1998) Melatonin effects on sleep, mood, and cognition in elderly with mild cognitive impairment. J Pineal Res 25(3), 177-83

Kessing LV (1998) Cognitive impairment in the euthymic phase of affective disorder. Psychol Med 28(5), 1027. 38

Kimura D, D'Amico C (1989) Evidence for subgroups of adextrals based on speech lateralization and cognitive patterns. Neuropsychologia 27(7), 977-86

Krabbendam L, Honig A, Wiersma J, Vuurman EF, Hofman PA, Derix MM, Nolen WA, Jolles J (2000)

Cognitive dysfunctions and white matter lesions in patients with bipolar disorder in remission. Acta Psychiatr Scand 101(4), 274-80

Lezak MD (1995) Neuropsychological Assessment. (3rd ed.). New York, Oxford University Press Luciana M, Bergund ED, Berman M, Hanson KL (2001) Effects of Tryptophan Loading and Tryptophan Depletion on Verbal, Spatial, and Affective Working Memory Functions in Healthy Adults. J Psychopharmacol, in press

Luciana M, Collins PF, Depue RA (1998) Opposing roles for dopamine and serotonin in the modulation of human spatial working memory functions. Cereb Cortex 8(3), 218-26

Luteijn F (1966) [A new abbreviated Groninger Intelligence Test]. Ned Tijdschr Psychol 21(10), 675-82 Manji HK, Moore GJ, Chen G (2000) Clinical and preclinical evidence for the neurotrophic effects of mood stabilizers, implications for the pathophysiology and treatment of manic-depressive illness. Biol Psychiatry 48(8), 740-54

Martinez-Aran A, Vieta E, Colom F, Reinares M, Benabarre A, Gasto C, Salamero M (2000) Cognitive dysfunctions in bipolar disorder, evidence of neuropsychological disturbances. Psychother Psychosom 69(1), 2 18

Menkes DB, Coates DC, Fawcett JP (1994) Acute tryptophan depletion aggravates premenstrual syndrome. J Affect Disord 32(1), 37-44 
Murphy FC, Sahakian BJ, Rubinsztein JS, Michael A, Rogers RD, Robbins TW, Paykel ES (1999) Emotional bias and inhibitory control processes in mania and depression. Psychol Med 29(6), 1307-21

Owen AM, Downes JJ, Sahakian BJ, Polkey CE, Robbins TW (1990) Planning and spatial working memory following frontal lobe lesions in man. Neuropsychologia 28(10), 1021-34

Owen AM, Sahakian BJ, Hodges JR, Polkey CE, Summers BA, Robbins TW (1995) Dopamine-dependent fronto-striatal planning deficits in early Parkinson's Disease. Neuropsychol 9, 126-40

Park SB, Coull JT, McShane RH, Young AH, Sahakian BJ, Robbins TW, Cowen PJ (1994) Tryptophan depletion in normal volunteers produces selective impairments in learning and memory. Neuropharmacology $33(3-4), 575-88$

Pollack I, Norman DA (1964) A non-parametric analysis of recognition experiments. Psyconomic Sciences I, $125-6$

Post RM, Weiss SRB (1997) Kindling and stress sensitization. In Young LT, Joffe RT (Eds), Bipolar Disorder. Biological models and their clinical application, $1^{\text {st }}$ ed. New York, Marcel Dekker Inc, 93-126

Rasgon N, McGuire M, Tanavoli S, Fairbanks L, Rapkin A (2000) Neuroendocrine response to an intravenous L-tryptophan challenge in women with premenstrual syndrome. Fertil Steril, 73(1), 144-9

Riedel WJ, Klaassen T, Deutz NEP, van Someren A, van Praag HM (1999) Tryptophan depletion in normal volunteers produces selective impairment in memory consolidation. Psychopharmacology 141, 362-9 Riedel WJ, Klaassen T, Griez E, Honig A, Menheere PPCA, Van Praag HM (2002) Dissociable Hormonal, Cognitive and Mood Responses to Neuroendocrine Challenge, Evidence for Receptor-Specific Serotonergic Dysregulation in Depressed Mood. Neuropsychopharmacol 26(3): 358-67.

Robbins TW (2000) From arousal to cognition, the integrative position of the prefrontal cortex. Prog Brain Res $126,469-83$

Robertson IH, Manly T, Andrade J, Baddeley BT, Yiend J (1997) 'Oops!', performance correlates of everyday attentional failures in traumatic brain injured and normal subjects. Neuropsychologia 35(6), 747-58

Rogers RD, Blackshaw AJ, Middleton HC, Matthews K, Hawtin K, Crowley C, Hopwood A, Wallace C, Deakin JF, Sahakian BJ, Robbins TW (1999) Tryptophan depletion impairs stimulus-reward learning while methylphenidate disrupts attentional control in healthy young adults, implications for the monoaminergic basis of impulsive behaviour. Psychopharmacology (Berl) 146(4), 482-91

Rosse RB, Schwartz BL, Zlotolow S, Banay-Schwartz M, Trinidad AC, Peace TD, Deutsch SL (1992) Effect of a low-tryptophan diet as an adjuvant to conventional neuroleptic therapy in schizophrenia. Clin Neuropharmacol 15(2), 129-41

Rossi A, Arduini L, Daneluzzo E, Bustini M, Prosperini P, Stratta P (2000a) Cognitive function in euthymic bipolar patients, stabilized schizophrenic patients, and healthy controls. J Psychiatr Res 34(4-5), 333-9

Rossi A, Daneluzzo E, Arduini L, Di Domenico M, Stratta P, Petruzzi C (2000b) Cognitive symptoms of mania in pure and mixed episodes evaluated with the Positive and Negative Syndrome Scale. Eur Arch Psychiatry Clin Neurosci 250(5), 254-6

Rossi A, Stratta P, Di Michele V, Gallucci M, Splendiani A, de Cataldo S, Casacchia M (1991) Temporal lobe structure by magnetic resonance in bipolar affective disorders and schizophrenia. J Affect Disord 21(1), 19-22 Rubinsztein JS, Michael A, Paykel ES, Sahakian BJ (2000) Cognitive impairment in remission in bipolar affective disorder. Psychol Med 30, 1025-36 
Rubinstein JS, Rogers RD, Riedel WJ, Mehta MA, Robbins TW, Sahakian BJ (2001) Acute dietary tryptophan depletion impairs maintenance of "affective set" and delayed visual recognition in healthy volunteers.

Psychopharmacology (Beri) 154(3), 319-26

Savard RJ, Rey AC, Post RM (1980) Halstead-Reitan Category Test in bipolar and unipolar affective disorders. Relationship to age and phase of illness. J Nerv Ment Dis 168(5), 297.304

Schmitt JA, Jorissen BL, Sobczak S, van Boxtel MP, Hogervorst E, Deutz NE, Riedel WJ (2000) Tryptophan depletion impairs memory consolidation but improves focussed attention in healthy young volunteers. $J$

Psychopharmacol 14(1), 21-9

Schmitt JAJ, Riedel WJ (1999) Shared and differential cognitive effects of serotonin reuptake inhibitors in healthy volunteers. Eur Neuropsychopharmacology 11, S203

Scott J, Stanton B, Garland A, Ferrier IN (2000) Cognitive vulnerability in patients with bipolar disorder. Psychol Med 30(2), 467-72

Shallice T (1982) Specific impairments of planning. Phil. Trans. of the Royal Society of London 298, 199-209 Sheehan D, Lecrubier Y, Janavs J, Knapp E, Weiller E ( 1994) MINI International Neuropsychiatric Interview. University of South Florida

Shimon H, Agam G, Belmaker RH, Hyde TM, Kleinman JE (1997) Reduced frontal cortex inositol levels in postmortem brain of suicide victims and patients with bipolar disorder. Am J Psychiatry 154(8), 1148-50 Slotten HA, Krekling S (1996) Does melatonin have an effect on cognitive performance?

Psychoneuroendocrinology 21(8), 673-80

Soares JC, Mann JJ (1997) The functional neuroanatomy of mood disorders. J Psychiatr Res 31(4), 393-432 Sobczak S, Honig A, Riedel WJ (2000) Acute Tryptophan Depletion in bipolar disorders; literature review and directives for further research. Acta Neuropsychiatrica 12 (3), 69-72

Sobczak S, Riedel WJ, Booij L, Aan het Rot M, Deutz NEP, Honig A (in press) Cognition following Acute Tryptophan Depletion, differences between first-degree relatives of bipolar disorder patients and matched healthy control volunteers. Psychol Med

Sobczak S, Honig A, Nicolson N, Riedel WJ (accepted 1). Acute Tryptophan Depletion enhances mood in firstdegree relatives of type II bipolar patients but not in first-degree relatives of type I bipolar patients and healthy matched controls. Neuropsychopharmacology

Sobczak S, Honig A, Duinen MV, Riedel WJ (accepted 2) Serotonergic dysregulation in bipolar disorders; a literature review of 5-HT challenge studies. Bipolar Disorders

Sobczak S, Honig A, Van Duinen MA, Riedel WJ (accepted 3) Mood, prolactine and cortisol responses following Intravenous L-tryptophan challenge; evidence for serotonergic vulnerability in first-degree relatives of bipolar patients. Int J Neuropsychopharmacol

Stoll AL, Renshaw PF, Yurgelun-Todd DA, Cohen BM (2000) Neuroimaging in bipolar disorder, what have we learned? Biol Psychiatry 48(6), 505-17

Stroop JR (1935) Studies of interference in serial verbal reactions. J Exp Psychol 18, 643-62

van Gorp WG, Altshuler L, Theberge DC, Wilkins J, Dixon W (1998) Cognitive impairment in euthymic bipolar patients with and without prior alcohol dependence. Arch Gen Psychiatry 55, 41-6

van Gorp WG, Altshuler L. Theberge DC, Mintz J (1999) Declarative and procedural memory in bipolar disorder. Biol Psychiatry 46, 525-31 
Walder DJ, Walker EF, Lewine RJ (2000) Cognitive functioning, cortisol release, and symptom severity in patients with schizophrenia. Biol Psychiatry 48(12), 1121-32

Winokur A, Lindberg ND, Lucki I, Phillips J, Amsterdam JD (1986) Hormonal and behavioral effects associated with intravenous L-tryptophan administration. Psychopharmacology Berl 88(2), 213-9

Wolfe J, Granholm E, Butters N, Saunders E, Janowsky D (1987) Verbal memory deficits associated with major affective disorders, a comparison of unipolar and bipolar patients. J Affect Disord 13(1), 83-92

Young LT, Warsh JJ, Kish SJ, Shannak K (1994) Reduced brain 5-HT and elevated NE turnover and metabolites in bipolar affective disorder. Biol Psychiatry 35(2), 121-7

Young RC, Biggs JT, Ziegler VE, Meyer DA. (1978) A rating scale for mania, reliability, validity and sensitivity. Br J Psychiatry 133, 429-35

Zubieta JK, Huguelet P, Ohl LE, Koeppe RA, Kilbourn MR, Carr JM, Giordani BJ, Frey, KA (2000) High vesicular monoamine transporter binding in asymptomatic bipolar I disorder, sex differences and cognitive correlates. Am J Psychiatry 157(10), 1619-28 


\title{
Lower high-density lipoprotein cholesterol, decreased $\omega 3$ and increased $\omega 6$ polyunsaturated fatty acids in first-degree relatives of bipolar patients
}

\begin{abstract}
Lower serum high-density lipoprotein cholesterol and increased ratio of $\omega 6 / \omega 3$ fatty acids have been reported in unipolar and bipolar depressed patients. These changes in cholesterol and fatty acid composition have been suggested to affect membrane viscosity and consequently serotonergic neurotransmitter expression, which may enhance serotonergic vulnerability.

The goal of this study was to investigate whether baseline cholesterol and fatty acids in healthy first-degree relatives of bipolar patients indicate a trait marker for bipolar disorders and whether these changes were associated with central serotonergic vulnerability. Baseline cholesterol and fatty acids were determined in healthy first-degree relatives of patients with bipolar disorders $(n=30)$ and healthy matched controls $(n=15)$ according to a parallel-group design. Central serotonergic vulnerability was assessed by neuroendocrine responses following acute intravenous tryptophan loading. The relationship between baseline serum cholesterol, fatty acids, cortisol and prolactine responses following tryptophan challenge was studied. First-degree relatives showed significantly lower plasma high-density lipoprotein cholesterol and C18:3 13 in phospholipids and cholesteryl esters and increased C20:4 $\omega 6$ and total $\omega 6$ fatty acids in phospholipids compared to controls. Lower total $\omega 3$ fatty acids in phospholipids and cholesteryl esters were associated with lowered baseline mood. Lower total $\omega 3$ and higher total $\omega 6$ fatty acids in phospholipids were positively associated with peak prolactine response to intravenous tryptophan challenge.
\end{abstract}


This is the first study which investigates baseline cholesterol and fatty acid status in healthy subjects at genetic risk for bipolar disorders in relation to serotonergic challenging.

Abnormalities in cholesterol and fatty acids in first-degree relatives of bipolar patients are in agreement with findings in bipolar and major depressed patients. Increased ratio of $\omega 6 / \omega 3$ fatty acids are related to central serotonergic vulnerability. As first-degree relatives of bipolar patients are free of any psychopathology, abnormalities in cholesterol and fatty acids may constitute a trait rather than a state marker for bipolar disorders.

S Sobczak, A Honig, A Christophe, M Maes, RWC Helsdingen, S De Vriese, WJ Riedel. Archives of General Psychiatry, submitted

\section{Introduction}

Abnormalities in cholesterol and fatty acids (FAs) homeostasis have been described in psychiatric patients, including unipolar depressed and manic bipolar patients (Hibbeln and Salem 1995; Horrobin 1990; Stoll et al. 1999a; Swartz 1990). The role of cholesterol and FAs in the pathophysiology of affective disorders has been related to changes in structural components of cell membranes in the brain. A decrease in cholesterol and FAs affect membrane microviscosity and consequently functioning of various neurotransmitter systems, such as tryptophan hydroxylase activity, serotonin (5-HT) uptake and monoamine oxidase activity (Buydens-Branchey et al. 2000; Terao et al. 2000; Engelberg 1992; Maes et al. 1994; Maes et al. 1996). Consequently, low brain-cell membrane cholesterol and changes in FAs may decrease 5-HT turnover in the brain and hence precipitate depression (Hibbeln et al. 1998b; Hibbeln et al. 1998a).

Significant lower fraction of cholesterol that is esterified, high-density lipoprotein cholesterol (HDL-C) and total cholesterol have now repeatedly been described in depressed patients (Olusi and Fido 1996; Maes et al. 1994; Maes et al. 1997a; Sarchiapone et al. 2001). Moreover, there is evidence for an inverse relationship between plasma cholesterol levels, severity of depression and suicidal behavior (Bocchetta et al. 2001; Sarchiapone et al. 2001; Maes et al. 1996; Morgan et al. 1993). In depression, lowered formation of cholesteryl esters may be related to decreased activity of lecithin: cholesterol acyltransferase (LCAT), a key enzyme that reacts preferentially with free cholesterol of the HDL-C particles to form cholesteryl esters. Esterification of HDL-C promotes transport of peripheral cholesterol to the liver (Subbaiah et al. 1990; Hunt and Groff 1990). 
In bipolar disorders (BD), both decreased (Swartz 1990) and increased (Brandrup and Randrup 1967) plasma cholesterol levels have been described. Manic episodes have been related more to lower cholesterol levels than depressive or mixed episodes (Hibbeln 1995). Polyunsaturated fatty acids (PUFAs) can be classified into 2 main groups: the $\omega 6$ and $\omega 3$ FAs, which refer to the position of the first double bound when counting from the methyl carbon atom at the distal end of the FA chain. Of the $\omega 3$ FAs, the parent FA is alpha-linolenic acid (ALA; 18:3 $\omega 3$ ) and of the $\omega 6$ FAs the parent FA is linoleic acid (LA; 18:2 $\omega 6$ ). As humans lack the desaturase enzyme, which inserts double bounds in FA chains in these positions, dietary intake is the only source of these PUFAs. Therefore, $\omega 6$ (e.g. in seed oil) and $\omega 3$ (e.g. in fish oil) FAs are nutritionally essential fatty acids (EFAs) (Hunt and Groff 1990; Shils and Young 1994). Depressed patients show depletion of $\omega 3$ FAs in red blood cell membranes, particularly docosahexaenoic acid (DHA; C22:603) (Edwards et al. 1998; Peet et al. 1998). Decreased $\omega 3$ fractions in cholesteryl esters and increased C20:4 $\omega 6 / C 20: 5 \omega 3$ (arachidonic acid, AA / eicosapentaenoic acid, EPA) ratio in cholesteryl esters and phospholipids have been described in depressed patients (Maes et al. 1996). The severity of depression has been associated with lower red blood cell membrane $\omega 3$ FAs and increased AA / EPA ratio in serum phospholipids (Adams et al. 1996; Edwards et al. 1998). $\omega 3$ FAs may be a promising therapy in $\mathrm{BD}$; BD patients receiving $\omega 3$ FAs therapy remained in remission for a significant longer time than subjects receiving placebo treatment (Stoll et al. 1999b; Kaplan 1999). Although abnormalities in cholesterol and FAs homeostasis in affective disorders have now repeatedly been described, it still remains unclear whether these changes are directly related to the pathogenesis of depression. It has been suggested that changes in food intake and starvation during severe depression might lead to abnormalities in cholesterol and FAs homeostasis (Christophe and Vermeulen 1992) and that changes in cholesterol and FAs indicate a state marker in depression. As clinical remission following antidepressant pharmacological therapy did not alter cholesterol and FAs levels in depressed patients (Maes et al. 1997b; Adams et al. 1996), abnormalities in cholesterol and FAs might indicate a trait rather than a state marker. In order to investigate the hypothesis that changes in cholesterol and FAs constitute a trait rather than a state marker, these parameters should be examined in healthy subjects at genetic risk for affective disorders (Sobczak et al. 2000).

Neuroendocrine responses following challenge with selective 5-HT stimulating agents, e.g. tryptophan (Trp), are important biological markers to assess brain 5-HT function (Riedel et al. 2002; Nurnberger et al. 1990). A single dose of $50-100 \mathrm{mg} / \mathrm{kg}$ i.v. Trp administration causes a significant increase in prolactine (PRL), possibly mediated by $5-\mathrm{HT}_{2} \mathrm{C}, 5-\mathrm{HT}_{2 \mathrm{~A}}$ and $5-\mathrm{HT}_{1 \mathrm{~A}}$ 
receptors. Studies on i.v. Trp challenge in BD showed blunted hormonal responses which provides evidence for 5-HT dysregulation in BD (Nurnberger et al. 1990).

As healthy first-degree relatives of bipolar patients $(\mathrm{FH})$ are at significant genetic risk for $\mathrm{BD}$, but do not show interference of psychotropic medication, they constitute a useful population to investigate trait markers for $\mathrm{BD}$. In this study cholesterol and FA status and its relation to central 5-HT vulnerability was investigated in FH subjects and matched controls. The aim of the present study was to examine i) whether HDL-C, total cholesterol and $\omega 3$ FAs were lower and $\omega 6$ FAs were higher (reflected in an increased $\omega 6 / \omega 3$ ratio) in healthy first-degree relatives of bipolar patients compared to healthy controls; as trait marker for $\mathrm{BD}$; ii) whether these changes are related to mood; iii) whether there are significant relationships between serum cholesterol, FAs and cortisol and prolactine responses to an i.v. tryptophan challenge, which indicate central 5-HT vulnerability.

\section{Methods}

\section{Subjects}

Subjects were FH subjects and matched healthy controls. FH subjects had at least one firstdegree relative with a type $\mathrm{I}$ BD or type II BD diagnosis. Family members were recruited via BD patients in treatment at the Department of Psychiatry, University Hospital Maastricht, via the consumer organization for manic-depressive patients and their families, and via advertisements in local newspapers. Healthy control subjects were also recruited via newspaper advertisement.

In the $\mathrm{FH}$ group, the main inclusion criterion was having at least one first degree relative with BD. Control subjects were free of any psychopathologic family loading. All subjects were interviewed with an abbreviated version of the Family History Research Diagnostic Criteria (FHRDC) to assess FH (Endicott 1975). Individual diagnoses (type I or type II BD, according to DSM IV) of the patients were verified via the patients' own psychiatrist, applying DSM IV criteria.

Each control subject was matched with 2 FH subjects with respect to gender, age, body mass index (BMI) and intelligence (IQ). IQ was estimated using Groninger Intelligence Test (GIT) subtasks (Vocabulary, Mental Rotation, Mental Arithmetic and Word Analogies) (Luteijn 1966).

Exclusion criteria of all subjects were: i) current or history of use of psychopharmacological medication; ii) lifetime psychiatric disorder including alcohol or drug abuse; iii) current active 
physical illness; iv) use of any medication known to affect fatty acid and cholesterol metabolism or endocrine functioning; v) subjects consuming a cholesterol or weight-reducing diet; and vii) pregnancy and current use of lactation.

Physical health was assessed by means of a health questionnaire, a standard physical examination by a physician and a urine screening. The urine test (Combur 8$)$ included assessment of leukocytes, nitrite, pH, protein, glucose, ketones, urobilinogen, bilirubin and blood. A Quick View, one-step pregnancy test (Quidel 8 ) was carried out in female subjects to check for unsuspected pregnancy.

A standardized psychiatric examination (Mini International Neuropsychiatric Interview; MINI) (Sheehan et al. 1994) was taken of all participants to examine the present psychiatric state according to DSM IV criteria. The (17-item) Hamilton Depression Rating Scale (HDRS) (Hamilton 1967), the Young Mania Rating Scale (YMRS) (Young et al. 1978) and the SCL-90 (Arrindell 1986) were used to verify the absence of depressive, manic and general psychiatric symptomatology (by use of cut-off values).

The Medical Ethics Committee of the Academic Hospital of Maastricht approved of the study. All participants signed informed consent.

\section{Methods}

The study used a parallel-group design. The groups were subjects with (FH) or without (controls) at least one first-degree relative with BD.

To eliminate response bias related to menstrual cycle, all pre-menopausal women were tested in the follicular phase of the menstrual cycle (Menkes et al. 1994; Rasgon et al. 2000). As FH subjects and matched controls consumed a no cholesterol or weight-reducing diet, we did not register daily nutritional intake.

On each test day, the subjects arrived at 9.00 a.m. after an overnight fast. The i.v. cannula was inserted immediately in a forearm vein. 20 minutes later, at 9.30 a.m. $(\mathrm{t}-30)$ (all time points $\mathrm{t}_{\mathrm{X}}$ refer to (-)X minutes (before) / after $\mathrm{t}_{0}$ ) baseline blood samples were taken for determination of cholesterol, FAs, PRL and cortisol. Blood samples to assess cholesterol and FAs were taken once, at $\mathrm{t}_{-30}$ on the first test day.

Cortisol and PRL were assessed following Trp challenge at $t_{60}, t_{75}, t_{90}$ and $t_{105}$ Thirty minutes after collection, serum tubes were centrifuged $(3000 \mathrm{rpm}, 10$ minutes) and serum was separated and frozen at $-80^{\circ} \mathrm{C}$ until thawed for analysis. Samples of FH subjects and controls were analyzed simultaneously and all samples from multiple tests in the same patient were measured in the same assay. 


\section{Cholesterol}

Free cholesterol, total cholesterol, HDL-C and triglycerides were assayed using enzymaticcolorimetric methods based on the technique of Allain et al. (1974) (Allain et al. 1974). Lowdensity lipoprotein cholesterol (LDL-C) was computed as total cholesterol - (HDL-C + triglycerides / 5). Very low-density lipoprotein cholesterol (VLDL-C) was computed as triglycerides / 5. The esterified-C ratio was computed as ( 1 - free cholesterol : total cholesterol) * 100. The ratio HDL-C / LDL-C was also computed.

The analytical inter-assay coefficients of variation (CV) were, respectively, as follows: free and total cholesterol, $0.9 \%$, HDL-C, $2.3 \%$ and triglycerides, $1.3 \%$.

\section{Fatty acids}

Assays of serum FA were carried out as previously described by Maes et al. (1999) (Maes et al. 1999). Serum lipids were extracted (Folch 1957) and the phospholipids and cholesteryl esters isolated by thin layer chromatography (Christophe and Matthijs 1967). Their FAs were converted into methyl esters (Muskiet 1983) whose weight percent composition was determined after separation on a $25 \mathrm{~m}$ x $250 \mu \mathrm{m}$ df Restek 2330 (cyanopropyl) column (initial temperature $150^{\circ} \mathrm{C} ; 1 \mathrm{~min}$ isothermal; programmed to $200{ }^{\circ} \mathrm{C}$ at $2{ }^{\circ} \mathrm{C} / \mathrm{min}$ ), installed in a Varian Model 3500 gas chromatograph equipped with a flame ionization detector $\left(285^{\circ} \mathrm{C}\right)$ and with a split/splitless injector $\left(275^{\circ} \mathrm{C}\right)$. Split ratio was $1 / 15$. Peak identification was done by spiking with authentic standards (Alltech). Peak integration and calculation was performed electronically with a Varian Model 4290 integrator. Results are given as percentage of total FAs in both phospholipids and cholesteryl esters. The following saturated fatty acids (SFAs), Monounsaturated fatty acids (MUFAs), PUFAs and dimethylaldehydes (dma), were determined in the phospholipid fraction: $\mathrm{C} 14: 0 ; \mathrm{C} 15: 0 ; \mathrm{C} 16: 0 ; \mathrm{C} 16: 0 \mathrm{dma} ; \mathrm{C} 16: 1 \mathrm{t} ; \mathrm{C} 16: 1 \omega 9$;

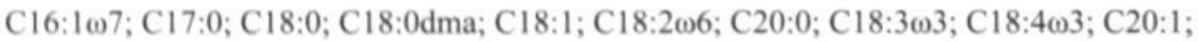

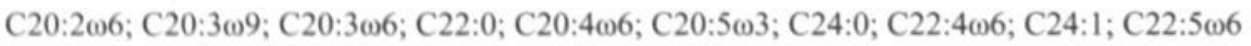

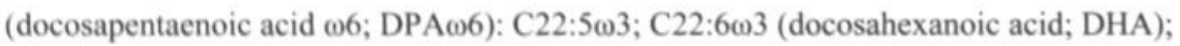
C25:0. The sums ( $\Sigma$ ) of the percentages of $\omega 3$ and $\omega 6$ FAs were computed as well as the

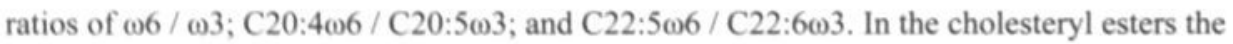
following FAs were assayed: $\mathrm{C} 14: 0 ; \mathrm{C} 15: 0 ; \mathrm{C} 16: 0 ; \mathrm{C} 16: 1 \omega 9 ; \mathrm{C} 16: 1 \omega 7 ; \mathrm{C} 16: 2 \omega 6 ; \mathrm{C} 17: 0$;

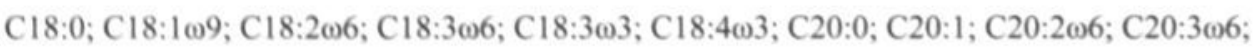

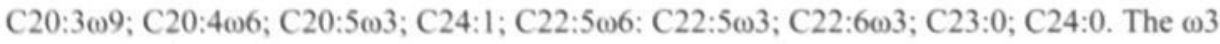
and $\omega 6$ FAs and ratios of $\omega 6 / \omega 3$ and c20:4 $\omega 6 /$ C 20:5 $\omega 3$ were computed. The analytical inter-assay $\mathrm{CV}$ was $8.5 \%(\mathrm{n}=45)$. 


\section{Cortisol / Prolactine}

Cortisol and PRL analyses were performed using an Automated Chemiluminescence's System (ACS: centaur) from Bayer, Germany. The analytical inter-assay CV was $1.6 \%$ for cortisol and $0.08 \%$ for prolactine. All samples from multiple tests in the same patient were measured in the same assay.

\section{Statistical Analysis}

Arctan transformations were used to reach normality of distribution and to adjust for heterogeneity of variance between study groups (i.e. ratio HDL-C / LDL-C, esterified cholesterol fraction and FAs).

Group mean differences (controls vs. FH) were assessed by means of analysis of variance (ANOVA). Relationships between cholesterol or FAs and baseline HDRS, YMRS and ( ${ }^{\circ} \log$ ) SCL-90-depression scores (SCL-90-dep), peak (determined as maximal response after Trp, corrected for placebo) prolactine and cortisol responses following Trp were checked by means of Pearson's product moment and regression analyses. The significance was set at $\alpha=0.05$ (two-tailed). Statistical analyses were performed with SPSS 9.0 for Windows.

\section{Results}

\section{Demographic data}

The included subjects were $30 \mathrm{FH}$ ( 10 men and 20 women) and 15 controls ( 4 men, 11 women), see table 1. Relatives were children $(n=20)$, parents $(n=8)$ and siblings $(n=2)$. Twenty-one had a first-degree relative with a type I BD diagnosis, and 9 subjects were relatives of type II BD patients.

The FH and control groups did not differ significantly with respect to age, body mass index (BMI), intelligence quotient (IQ) and SCL-90 dep, but FH subjects scored significant higher on baseline HDRS [t=2.27, df 1,39.6; $\mathrm{p}<0.05]$.

Of the female subjects, 21 were pre-menopausal and 10 were postmenopausal.13 women used oral anti-conceptives. 12 subjects were smokers; 10 in the FH group and 2 controls. Values of FAs were missing for 2 subjects in the $\mathrm{FH}$ group. 
Table 1. Demographic characteristics; bipolar disorder family loading $\left(1^{\text {th }}, 2^{\text {nd }}\right.$ and $3^{\text {rd }}$ degree $)$, SCL-90, Young Mania Rating Scale (YMRS) and Hamilton Depression Rating Scale (HDRS) total scores; $n=45$, mean ( \pm SE).

\begin{tabular}{|lll|}
\hline Measure & FH & Controls \\
\hline \hline $\begin{array}{l}\text { Women } \\
\text { Men } \\
\text { Family members: }\end{array}$ & $\mathrm{n}=20$ & $\mathrm{n}=11$ \\
Bipolar disorder & 1.3 & $\mathrm{n}=4$ \\
Age & & 0.0 \\
IQ \\
BMI & $40 \pm 3.0$ & $38 \pm 3.6$ \\
SCL-90-dep & $116 \pm 2.8$ & $116 \pm 3.6$ \\
YMRS \\
HDRS
\end{tabular}

\section{Cholesterol}

Table 2 shows the measurements of serum cholesterol. In FH subjects, HDL-C was significantly lower $[\mathrm{F}=7.62$, df 1,$43 ; \mathrm{p}<0.05]$ and the HDL-C / LDL-C ratio tended to be lower $[\mathrm{F}=2.92$, df 1,$43 ; \mathrm{p}<0.10]$ compared to controls (see figure 1).

Triglycerides, VLDL-C and esterified-C did not differ between $\mathrm{FH}$ and control groups.

Decreased HDL-C in FH

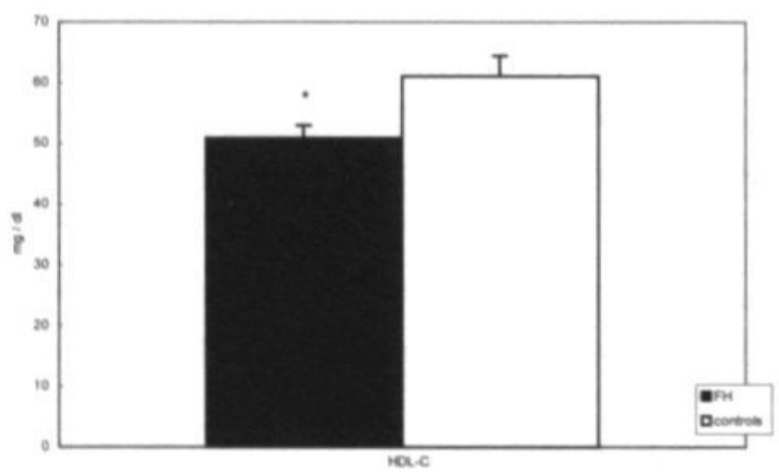

Figure 1. Decreased high-density lipoprotein cholesterol (HDL-C) in first-degree relatives of bipolar patients (FH) compared to controls. $* \mathbf{p}<0.05$ 
Table 2. Measurements of serum cholesterol in first-degree relatives of bipolar patients (FH) and controls, total cholesterol, free cholesterol and esterified cholesterol as \% of total cholesterol, triglycerides, high-density lipoprotein cholesterol (HDL-C), low-density lipoprotein cholesterol (LDL-C), very-low-density lipoprotein cholesterol (VLDL), and ratio HDL-C / LDL-C; mean ( \pm SE). $n=45,{ }^{\mathrm{TS}} \mathrm{p}<0.1, \cdot \mathrm{p}<0.05$.

\begin{tabular}{lll}
\hline & \multicolumn{1}{c}{ FH } & Controls \\
\hline Total cholesterol (mg / dl) & $206.27(10.15)$ & $203.73(11.48)$ \\
Esterified cholesterol (\%) & $72.11(1.80)$ & $73.78(0.26)$ \\
Free cholesterol (\%) & $27.89(1.80)$ & $26.22(0.26)$ \\
HDL-C (mg / dl) & $50.96(1.98)^{*}$ & $61.07(3.35)$ \\
Triglycerides (mg / dl) & $114.30(10.03)$ & $102.33(13.35)$ \\
LDL-C (mg / dl) & $134.04(8.91)$ & $122.20(10.80)$ \\
VLDL-C (mg / dl) & $22.86(2.01)$ & $20.47(2.67)$ \\
HDL-C / LDL-C & $0.45(0.04)^{\mathrm{Ts}}$ & $0.56(0.06)$ \\
\hline
\end{tabular}

Fatty acids

Serum phospholipids

Table 3 shows the FA composition in serum phospholipids of FH subjects and healthy controls. FH subjects showed significant increased $\Sigma \omega 6[\mathrm{~F}=5.52$, df 1,$41 ; \mathrm{p}<0.05]$ due to higher $\mathrm{C} 20: 4 \omega 6[\mathrm{~F}=6.03$, df 1,$41 ; \mathrm{p}<0.05]$. PUFAs $[\mathrm{F}=9.45$, df 1,$41 ; \mathrm{p}<0.05]$ were increased in $\mathrm{FH}$ compared to controls (see figure 2). Though $\Sigma \omega 3$ did not differ significantly between $\mathrm{FH}$ and control subjects, $\mathrm{C} 18: 3 \omega 3$ was significant lower $[\mathrm{F}=9.90, \mathrm{df} 1,41 ; \mathrm{p}<0.05]$ in $\mathrm{FH}$ subjects and figure 2 shows a tendency to lower ratio $\omega 6 / \omega 3$ in the $\mathrm{FH}$ group.

Increased ratio omega-6/ omega-3 in FH

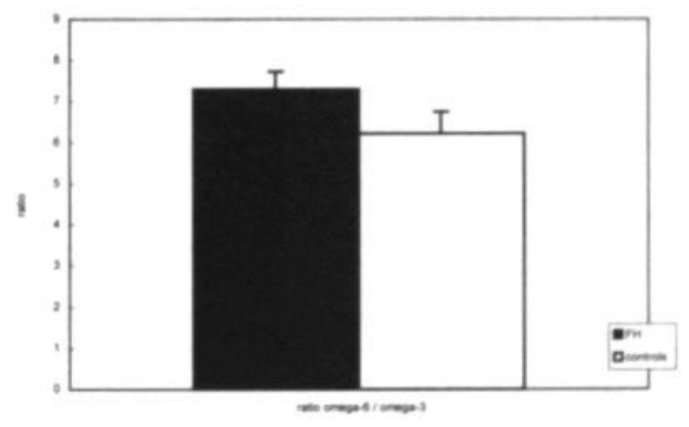

Figure 2. Increased ratio $\omega 6$ / $\omega 3$ of plasma phospholipids in first-degree relatives of bipolar patients (FH) compared to controls. 
MUFAs were lower in FH subjects compared to controls [F=5.60, df 1,$41 ; \mathrm{p}<0.05]$.

Table 3. Fatty acid composition (wt $\%$ of total) of plasma phospholipids and cholesteryl esters in first-degree relatives of bipolar patients $(\mathrm{FH})$ and controls; mean $( \pm \mathrm{SE}) . \mathrm{n}=45,{ }^{\mathrm{Ts}} \mathrm{p}<0.1,{ }^{*} \mathrm{p}<0.05$.

\section{Phospholipids}

\section{Cholesteryl esters}

\begin{tabular}{lcccl}
\hline \multicolumn{1}{c}{ Fatty acids } & FH & Controls & \multicolumn{1}{c}{ FH } & \multicolumn{1}{c}{ Controls } \\
\hline ESFA & $45.92(0.30)$ & $46.01(0.46)$ & $13.79(0.28)$ & $14.33(0.42)$ \\
EMUFA & $13.00(0.24)^{*}$ & $14.41(0.63)$ & $20.88(0.46)$ & $22.62(0.94)$ \\
EPUFA & $39.70(0.29)^{*}$ & $38.00(0.53)$ & $63.79(0.53)^{*}$ & $61.70(1.07)$ \\
$\mathbf{2 0 : 3 \omega 9}$ & $0.12(0.01)$ & $0.13(0.01)$ & $0.08(0.03)$ & $0.05(0.01)$
\end{tabular}

PUFA 06

\begin{tabular}{|c|c|c|c|c|}
\hline $18: 2 \omega 6$ & $20.99(0.45)$ & $19.80(1.06)$ & $53.25(0.75)$ & $52.58(1.28)$ \\
\hline 20:2ø6 & $0.30(0.02)$ & $0.31(0.01)$ & $0.06(0.01)$ & $0.06(0.00)$ \\
\hline 20:3 $\omega 6$ & $2.64(0.12)$ & $2.65(0.21)$ & $0.68(0.04)$ & $0.69(0.04)$ \\
\hline $20.4 \omega 6(\mathrm{AA})$ & $9.62(0.28)^{*}$ & $8.53(0.34)$ & $6.99(0.31)$ & $5.98(0.35)$ \\
\hline $22: 4 \omega 6$ & $0.61(0.02)$ & $0.58(0.06)$ & $0.00(0.00)$ & $0.00(0.00)$ \\
\hline 2:5 & $0.21(0.02)$ & $0.21(0.03)$ & $0.04(0.03)$ & $0.02(0.04)$ \\
\hline$\omega 6$ & $34.37(0.40)^{*}$ & $32.09(0.96)$ & $61.26(0.62)$ & $59.61(1.13)$ \\
\hline
\end{tabular}

PUFAa3

$\begin{array}{lllll}\mathbf{1 8 : 3} 3 \mathbf{3} & 0.14(0.02)^{*} & 0.31(0.08) & 0.43(0.025)^{*} & 0.54(0.03) \\ \mathbf{1 8 : 4 \omega 3} & 0.10(0.01) & 0.08(0.01) & 0.07(0.01) & 0.07(0.01) \\ \mathbf{2 0 : 5} 3 \mathbf{3} \text { (EPA) } & 0.93(0.16) & 0.99(0.14) & 1.18(0.32) & 0.79(0.10) \\ 22: 5 \omega 3 & 0.74(0.04) & 0.78(0.07) & 0.02(0.00) & 0.02(0.01) \\ 22: 6 \omega 3 \text { (DHA) } & 3.30(0.18) & 3.61(0.51) & 0.80(0.06) & 0.66(0.06) \\ \Sigma \omega 3 & 5.21(0.33) & 5.77(0.56) & 2.48(0.34) & 2.08(0.16)\end{array}$

Ratios

$\Sigma \omega 6 / \omega 3$

AA/EPA

$7.29(0.43)^{\mathrm{Ts}}$

$6.22(0.52)$

33.01 (3.02)

$31.62(2.98)$

DPA๗6/DHA

$16.84(1.88)$

$12.15(2.20)$

$12.90(1.64)$

$9.69(1.74)$

$0.07(0.01)$

$0.06(0.01)$

$0.04(0.02)$

$0.05(0.03)$ 


\section{Senum cholesteryl esters}

In table 3, the FA composition of cholesteryl esters is presented. C18:3 3 [F=7.44, df 1,41; $p<0.05]$ was significantly lower and PUFAs [F=4.22, df $1.41 ; p<0.05]$ were higher in $F H$ subjects compared to controls.

Other FA measures in cholesteryl esters did not differ significantly between $\mathrm{FH}$ and control groups.

\section{Intercorrelations}

\section{Cholesterol}

Correlation analyses of free cholesterol , triglycerides, HDL-C, LDL-C, VLDL-C, ratio HDLC/LDL-C, esterified-C with smoking behavior, HDRS, YMRS, peak PRL and peak cortisol responses revealed no significant associations. One-tailed significant negative correlations were present between SCL-90-dep and triglycerides or VLDL-C [ $r=-0.30, p<0.1]$.

\section{Fatry acids}

There were significant associations between peak PRL response to Trp and $\Sigma 03[r=-0.47$, $\mathrm{p}<0.01], \Sigma \omega 6[\mathrm{r}=0.60, \mathrm{p}<0.01]$, PUFAs [ $\mathrm{r}=0.43, \mathrm{p}<0.01]$, and ratio $\omega 6 / \omega 3[\mathrm{r}=0.59, \mathrm{p}<0.01]$ in phospholipids (see figure 3 ).

Regression equation: maximal PRL response to $\operatorname{Trp}=-2.5+1.43 *$ ratio $\omega 6 / \omega 3$.

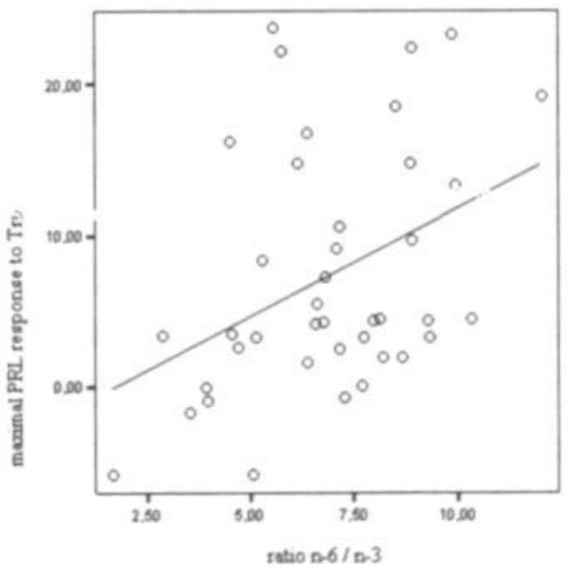

Figure 3. Positive association between ratio $\omega 6 / \omega 3 \mathrm{FAs}$ in phospholipids and maximal prolactine (PRL) response (in $\mu g /$ dl) to an i.v. tryptophan challenge (corrected for placebo). 
SCL-90-dep scale correlated significantly with $\Sigma \omega 3$ FAs in phospholipids $[r=-0.40, p<0.05$ ] and cholesteryl esters $[r=-0.35, p<0.05]$ and with the ratio $\mathrm{C} 20: 4 \omega 6 / \mathrm{C} 20: 5 \omega 3[\mathrm{r}=0.31$, $\mathrm{p}<0.05]$ and ratio $\mathrm{C} 22: 5 \omega 6 / \mathrm{C} 22: 6 \omega 3[\mathrm{r}=0.42, \mathrm{p}<0.05]$ in phospholipids. HDRS rating was negatively associated with SFAs in phospholipids [ $\mathrm{r}=-0.40, \mathrm{p}<0.05]$. Smoking behavior, YMRS and peak cortisol responses did not correlate with FAs in phospholipids and cholesteryl esters.

\section{Discussion}

The first major findings of this study were a significantly lower baseline plasma HDL-C and

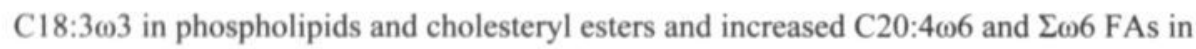
phospholipids in FH subjects compared to controls. PUFAs were higher in phospholipids and cholesteryl esters in FH subjects. Second, lower $\Sigma \omega 3$, higher $\Sigma \omega 6$, PUFAs and increase in ratio $\omega 6 / \omega 3$ in phospholipids were positively associated with peak PRL response to i.v. Trp challenging. An increase in depressed mood was associated with lower $\Sigma \omega 3$ FAs in phospholipids and cholesteryl esters.

To our knowledge, this is the first study which investigates cholesterol and FAs in healthy subjects at risk for affective disorders. Lower total cholesterol and HDL-C have also been found in depressed patients which is in agreement with the results of the present study (Buydens-Branchey et al. 2000; Maes et al. 1997a). High-density lipoprotein plays an important role in transport of cholesterol to the liver. Lower HDL-C may affect adequate cholesterol catabolism. In depression, the combination of lower HDL-C and anti-oxidant activity by vitamin $\mathrm{E}$ may result in membrane abnormalities, cellular dysfunctions and also cardiovascular pathology (Bilici et al. 2001; Maes et al. 2000; Booth-Kewley and Friedman 1987). Although some (Olusi and Fido 1996) but not all research data (Hibbeln and Salem 1995; Maes et al. 1994) indicate that low cholesterol may be a state marker in depression, we found no significant correlations between HDL-C or total cholesterol levels and mood in healthy subjects at genetic risk for $\mathrm{BD}$. In $\mathrm{BD}$ patients, lower plasma cholesterol levels have been described (Swartz 1990; Hibbeln and Salem 1995). As we found low HDL-C in FH subjects which were free of psychopathology, the present findings suggest low HDL-C to be a trait rather than a state marker in BD.

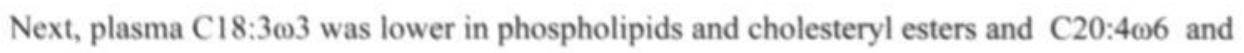
¿ 06 FAs were higher in phospholipids in FH subjects compared to controls. Independent of $\mathrm{FH}$, lower $\Sigma \omega 3 \mathrm{FAs}$ were associated with a more depressed mood. These findings are in 
concurrence with findings in BD and depressed patients and may again suggest a trait marker for BD. In BD patients $\omega 3$ FAs supplementation has mood stabilizing effects which might be ascribed to stabilization of the 5-HT system and its anti-kindling properties (Stoll et al. 1999a; Stoll et al. 1999b; Kaplan 1999; Sullivan et al. 1994). Repletion of $\omega 3$ FAs in BD and FH subjects may therefore influence membrane functioning and signal transduction in the brain resulting in normalization of mood (Sullivan et al. 1994; Stoll et al. 1999a). Literature on FAs in $\mathrm{BD}$ is limited, but the abnormalities in FAs as described in FH subjects are in agreement with findings in major depression. In depressed patients, lower $\omega 3$, higher $\omega 6$ FAs and higher ratio $\omega 6 / \omega 3$ have been described (Maes et al. 1996; Maes et al. 1999; Edwards et al. 1998; Adams et al. 1996). However, PUFAs were unexpectedly higher in FH subjects compared to controls. Higher PUFAs in FH are due to the increase in $\omega 6$ PUFAs at the expense of a compensatory decrease in MUFAs.

The present study showed no changes in esterified cholesterol in $\mathrm{FH}$ subjects, which might suggest no changes in LCAT activity. The results of Maes et al., $(1994,1999)$ suggested decreased esterified cholesterol in depressed patients, which might be related to increased proinflammatoire cytokines in depression (Maes et al. 1994; Maes et al. 1999). As FH subjects were healthy and free of any psychopathology, acute activation of the inflammatory response system and consequently changes in esterified cholesterol were not expected.

In the second part of the study, the association between baseline cholesterol and FAs with hormonal responses to an i.v. Trp challenge was investigated. Lower $\Sigma \omega 3$ and higher $\Sigma \omega 6$ FAs in all subjects was accompanied by enhanced PRL response following i.v. Trp challenge. This suggests that the abnormalities in FAs in FH subjects may be associated with increased 5-HT receptor sensitization. In general, 5-HT receptor sensitization indicates 5-HT vulnerability in subjects at risk for affective disorders (Riedel et al. 2002). Thus, these results provide evidence for a direct relationship between peripheral FA level and central 5-HT functioning. A shift towards lower $\omega 3$ and higher $\omega 6 \mathrm{FAs}$, as described in $\mathrm{FH}$ subjects and major depressed patients, may therefore explain central 5-HT dysfunctions, severity of depression and suicidal behavior in these subjects (Adams et al. 1996; Maes et al. 1996; Peet et al. 1998). Indeed, deficits in $\omega 3$ FAs have been associated with reduced brain 5 hydroxyindoleacetic (5-HIAA) concentrations and increased 5-HT receptor sensitization in humans (Hibbeln et al. 1998a; Hibbeln et al. 1998b). The beneficial effects of treatment with $\omega 3$ FAs in BD and depressed patients may thus be obtained by an improvement in 5-HT functioning (Stoll et al. 1999b; Stoll et al. 1999a; Sullivan et al. 1994; Mirnikjoo et al. 2001). In depressed patients, suicide and central 5-HT dysfunctions have also been related to low 
HDL-C and total cholesterol (Buydens-Branchey et al. 2000; Sarchiapone et al. 2001; Engelberg 1992; Bocchetta et al. 2001; Weidner et al. 1992; Maes et al. 2000). The findings of the present study provide no evidence for an association between cholesterol and central 5HT vulnerability. In previous studies, no significant correlation between serum cholesterol levels and brain 5-HIAA levels or d-fenfluramine-induced PRL and cortisol response was shown in depressed patients and healthy controls (Sarchiapone et al. 2001; Hibbeln et al. 1998a). Hence, Buydens-Branchey et al.(2000) and Terao et al. (2000) found a significant negative association between lower HDL-C, serum total cholesterol and neuroendocrine responses to oral meta-chlorophenylpiperazine (m-CPP) (Buydens-Branchey et al. 2000; Terao et al. 2000).

Potential confounders were not expected to explain abnormalities in cholesterol and FAs in FH subjects. Firstly, FH subjects were successfully matched to controls with respect to age, gender and BMI. Secondly, all subjects were screened for no cholesterol-restricted or weightreducing diet. In addition, there were no abnormalities in C20:3 $\omega 9$ (Mead acid) in any of the subjects, suggesting that a dietary restriction in LA, LNA, $\omega 3$ or $\omega 6$ FAs was not present (Christophe and Vermeulen 1992). Statistical analyses revealed no significant correlation between smoking behavior and cholesterol and FAs.

Concluding, the findings of the present study showed abnormalities in baseline HDL-C, $\omega 3$ and $\omega 6$ FAs in FH subjects, which are in concurrence with findings in patients with BD. As FH subjects are at genetic risk for BD but free of psychopathology and concurrent psychotropic medication, abnormalities in cholesterol and FAs constitute a trait rather than a state marker in BD. Abnormalities in $\omega 3$ and $\omega 6$ FAs in our study are related to 5-HT receptor sensitivity and may affect 5-HT vulnerability in FH subjects of BD patients.

\section{References}

Adams PB, Lawson S, Sanigorski A, Sinclair AJ (1996) Arachidonic acid to eicosapentaenoic acid ratio in blood correlates positively with clinical symptoms of depression. Lipids 31 Suppl: S157-61

Allain CC, Poon LS, Chan CS, Richmond W, Fu PC (1974) Enzymatic determination of total serum cholesterol. Clin Chem 20: 470-5

Arrindell WA, Ettema, J.H.M. (1986) SCL-90. Een multidimensionele psychopathologie indicator [SCL-90. A multidimensional indicator of psychopathology]. Swets \& Zeitlinger., Swets \& Zeitlinger

Bilici M, Efe H, Koroglu MA, Uydu HA, Bekaroglu M, Deger O (2001) Antioxidative enzyme activities and lipid peroxidation in major depression: alterations by antidepressant treatments. J Affect Disord $64: 43-51$ 
Bocchetta A, Chillotti C, Carboni G, Oi A, Ponti M. Del Zompo M (2001) Association of personal and familial suicide risk with low serum cholesterol concentration in male lithium patients. Acta Psychiatr Scand 104: 37-41 Booth-Kewley S, Friedman HS (1987) Psychological predictors of heart disease: a quatntitative review. Psychol Bull 101: 343-62

Brandrup E, Randrup A (1967) A controlled investigation of plasma lipids in manic-depressives. Br J Psychiatry 113: $987-92$

Buydens-Branchey L, Branchey M, Hudson J, Fergeson P (2000) Low HDL cholesterol, aggression and altered central serotonergic activity. Psychiatry Res 93: 93-102

Christophe A, Matthijs F (1967) New method for the determination of the fatty acid pattern of serum lipid classes. Clin Chim Acta 16: 39-43

Christophe A, Vermeulen, A. (1992) Effects of weight loss on the fatty acid composition of serum lipids in obese women. Ann Nutr Metab 36: 336-42

Edwards R, Peet M, Shay J, Horrobin D (1998) Omega-3 polyunsaturated fatty acid levels in the diet and in red blood cell membranes of depressed patients. J Affect Disord 48: 149-55

Endicott J, Andreasen NC, Spitzer RL (1975) Family History -Research Diagnostic Criteria. Biometrics Research, New York State Psychiatric Institute, Biometrics Research, New York State Psychiatric Institute Engelberg H (1992) Low serum cholesterol and suicide. Lancet 339: 727-9

Folch J, Lees M, Sloane-Staly GH (1957) A simple method for the isolation and perification of total lipids from animal tissues. Journal of Biological Chemistry 226: 497-509

Hamilton M (1967) Development of a rating scale for primary depressive illness. Br J Soc Clin Psychol 6: 27896

Hibbeln JR, Salem N (1995) Dietary polyunsaturated fatty acids and depression; when cholesterol does not satisfy. American journal of Clinical Nutrition $62: 1-9$

Hibbeln JR, Linnoila M, Umhau JC, Rawlings R, George DT, Salem N, Jr. (1998a) Essential fatty acids predict metabolites of serotonin and dopamine in cerebrospinal fluid among healthy control subjects, and early-and lateonset alcoholics. Biol Psychiatry 44: 235-42

Hibbeln JR, Umhau JC, Linnoila M, George DT, Ragan PW, Shoaf SE, Vaughan MR, Rawlings R, Salem N, Jr. (1998b) A replication study of violent and nonviolent subjects: cerebrospinal fluid metabolites of serotonin and dopamine are predicted by plasma essential fatty acids. Biol Psychiatry 44: 243-9

Horrobin DF (1990) Essential fatty acids, psychiatric disorders and neuropathies. In: Horrobin DF (ed) Omega-6 Essential Fatty Acids: Pathophysiology and Roles in Clinical Medicine. Wiley-Liss, New york, 303-20

Hunt SA, Groff JL (1990) Advanced nutrition and human metabolism. West Publishing Company, West Publishing Company

Kaplan A (1999) Omega-3 Fatty Acids Evaluated for bipolar disorders. Psychiatric Times I6(12)

Luteijn F (1966) [A new abbreviated Groninger Intelligence Test]. Ned Tijdschr Psychol 21: 675-82

Maes M, Christophe A, Delanghe J, Altamura C, Neels H, Meltzer HY (1999) Lowered omega3 polyunsaturated fatty acids in serum phospholipids and cholesteryl esters of depressed patients. Psychiatry Res 85: 275-91

Maes M, De Vos N, Pioli R, Demedts P, Wauters A, Neels H, Christophe A (2000) Lower serum vitamin E concentrations in major depression. Another marker of lowered antioxidant defenses in that illness. J Affect Disord 58: 241-6 
Maes M, Delanghe J, Meltzer HY, Scharpe S, D'Hondt P, Cosyns P (1994) Lower degree of esterification of serum cholesterol in depression: relevance for depression and suicide research. Acta Psychiatr Scand 90: 252-8 Maes M, Smith R, Christophe A, Cosyns P, Desnyder R, Meltzer H (1996) Fatty acid composition in major depression: decreased omega 3 fractions in cholesteryl esters and increased C20:4 omega 6/C20:5 omega 3 ratio in cholesteryl esters and phospholipids. J Affect Disord 38: 35-46

Maes M, Smith R, Christophe A, Vandoolaeghe E, Van Gastel A, Neels H, Demedts P, Wauters A, Meltzer HY (1997a) Lower serum high-density lipoprotein cholesterol (HDL-C) in major depression and in depressed men with serious suicidal attempts: relationship with immune-inflammatory markers. Acta Psychiatr Scand 95: 21221

Maes M, Verkerk R, Vandoolaeghe E, Van Hunsel F, Neels H, Wauters A, Demedts P, Scharpe S (1997b) Serotonin-immune interactions in major depression: lower serum tryptophan as a marker of an immuneinflammatory response. Eur Arch Psychiatry Clin Neurosci 247: 154-61

Menkes DB, Coates DC, Fawcett JP (1994) Acute tryptophan depletion aggravates premenstrual syndrome. J Affect Disord 32: 37-44

Mirnikjoo B, Brown SE, Kim HF, Marangell LB, Sweatt JD, Weeber EJ (2001) Protein kinase inhibition by omega-3 fatty acids. J Biol Chem 276: $10888-96$

Morgan RE, Palinkas LA, Barrett-Connor EL, Wingard DL (1993) Plasma cholesterol and depressive symptoms in older men. Lancet 341: 75-9

Muskiet FAJ, Van Dormaal, JJ, Martini IA, Wolthers BG, Van der Silk W (1983) Capillary gas chromatographic profiling of total long-chain fatty acids and cholesterol in biological materials. Journal of Chromatography 278 : $231-44$

Nurnberger Jl, Jr., Berrettini W, Simmons Alling S, Lawrence D, Brittain H (1990) Blunted ACTH and cortisol response to afternoon tryptophan infusion in euthymic bipolar patients. Psychiatry Res 31: 57-67

Olusi SO, Fido AA (1996) Serum lipid concentrations in patients with major depressive disorder. Biol Psychiatry 40: 1128-31

Peet M, Murphy B, Shay J, Horrobin D (1998) Depletion of omega-3 fatty acid levels in red blood cell membranes of depressive patients. Biol Psychiatry 43: 315-9

Rasgon N, McGuire M, Tanavoli S, Fairbanks L, Rapkin A (2000) Neuroendocrine response to an intravenous L-tryptophan challenge in women with premenstrual syndrome. Fertil Steril 73: 144-9

Riedel W, Klaassen T, Griez, E, Honig, A, Menheere, PPCA, van Praag HM (2002) Dissociable hormonal, cognitive and mood responses to neuroendocrine challenge: evidence for receptor-specific serotonergic dysregulation in depressed mood. Neuropsychopharmacol 26(3): 358-67.

Sarchiapone M, Camardese G, Roy A, Della Casa S, Satta MA, Gonzalez B, Berman J, De Risio S (2001) Cholesterol and serotonin indices in depressed and suicidal patients. J Affect Disord 62: $217-9$

Sheehan D, Lecrubier Y, Janavs J, Knapp E, Weiller E, et al (1994) MINI International Neuropsychiatric Interview. University of South Florida, Tampa

Shils ME, Young VR (1994) Modern nutrition in health and disease. Lea and Febiger, Philadelphia

Sobczak S, Honig A, Riedel WJ (2000) Acute Tryptophan Depletion in bipolar disorders; literature review 'nd directives for further research. Acta Neuropsychiatrica 12 (3): 69-72 
Stoll AL, Locke CA, Marangell LB, Severus WE (1999a) Omega-3 fatty acids and bipolar disorder: a review. Prostaglandins Leukot Essent Fatty Acids 60: 329-37

Stoll AL, Severus WE, Freeman MP, Rueter S, Zboyan HA, Diamond E, Cress KK, Marangell LB (1999b) Omega 3 fatty acids in bipolar disorder: a preliminary double-blind, placebo-controlled trial. Arch Gen Psychiatry 56: 407-12

Subbaiah PV, Banerji B, Gregg RE, Bagdade JD (1990) Molecular species of cholesteryl esters formed in abetalipoproteinemia: effect of apoprotein B-containing lipoproteins. J Lipid Res 31: 927-32

Sullivan PF, Joyce PR, Bulik CM, Mulder RT, Oakley-Browne M (1994) Total cholesterol and suicidality in depression. Biol Psychiatry 36:472-7

Swartz CM (1990) Albumin decrement in depression and cholesterol decrement in mania. J Affect Disord 19: 173-6

Terao T, Nakamura J, Yoshimura R, Ohmori O, Takahashi N, Kojima H, Soeda S, Shinkai T, Nakano H, Okuno T (2000) Relationship between serum cholesterol levels and meta- chlorophenylpiperazine-induced cortisol responses in healthy men and women. Psychiatry Res 96: 167-73

Weidner G, Connor SL, Hollis JF, Connor WE (1992) Improvements in hostility and depression in relation to dietary change and cholesterol lowering. The Family Heart Study. Ann Intern Med 117: 820-3

Young RC, Biggs JT, Ziegler VE, Meyer DA (1978) A rating scale for mania: reliability, validity and sensitivity. Br J Psychiatry 133: 429-35 


\section{Epilogue}

The primary aim of this thesis was to study the vulnerability of the central serotonergic system in first-degree relatives of bipolar patients (FH). First-degree family members of bipolar patients are at a significant genetic risk (10-20\%) compared to controls in the general population (1-5\%) to develop bipolar disorders (BD). This research project was conceived to gain insight in the serotonergic vulnerability in $\mathrm{FH}$ subjects and thereby in the pathophysiology of BD.

The increased genetic risk to $\mathrm{BD}$ in healthy $\mathrm{FH}$ subjects may be reflected in biological marker systems. Biological markers which are present in healthy $\mathrm{FH}$ subject and BD patients but not in healthy subjects without an increased genetic risk to $\mathrm{BD}$, are suggested to constitute trait markers for BD. The advantage of investigating healthy FH subjects in search for biological markers is the lack of interference of current or past psychopathology and psychotropic medication.

Disturbances in brain serotonin (5-hydroxytryptophan; 5-HT) activity have been assumed to exist in affective disorders including BD. We examined the vulnerability to central 5-HT dysfunction in FH subjects by means of 2 experimental manipulations. The experimental manipulations were based on changes of central 5-HT activity following dietary modifications (i.e. at the level of amino acid and protein manipulations) in brain tryptophan (Trp) availability. Brain 5-HT was lowered following Acute Tryptophan depletion (ATD) and elevated by intravenous (i.v) Trp loading. The effects of ATD in FH were described in the first part of the thesis. In the second part, the results of i.v. Trp challenge in FH were presented. We investigated whether FH subjects were more vulnerable to dysregulation of mood, cognition and hormonal release following ATD and i.v. Trp. In BD and major depression, abnormalities in cholesterol and fatty acids have been described and related to 5HT dysfunctions in the brain. The relation between plasma levels of cholesterol, fatty acids and central 5-HT vulnerability was also investigated. Effects in FH subjects were compared with effects in healthy matched controls. 
In this final chapter an attempt is made to integrate the findings presented in the preceding chapters. This will be discussed with reference to four dependent measures in this thesis: mood, cognition, hormones and lipid metabolism (i.e. cholesterol and fatty acids).

Differences between FH I and FH II will be discussed and possible biological explanations given. Conclusions will be drawn with respect to 5-HT vulnerability and cholesterol and fatty acids metabolism in FH subjects. Based on the results of the present studies, directives for future research will be given.

\section{Summary and integrative findings}

Serotonergic vulnerability to bipolar disorders is reflected in mood response following serotonergic manipulations in first-degree relatives of type II bipolar patients specifically We found no overall differences between controls and FH subjects in respectively ATD and Trp-induced mood responses. However, FH II subjects showed different mood responses following Trp manilupations, i.e. ATD (chapter 3 and chapter 6). Following ATD, FH II subjects reported an overall elevation in mood, i.e. less feelings of anger, whereas FH I subjects and controls experienced a slight mood lowering.

We argue that mood changes following ATD in FH II subjects indicate 5-HT vulnerability. This 5-HT vulnerability in FH II is explained by the same 5-HT dysfunctions found in unipolar depressed patients and their first-degree relatives (Klaassen et al. 1999; Delgado et al. 1989; Delgado et al. 1991). Hence, subjects vulnerable to unipolar depression show enhanced mood-lowering following ATD (Klaassen et al. 1999), whereas FH subjects who are vulnerable to $\mathrm{BD}$ show an elevation of mood. Elevation in mood has also been reported following ATD in remitted BD patients (Cappiello et al. 1997). This discrepancy in mood response between FH II subjects and relatives of unipolar depressed patients may be due to a vulnerability to (hypo)mania in FH II. Mania is also associated with hyposerotonergic activity (Prange et al. 1974; Goodwin and Jamison 1990; Price et al. 1990). The direction of moodchanges can be explained by vulnerability to (hypo)mania respectively depression. It is therefore argued that general vulnerability to affective disorders in $\mathrm{FH}$ II predicts pronounced ATD-induced mood changes.

The overall mood-lowering effect of i.v Trp loading was unexpected but may be partially explained by sedation (Price et al. 1989; Winokur et al. 1986). Nevertheless, especially FH II subjects reported a distinct mood response compared to FH I and controls. Suicide is more prevalent in BD type II than BD type I patients (Rihmer 1999) and has been associated with 5-HT dysfunction (Pfeffer et al. 1998; Roy et al. 1989; Asberg 1997; Meltzer et al. 1984). 
Therefore suicide provides another independent indication that the pathophysiology of FH II but not of $\mathrm{FH} \mathrm{I}$ is associated with 5-HT vulnerability.

The fact that the effects of ATD and Trp on mood in FH II were modest hampers firm conclusions about the existence of central 5-HT vulnerability in FH. Modest effects were probably due to: i) the relatively low number of included FH II subjects, ii) the marginal effects of Trp manipulations on brain 5-HT function, iii) the difficulty of registering slight mood changes in otherwise healthy subjects.

Nevertheless, one of the prime findings in this dissertation is that the separate effects of ATD and $\mathrm{Trp}$ on mood suggest 5-HT vulnerability in FH II but not in FH I subjects and controls.

Cognitive dysfunction in first-degree relatives of bipolar patients constitute a trait marker for bipolar disorders.

Compared to controls, FH subjects showed cognitive deficits on i.e. planning, memory. psychomotor performance, focused and divided attention independent of 5-HT modulations (chapter 4 and chapter 7). The fact that cognitive impairments exist in $\mathrm{FH}$ subjects and persist during clinical remission in BD suggests that these parameters reflect a trait marker for BD (Zubieta et al. 2000; Henry et al. 1973; van Gorp et al. 1998; Murphy et al. 1999; Krabbendam et al. 2000; Coffman et al. 1990; Atre-Vaidya et al. 1998; Ferrier et al. 1999; Rubinsztein et al. 2000). Moreover, the cognitive deficits in FH subjects were mainly attributed to impaired performance in FH I and not in FH II subjects. Compared to FH II and controls, FH I subjects showed significantly impaired performance on planning, memory and psychomotor performance. Thus cognition as a general trait marker for BD seems to be quite inappropriate. Cognition seems to be more specific as a trait marker in BD type I psychopathology. Another subgroup of psychiatric patients who constitutes specific cognitive impairments as trait markers are schizophrenic patients (Krabbendam et al. 2000). We therefore argue that the cognitive impairments in FH I implicate symptoms of psychotic disorders (Sobczak et al. in press; Krabbendam et al. 2000) more than of a primary affective disorder (Dickerson et al. 2001; Morice 1990; Borkowska et al. 2001). Whether 5-HT vulnerability is involved in the pathogenesis of cognitive dysfunctions in $\mathrm{FH} \mathrm{I}$ and $\mathrm{BD}$ remains speculative, it could be hypothesized that vulnerability of dopaminergic and noradrenergic systems are involved in cognitive dysfunctions (Schmitt and Riedel 1999). 
Serotonergic vulnerability in first-degree relatives of bipolar patients might affect cognitive processes mediated by frontal lobe areas

The results of ATD showed detrimental effects on planning in FH subjects, but not in controls (chapter 4). Following Trp, FH subjects showed impaired planning performance and attention (chapter 7).

Planning and attention are cognitive functions which are primarily regulated by frontal brain areas (Owen et al. 1990). This suggest that mainly frontal-lobe related cognitive functions are vulnerable to 5-HT dysfunctions in FH (Dagher et al. 1999; Elliott et al. 1997; Murphy et al. 1999; Rubinsztein et al. 2001). Indeed, we found no differences between FH and controls in effects of ATD and Trp on more temporal lobe mediated cognitive functions such as memory, learning and psychomotor performance. These results are in agreement with findings in BD patients, who showed improvement of planning deficits after clinical recovery which involves an increase in 5-HT activity (Rubinsztein et al. 2000).

The fact that both a decrease and increase in central Trp may impair planning performance can be explained by the following mechanism: in FH subjects the 5-HT system is not pathologically disturbed but only vulnerable to dysfunctions. Probably an endogenous compensatory brain mechanism conceals the potential central 5-HT dysfunction in FH subjects. Following ATD and Trp, acute changes in 5-HT occur. Independent of the direction of 5-HT modulations, these may be regarded as stressors and thereby transiently disturb the equilibrium between 5-HT and the compensatory mechanism. Consequently cognitive impairments will occur. This hypothesis is consistent with the kindling and stress sensitization theory of Post and Weiss (1997) which includes neural changes in the brain in response to stressors during the pre-morbid state. In FH subjects, this stress sensitization will result in brain abnormalities, disturbance of the compensatory mechanism and ultimately in $\mathrm{BD}$ psychopathology.

Hence, the increased vulnerability in FH to cognitive deficits following ATD and Trp may also be explained by their initial suboptimal performance (as has been described above). On the other hand baseline impairments on memory and psychomotor performance in FH did not result in more pronounced cognitive deficits following ATD and Trp. This explanation also suggest vulnerability to ATD and Trp-induced cognitive impairments to be more pronounced in FH I. Indeed, the results showed some evidence for more pronounced cognitive effects of ATD and Trp in FH I (i.e. on planning). 
In conclusion, FH subjects show 5-HT vulnerability affecting cognitive functions located mainly in frontal brain areas. The findings seem to be consistent with initial cognitive dysfunctions in FH I subjects.

Usage of cortisol and PRL responses following ATD and Trp as biological markers provides some evidence for 5-HT vulnerability in $\mathrm{FH}$.

Cortisol response following stress was lowered after ATD in FH subjects whereas it tended to increase in controls (chapter 3). Trp induced a robust elevation of PRL and cortisol release, however no significant differences were found in hormonal responses between $\mathrm{FH}$ and controls (chapter 6). Controls and FH subjects did not show differences in baseline cortisol and prolactine levels prior to experimental 5-HT manipulations.

As the methodological procedures between the studies with respect to hormonal assessments differed in several ways, results from comparisons of the findings must be interpreted with caution.

The decrease in cortisol following ATD in FH provides some evidence for a disturbance in the connection of 5-HT and HPA-axis functioning. Previous studies showed no significant effects of ATD on cortisol release, however findings are limited (Price et al. 1998; Goddard et al. 1995). To our knowledge there were no studies which investigated the effects of stressinduced cortisol response following ATD. The fact that assessment of stress-induced cortisol response following ATD differentiated between FH subjects and controls suggests that stressinduction following 5-HT challenges is a sensitive procedure to investigate 5-HT vulnerability. Results of i.v. Trp challenge on hormones did not confirm 5-HT vulnerability in FH. Possibly, including a stress-inducing task following the i.v. Trp challenge will make the i.v. Trp challenge more sensitive to assess 5-HT vulnerability in FH.

In BD patients, there is evidence for 5-HT mediated abnormalities in cortisol release (Vieta et al. 1999; Rybakowski and Twardowska 1999). Following i.v. Trp challenge a blunted cortisol response has been described in BD patients compared to controls (Nurnberger et al. 1990). Nevertheless, using hormones as peripheral markers to indicate 5-HT dysfunction following 5-HT challenges in BD revealed inconsistent results and interfering factors such as current mood-state and usage of psychotropic medication might partially explain the findings (Sobczak et al. accepted; Van Praag et al. 1987). Thus, usage of hormonal responses as biological markers following ATD and Trp in BD and FH subjects remains speculative and needs further investigation. 
Compared to FH I and controls, FH II subjects showed a tendency towards a more pronounced Trp-induced PRL response. However, overall effects of ATD and Trp on cortisol and PRL were similar in FH I and FH II.

Thus using cortisol and PRL as biological markers provides some evidence for 5-HT vulnerability in FH. However the effects were borderline, and might probably be improved by methodological adjustments i.e. including a stress-inducing procedure prior to hormonal assessments.

Abnormalities in cholesterol and fatty acids in first-degree relatives of bipolar patient suggest a biological marker for bipolar disorders which is probably related to serotonergic vulnerability.

FH subjects showed lower baseline plasma high-density lipoprotein-cholesterol (HDL-C) and

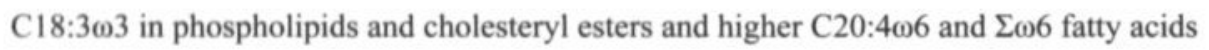
(FAs) in phospholipids compared to controls. These findings are in agreement with lower cholesterol levels, i.e. HDL-C and increased $\omega 3$ / $\omega 6$ ratio in BD and unipolar depressed patients (Buydens-Branchey et al. 2000; Swartz 1990; Hibbeln and Salem 1995; Maes et al. 1997). In depression, low cholesterol and changes in FAs have been suggested to constitute state markers (Olusi and Fido 1996). Hence as FH subjects are free of psychopathology and psychotropic medication, the low HDL-C and abnormalities in FAs provide evidence for trait rather than state markers to $\mathrm{BD}$.

Abnormalities in cholesterol and FAs may affect membrane microviscosity, receptor functioning, 5-HT transportation and turnover in the brain and hence precipitate BD and depression (Buydens-Branchey et al. 2000; Terao et al. 2000; Engelberg 1992; Maes et al. 1994; Maes et al. 1996; Hibbeln et al. 1998a; Hibbeln et al. 1998b). Indeed we found a significant positive association between increase in ratio $\omega 6 / \omega 3$ and peak PRL response to i.v. Trp challenging. At baseline, lower $\Sigma \omega 3$ FAs were also associated with lower mood in FH and control subjects. Probably, the abnormalities in FAs in FH subjects are associated with altered 5-HT receptor sensitization and reflect 5-HT vulnerability to BD. This implies a direct relationship between peripheral FAs levels, central 5-HT functioning and mood.

The abnormalities in cholesterol and FAs may influence the view on 5-HT vulnerability to BD tremendously. It is suggested that abnormalities in metabolism of cholesterol and FAs may be related to changes in brain 5-HT and psychopathology. A shift towards lowered $\omega 3$ and HDL-C and increased $\omega 6$ FAs has been related to 5-HT dysfunctions, severity of depression and suicidal behavior in major depressed patients (Adams et al. 1996; Maes et al. 
1996; Peet et al. 1998; Buydens-Branchey et al. 2000; Sarchiapone et al. 2001; Bocchetta et al. 2001; Engelberg 1992; Rabe-Jablonska and Poprawska 2000; Weidner et al. 1992). As $\omega 9$ FAs did not differ between groups, we do not assume that differences in dietary intake explain the changes in cholesterol and FAs metabolism in depression and BD. The results suggest a genetically predisposition for disturbances in HDL-C, $\omega 3$ and $\omega 6$ FAs metabolism in BD. How abnormalities in cholesterol and FAs are genetically linked with BD psychopathology remains unresolved and should be investigated in future research. Despite the fact that these subject were healthy, the magnitude of lipid abnormalities resemble abnormalities described in $\mathrm{BD}$ and major depression. This suggests that there is probably a complex genetic relation between lipid abnormalities and neurotransmitter dysfunctions which may ultimately result in BD psychopathology. To elucidate these hypotheses, future research should concentrate on genetic linkage between enzymes of lipid metabolism and genes associated with BD.

The abnormalities in cholesterol and FAs tended to be more pronounced in FH I subjects compared to FH II. Changes in cholesterol and FAs has been associated with cognitive dysfunction and white matter changes in the brain (Yehuda et al., 1999; Benton et al. 1995; Muldoon et al., 1997). In BD patients, structural brain changes have been associated with impaired cognitive performance (Dupont et al., 1990). It sounds thus plausible that the changes in HDL-C, $\omega 3$ and $\omega 6$ FAs in FH I may explain the cognitive deficits. Hence, in this study the number of participating FH II subjects was too low to draw general conclusions about cholesterol and FAs abnormalities in these subjects.

In conclusion, abnormalities in cholesterol and FAs in FH subjects indicate biological vulnerability to BD and may underlie 5-HT vulnerability. In future research, brain imaging should be applied to investigate the relationship between abnormalities in cholesterol, FAs, cognitive dysfunctions and structural brain changes in $\mathrm{FH}, \mathrm{BD}$ patients and several control groups including healthy subjects, subgroups of psychiatric and somatic patients.

\section{First-degree relatives of type I and type II bipolar patients show a biological distinction.}

The integrative findings of the presented studies provide evidence for a biological distinction between FH I and FH II subjects.

In general, FH II subjects were more vulnerable to mood changes following 5-HT manipulations by ATD. FH I subjects were characterized by cognitive deficits and a tendency towards more pronounced vulnerability to 5-HT induced cognitive changes. It is concluded that FH II subjects share more symptoms of primary affective disorders whereas FH I subjects show characteristics of primary psychotic disorders. Vulnerability to mood changes in FH II 
seemed to be directly related to changes in brain 5-HT levels which indicates central 5-HT vulnerability in these subjects. There was less evidence for 5-HT vulnerability in FH I subjects. We suggest that the cognitive dysfunctions in FH I may be a consequence of central vulnerability to dysfunctions in other neurotransmitter, e.g. dopamine and / or noradrenaline and / or structural brain changes in which abnormalities in cholesterol and FAs play an important role.

\section{Conclusions}

The use of acute experimental dietary Trp manipulations turned out to be a useful method to investigate 5-HT vulnerability to $\mathrm{BD}$. In this thesis it was demonstrated that mood, cognitive and hormonal responses to changes in central Trp availability indicate central 5-HT vulnerability. Changes in mood following 5-HT manipulations tended to be more prominent in FH II subjects (chapter 3 and 6). FH I subjects specifically showed cognitive deficits (chapter 4 and 7) and tended to be more vulnerable to cognitive changes following ATD and Trp challenging. The stress-induced cortisol release was blunted in FH subjects following ATD. This suggests that the relationship between 5-HT and HPA-axis functioning is altered in FH (chapter 3). Hormonal responses to Trp and ATD as indicator of 5-HT vulnerability did not distinguish between FH I and FH II (chapter 3 and 6). In FH subjects, abnormalities in cholesterol and FAs have been described and linked with central 5-HT vulnerability (chapter 8 ). We assume that changes in lipid metabolism may play an important role in 5-HT vulnerability to BD.

In conclusion, the studies described in this thesis show a biological distinction between $\mathrm{FH} \mathrm{I}$ and FH II subjects. As FH II subjects were more vulnerable to mood changes following 5-HT manipulations, we suggest that 5-HT vulnerability seem to be more specifically present in FH II subjects. The fact that both a decrease and increase in 5-HT result in mood changes implies that these subjects are generally vulnerable to a 5-HT imbalance. FH I subjects seemed to be less vulnerable to 5-HT changes. Cognitive deficits in FH I may constitute a trait marker to BD which may be explained by disturbances in other neurotransmitter systems or lipid metabolism.

When interpreting the results it must be kept in mind that effects of 5-HT manipulations were measured in healthy subjects instead of patients who will probably show more pronounced effects on mood, cognition and hormonal release. FH subjects do not show psychopathology and potential 5-HT dysfunctions are probably compensated for by biological coping mechanisms. This may explain why we did not report the same magnitude of effects of ATD 
and $\operatorname{Trp}$ as found in BD and unipolar depressed patients. Next, the number of included FH II was relatively low compared to FH I subjects. Therefore, effects in FH II subjects may be preliminary and further research on 5-HT vulnerability should distinguish between FH I and FH II.

In search for biological markers to $\mathrm{BD}$, the findings of abnormalities in cholesterol and $\mathrm{FAs}$ seemed to be very promising. Probably there is an important relationship between lipid metabolism and brain neurotransmitter functioning. Changes in cholesterol and FAs seemed to be an important process which may explain neurotransmitter dysfunctions in BD, depression and possibly other psychiatric disorders. Further research to biological markers in BD should investigate the role of cholesterol and FAs in brain neurotransmitter functioning. i.e. 5-HT, dopamine and noradrenaline in type I and type II BD patients and their first-degree relatives.

\section{References}

Adams PB, Lawson S, Sanigorski A, Sinclair AJ (1996) Arachidonic acid to eicosapentaenoic acid ratio in blood correlates positively with clinical symptoms of depression. Lipids 31 Suppl: S157-61

Asberg M (1997) Neurotransmitters and suicidal behavior. The evidence from cerebrospinal fluid studies. Ann $\mathrm{N}$ Y Acad Sci 836: 158-81

Atre-Vaidya N, Taylor MA, Seidenberg M, Reed R, Perrine A, Glick-Oberwise F (1998) Cognitive deficits, psychopathology, and psychosocial functioning in bipolar mood disorder. Neuropsychiatry Neuropsychol Behav Neurol 11: 120-6

Benton D (1995) Do low cholesterol levels slow mental processing? Psychosom Med 57: 50-53

Bocchetta A, Chillotti C, Carboni G, Oi A, Ponti M, Del Zompo M (2001) Association of personal and familial suicide risk with low serum cholesterol concentration in male lithium patients. Acta Psychiatr Scand 104: $37-41$

Borkowska A, Rybakowski JK (2001) Neuropsychological frontal lobe tests indicate that bipolar depressed patients are more impaired than unipolar. Bipolar Disorders 3: 88-94

Buydens-Branchey L, Branchey M, Hudson J, Fergeson P (2000) Low HDL cholesterol, aggression and altered central serotonergic activity. Psychiatry Res 93: 93-102.

Cappiello A, Sernyak MJ, Malison RT, McDougle CJ, Heninger GR, Price LH (1997) Effects of acute tryptophan depletion in lithium-remitted manic patients: a pilot study. Biol Psychiatry 42: 1076-8

Coffman JA, Bornstein RA, Olson SC, Schwarzkopf SB, Nasrallah HA (1990) Cognitive impairment and cerebral structure by MRI in bipolar disorder. Biol Psychiatry 27: $1188-96$

Dagher A, Owen AM, Boecker H, Brooks DJ (1999) Mapping the network for planning: a correlational PET activation study with the Tower of London task. Brain 122: 1973-87

Delgado PL, Charney DS, Price LH, Landis H, Heniger GR (1989) Neuroendocrine and behavioral effects of dietary tryptophan restriction in healthy subjects. Life Sciences $45: 2323-32$ 
Delgado PL, Price LH, Miller HL, Salomon RM, Licinio J, Krystal JH, Heninger GR, Charney DS (1991) Rapid serotonin depletion as a provocative challenge test for patients with major depression: relevance to antidepressant action and the neurobiology of depression. Psychopharmacol Bull 27: 321-30

Dickerson FB, Sommerville J, Origoni AE, Ringel NB, Parente F (2001) Outpatients with schizophrenia and bipolar I disorder: Do they differ in their cognitive and social functioning? Psychiatry Res 102: 21-7

Dupont JS, Butters N, Schafer K, Wilson T, Hesselink J, Gillin JC (1990) Diagnostic specificity of focal white matter abnormalities in bipolar and unipolar mood disorder. Biological Psychiatry 38: 482-6

Elliott R, Sahakian BJ, Matthews K, Bannerjea A, Rimmer J, Robbins TW (1997) Effects of methylphenidate on spatial working memory and planning in healthy young adults. Psychopharmacology 131: 196-9

Engelberg H (1992) Low serum cholesterol and suicide. Lancet 339: 727-9.

Ferrier IN, Stanton BR, Kelly TP, Scott J (1999) Neuropsychological function in euthymic patients with bipolar disorder. British Journal of Psychiatry 17: 246-51

Goddard AW, Charney DS, Germine M, Woods SW, Heninger GR, Krystal JH, Goodman WK, Price LH (1995) Effects of tryptophan depletion on responses to yohimbine in healthy human subjects. Biol Psychiatry 38: 74-85 Goodwin FK, Jamison KR (1990) Manic-Depressive Illness. Oxford University Press, Oxford University Press Henry GM, Weingartner H, Murphy DL (1973) Influence of affective states and psychoactive drugs on verbal learning and memory. Am J Psychiatry 130: 966-71.

Hibbeln JR, Salem N (1995) Dietary polyunsaturated fatty acids and depression; when cholesterol does not satisfy. Am J Clin Nutr 62: 1-9

Hibbeln JR, Linnoila M, Umhau JC, Rawlings R, George DT, Salem N, Jr. (1998a) Essential fatty acids predict metabolites of serotonin and dopamine in cerebrospinal fluid among healthy control subjects, and early- and lateonset alcoholics. Biol Psychiatry 44: 235-42

Hibbeln JR, Umhau JC, Linnoila M, George DT, Ragan PW, Shoaf SE, Vaughan MR, Rawlings R, Salem N, Jr. (1998b) A replication study of violent and nonviolent subjects: cerebrospinal fluid metabolites of serotonin and dopamine are predicted by plasma essential fatty acids. Biol Psychiatry 44: 243-9

Klaassen T, Riedel WJ, van Someren A, Deutz NEP, Honig A, van Praag HM (1999) Mood effects of 24-hour tryptophan depletion in healthy first degree relatives of patients with affective disorders. Biol Psychiatry 46 : 489-97

Krabbendam L, Honig A, Wiersma J, Vuurman EF, Hofman PA, Derix MM, Nolen WA, Jolles J (2000) Cognitive dysfunctions and white matter lesions in patients with bipolar disorder in remission [In Process Citation]. Acta Psychiatr Scand 101: 274-80

Maes M, Delanghe J, Meltzer HY, Scharpe S, D'Hondt P, Cosyns P (1994) Lower degree of esterification of serum cholesterol in depression: relevance for depression and suicide research. Acta Psychiatr Scand 90: 252-8 Maes M, Smith R, Christophe A, Cosyns P, Desnyder R, Meltzer H (1996) Fatty acid composition in major depression: decreased omega 3 fractions in cholesteryl esters and increased $C 20: 4$ omega 6/C20:5 omega 3 ratio in cholesteryl esters and phospholipids. J Affect Disord 38: 35-46

Maes M, Smith R, Christophe A, Vandoolaeghe E, Van Gastel A, Neels H, Demedts P, Wauters A, Meltzer HY (1997) Lower serum high-density lipoprotein cholesterol (HDL-C) in major depression and in depressed men with serious suicidal attempts: relationship with immune-inflammatory markers. Acta Psychiatr Scand 95: 212 21 
Meltzer HY, Perline R, Tricou BJ, Lowy M, Robertson A (1984) Effect of 5-hydroxytryptophan on serum cortisol levels in major affective disorders. II. Relation to suicide, psychosis, and depressive symptoms. Arch Gen Psychiatry 41: $379-87$

Morice R (1990) Cognitive inflexibility and pre-frontal dysfunction in schizophrenia and mania. Britisch Journal of Psychiatry 157: $50-4$

Muldoon MF, Ryan CM, Matthews KA, Manuck SB (1997) Serum cholesterol and intellectual performance. Psychosom Med 59: 382-7

Murphy FC, Sahakian BJ, Rubinsztein JS, Michael A, Rogers RD, Robbins TW, Paykel ES (1999) Emotional bias and inhibitory control processes in mania and depression. Psychol Med 29: 1307-21

Nurnberger J, Jr., Berrettini W, Simmons Alling S, Lawrence D, Brittain H (1990) Blunted ACTH and cortisol response to afternoon tryptophan infusion in euthymic bipolar patients. Psychiatry Res 31: 57-67

Olusi SO, Fido AA (1996) Serum lipid concentrations in patients with major depressive disorder. Biol Psychiatry 40: 1128-31.

Owen AM, Downes JJ, Sahakian BJ, Polkey CE, Robbins TW (1990) Planning and spatial working memory following frontal lobe lesions in man. Neuropsychologia 28: 1021-34

Peet M, Murphy B, Shay J, Horrobin D (1998) Depletion of omega-3 fatty acid levels in red blood cell membranes of depressive patients. Biol Psychiatry 43: $315-9$

Pfeffer CR, McBride PA, Anderson GM, Kakuma T, Fensterheim L, Khait V (1998) Peripheral serotonin measures in prepubertal psychiatric inpatients and normal children: associations with suicidal behavior and its risk factors. Biol Psychiatry 44: 568-77

Post RM, Weiss SRB (1997) Kindling and stress sensitization. In: Young LT, Joffe RT (ed) Bipolar Disorder. Biological models and their clinical application. Marcel Dekker, Inc., New York, pp 93-126

Prange AJ, Jr., Wilson IC, Lynn CW, Alltop LB, Stikeleather RA (1974) L-tryptophan in mania. Contribution to a permissive hypothesis of affective disorders. Arch Gen Psychiatry 30: 56-62

Price LH, Charney DS, Delgado PL, Heniger GR (1990) Lithium and serotonin function:implications for the serotonin hypothesis of depression. Psychopharmacology 100:3-12

Price LH, Malison RT, McDougle CJ, Pelton GH, Heninger GR (1998) The neurobiology of tryptophan depletion in depression: effects of intravenous tryptophan infusion. Biol Psychiatry 43: 339-47

Price LH, Ricaurte GA, Krystal JH, Heninger GR (1989) Neuroendocrine and mood responses to intravenous Ltryptophan in 3,4- methylenedioxymethamphetamine (MDMA) users. Preliminary observations [see comments]. Arch Gen Psychiatry 46: 20-2

Rabe-Jablonska J, Poprawska I (2000) Levels of serum total cholesterol and LDL-cholesterol in patients with major depression in acute period and remission. Med Sci Monit 6: 539-47.

Riedel WJ, Klaassen T, Griez E, Honig A, Menheere PPCA, van Praag HM (2002) Dissociable hormonal, cognitive and mood responses to neuroendocrine challenge: evidence for receptor-specific serotonergic dysregulation in depressed mood. Neuropsychopharmacol 26(3): 358-67.

Rihmer Z, Pestality P (1999) Bipolar II disorder and suicidal behavior. The Psychiatric Clinics of North America 22 (3): $667-73$

Roy A, De Jong J, Linnoila M (1989) Cerebrospinal fluid monoamine metabolites and suicidal behavior in depressed patients. A 5-year follow-up study. Arch Gen Psychiatry 46: 609-12 
Rubinsztein JS, Michael A, Paykel ES, Sahakian BJ (2000) Cognitive impairment in remission in bipolar affective disorder. Psychological Medicine 30: 1025-36

Rubinsztein JS, Rogers RD, Riedel WJ, Mehta MA, Robbins TW, Sahakian BJ (2001) Acute dietary tryptophan depletion impairs maintenance of "affective set" and delayed visual recognition in healthy volunteers.

Psychopharmacology (Berl) 154: 319-26.

Rybakowski JK. Twardowska K (1999) The dexamethasone/corticotropin-releasing hormone test in depression in bipolar and unipolar affective illness. J Psychiatr Res 33: 363-70

Sarchiapone M, Camardese G, Roy A, Della Casa S, Satta MA, Gonzalez B, Berman J, De Risio S (2001)

Cholesterol and serotonin indices in depressed and suicidal patients. J Affect Disord 62: 217-9.

Schmitt JAJ, Riedel WJ (1999) Serotonergic antidepressants effects on vigilance and cognition. European Neuropsychopharmacology 9: S241

Sobczak S, Honig A, van Duinen MA, Riedel WJ (accepted) Serotonergic dysregulation in bipolar disorders; a literature review of 5-HT challenge studies. Bipolar Disorders

Sobczak S, Riedel WJ, Booij L, Aan het Rot M, Deutz NEP, Honig A (accepted) Cognition following Acute Tryptophan Depletion: differences between first-degree relatives of bipolar disorder patients and matched healthy control volunteers. Psychological Medicine

Stahl SM (1998) Mechanism of action of serotonin selective reuptake inhibitors. Serotonin receptors and pathways mediate therapeutic effects and side effects. J Affect Disord 51: 215-35

Swartz CM (1990) Albumin decrement in depression and cholesterol decrement in mania. J Affect Disord 19: $17 / 3-6$.

Terao T, Nakamura J, Yoshimura R, Ohmori O, Takahashi N, Kojima H, Soeda S, Shinkai T, Nakano H, Okuno T (2000) Relationship between serum cholesterol levels and meta- chlorophenylpiperazine-induced cortisol responses in healthy men and women. Psychiatry Res 96: 167-73.

van Gorp WG, Altshuler L, Theberge DC, Wilkins J, Dixon W (1998) Cognitive impairment in euthymic bipolar patients with and without prior alcohol dependence. Arch Gen Psych 55: 41-6

Van Praag HM, Lemus C, Kahn R (1987) Hormonal probes of central serotonergic activity: do they really exist? Biol-Psychiatry 22: 86-98

Vieta E, Martinez-De-Osaba MJ, Colom F, Martinez-Aran A, Benabarre A, Gasto C (1999) Enhanced corticotropin response to corticotropin-releasing hormone as a predictor of mania in euthymic bipolar patients.

Psychol Med 29: 971-8

Weidner G, Connor SL, Hollis JF, Connor WE (1992) Improvements in hostility and depression in relation to dietary change and cholesterol lowering. The Family Heart Study. Ann Intern Med 117: 820-3.

Winokur A, Lindberg ND, Lucki I, Phillips J, Amsterdam JD (1986) Hormonal and behavioral effects associated with intravenous L-tryptophan administration. Psychopharmacology Berl 88: 213-9

Yehuda S, Rabinovitz S, Mostofsky DI (1999) Essential fatty acids are mediators of brain biochemistry and cognitive functions. Journal of Neuroscience Research 56: 565-70

Zubieta JK, Huguelet P, Ohl LE, Koeppe RA, Kilbourn MR, Carr JM, Giordani BJ, Frey KA (2000) High vesicular monoamine transporter binding in asymptomatic bipolar I disorder; sex differences and cognitive correlates. Am J Psychiatry 157: 1619-28. 


\section{Samenvatting}

Eerstegraads familieleden van manisch-depressieve patiènten die zelf nooit kenmerken hebben gehad van een manisch-depressieve stoornis (MDS) hebben genetisch een verhoogd risico om ook MDS te ontwikkelen. Het primaire doel van dit proefschrift was het in kaart brengen van biologische factoren die de kwetsbaarheid voor MDS bij gezonde familieleden van MDS patiènten weergeven. Disfunctioneren van het serotonine (5-hydroxytryptofaan; 5 HT) systeem in de hersenen van MDS fungeerde hierbij als uitgangspunt. Door het bestuderen van het 5-HT systeem bij familieleden, die een verhoogd risico hebben, kan een uitspraak gedaan worden over de betrokkenheid van 5-HT bij MDS. Het functioneren van het 5-HT systeem kan onderzocht worden met behulp van experimentele manipulaties die de activiteit van 5-HT in de hersenen verlagen of verhogen. De 5-HT functies bij gezonde eerstegraads familieleden van MDS patiënten werden vergeleken met een qua leeftijd, geslacht en opleiding vergelijkbare controle groep zonder verhoogd genetisch risico. Een abnormale 5 HT functie bij normaal gedrag duidt op een 'kwetsbaar' serotonine systeem. Aangenomen wordt dat een serotonerge kwetsbaarheid bij familieleden van MDS patiënten gegeneraliseerd kan worden naar MDS patiënten, d.w.z. dat 5-HT dus mogelijk een rol speelt in de pathofysiologie van MDS. In dit proefschrift werd de serotonerge kwetsbaarheid onderzocht met behulp van twee experimentele procedures: Acute Tryptofaan Depletie (ATD) en intraveneuze (i.v.) tryptofaan (Trp) toediening. Het eerste gedeelte van het proefschrift beschrijft onderzoeken waarbij gebruik werd gemaakt van ATD. In het tweede gedeelte worden effecten van Trp toediening en de relatie met cholesterol en vetzuren uitgewerkt. De serotonerge kwetsbaarheid wordt in dit proefschrift bepaald door effecten van de ATD en Trp op 3 soorten afhankelijke variabelen: stemming, cognitie en hormonale responsen. In alle onderzoeken wordt een onderscheid gemaakt tussen familieleden van type I en type II MDS patiënten.

Hoofdstuk $l$ bevat een algemene inleiding over de onderwerpen en onderzoeken die in dit proefschrift aan bod komen. Aan de orde komen onder andere het genetische risico bij 
familieleden en de relevantie om biologische risicofactoren te onderzoeken die een betere inschatting van de kans op het krijgen van MDS weergeven. Er werd een korte inleiding gegeven tot de indeling van verschillende classificaties van MDS en de daaraan gerelateerde symptomatologie. Het verschil tussen depressie, manie en hypomanie, type I en type II MDS wordt uitgelegd. Het onderzoeken van een serotonerge kwetsbaarheid bij familieleden van MDS patiënten is gebaseerd op reeds eerder beschreven disfuncties van het 5-HT systeem in de hersenen van MDS patiënten. De aanmaak van 5-HT in de hersenen is direct afhankelijk van de beschikbaarheid van het aminozuur Trp. ATD is een methode waarbij de hoeveelheid beschikbaar Trp in de hersenen daalt na inname van een eiwitdrankje waarin het aminozuur Trp ontbreekt. Aan de andere kant heeft een i.v. toediening van Trp een verhoging van Trp en 5-HT in de hersenen tot gevolg. ATD en i.v. Trp toediening zijn dus aminozuur manipulaties die geschikt zijn om de serotonerge kwetsbaarheid bij familieleden van MDS patiënten te onderzoeken. Eveneens wordt de relatie tussen serotonerge kwetsbaarheid en afwijkingen in de cholesterol en vetzuur huishouding bij familieleden van MDS patiënten onderzocht. In dit hoofdstuk wordt een overzicht gegeven van de doelstellingen die ten grondslag liggen aan de verschillende onderzoeken die beschreven staan in dit proefschrift.

In hoofdstuk 2,3 en 4 wordt de serotonerge kwetsbaarheid bij MDS onderzocht met behulp van ATD. Hoofdstuk 2 bevat een literatuurstudie naar de effecten van ATD bij MDS patiënten. In hoofdstuk 3 en 4 worden de effecten van ATD en placebo bij 30 gezonde eerstegraads familieleden van MDS patiënten en 15 gematchte controle proefpersonen gepresenteerd. De serotonerge manipulaties bestaan uit inname van een $75 \mathrm{gr}$ aminozuur mengsel met Trp (placebo) en zonder Trp (ATD). In ieder hoofdstuk worden specifieke hypothesen van dit onderzoek uitgewerkt.

Een literatuurstudie naar de effecten van ATD bij MDS patiënten is beschreven in hoofdstuk 2. Het aantal onderzoeken naar de stemmingsveranderingen na ATD bij MDS patiënten was beperkt en vertoonde inconsistente resultaten; er waren maar 3 artikelen over ATD bij MDS patiënten beschikbaar. Inconsistente bevindingen die beschreven zijn in de artikels hangen mogelijk samen met verschillende gevolgde methodologische procedures en / of verschillen in eigenschappen van de MDS patiënten die onderzocht werden. De gehanteerde methodologische procedures en proefpersonen selectie bij deze verschillende onderzoeken worden kritisch becommentarieerd. Vervolgens worden aanbevelingen gedaan voor een 
gestandaardiseerd onderzoeksprotocol ten behoeve van onderzoek naar de serotonerge kwetsbaarheid bij MDS.

In hoofdstuk 3 wordt de serotonerge kwetsbaarheid van eerstegraads familieleden van MDS patiěnten onderzocht. De effecten van ATD versus placebo op stemming en cortisol secretie worden onderzocht bij familieleden en vergeleken met gezonde controle personen. Cortisol wordt gemeten in speeksel, zowel voor als na een stresserende procedure, de zogenaamde stress-inducerende spreek taak (SIST). Uit de resultaten blijkt dat eerstegraads familieleden van type II MDS patiěnten meer gevoelig zijn voor de effecten van ATD vergeleken met familieleden van type I patiënten en controle personen. Familieleden van type II patiēnten rapporteren juist een verhoging in stemming, terwijl een gelijkwaardige daling in stemming werd gevonden bij familieleden van type I patiënten en controle personen. De stress geīnduceerde cortisol response is verlaagd na ATD bij familieleden, maar niet bij controle personen.

Geconcludeerd wordt dat de effecten van ATD op stemming bij familieleden van type II patiēnten in overeenstemming zijn met bevindingen bij MDS patiënten. Eerder onderzoek heeft aangetoond dat MDS patiënten na ATD een tijdelijke toename in manische symptomen kunnen ervaren. Het huidige onderzoek suggereert daarom een serotonerge kwetsbaarheid bij familieleden van type II MDS patiënten. Daarnaast waren er zowel bij familieleden van type I en type II patiënten aanwijzingen voor een serotonerge kwetsbaarheid vanwege een afwijkende hormonale respons op ATD.

Hoofdstuk 4 beschrijft de effecten van ATD op cognitieve processen, met name planning, geheugen, leren en aandacht. Uit eerder onderzoek blijkt dat 5-HT een belangrijke rol speelt bij het functioneren van diverse cognitieve processen. MDS patiënten hebben veelal ernstige cognitieve disfuncties die mogelijk terug te voeren zijn op een abnormaal functionerend centraal 5-HT systeem. In dit onderzoek worden de cognitieve prestaties op de afzonderlijke cognitieve taken gemeten voor ATD (baseline) en 5 uur na ATD. ATD heeft bij familieleden een negatief effect op snelheid van informatieverwerking gemeten met de planningstaak, maar niet bij controle personen. Onafhankelijk van de effecten van ATD is de cognitieve capaciteit op o.a. planning en geheugen verminderd bij eerstegraads familieleden van type I patiënten vergeleken met familieleden van type II patiënten en controle personen. In zowel familieleden als controle personen heeft ATD een afname in de prestatie op consolidatie van nieuwe informatie in het lange termijn geheugen en snelheid van informatieverwerking tot gevolg. 
De effecten van ATD op planning worden geïnterpreteerd als aanwijzingen voor een serotonerge kwetsbaarheid gelokaliseerd in frontale hersengebieden van eerstegraads familieleden. Geconcludeerd wordt voorts dat de cognitieve defecten bij familieleden van type I patiënten mogelijk een overeenkomst vertonen met symptomen van een psychotische stoornis. Cognitieve stoornissen kunnen gezien worden als potentiële markers die een aanleg voor MDS weerspiegelen.

In de hoofdstukken 5, 6, 7 en 8 wordt de serotonerge kwetsbaarheid voor MDS onderzocht met behulp van zogenaamde acute manipulaties die het centrale serotonerg systeem stimuleren. Hoofdstuk 5 beschrijft een literatuur studie naar de acute effecten van 5-HT verhogingen bij MDS patiënten. In hoofdstuk 6 en 7 worden de resultaten van een onderzoek naar de effecten van 7.0gr intraveneuze Trp toediening (opgelost in $1000 \mathrm{cc}$ water en fysiologische zout) en placebo (1000cc fysiologisch zout) bij 30 gezonde familieleden van MDS patiënten en 15 gematchte controle personen beschreven. In hoofdstuk 6 staan de effecten van Trp op stemming en hormoon respons weergegeven. Hoofdstuk 7 behandelt de effecten van Trp op cognitie. Een mogelijke relatie tussen serotonerge kwetsbaarheid bij familieleden en afwijkingen in de cholesterol en vetzuur huishouding werd onderzocht in hoofdstuk 8 .

Hoofdstuk 5 beschrijft een literatuur studie naar de effecten van acute 5-HT verhogingen bij MDS patiënten. De hormoon responsen van o.a. cortisol, prolactine (PRL) en adrenocorticotroop hormoon $(\mathrm{ACTH})$ op 5-HT verhogingen blijken goede indicatoren te zijn voor het onderzoeken van de serotonerge kwetsbaarheid. In het algemeen kan worden aangenomen dat een verlaagde 5-HT geïnduceerde hormoon respons het gevolg is van o.a. post-synaptische desensitisatie van 5-HT receptoren of presynaptische neurotransmitter depletie. Daarentegen kan een verhoogde 5-HT geïnduceerde hormoon respons juist een sensitisering van post-synaptische 5-HT receptoren indiceren. De bij MDS patie̋nten toegepaste acute 5-HT verhogingen zijn: acute intraveneuze en orale toediening van d,1fenfluramine, tryptofaan, 5-hydroxytryptofaan, ipsapirone and buspirone. De effecten van deze 5-HT verhogende stoffen worden apart gepresenteerd voor respectievelijk MDS patiënten in remissie of gedurende een manische of depressieve episode. De literatuur geeft aanwijzingen voor een mogelijke verlaagde prolactine response bij manische en depressieve $\mathrm{BD}$ patiënten en een verlaagde cortisol response bij MDS patiènten in remissie. De conclusie is dat aan zowel depressie als manie mogelijk vergelijkbare serotonerge disfuncties ten 
grondslag liggen. Er wordt gesuggereerd dat een lagere cortisol response een chronisch disfunctioneren van het serotonine systeem weerspiegelt terwijl veranderingen in prolactine response juist meer een indicatie geven van stemmingsgebonden veranderingen in de serotonine huishouding.

In hoofdstuk 6 wordt de serotonerge kwetsbaarheid voor MDS onderzocht bij gezonde eerstegraads familieleden van MDS patiènten. De serotonerge kwetsbaarheid wordt gemeten door middel van veranderingen in stemming, cortisol en prolactine in respons op een acute i.v. Trp toediening. Een verhoogde of verlaagde hormoon respons is indicatief voor een verandering in pre- en post-synaptische neurotransmitter activiteit en 5-HT receptor gevoeligheid in de hersenen. Intraveneuze toediening van Trp resulteert in een verlaging van stemming en verhoogde afgiften van cortisol en prolactine. In beginsel lijken er geen verschillen te bestaan tussen familieleden van MDS patiënten en controle personen. De resulaten tonen echter enige evidentie voor een biologisch verschil tussen eerstegraads familieleden van type I en type II patiënten. Ten eerste induceert Trp een marginale toename in manische symptomen bij familieleden van type II patiènten en niet bij familieleden van type I patiënten en controle personen. Ten tweede lijkt de door Trp geĭnduceerde prolactine respons bij familieleden van type II patiënten hoger vergeleken met de andere groepen. De effecten van Trp op stemming en hormonen bij familieleden van type I patiënten verschillen niet met de effecten in controle personen.

Bij het onderzoek dat beschreven wordt in hoofdstuk 7 is de serotonerge kwetsbaarheid bij familieleden van MDS patiënten aan de hand van cognitieve effecten van een acute i.v. Trp toediening bestudeerd. De gemeten cognitieve parameters zijn o.a.: planning, leren, werkgeheugen, gerichte, verdeelde en volgehouden aandacht en de snelheid van psychomotorisch functioneren. De cognitieve prestaties werden gemeten 3 uur na toediening van Trp. De cognitieve prestaties op planning en aandacht taken is lager na Trp bij familieleden, maar niet bij controle personen. Onafhankelijk van Trp, is het cognitief functioneren van familieleden op geheugen, gerichte en verdeelde aandacht en psychomotore reactietijd significant slechter dan bij controle personen. De cognitieve disfuncties zijn meer uitgesproken bij familieleden van type I dan bij familieleden van type II patiënten. Trp resulteert in een significante verslechtering van geheugen en psychomotore reactietijd bij familieleden en controle personen. Er wordt geconcludeerd dat de gevonden cognitieve beperkingen na Trp bij familieleden aanwijzingen zijn voor serotonerge kwetsbaarheid die 
frontaal-gemedieerde cognitieve processen beïnvloeden. De cognitieve beperkingen bij familieleden vormen mogelijke biologische markers voor een verhoogd risico MDS te ontwikkelen.

De rol van afwijkingen in de cholesterol- en vetzuurhuishouding in de pathofysiologie van MDS werd bestudeerd in hoofdstuk 8 . Een verlaagde 'high-density lipoprotein cholesterol' (HDL-C) en een verhoogde $\omega 6 / \omega 3$ ratio is reeds eerder aangetoond bij zowel unipolair depressieve en MDS patiënten. Deze veranderingen in cholesterol en vetzuren beïnvloeden het functioneren van de celmembraan, receptoren en celtransportmechanismen en zijn daarom gerelateerd aan 5-HT neurotransmitter disfuncties in het brein. De primaire doelstellingen die ten grondslag liggen aan dit onderzoek zijn: i) het bestuderen van mogelijke afwijkingen in de cholesterol en vetzuur status bij familieleden van MDS patiënten welke indicatief zouden kunnen zijn voor een verhoogd risico om MDS te ontwikkelen, ii) bestuderen of afwijkingen in cholesterol en vetzuur status gerelateerd zijn aan de gemeten serotonerge kwetsbaarheid in het brein gemeten m.b.v. maximale cortisol en prolactine respons na Trp. De baseline bepalingen van cholesterol en vetzuren werden gemeten bij familieleden en controle personen volgens een parallelgroep design. Vergeleken met controle personen is HDL-C en C18:3 $\omega 3$ significant lager en $\mathrm{C} 20: 4 \omega 6$ en totaal $\omega 6$ vetzuren significant hoger bij familieleden. Een lagere totaal $\omega 3$ vetzuurstatus is gerelateerd aan een lagere baseline stemming. Er is een significant positieve correlatie tussen een lage totaal $\omega 3$ en hoge totaal $\omega 6$ en maximale prolactine respons na Trp. De afwijkingen in cholesterol- en vetzuurstatus bij familieleden komen overeen met bevindingen bij MDS patie̋nten. Daarom wordt gesuggereerd dat de gevonden afwijkingen een biologisch risico voor MDS reflecteren. Afwijkingen in $\omega 3$ en $\omega 6$ vetzuren zijn daarnaast positief geassocieerd met indicatoren voor een serotonerge kwetsbaarheid. Dit wijst mogelijk in de richting van een directe causale relatie tussen disfunctioneren van 5-HT in het brein en afwijkingen in de vetzuurhuishouding.

In hoofdstuk 9 worden de bevindingen van de verschillende gerapporteerde onderzoeken in dit proefschrift geĭntegreerd en bediscussieerd. Uit de onderzoeken in dit proefschrift blijkt dat manipulaties van het aminozuur Trp goede mogelijkheden biedt om de serotonerge kwetsbaarheid bij eerstegraads familieleden van MDS patiënten te onderzoeken. De door ATD en Trp geĭnduceerde veranderingen in stemming, cognitie en hormonen fungeren als goede parameters voor de centrale serotonerge kwetsbaarheid. Uit de resultaten blijkt dat familieleden van type II patiēnten meer gevoelig zijn voor stemmingsveranderingen t.g.v. een 
serotonerge disbalans. Familieleden van type II patiènten rapporteren na ATD en Trp een verhoging in stemming respectievelijk een marginale toename van manische symptomen. Familieleden van type I patiěnten en controle personen ervaren juist een daling in stemming na beide experimentele manipulaties. Daarentegen worden familieleden van type I patiěnten juist gekenmerkt door cognitieve defecten. Deze cognitieve disfuncties indiceren mogelijk een biologisch risico voor MDS. De cognitieve effecten van ATD en Trp lijken meer uitgesproken bij familieleden van type I patiēnten. Het gebruik van cortisol en prolactine als perifere markers geeft enige aanwijzingen voor een serotonerge kwetsbaarheid bij familieleden van MDS patiënten. De hormoonparameters toonden geen onderscheid bij familieleden van type I en type II patiēnten. Mogelijk zou de gevoeligheid van hormonale responsen als biologische markers bevorderd worden m.b.v, een stressinducerende procedure. Uit baseline metingen van cholesterol en vetzuren blijken lagere HDL-C en $\omega 3$ en hogere $\omega 6$ vetzuur plasma spiegels bij familieleden van MDS patiënten. Deze afwijkingen komen overeen met bevingen bij MDS en unipolair depressieve patiënten. Er wordt geconcludeerd dat deze veranderingen in cholesterol en vetzuren een biologische kwetsbaarheid voor MDS indiceren. Lagere plasma $\omega 3$ en hogere $\omega 6$ plasma spiegels zijn gerelateerd aan een verhoogde maximale prolactine respons na Trp. Dit impliceert een belangrijke verband tussen verandering in vetzuren en serotonerge kwetsbaarheid voor MDS en mogelijk andere psychiatrische aandoeningen.

Concluderend kan gesteld worden dat de onderzoeken in dit proefschrift aanwijzingen geven voor een biologisch onderscheid, familieleden van $\mathrm{BD}$ patiënten en controle personen en meer in het bijzonder tussen familieleden van type I en type II patiënten. Familieleden van type II patiënten tonen overeenkomsten met een affectief spectrum waarin serotonerge kwetsbaarheid een rol speelt. Daarentegen lijkt de serotonerge kwetsbaarheid minder uitgesproken bij familieleden van type I patiënten. Zij vertonen juist meer eigenschappen die zouden kunnen passen bij een primair psychotische stoornis. Mogelijk spelen andere neurotransmitter systemen zoals dopamine en noradrenaline bij deze laatste groep een meer prominente rol. Veranderingen in cholesterol en vetzuur metabolisme zijn waarschijnlijk betrokken bij biologische disfuncties die aan de pathofysiologie van MDS ten grondslag liggen. Ten einde de pathofysiologie bij BD beter te begrijpen is het belangrijk om de relaties van cholesterol, vetzuren, cognitie, stemming en neurotransmitter disfuncties in het brein verder uit te diepen. Het zou kunnen dat herstellen van een verstoorde cholesterol en vetzuur huishouding bij BD patiënten een therapeutische werking heeft. Verder onderzoek is naar de specificiteit van de serotonerge kwetsbaarheidsfactoren die in dit proefschrift worden gerapporteerd is gerechtvaardigd. 


\section{Summary}

Healthy first-degree relatives of bipolar patients $(\mathrm{FH})$ possess a significantly increased risk to develop BD later in life. The primary goal of this thesis was to search for biological factors which reflect vulnerability to bipolar disorders (BD) in FH subjects. It was hypothesized that one important factor is an imbalance of serotonin (5-hydroxytryptophan; 5-HT) in the brain. It is assumed that investigating the 5-HT system in subjects at genetic risk for BD provides information on 5-HT functioning in BD. The functions of 5-HT can be investigated by experimental manipulations of the 5-HT system. In this thesis, 5-HT functioning was assessed in $\mathrm{FH}$ and matched controls following two experimental procedures: Acute tryptophan Depletion (ATD) and intravenous (i.v.) tryptophan loading (Trp). Abnormal 5-HT functions in FH is called 'serotonergic vulnerability'. Serotonergic vulnerability in FH may be generalized to BD patients and suggests involvement of 5-HT in BD psychopathology. The first part of this thesis describes studies in which brain 5-HT was lowered by means of ATD. In the second part, the effects of i.v. Trp loading and its relation with cholesterol and fatty acids were presented. Central 5-HT vulnerability following ATD and i.v. Trp challenge was assessed by 3 kinds of dependent measures: mood, cognition and hormonal responses. In all studies, a distinction was made between relatives of BD type I (FH I) and BD type II patients (FH II).

Chapter I provides a general introduction to the topics and studies addressed in this thesis. The genetic risk of $\mathrm{FH}$ subjects to $\mathrm{BD}$ was explained. The relevance of investigating biological risk factors which indicate the true risk to develop BD was described. A short introduction to the classification of BD and its symptomatology was given. The terms depression, mania and hypomania and the difference between type I and type II BD psychopathology were explained. The relevance of investigating the brain 5-HT system in FH comes from previously described central 5-HT dysfunctions in BD. The production of 5-HT in the brain is directly dependent on the availability of Trp. ATD can be achieved by 
consuming an amino-acid drink which is devoid of Trp. Intravenous Trp loading will increase brain Trp and thus 5-HT. In this chapter, ATD and i.v. Trp loading are dietary manipulations of the 5-HT system which were proposed as useful methods to investigate vulnerability to 5HT dysfunction in FH. The challenge of this thesis was primary to initiate a search for biological markers in FH, based on the imbalance in brain 5-HT functioning. An overview of aims of the different studies presented in this thesis was given.

In chapter 2,3 and 4 5-HT vulnerability to BD was studied by means of ATD. A literature review of ATD in BD patients was given in chapter 2. Chapter 3 and 4 provides results of a study in which the effects of ATD and placebo were investigated in a double-blind cross-over design in 30 healthy first-degree relatives of BD patients and 15 matched controls. The $75 \mathrm{~g}$ amino-acid drink was devoid of $\operatorname{Trp}$, but in the placebo mixture $3.0 \mathrm{~g} \operatorname{Trp}$ was added. Each chapter dealt with specific hypothesis of this study.

In chapter 2 a review of studies on ATD in BD patients is given. Literature was limited to three studies, which revealed inconsistent results on mood modification. These inconsistencies may be attributed to differences in methodological procedures and / or characteristics of included BD patients. Patient selection, methodological aspects and procedures of these studies were critically considered. Recommendations for a standardized research protocol to test $5-\mathrm{HT}$ vulnerability to BD were proposed.

In chapter 3, 5-HT vulnerability was studied in FH by means of ATD. The effects on mood and cortisol release in FH subjects were compared with effects in healthy matched controls. Following ATD and placebo, salivary cortisol response was also assessed during a stressinducing speech task (SIST). The results described an elevation in mood in FH II subjects, whereas mood was equally lowered in controls and FH I subjects following ATD. The SIST resulted in a significant increase in saliva cortisol. ATD was followed by a decrease in SISTinduced cortisol response in both FH subgroups, but not in the controls. The results were in agreement with a previous study in which BD patients reported an increase in mood following ATD. Thus it was concluded that this study showed 5-HT vulnerability in FH II subjects which affected mood. 5-HT vulnerability reflected in hormonal abnormalities was seen in both FH I and FH II subjects. 
Chapter 4 describes the results of ATD on cognitive performance which was measured in the domains of planning, learning, working memory, retrieval, focused and divided attention and concept-shifting. Serotonergic circuits have been proposed to mediate cognitive processes. In $\mathrm{BD}$, cognitive impairments are often seen, possibly in relation to lowered brain 5-HT. Cognitive performance was assessed at baseline and 5 hours after ATD. The results showed ATD-induced impairments on speed of information processing on the planning task in FH but not in controls. Independent of ATD, cognitive impairments were pronounced in FH I compared to FH II and controls, i.e. on planning and memory. In all subjects, ATD impaired consolidation of new information in long-term memory and speed of information processing. The effects of ATD on planning were interpreted as 5-HT vulnerability affecting frontal lobe areas in FH subjects. It was suggested that the cognitive dysfunctions in FH I reflect symptoms present in psychotic disorders and may be regarded as possible trait markers to BD.

Chapter 5,6, 7 and 8 cover assessment of 5-HT vulnerability to BD by means of 5-HT challenge procedures which stimulate brain 5-HT release. Chapter 5 describes a literature review of 5-HT challenges in BD patients. In chapter 6 and 7 the results of a study in which the effects of an $7.0 \mathrm{~g}$ i.v. Trp challenge (dissolved in $1000 \mathrm{cc}$ water/ saline) and placebo (1000cc saline solution) on mood, neuroendocrine responses (chapter 6) and cognition (chapter 7) were investigated in $30 \mathrm{FH}$ subjects and 15 matched controls in a double-blind cross-over design. Chapter 8 describes the relationship between abnormalities in cholesterol, fatty-acids (FAs) and central 5-HT vulnerability.

A literature review on 5-HT challenges in BD patients is presented in chapter 5. Assessment of neuroendocrine functioning, i.e. cortisol, prolactin (PRL) and adrenocorticotropic hormone $(\mathrm{ACTH})$, following acute 5-HT challenging has been provided as a useful method to investigate 5-HT vulnerability. In general it is assumed that following challenging, blunting of hormonal responses is indicative of i.e. post-synaptic receptor desensitization or depletion of presynaptic neurotransmitter whereas an enhanced response might suggest sensitization of receptors. Reviewed 5-HT challenge paradigms were acute administration of oral and intravenous (i.v.) dosage of: d,l-fenfluramine, tryptophan, 5-hydroxytryptophan, ipsapirone and buspirone. Effects of challenges were described separately for manic, depressed and euthymic BD patients. The literature shows evidence for a blunted PRL in mania and depression as well as blunted cortisol in euthymic BD patients. This might suggest that in both mania and depression similar 5-HT difunctions are involved. It is speculated that 
blunting of cortisol responses in euthymic BD patients may be a result of chronically altered 5-HT functioning, whereas changes in PRL release following 5-HT challenges reflect more state-dependent changes in 5-HT activity. 5-HT responsivity in BD patients has also been associated with pharmacological treatment, suicidal behavior, weight loss and age.

In chapter 6 intravenous Trp loading resulted in lowered mood and increased cortisol and prolactine release. There were no differences in these mood and hormonal responses between FH and control subjects. There was some evidence for different hormonal and mood responses in FH II subjects compared to FH I and controls. FH II subjects showed an increase in manic symptoms and attenuated mood-lowering effects of Trp compared to FH I and healthy controls. There were no differences in mood response between FH I and controls. PRL and cortisol responses increased following Trp, but did not differ between FH and controls. PRL response was slightly higher in FH II compared to FH I and controls. The results do not provide evidence for central 5-HT vulnerability in FH but might give some indication of a biological differentiation between $\mathrm{FH} \mathrm{I}$ and $\mathrm{FH} \mathrm{II}$.

The study presented in chapter 7 investigated 5-HT vulnerability in $\mathrm{FH}$ indicated by cognitive performance on planning, learning, working memory, retrieval, focused, divided and sustained attention and psychomotor reaction time (RT) following i.v. Trp challenge. Performance was assessed 3 hours after Trp infusion. The results showed impaired planning and attention following Trp in FH subjects but not in controls. Independent of Trp, FH subjects showed cognitive deficits on memory, focused and divided attention and psychomotor performance. Compared to $\mathrm{FH} \mathrm{II,} \mathrm{cognitive} \mathrm{deficits} \mathrm{in} \mathrm{FH} \mathrm{I} \mathrm{were} \mathrm{more}$ pronounced. Trp impaired memory and psychomotor performance significantly in all groups. It was concluded that cognitive deficits in FH following Trp may reflect central 5-HT vulnerability affecting cognitive domains localized in frontal brain areas. It was suggested that the cognitive impairments in $\mathrm{FH}$ independent of Trp represent a trait maker for BD.

The role of abnormalities in cholesterol and fatty acids in BD pathophysiology has been investigated in chapter 8 . In unipolar and BD patients, lower serum high-density lipoprotein cholesterol (HDL-C) and increased ratio of $\omega 6 / \omega 3$ FAs have been reported and related membrane, receptor and 5-HT neurotransmitter dysfunctions in the brain. The aims of this study were: i) to investigate whether FH subjects expressed abnormalities in baseline serum cholesterol and FAs which may represent a trait marker for BD, ii) and whether these 
abnormalities were related to central 5-HT vulnerability as assessed by peak cortisol and PRL responses following i.v. Trp challenging. Baseline cholesterol and FAs were determined in $\mathrm{FH}$ and controls according to a parallel-group design. The results showed significantly lower HDL-C and C18:3 13 and increased C20:4 06 and total $\omega 6$ FAs compared to controls. Lower total $\omega 3$ FAs were associated with lowered baseline mood. Lower total $\omega 3$ and higher total $\omega 6$ FAs were positively associated with peak PRL response following Trp. It was concluded that the abnormalities in cholesterol and FAs in FH paralleled that found in BD patients and may thus represent a trait rather than a state marker for BD. 5-HT vulnerability was positively associated with lower $\omega 3$ and higher $\omega 6$ FAs, which provided evidence for a direct causal relationship between brain 5-HT dysfunction and abnormalities in FAs metabolism.

A summary of the findings and integrative results is provided in chapter 9 . The studies presented in this thesis show that dietary manipulations of Trp provide useful methods to investigate 5-HT vulnerability for BD in $\mathrm{FH}$. Changes in mood, cognition, and hormonal releases following ATD and i.v. Trp loading seem to be appropriate parameters to indicate central 5-HT vulnerability. The results showed that FH II subjects were more vulnerable to the effects of a serotonergic imbalance on mood. Whereas FH I and controls reported a lowered mood following ATD and i.v. Trp, FH II subjects showed an elevation in mood and a significant increase in manic symptomatology. On the other hand, FH I subjects were characterized by cognitive deficits and a tendency towards more pronounced cognitive impairments following ATD and Trp challenging. Cognitive deficits may therefore constitute a trait marker to BD in FH I. Usage of cortisol and PRL responses following ATD and Trp as biological markers provides some evidence for 5-HT vulnerability in FH but did not differentiate between $\mathrm{FH} \mathrm{I}$ and $\mathrm{FH}$ II. It was argued that including a stress-inducing procedure might increase the sensitivity of hormonal parameters as peripheral markers of brain 5-HT functioning in FH. Assessment of cholesterol and FAs showed significant lower baseline HDL-C, $\omega 3$ FAs and higher $\omega 6$ FAs in FH. These abnormalities were in agreement with findings in BD and unipolar depressed patients. It was concluded that these abnormalities in FH constitute a trait marker to BD rather than a state marker. Lower $\omega 3$ and higher $\omega 6$ FAs were positively associated with an elevated PRL response following Trp. This indicates an important association between altered FAs metabolism and 5-HT vulnerability.

In conclusion, the studies presented in this thesis provide evidence for a biological distinction between FH I and FH II. FH II subjects show 5-HT vulnerability and characteristics of an affective pattern. 5-HT vulnerability is less pronounced in FH I subjects. FH I subjects show 
symptoms of primary psychotic disorders in which other neurotransmitters e.g. dopamine, noradrenaline might be involved. Abnormalities in cholesterol and FAs probably play an important role in biological dysfunctions in BD. The relation between cholesterol, FAs, cognition, mood and brain neurotransmitter functioning should be further elucidated. Research is also necessary to investigate the specificity of factors of 5-HT vulnerability which are described in this thesis. 


\section{Dankwoord}

Een proefschrift schrijven doe je niet alleen. Dankzij de geweldige inzet van vele anderen heb ik dit proefschrift zo snel en zo succesvol kunnen voltooien. Ik wil allen danken die hebben meegewerkt aan de totstandkoming van dit proefschrift.

I $\mathrm{k}$ wil de mensen danken die onbaatzuchtig hebben deelgenomen aan de experimenten. De Nederlandse Stichting voor Manisch-Depressieven (NSMD) heeft zich enorm ingezet bij de benadering en werving van manisch-depressieve patiênten en hun familieleden. In het bijzonder Friedus Crijns bedankt.

Jim van Os, promotor, bedankt voor je inzet om aan het einde van de race, snel de finish te behalen. Bedankt voor jouw betrokkenheid en bijdrage bij de afronding van het proefschrift. I $k$ dank de leden van de leescommissie voor het beoordelen van het manuscript en de leden van de corona voor de interesse en inzet bij deze promotie.

Adriaan Honig en Wim Riedel, co-promotoren, dankzij jullie begeleiding heb ik het proefschrift zo snel kunnen afronden. Bedankt dat jullie ondanks mijn verrassingen (een studie, een zwangerschap) in mij zijn blijven geloven en dat jullie er alles aan hebben gedaan om de promotie te doen slagen. Bedankt voor de hele fijne samenwerking. Adriaan, bedankt voor je fanatieke inzet en snelle nakijkwerk en je enthousiasme voor het onderzoek. Jouw gedrevenheid was voor mij een belangrijke stimulans. En je ziet...als je iets echt wilt, kan het allemaal.

Wim wil ik bedanken voor alle mogelijkheden die hij mij heeft gegeven om onderzoek te doen binnen de psychofarmacologie. Ik wil je met name bedanken voor je statistische kennis en puzzelwerk bij het interpreteren en verklaren van moeilijke cognitieve bevindingen.

Bedankt voor je 24-uurs bereikbaarheid, via de telefoon of e-mail, zelfs op zondag. Bij jou kon ik altijd terecht. 
Nancy Nicolson, bedankt voor je enthousiaste medewerking bij het cortisol-gedeelte. Michael Maes bedankt voor het delen van je kennis over vetzuren en cholesterol. Armand Christophe bedankt voor de betrokkenheid en hulp bij de vetzuur analyses.

Ik wil eenieder bedanken die op de werkvloer heeft meegeholpen met het regelen en uitvoeren van het onderzoek. Afdeling Bl en al haar personeel, Erik Vuurman en Nico Rozendaal. Jacqueline Strik, Monique de Koning en Mark Theunissen, bedankt voor jullie medische ondersteuning in het onderzoek. Anita van Oers, bedankt voor je hulp bij het testen van proefpersonen en het geknutsel met databestanden, iedere keer weer. Veel plezier heb ik beleefd aan de samenwerking met studenten. $\mathrm{Zij}$ hebben een groot deel van de organisatie van het onderzoek op hun naam staan. Mede dankzij de kwaliteit van hun werk en hun fanatieke inzet hebben de onderzoeken snelle voortgang geboekt. Ik dank Marije aan het Rot en Linda Booij voor hun hulp bij het tryptofaan-depletie onderzoek. Dankzij Marije heb ik soms het gevoel dat ik ook iets begrijp van computers. Linda, bedankt voor je kwalitatieve inzet bij met name de analyses. Het trytofaan challenge onderzoek staat op naam van Marlies van Duinen. Geweldig hoe jij alles tot in de puntjes wist te regelen. Met jouw doorzettingsvermogen kom je er zeker! Daarnaast zijn er nog Suzanne Teunisse, Raphael Helsdingen, Nienke de Graauw en Jeroen Granzier. Bedankt voor jullie inzet tijdens de testdagen. Ik wil Tessa bedanken voor haar goede opvolging van alles waar ik mee bezig was. Ik zie je wel tijdens de co-schappen (wie eerst?).

Bas van de Poel en Toon Jacobs, bedankt voor de hulp bij het maken van het boekje.

Ron van de Sterren en Brenda Jorissen bedankt voor het zijn van paranimf. Ron bedankt voor al zo lang echte vriendjes zijn en ...... ik weet al wat ik ga zeggen als we later met onze grijze haren ergens op een bankje zitten en kletsen over vroeger.

Brenda, met jou is het allemaal begonnen, een individueel keuze blok tijdens onze studie BGK. Onze samenwerking was een succes; we liepen samen stage en we werden samen AIO. Ik ben blij dat daarom juist jij naast me staat tijdens mijn promotie. Ook een klein afscheid (op de werkvloer altans), want ik vrees dat na 6 jaar onze carrièrepaden zich gaan scheiden. Brenda ik hoop dat ik in de toekomst nog vele mensen ontmoet zoals jij. Bedankt voor je gezelligheid, je aanstekelijke lach en je caviaverhalen.

Dan wil ik uiteraard Jeroen Schmitt bedanken voor zijn adviezen en hulp, voor zijn kameraadschap en voor het bieden van een luisterend oor als het allemaal niet helemaal ging zoals ik wilde. Bedankt voor je positieve energie, ik ben blij dat jij mijn kamergenoot was. Ik hoop dat we nog vaak met onze boys gaan spelen. 
Mijn ouders, bedankt dat jullie mij de mogelijkheid bieden om eeuwig student te zijn en dat ik het doorzettingsvermogen en werklust van jullie heb mogen erven. Ik dank Gemelle voor het zijn van een fijne zus waar ik trots op ben. En de Janssens... bedankt voor jullie enthousiaste berokkenheid. Mijn vriendinnen, in het bijzonder Esther, Vicky, Francis, Carla \& Marjon bedankt voor jullie vriendschap. Ilse en Pien bedankt voor jullie lieve hulp.

Robert......tja zoals je altijd zegt, woorden schieten tekort...maar toch wil ik je graag bedanken want alleen met jouw steun, begrip en positieve energie heb ik dit alles kunnen doen. Bedankt dat je mij de vrijheid gaf om op de meest onmogelijke tijden te werken of studeren. Bedankt dat je mij in alles wat ik doe en wil ondersteun. Ik ben overgelukkig dat ik jouw investering in de toekomst mag zijn. Lieve Fabian, jouw komst was de motor van dit proefschrift. Bedankt dat je besloten hebt je leven met Robert en mij te delen. Jij maakt ons de koning te rijk!!!! 


\section{Curriculum Vitae}

Sjacko Sobczak werd op 21 augustus 1973 geboren in Heerlen. In 1992 behaalde zij het Atheneum-B diploma aan het Sint-Janscollege te Hoensbroek. Na wat omzwervingen ging zij in 1993 Gezondheidswetenschappen studeren aan de Universiteit Maastricht met als afstudeerrichtingen Biologische Gezondheidskunde en Bewegingswetenschappen. Reeds tijdens haar studie toonde ze bijzondere interesse in de psychofarmacologie en relaties tot psychopathologie. Sjacko participeerde in onderzoeken naar de effecten van trytofaan depletie respectievelijk phosphatidylserine op cognitie. Eveneens deed zij verschillende literatuurstudies naar: stoornissen in de bewegingsturing bij de ziekte van Parkinson, neurotransmitter veranderingen bij de ziekte van Alzheimer en oxidatieve stress en de repons van het antioxidant systeem bij lichamelijke inspanning. In 1998 studeerde zij af en werd zij aangesteld als assistent in opleiding bij de vakgroep Psychiatrie en Neuropsychologie, discipline psychofarmacologie en biologische psychiatrie van de Universiteit Maastricht. In 2000 ging een grote levenswens in vervulling en kreeg zij eindelijk de kans, na tig keer te zijn uitgeloot, om geneeskunde te gaan studeren aan dezelfde universiteit. In de laatste fase van haar promotie was Sjacko dus mede actief in het volgen van onderwijs. Vanaf heden zal Sjacko zich primair richtten op het voltooien van haar opleiding tot arts en op de liefdevolle zorg voor haar zoon Fabian. 


\section{List of Publications}

\section{Articles}

Sobczak S, Honig A, Riedel WJ (2000) Acute Tryptophan Depletion in bipolar disorders; literature review and directives for further research. Acta Neuropsychiatrica 12 (3): 69-72 Sobczak S, Honig A, Schmitt JAJ, Riedel WJ (submitted) Pronounced cognitive deficits following an intravenous 1-Tryptophan challenge in first-degree relatives of bipolar patients compared to healthy controls. Neuropsychopharmacology

Sobczak S, Honig A, Cristophe A, Maes M, Helsdingen RWC, De Vriese S, Riedel WJ (submitted) Lower high-density lipoprotein cholesterol, decreased $\omega 3$ and increased $\omega 6$ polyunsaturated fatty acids in first-degree relatives of bipolar patients. Archives of General Psychiatry

Sobczak S, Honig A, Van Duinen MA, Riedel WJ (accepted) Serotonergic dysregulation in bipolar disorders; a literature review of 5-HT challenge studies. Bipolar Disorders Sobczak S, Honig A, Nicolson N, Riedel WJ (accepted) Acute Tryptophan Depletion enhances mood in first-degree relatives of type II bipolar patients but not in first-degree relatives of type I bipolar patients and healthy matched controls. Neuropsychopharmacology Sobczak S, Honig A, Van Duinen MA, Riedel WJ (accepted) Mood, prolactine and cortisol responses following intravenous L-tryptophan challenge; evidence for serotonergic vulnerability in first-degree relatives of bipolar patients. International Journal of Neuropsychopharmacology

Sobczak S, Riedel WJ, Booij L, Aan het Rot M, Deutz NEP, Honig A (in press) Cognition following Acute Tryptophan Depletion: differences between first-degree relatives of bipolar disorder patients and matched healthy control volunteers. Psychological Medicine Riedel WJ, Sobczak S, Nicolson NA, Honig A (submitted) Further evidence for the role of 5-HT in bipolar disorder: Acute Tryptophan Depletion attenuates stress-induced cortisol response in healthy Ist degree relatives. Acta Neuropsychiatrica 
Schmitt JAJ, Jorissen BL, Sobczak S, Van Boxtel MPJ, Hogervorst E, Deutz NEP, Riedel WJ (2000) Tryptophan depletion impairs memory consolidation, but improves focused attention in healthy young volunteers. Journal of Psychopharmacology 14(1): 21-9

\begin{abstract}
s
Sobczak S, Riedel WJ, Honig AH (2000) Memory performance and cortisol response following acute tryptophan depletion. 4th Dutch Endo-Neuro Meeting, Doorwerth Sobczak S, Riedel WJ, Honig AH, Maes M (2001) Acute tryptophan Depletion in first-degree relatives of bipolar patients: Effects on mood, cognition and cortisol release. 4th International Conference on Bipolar Disorder, Pittsburgh, Pennsylvania Aan het Rot M, Sobczak S, Booij L, Honig A, Rogers RD, Sahakian BJ, Riedel WJ (in press) The influence of Tryptophan depletion on decision making in healthy first-degree relatives of bipolar patients and controls. International Journal of Neuropsychopharmacology Kilkens TOC, Sobczak S, Riedel WJ, Honig A, Brummer R-JM, van Nieuwenhoven MA (2001) Does a rectal barostatprocedure induce stress in healthy subjects? Gastroenterology 120:A398
\end{abstract}





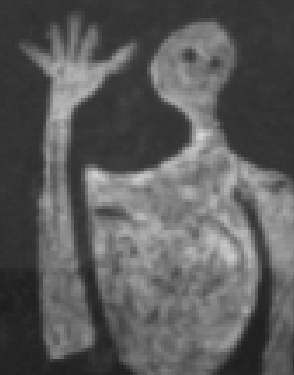

\section{Serotonin and bipolar disorders}

\section{Serotonergic vulnerability in first-degree relatives of patient with bipolar disorder}

Bipolar Disorders are the most hereditary of psychiatric syndromes. Whereas the lifetime risk to develop bipolar disorders in the population is $1.5 \%$, healthy first-degree relatives of bipolar patients show a $10-20$ times increased risk. As yet no markers which reflect biological vulnerability for bipolar disorders are available. The present research project was conceived to gain more insight in the pathophysiology of bipolar disorders. In this thesis serotonergic vulnerability was assessed as the behavioural and hormonal responses to two different experimental manipulations of dietary intake of the amino-acid tryptophan in first degree relatives of bipolar patients and in healthy control subjects without a genetic risk at bipolar psychopathology.

This thesis showed two major findings. First the studies were indicative of a biological distinction between relatives of type I bipolar patients and relatives of type II bipolar patients. Relatives of type II bipolar patients were more likely to show mood changes following acute tryptophan manipulations, which suggests a vulnerable serotonergic system in these subjects. Independent of tryptophan, relatives of type I patients showed cognitive impairments on frontal and temporal lobe mediated cognitive tasks, i.e. memory and attention. The relation between serotonin and these cognitive deficits remains speculative.

Second, relatives of bipolar patients showed decreased high-density lipoprotein cholesterol, decreased $w 3$ and increased w6 fatty acids compared to controls. These striking new results seem precisely to resemble those described in bipolar and unipolar depressed patients. There was also a positive association between abnormalities in fatty acids and brain serotonergic functioning. These results suggests an important role of lipids in central serotonergic functioning and the pathophysiology of bipolar disorders. 